Fabiano F. Albertoni

\title{
Análise faunística de Saturniidae (Insecta, Lepidoptera) em fragmento de Mata Atlântica do Estado de São Paulo, Brasil
}

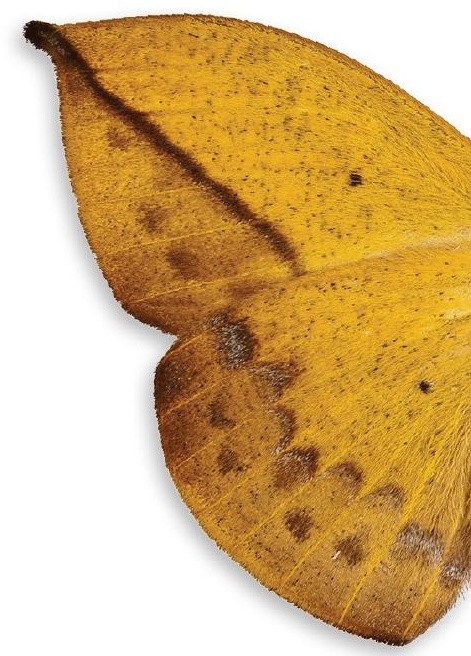

São Paulo 


\section{UNIVERSIDADE DE SÃO PAULO \\ Museu de Zoologia}

Fabiano F. Albertoni

Análise faunística de Saturniidae (Insecta, Lepidoptera) em fragmento de Mata Atlântica do Estado de São Paulo, Brasil 


\title{
ANÁLISE FAUNÍSTICA DE SATURNIIDAE (INSECTA, LEPIDOPTERA) EM FRAGMENTO DE MATA ATLÂNTICA DO ESTADO DE SÃO PAULO, BRASIL
}

\author{
Dissertação (Mestrado) - Programa de Pós- \\ Graduação em Sistemática, Taxonomia Animal \\ e Biodiversidade, Museu de Zoologia da \\ Universidade de São Paulo.
}

Orientador: Prof. Dr. Marcelo Duarte da Silva

SÃO PAULO

2014 


\section{Fotos da capa:}

Asa à esquerda: Vista dorsal de Rhescyntis pseudomartii Lemaire, 1976 (Arsenurinae).

Asa à direita: Vista ventral de Oxytenis modestia (Cramer, 1780) (Oxyteninae).

Abaixo, da esquerda para direita em vista ventral: Hyperchiria incisa Walker, 1855

(Hemileucinae), Copaxa canella Walker, 1855 (Saturniinae) e Adelowalkeria flavosignata (Walker, 1865) (Ceratocampinae).

Não autorizo a reprodução total ou parcial deste trabalho, por qualquer meio convencional ou eletrônico.

I do not authorize the reproduction of this work in part or entirely by any means eletronic or conventional. 


\section{Ficha Catalográfica}

Albertoni, Fabiano F.

Análise faunística de Saturniidae (Insecta, Lepidoptera) em fragmento de mata atlântica do estado de São Paulo, Brasil.

194 fls.

Dissertação (Mestrado) - Programa de Pós-Graduação em Sistemática, Taxonomia Animal e Biodiversidade, Museu de Zoologia da Universidade de São Paulo. Entomologia.

1. Saturniidae - Mata Atlântica 2. Biodiversidade - Mata Atlântica I. Silva, Marcelo Duarte (orient.).

\section{Banca examinadora}

Prof. Dr. Instituição:

Julgamento: Assinatura:

Prof. Dr. Instituição:

Julgamento: Assinatura:

Prof. Dr. Marcelo Duarte da Silva (orientador) Instituição: Museu de Zoologia da USP Julgamento: Assinatura: 
Dedicado aos insetos e a toda infinitude de sua biodiversidae 


\section{Agradecimentos}

São muitas as pessoas que contribuíram para que este trabalho fosse realizado, finalizado e que, na medida do possível, ficasse um pouco melhor do que ficaria sem suas ajudas, opiniões e apoio diversos.

Ao professor Marcelo Duarte por aceitar o desafio de orientar essa pessoa embaraçada, pela paciência, sugestões e pelo período de ótima convivência.

Quero muito agradecer a querida Sônia Aparecida Casari por ter me recebido tão bem desde a primeira vez (para "fazer estágio" em 2005) e em todas as outras em que fui ao museu, e assim, me incentivar a voltar várias e várias vezes; e ao professor Sergio Antônio Vanin pelas conversas e pelo forte incentivo em desenvolver o mestrado no Museu de Zoologia.

Aos meus pais por me apoiarem sempre e buscarem me orientar nas decisões mais difíceis. Ao meu amoreco, Mônica Antunes Ulysséa, pela convivência, e não apenas por me aguentar bravamente nestes últimos momentos de dissertação, mas ainda, conseguir dedicar muito do seu tempo para me ajudar em várias questões ligadas ao desenvolvimento e conclusão deste trabalho.

As pessoas que participaram ativamente da construção de distintos momentos desse projeto montando exemplares, ajudando na identificação e dando os mais variados suportes para o bom desenvolvimento do estudo, a equipe técnica Ednalva Maciel Lisboa e Renato de Oliveira e Silva. Também contribuíram montando exemplares e/ou acompanhando-me nas campanhas de campo os amigos Daniela Bená, Felipe Francisco Barbosa, Glaucia Marconato, o Jujuba Juares Fuhrmann, o careca Lucas Waldvogel Cardoso e o Exu Simeão Moraes. O parceiro de campo e de projeto Pedro Ivo Chiquetto Machado que coletou vários saturniídeos e propiciou, por vezes, com a sua presença, minha permanência mais calma dentro do alojamento para preparar comida durante as frenéticas noites de coleta. A todo pessoal do laboratório pela harmoniosa e divertida convivência, e por me fazerem apreender muito ao longo destes dois anos, aqueles já citados e também a bichinha Ananda Regina, a figuríssima Lívia Pinheiro e o gringo Anderson Muños. Tem também o amigo e ecólogo Carlos André Zucco que nunca hesitou um momento em procrastinar o desenvolvimento de sua tese de doutorado para trocar ideias sobre as análises dos dados e até para fazer algumas, incluindo o belo mapa presente neste trabalho. 
Ao Museu de Zoologia na forma das pessoas que ali trabalham e fazem desta instituição um grande centro de pesquisa e convivência. À Ana Maria Vasquez e Carlos Campaner pela assistência nas solicitações à SABESP para estadia na EBB. Agradeço muito o fato de termos a melhor biblioteca do mundo, que se não for devido à representatividade dos volumes do acervo, se torna a melhor, graças à dedicação das queridas bibliotecárias Dione Seripierri e Marta Lúcia Zamana, sempre muito atenciosas e gentis; e naturalmente às pessoas que compõe os bastidores dessa maravilhosa biblioteca. Às pessoas da secretaria da pós-graduação, Marta Maria Cardeira Grobel, Omair Guilherme Tizzot Filho e Sônia Favaro de Araujo, que se desdobram para entender ou buscar informações sobre as mais diversas dúvidas dos discentes e buscam sempre ajudar da melhor forma possível. Gostaria de agradecer também a rapaziada da segurança que fazem um ótimo trabalho e sempre me trataram muito bem, Altair Aparecido Casemiro, Eliseu dos Santos Pereira, Claudio Reberti Servilha, Sergio Nunes Torres e Vanderlei Tadeu Moreira dos Santos. E também à Célia Regina Jacyntho da Silva, por preparar o café nosso de cada tarde.

Aos cuidadores da Estação Biológica de Boraceia que adoravam cortar grama ao lado do alojamento, nos dias seguintes a uma noite inteira de coleta, para ficarem rindo da minha cara depois (brincadeira, isso só aconteceu uma vez), mas foram muitas as vezes em que me ajudaram ou socorreram das mais diversas formas, Firmino Rodrigues Gomes e Geraldo Masélio dos Santos.

À SABESP por todo apoio ao longo do estudo em especial ao geógrafo Rodrigo Ferraz Moreira por fornecer os dados meteorológicos do período desejado e muitos outros arquivos associados à região da reserva a qual está inserida a Estação Biológica de Boraceia.

À FAPESP pelo suporte financeiro sob o processo 2012/02441-1, além dos auxílios concedidos ao laboratório para criação da infraestrutura que permitiu o desenvolvimento desse trabalho (FAPESP: processos 2002/13898-0, 2010/14682-8, 2011/50225-3; CNPq/ SISBIOTA: processo 563332/2010-7).

E certamente há aqueles, que não estou me lembrando neste "correr do fim", mas que contribuíram de alguma maneira com este estudo, ou paralelamente, contribuíram agregando-me conhecimento pessoal, ou com a formidável saúde da boêmia. 
“... nenhuma espécie de borboleta se tornará rara e jamais será extinta por culpa dos caçadores profissionais. Sua segurança só pode ser quebrada se as plantas-alimento que sustentam as lagartas forem exterminadas na área. Aí sim, as borboletas irão desaparecer."

Comentou, Rob de Goés

De um susto respondeu Manoel de Barros

"Eu não sabia que as pedrinhas do rio que eu guardava no bolso fossem de posse das rãs." 


\section{RESUMO}

O presente estudo listou e analisou a composição e a estrutura da comunidade de saturnídeos atraídos por luz da Estação Biológica de Boraceia (EBB), Salesóplis, São Paulo, Brasil. A EBB pertence ao Museu de Zoologia da Universidade de São Paulo (MZUSP) e compreende uma área de 96 ha, por sua vez localizada dentro do maior remanescente brasileiro de Mata Atlântica da atualidade. A fauna de Saturniidae foi levantada através de exemplares da coleção de Lepidoptera do MZUSP, sendo estes dados complementados com 13 meses de coletas recentes, entre 2012 e 2013, quando foram realizadas coletas noturnas de 12 horas, por quatro noites em cada mês. Adicionalmente, foi produzida uma lista de 114 espécies de Saturniidae coletados no bioma Mata Atlântica, para muitas das quais foram gerados registros fotográficos in situ e de exemplares montados. Os dados oriundos deste levantamento foram comparados com outros estudos sobre Saturniidae realizados no Brasil e demonstraram número elevado de espécies para EBB (119 espécies) quando comparado aos dados disponíveis de outros levantamentos, como os de Saturniidae do Rio Grande do Sul, do Paraná e do bioma (ou ecótono) Cerrado. Os dados das coletas recentes (2012-2013) foram comparados com a assembleia destes lepidópteros amostrada em 25 meses consecutivos durante os anos de 1948 a 1950. Esta comparação demonstrou que a riqueza e a uniformidade das espécies registradas recentemente (2012-2013) é significativamente próxima daquela registrada no período histórico (1948-1950). Alguns exemplares representaram novos registros de espécies para EBB, e algumas espécies foram coletadas exclusivamente em algum momento de todo o período histórico. A área de coleta demonstrou grande densidade de espécies do gênero Hylesia Hübner, 1920 com pelo menos 15 espécies (sendo destas 3 morfoespécies) coletadas em 1.158 exemplares. Estes resultados asseguram a importância do remanescente de Mata Atlântica da Serra do Mar para manutenção de espécies de Saturniidae e ainda, demonstram a significância da EBB para estudos faunísticos de insetos da Mata Atlântica. Algumas avaliações sobre as distribuições sazonal e circadiana dos exemplares coletados em 2012-2013 apontaram padrões que poderão ser utilizados para testar hipóteses de comportamento e biologia das espécies. As espécies apresentaram tanto distribuição restrita ao longo do ano, quanto foram mais amplamente distribuídas. Da mesma forma algumas espécies apresentaram altos picos de abundâncias em períodos restritos da noite, enquanto outras ocorreram em distintos horários. A avaliação da alternância de espécies ao longo do ano e ao longo da noite indicou que há alta alternância de espécies para ambos os ciclos, ressaltando a importância de um levantamento que se ocupe com coletas 
durante todos os meses do ano e durante todo o período noturno. Demonstrou ainda, que a flutuação de abundância das espécies agrupadas em cada uma das cinco subfamílias representadas nas amostras, seguem padrões tanto semelhantes, quanto contrastantes.

Palavras-chave: mariposas, biodiversidade, ciclo sazonal, ciclo circadiano, lista de espécies, inventário faunístico. 


\section{ABSTRACT}

This study evaluated and summarized the composition and structure of the saturniid community attracted to light trapping in a remnant of Atlantic Rainforest of the Boraceia Biological Station (EBB), Salesópolis, São Paulo, Brazil. The EBB belongs to Zoological Museum of University of São Paulo (MZUSP) and comprises a 96 ha area located inside the largest Brazilina remananent of the Atlantica Rain Forest. The Saturniidae fauna of this reserve was inventoried based on the specimens deposited at the MZUSP, and it was complemented with 13 months of recently field samplings between 2012 and 2013. Complementary field sampling was based on nocturnal collections of 12 hours along four nights on each of the 13 months. As a result we listed 114 species of the family Saturniidae. Many species were photographed in situ, for illustration of the dorsal and ventral habitus of each species we used the pinned specimens of the collection. Comparisons with other inventories of Saturniidae conducted in different Brazilian localities were performed and demonstrated an elevated number of species in EBB when compared to the data available from other inverntories, from Rio Grande do Sul state, Paraná state and the Savana bioma. Recent field samplings (2012-2013) were compared with the assemblage of saturniids from 25 consecutive months between 1948 and 1950. This comparison demonstrated that the richness and the uniformity of the species recentelly registered (2012-2013) is similar to that from the historical period (1948-1950). Few specimens constituted new record for EBB and other few were sampled exclusively on the whole range of the historical period. The studied area indicated high density of species of Hyleisa Hübner, 1920 with at least 15 species (with three morphospecies) collected, distributed in 1.158 specimens. The results stress the importance of the Serra do Mar Atlatic forest remanent to the conservation of the species of Saturniidae and yet, demonstrate the importance of EBB for the study of insects from the Atlantic Rain Forest. The analysis related to the seasonality and circadian pattern of the recently collected specimens (2012-2013) can be further used to test hypothesis of behavior and biology of the species. The abundance of species showed distinct fluctuation along the year, while some had concentrated distribution, others were broadly sampled along several months. Similarly, some species presented high pics of abundance on restricted periods during the night, while other speces were sampled in several distinct periods. The evaluation of the interchange of species during the year and during the night indicated hight interchanging of species for both cicles, sazonal and cyrcadina, stressing the importance of inventories of Saturniidae with effort along the entire year and along the hole night period. 
The same evaluation also demonstrated that the fluctuation of the abundance of species grouped by subfamilies follow similar and contrasting patters depending on the subfamilies that are being compaired.

Key words: moths, biodiversity, seasonality, circadian cycle, species list, fauna survey. 


\section{Lista de Tabelas}

Tabela 1. Anos e meses em que exemplares de Saturniidae (Lepidoptera) foram amostrados na Estação Biológica de Boraceia, Salesópolis, SP, Brasil entre 1942 e 2013.

Tabela 2. Número de espécies e de exemplares de cada gênero e de cada subfamília de Saturniidae da Estação Biológica de Boraceia, Salesópolis, SP, Brasil de 1942 a 2013. Ginandro $=$ Ginandromorfo.

Tabela 3. Lista das espécies de Saturniidae (Lepidoptera) coletados na Estação Biológica de Boraceia, Salesópolis, SP, Brasil entre 1942 e 2013. Gin = Ginandromorfo. 35

Tabela 4. Listagem das 35 espécies coletadas na Estação Biológica de Boraceia, Salesópolis, SP, Brasil que ocorreram apenas em um dos dois períodos analisados, 1948-1950 ou 20122013, estando discriminados o número de amostras (data de referência) e o número de exemplares (n) em que cada espécie foi coletada.

Tabela 5. Lista das 96 espécies coletadas na Estação Biológica de Boraceia, Salesópolis, SP, Brasil que ocorreram nos períodos analisados, 1948-1950 e 2012-2013, estando discriminados o número de amostras (data de referência) e o número de exemplares (n) em que cada espécie foi coletada. 44 


\section{Lista de Figuras}

Figuras 1. Localização da área de coleta, Estação Biológica de Boraceia, Salesópolis, SP, Brasil. (A) Mapa do Brasil com o Estado de São Paulo destacado com cinza escuro; (B) Imagem de satélite com a área de coletada (EBB Castelinho) e arredores.

Figuras 2-5. Estação Biológica de Boraceia, Salesópolis, SP, Brasil: Entorno da "Casa dos Biologistas" (sensu Travassos \& Camargo 1958) ou "Castelinho", trata-se de uma das casas de alojamento dos pesquisadores que tem sido historicamente utilizada para coleta de insetos noturnos atraídos por armadilhas luminosas. (2) Vista do fim de tarde a partir do "Castelinho"; (3) mesma vista à noite com lâmpadas utilizadas para coleta desligadas; (4) vista do fim de tarde, foto tirada do fundo da casa ("Castelinho”); (5) mesma vista à noite com lâmpadas utilizadas para coleta ligadas. Fotos: Fabiano F. Albertoni.

Figuras 6-7. Estação Biológica de Boraceia, Salesópolis, SP, Brasil: Entorno da "Casa dos Biologistas" ou "Castelinho". (6) Vista do fim de tarde da floresta em frente ao "Castelinho" com nevoeiro típico da região; (7) vista a partir da parte de trás do "castelinho" em um momento de intenso nevoeiro. Fotos: Fabiano F. Albertoni. 7

Figuras 8-9. Estação Biológica de Boraceia, Salesópolis, SP, Brasil: Amostragem de Saturniidae na "Casa dos Biologistas" (sensu Travassos \& Camargo 1958) ou "Castelinho". (8) Coleta de 25 de março de 2012, às 7:00h; (9) coleta de 22 de abril de 2012, às 23:10h. Fotos: Fabiano F. Albertoni. 16

Figuras 10-13. Estação Biológica de Boraceia, Salesópolis, SP, Brasil: Amostragem de Saturniidae. (10) Mariposas atraídas pela lâmpada da varanda da casa; (11) protocolo de coleta com preenchimento iniciado e uma Oxytenis bicornis pousada sobre ele; (12) sistema de organização e materiais utilizados nas coletas para amostrar os Saturniidae a cada intervalo de 30 minutos; (13) saturniídeos referentes a uma unidade de amostra de 30 minutos. Fotos: Fabiano F. Albertoni.

Figuras 14-20. Tratamento físico dado ao material inserido na coleção e registro fotográfico, exemplares de Automeris bilinea (Walker). Amostragem de Saturniidae. (14) Mariposa alfinetada com suas respectivas etiquetas; (15) vista dorsal; (16) vista ventral; (17) vista dorsal com as respectivas etiquetas do exemplar; (18) exemplar em campo pousado em posição de descanso; (19) envelope com dados de coleta e contendo exemplar de Othorene 
purpurascens (Schaus); (20) thumbnail do arquivo referente à vista dorsal do exemplar com respectivo nome do arquivo. Fotos: Fabiano F. Albertoni.

Figura 21. Print screen da página do banco de dados do Access ilustrando relacionamentos e campos das tabelas.

Figuras 22-23. Assembleia de Saturniidae da Estação Biológica de Boraceia, Salesópolis, SP, Brasil. (22) Abundância relativa e (23) riqueza relativa do número de exemplares de cada subfamília de Saturniidae coletados entre 1942 e $2013 .$.

Figuras 24-25. Curvas de rarefação. (24) Curva com extrapolação (de 1,5x=9.360 exemplares) no número de exemplares (extrapolation on individual-based rarefaction), cálculo analítico; a linha pontilhada indica valores extrapolados à partir do número observado de exemplares (6.240) e (25) curva com interpolação randomizada do número de amostras (sample-based rarefaction) dos exemplares de Saturniidae coletados entre 1942 e 2013 na Estação Biológica de Boraceia, Salesópolis, SP, Brasil. Cada mês em que houve coleta representa uma unidade amostral, totalizando 176 unidades. As áreas cinzas correspondem aos intervalos com $95 \%$ de confiança.

Figuras 26-27. Abundância e número de espécies de Saturniidae, na Estação Biológica de Boraceia, Salesópolis, SP, Brasil. (26) Abundância e riqueza de espécies coletadas para cada uma das subfamílias durante os 25 meses de campanha entre 1948 e 1950; (27) abundância e número de espécies coletadas para cada uma das subfamílias durante os 13 meses de campanha entre 2012 e 2013.

Figura 28. Abundância absoluta e relativa das espécies classificadas como comuns (abundância relativa entre 0,5\% e 1\%) ou mais abundantes coletados em 25 meses entre 1948 e 1950, na Estação Biológica de Boraceia, SP, Brasil. No gráfico foram representadas 33 espécies. 40

Figuras 29-30. Curvas de rarefação. (29) Rarefação com base nos exemplares (individualbased rarefaction); linhas pontilhadas indicam extrapolação do número de exemplares observados para as coletas históricas; (30) rarefação com base nas amostras (sample-based rarefaction); círculos abertos correspondem aos valores gerados pelo estimador de riqueza Chao 1. Áreas cinza correspondem aos interevalos com 95\% de confiança. Coletas realizadas entre 1948-1950 e 2012-2013 na Estação Biológica de Boraceia, SP, Brasil sendo que para as coletas entre 1948-1950 o número de exemplares foi extrapolado em três vezes. 
Figura 31. Abundância absoluta e relativa das espécies classificadas como comuns (abundância relativa entre $0,5 \%$ e $1 \%$ ) ou mais abundantes, coletadas nos 13 meses entre 2012 e 2013, na Estação Biológica de Boraceia, SP, Brasil. No gráfico foram representadas 54 das 96 espécies.

Figura 32. Diagrama da análise por Escalonamento Multidimensional Não-métrico (NMDS) das comunidades representadas pelos 25 meses de 1948-1950 (pontos vermelhos) e pelos 13 meses de 2012-2013 (pontos cinzas), da Estação Biológica de Boraceia, Salesópolis, SP, Brasil.

Figura 33. Diagrama da Análise de Correspondência (CA) entre as comunidades de 19481950 (pontos pretos) e de 2012-2013 (cruzes vermelhas) da Estação Biológica de Boraceia, Salesópolis, SP, Brasil. A comparação foi feita com os 12 meses do ano para cada época de coleta e assim, os dados dos meses com repetição (por exemplo, março de 2012 e março de 2013) foram somados.

Figura 34. Proporção do número de espécies de todas as subfamílias em três listas de espécies de Saturniidae do Brasil e das espécies coletadas na Estação Biológica de Boraceia (1942-2013). Paraná (Marinoni et al. 1997), Rio Grande do Sul (Nunes et al. 2004; Specht et al. 2005; Prestes et al. 2008; Corseuil 2013), Bioma Cerrado (Camargo et al. 2008).... 48

Figura 35. Curva de rarefação com extrapolação (para 4.881 exemplares) no número de exemplares (extrapolation on individual-based rarefaction), coletados entre 1986 e 1987 em oito localidades do Estado do Paraná, Brasil (Marinoni et al. 1997). A rarefação atinge 88 espécies com 3.575 exemplares e fixou seu valor máximo de 88,4 espécies nos últimos 8 exemplares, de um total de 4.88, sendo que 88,39 espécies foi atingido com 4.798 exemplares , permanecendo assim nos 76 "penúltimos" exemplares.

Figuras 36-37. Curvas de rarefação com base nos exemplares e nas amostras para cada período. (36) 1948-1950 e (37) 2012-2013, dos exemplares coletados na Estação Biológica de Boraceia, Salesópolis, SP, Brasil.

Figura 38. Análise de componente principal (PCA) das subfamílias de acordo com as temperaturas, número de intervalos de tempo referente à determinada temperatura e a abundância pertinente a cada espécie que foi coletada. Os valores das temperaturas foram ranqueados em 17 categorias: $\left(\mathrm{T}^{\circ} 1\right)<8,9^{\circ} \mathrm{C}$; $\left(\mathrm{T}^{\circ} 2\right) 9^{\circ}-9,9^{\circ}$; $\left(\mathrm{T}^{\circ} 3\right) 10^{\circ}-10,9^{\circ}$; $\left(\mathrm{T}^{\circ} 4\right) 11^{\circ}-11,9^{\circ}$;

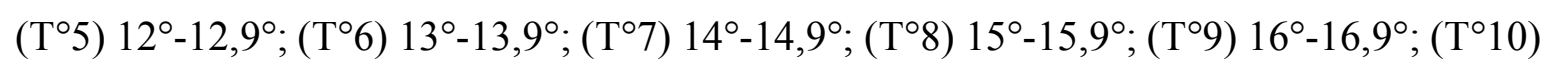

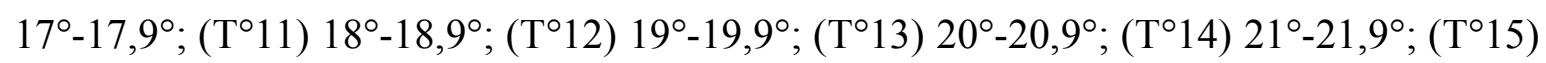


$22^{\circ}-22,9^{\circ} ;\left(\mathrm{T}^{\circ} 16\right) 23^{\circ}-23,9^{\circ}$ e $\left(\mathrm{T}^{\circ} 17\right)>24^{\circ}$. As figuras geométricas delimitam os pontos mais externos pertencentes a cada uma das cinco subfamílias de Saturniidae coletadas na Estação Biológica de Boraceia, Salesópolis, SP, Brasil entre março de 2012 e março de 2013. Arsenurinae, linha preta; Ceratocampinae, linha vermelha; Hemileucinae, linha azul; Oxyteninae, linha verde escuro e Saturniinae, linha verde água. .57

Figura 39. Variação dos intervalos de tempo por ranque de temperatura (barras) e variação do total de indivíduos coletados por ranque de temperatura (linha). Os intervalos de tempo foram ranqueados em seis categorias: nenhum exemplar coletado (barra cinza), com até cinco exemplares coletados (barra preta), de 6 a 10 exemplares coletados (barra verde), de 11 a 15 exemplares coletados (barra rosa), de 16 a 20 exemplares coletados (barra azul) e com mais de 20 exemplares coletados (barra vermelha). Os valores apresentados são porcentagens relativas ao total de intervalos em que cada categoria de temperatura foi registrada.. . 58

Figura 40. Relação entre a proporção do número de exemplares coletados em cada categoria de temperatura, e a proporção do número de intervalos de tempo em que a variação de temperatura relativa a cada categoria foi registrada. .58

Figura 41. Relação entre a proporção do número de espécies coletados em cada categoria de temperatura, e a proporção do número de intervalos de tempo em que a variação de temperatura relativa a cada categoria foi registrada.

Figura 42. Análise de componente principal (PCA) das médias de temperaturas registradas em cada intervalo de tempo em relação ao número de intervalos, à abundância e ao número de espécies que ocorreram nas respectivas médias de temperatura, das coletas de Saturniidae realizadas na Estação Biológica de Boraceia, Salesópolis, SP, Brasil entre março de 2012 e março de 2013.

Figura 43. Análise de componente principal (PCA) dos 1.220 intervalos de tempo com suas respectivas médias de temperaturas, abundâncias e número de espécies de Saturniidae coletados na Estação Biológica de Boraceia, Salesópolis, SP, Brasil entre março de 2012 e março de 2013. A elipse representa distribuição de $95 \%$ dos dados e o polígono irregular liga os pontos mais externos.

Figura 44. Abundância, número de espécies de Saturniidae e dados climáticos (temperatura e pluviosidade) para cada um dos 13 meses de coleta (março a dezembro de 2012 e janeiro a março de 2013) na Estação Biológica de Boraceia, SP, Brasil. 
Figura 45. Abundância e número de espécies de Saturniidae para os 24 intervalos $\left(1^{\circ}-12^{\circ}\right.$ : 18:00-00:00h e $13^{\circ}-24^{\circ}:$ 00:00-06:00h) das 51 noites de coletas na Estação Biológica de Boraceia, SP, Brasil.

Figura 46. Distribuição da abundância relativa dos exemplares (machos e fềmeas) de Saturniidae amostrados durante os 13 meses de coletas (março de 2012 a março de 2013) na Estação Biológica de Boraceia, SP, Brasil.....

Figura 47. Distribuição da abundância e do número de espécies de Saturniidae (somente fêmeas) nos 24 intervalos de amostra (1-12: 18:00-00:00h e 13-24: 00:00-06:00h) durante as 51 noites de coletas na Estação Biológica de Boraceia, SP, Brasil. Inclui Hylesia sp. para abundância absoluta e como espécie.

Figura 48. Distribuição da abundância e do número de espécies de Saturniidae (somente machos) nos 24 intervalos de amostra (1-12: 18:00-00:00h e 13-24: 00:00-06:00h) durante as 51 noites de coletas na Estação Biológica de Boraceia, SP, Brasil. Inclui Hylesia sp. para abundância absoluta e como espécie.

Figura 49. Análise de correspondência (CA) entre presença e ausência de cada espécie de Saturniidae e os 24 intervalos de tempo (1-12: 18:00-00:00h e 13-24: 00:00-06:00h) sendo cada intervalo a soma dos seus respectivos intervalos, nas 51 noites de coleta na Estação Biológica de Boraceia, SP, Brasil.

Figura 50. Análise de correspondência (CA) entre abundância de cada espécie de Saturniidae e os 24 intervalos de tempo (1-12: 18:00-00:00h e 13-24: 00:00-06:00h), sendo cada intervalo a soma dos seus respectivos intervalos nas 51 noites de coleta, na Estação Biológica de Boraceia, SP, Brasil.

Figura 51. Ranque de abundância dos machos de cada uma das 96 espécies de Saturniidae dos 24 intervalos de tempo (1-2: 18:00-00:00h e 13-24: 00:00- 06:00h), sendo cada intervalo a soma dos seus respectivos intervalos nas 51 noites de coleta na Estação Biológica de Boraceia, SP, Brasil. .68

Figura 52. Ranque de abundância dos machos de cada uma das 96 espécies de Saturniidae dos 13 meses (março a dezembro de 2012 e janeiro a março de 2013), de coleta, na Estação Biológica de Boraceia, SP, Brasil. 
Figura 53. Ranque de abundância dos machos de cada uma das 97 espécies de Saturniidae dos 25 meses (março a dezembro de 1948, março a dezembro de 1949 e janeiro a março de 1950), de coleta, na Estação Biológica de Boraceia, SP, Brasil.

Figura 54. Variação da abundância e do número de espécies de Arsenurinae coletados durante 13 meses (A) e 24 intervalos de tempo das 51 noites de coleta (B) na Estação Biológica de Boraceia, SP, Brasil.

Figuras 55-57. (A) Distribuição sazonal e (B) circadiana de (55) Arsenura biundulata Schaus, 1906; (56) Copipteryx sonthotnnaxi Ém. André, 1905; e (57) Titaea tamerlan (Maassen, 1869) (Arsenurinae), coletadas na Estação Biológica de Boraceia, Salesópolis, SP, Brasil entre março de 2012 e março de 2013 74

Figura 58. Ranque de abundância dos machos de cada uma das nove espécies de Arsenurniae (199 exemplares) nos 13 meses (março a dezembro de 2012 e janeiro a março de 2013), de coleta, na Estação Biológica de Boraceia, SP, Brasil. .75

Figura 59. Ranque de abundância dos machos de cada uma das nove espécies de Arsenurniae (199 exemplares) nos 24 intervalos de tempo (1-2: 18:00-00:00h e 13-24: 00:0006:00h), sendo cada intervalo a soma dos seus respectivos intervalos nas 51 noites de coleta na Estação Biológica de Boraceia, SP, Brasil. .75

Figura 60. Variação da abundância e do número de espécies de Ceratocampinae coletados durante 13 meses (A) e 24 intervalos de tempo das 51 noites de coleta (B) na Estação Biológica de Boraceia, SP, Brasil. .76

Figuras 61-69. Distribuição (A) sazonal e (B) circadiana de (61) Adeloneivaia fallax (Boisduval, 1872); (62) Adelowalkeria falvosignata Walker, 1865; (63) Adelowalkeria tristygma (Boisduval, 1872); (64) Almeidella almeidai Oiticica, 1946; (65) Othorene cadmus (Herrich-Schäffer, [1854]); (66) Othorene purpurascens (Schaus, 1905); (67) Eacles ducalis Walker; 1855; (68) Eacles imperialis (Drury, 1773); e (69) Eacles mayi Schaus, 1920 (Ceratocampinae), coletadas na Estação Biológica de Boraceia, Salesópolis, SP, Brasil entre março de 2012 e março de 2013

Figura 70. Ranque de abundância dos machos de cada uma das 18 espécies de Ceratocampinae (606 exemplares) nos 13 meses (março de 2012 a março de 2013) de coleta, na Estação Biológica de Boraceia, SP, Brasil. 
Figura 71. Ranque de abundância dos machos de cada uma das 18 espécies de Ceratocampinae (606 exemplares) nos 24 intervalos de tempo (1-2: 18:00-00:00h e 13-24: 00:00-06:00h) de coleta, na Estação Biológica de Boraceia, SP, Brasil.

Figuras 72-73. Variação da abundância e do número de espécies de Hemileucinae coletados durante (72) 13 meses e (73) 24 intervalos de tempo das 51 noites de coleta na Estação Biológica de Boraceia, SP, Brasil. Abundância e número de espécies não incluem Hylesia sp. 84

Figura 74. Ranque de abundância dos machos de cada uma das 59 espécies de Hemileucinae nos 13 meses (março a dezembro de 2012 e janeiro a março de 2013) de coleta, na Estação Biológica de Boraceia, SP, Brasil. 86

Figura 75. Ranque de abundância dos machos de cada uma das 59 espécies de Hemileucinae nos 13 meses (março a dezembro de 2012 e janeiro a março de 2013), sendo cada um dos 24 intervalos de tempo a soma dos seus respectivos intervalos nas 51 noites de coleta, na Estação Biológica de Boraceia, SP, Brasil.

Figuras 76-80. Distribuição sazonal (A) e circadiana (B) de (76) Automeris basalis (Walker, 1855); (77) Automeris beckeri (Herrich-Schäffer, [1856]); (78) Automeris bilinea (Walker, 1855); (79) Automeris illustris (Walker, 1855); e (80) Automeris inornata (Walker, 1855), coletadas na Estação Biológica de Boraceia, Salesópolis, SP, Brasil entre março de 2012 e março de 2013 .90

Figuras 81-84. Distribuição sazonal (A) e circadiana (B) de (81) Cerodirphia sp.1; (82) Cerodirphia opis (Schaus, 1892); (83) Cerodirphia vagans (Walker, 1855); e (84) Cerodirphia zikani (Schaus, 1921), coletadas na Estação Biológica de Boraceia, Salesópolis, SP entre março de 2012 e março de 2013. .92

Figuras 85-88. Distribuição sazonal (A) e circadiana (B) de (85) Dirphia muscosa Schaus, 1898; (86) Dirphia baroma (Schaus, 1906); (87) Dirphia dolosa Bouvier, 1929; e (88) Dirphia fornax (Druce, 1903), coletadas na Estação Biológica de Boraceia, Salesópolis, SP, Brasil entre março de 2012 e março de 2013 .94

Figuras 89-91. Distribuição sazonal (A) e circadiana (B) de (89) Hylesia metapyrrha (Walker, 1855); (90) Hylesia nanus (Walker, 1855); e (91) Hylesia scortina Draudt, 1929, coletadas na Estação Biológica de Boraceia, Salesópolis, SP, Brasil entre março de 2012 e março de 2013. .96 
Figuras 92-99. Distribuição sazonal (A) e circadiana (B) de (92) Hylesia falcifera (Hübner, 1825); (93) Hylesia maurex Draudt, 1929; (94) Hylesia munonia Schaus, 1927; (95) Hylesia oratex Dyar, 1913; (96) Hylesia paulex Dognin, 1922; (97) Hylesia vindex Dyar, 1913; (98) Hylesia sp.1; e (99) Hylesia sp., coletadas na Estação Biológica de Boraceia, Salesópolis, SP, Brasil entre março de 2012 e março de 2013 100

Figuras 100-101. Distribuição sazonal (A) e circadiana (B) de (100) Pseudautomeris coronis (Schaus, 1913); e (101) Pseudautomeris hubneri (Boisduval, 1875), coletadas na Estação Biológica de Boraceia, Salesópolis, SP, Brasil entre março de 2012 e março de 2013.

Figuras 102-105. Distribuição sazonal (A) e circadiana (B) de (102) Dirphiopsis epiolina (R. Felder \& Rogenhofer, 1874); (103) Dirphiopsis picturata (Schaus, 1913); (104) Lonomia obliqua Walker, 1855; e (105) Periga falcata Walker, 1855, coletadas na Estação Biológica de Boraceia, Salesópolis, SP, Brasil entre março de 2012 e março de 2013. 104

Figuras 106-107. Distribuição sazonal (106) e circadiana (107) de Oxytenis bicornis Jordan, 1924 e Oxytensi modestia (Cramer, 1780) (Oxyteninae), coletadas na Estação Biológica de Boraceia, Salesópolis, SP, Brasil entre março de 2012 e março de 2013. F = exemplares fêmeas; $\mathrm{M}=$ exemplares machos. 105

Figuras 108-109. Variação da abundância e do número de espécies de Saturniinae coletadas durante 13 meses na Estação Biológica de Boraceia, SP, Brasil. 106

Figuras 110-113. Distribuição sazonal (A) e circadiana (B) de (110) Copaxa canella Walker, 1855; (111) Copaxa decrescens Walker, 1855; (112) Rothschildia aurota (Cramer, 1775); e (113) Rothschildia hopfferi (C. \& R. Felder, 1859) (Saturniinae), coletadas na Estação Biológica de Boraceia, Salesópolis, SP, Brasil entre março de 2012 e março de 2013. 108

Figura 114. Ranque de abundância dos machos de cada uma das oito espécies de Saturniinae (143 exemplares) nos 13 meses (março a dezembro de 2012 e janeiro a março de 2013) de coleta, na Estação Biológica de Boraceia, SP, Brasil. 109

Figura 115. Ranque de abundância dos machos de cada uma das oito espécies de Saturniinae (143 exemplares) nos nos 13 meses (março a dezembro de 2012 e janeiro a março de 2013), sendo cada um dos 24 intervalos de tempo a soma dos seus respectivos intervalos nas 51 noites de coleta, na Estação Biológica de Boraceia, SP, Brasil. 110 


\section{SUMÁRIO}

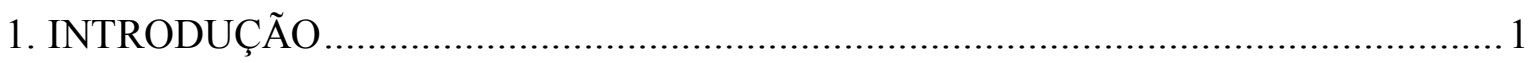

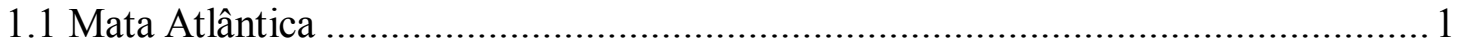

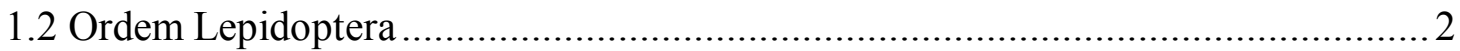

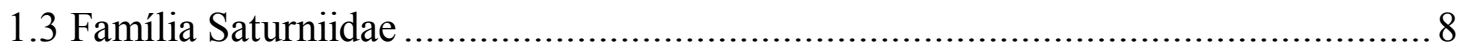

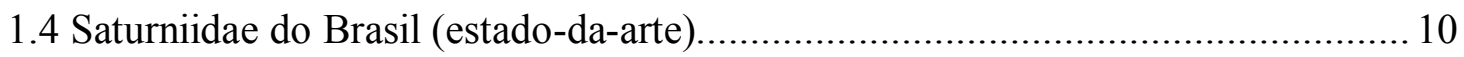

1.5 O cenário de São Paulo e a Estação Biológica de Boraceia..................................2

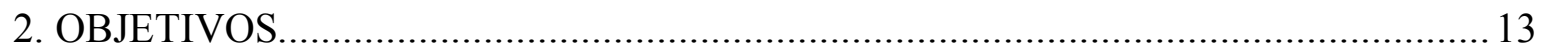

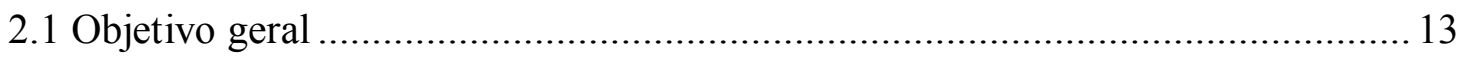

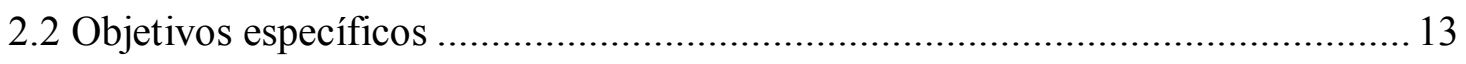

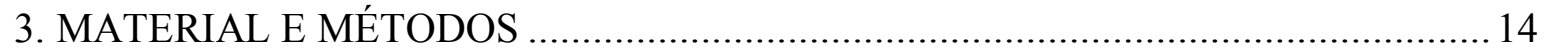

3.1 Área de Estudo (Figs. 1-7) ......................................................................... 14

3.2 Metodologia de coleta e identificação das espécies........................................... 14

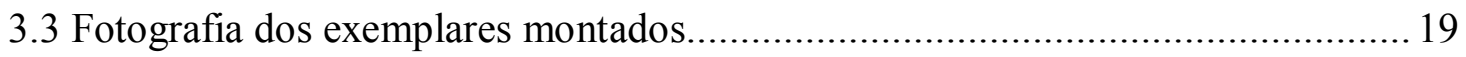

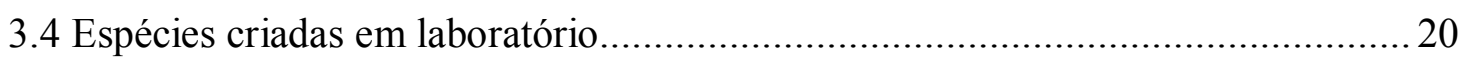

3.5 Procedimentos gerais para análise dos dados ............................................... 20

3.5.1 Levantamento de Saturniidae (Insecta, Lepidoptera) atraidos por luz da Estação Biológica de Boraceia. A fauna atual e uma retrospectiva de quase 70 anos 23

3.5.2 Atividade temporal de 96 espécies de Saturniidae ao longo de 51 noites de coleta na Estação Biológica de Boraceia (Salesópolis, SP, Brasil) ......................... 26

4. RESULTADOS E DISCUSSÃO ....................................................................... 28

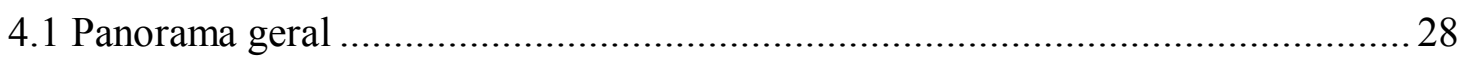

4.2 Levantamento de Saturniidae (Insecta, Lepidoptera) atraídos por luz da Estação Biológica de Boraceia. A fauna atual e uma retrospectiva de quase 70 anos .............. 30

4.2.1 A assembleia de Saturniidae da Estação Biológica de Boraceia .................... 30

4.2.2 Avaliação histórica das espécies de Saturniidae registradas entre 1948 e 1950

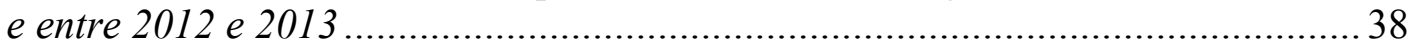

4.2.3 As espécies de Saturniidae da Estação Biológica de Boraceia e outros levantamentos 
4.2.4 A fauna de Saturniidae da Estação Biológica de Boraceia hoje e cerca de 70 anos atrás

4.3 Potencial dos dados coletados para avaliação da relação das espécies da Estação

Biológica de Boraceia com variáveis temporais e ambientais .56

4.3.1 Correlações das distribuições de abundância e do número de espécies e de táxons supraespecificos com temperatura e número de intervalos de coleta. .........56

4.3.2 Correlações das distribuições de abundância e do número de espécies e táxons supraespecificos com variáveis temporais

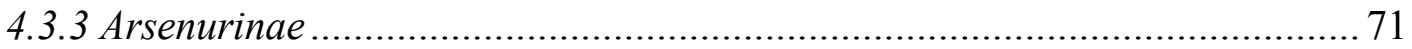

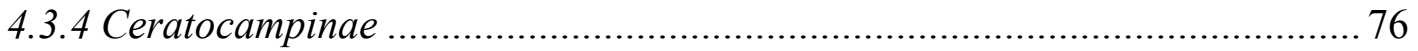

4.3.5 Hemileucinae ................................................................................. 83

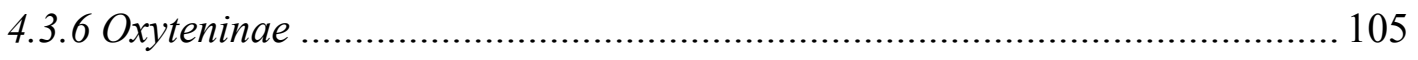

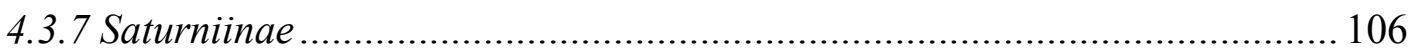

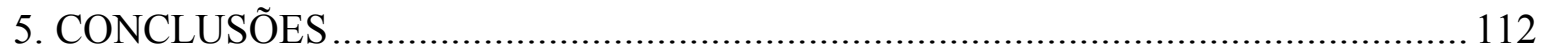

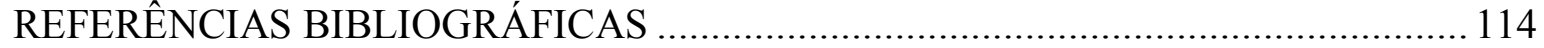

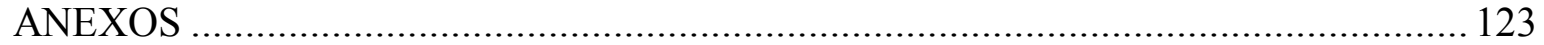

Anexo A. Primeira página do protocolo utilizado durante as coletas....................... 123

Anexo B. Segunda página do protocolo utilizado durante as coletas....................... 124

Anexo C. Lista do material dissecado. Somente machos foram dissecados (pp.126-127).

Anexo D. Lista do número de exemplares fotografados de todas as espécies organizadas por subfamílias e por ordem alfabética de espécies (pp. 128-130).

Anexo E. Lista dos exemplares fotografados associados ao número de tombo e ao número da etiqueta relacionada à foto (pp. 131-136).

Anexo F. Exemplares fotografados agrupados por subfamília e nomes de espécie em ordem alfabética. Medidas após símbolo de macho e fềmea correspondem à envergadura do exemplar; VD - vista dorsal e VV - vista ventral. 136

Anexo G. Número de semaforontes imaturos de cada espécie (por ordem alfabética) depositados na coleção de imaturos de Lepidoptera do MZSP. Espécies de famílias distintas de Saturniidae apresentam o nome da respectiva família entre parênteses.. 189 Anexo H. Fotografia dos imaturos criados em laboratório. 190 


\section{INTRODUÇÃO}

\subsection{Mata Atlântica}

A Mata Atlântica é considerada uma das grandes prioridades para a conservação de biodiversidade em todo o continente americano (Mittermeier et al. 1998; Myers et al.2000). Em estado crítico, sua cobertura florestal encontra-se bastante reduzida. Estima-se que restam entre $11,73 \%$ e $16 \%$ da área original, sendo que $42 \%$ desta área restante está representada por fragmentos menores que 250 ha (Ribeiro et al. 2009)

Distribuída por 17 estados brasileiros, ocorrendo continuamente entre o Rio Grande do Norte e o Rio Grande do Sul ao longo de 23 graus de latitude sul e cerca de $5000 \mathrm{~km}$ ao longo da costa, adentrando para o interior nas regiões Sudeste, Sul e Centro-Oeste, e ainda cruzando as fronteiras com o Paraguai e a Argentina, esse bioma é composto por uma série de fitofisionomias bastante diversificadas determinadas pela proximidade da costa, relevo, tipos de solo e regimes pluviométricos. Essas características são responsáveis pela evolução de um rico complexo biótico de natureza florestal (Brown 1991; Brown \& Brown 1992; Dean 1995; Pinto et al. 1997; Brown \& Freitas 2000a, b; Oliveira-Filho \& Fontes 2000).

Apesar da devastação acentuada, a Mata Atlântica ainda contém uma parcela significativa da diversidade biológica do Brasil, com altos níveis de endemismo. Nosso conhecimento sobre seus indicadores ecológicos, no entanto, avança muito lentamente, comparado à velocidade e intensidade com que atuam os fatores de degradação. Pinto et al. (2006) comentam, por exemplo, que, das 12 espécies de marsupiais consideradas endêmicas e/ou ameaçadas de extinção, apenas duas, Philander frenata (Olfers, 1818) e Didelphis aurita (Wied, 1826), apareceram em mais de dez publicações ao longo de dez anos. Para muitas espécies, a literatura científica se resume ao trabalho de descrição da espécie ou permanece apenas na forma de trabalhos acadêmicos (monografias, dissertações e teses), frequentemente dificultando o estabelecimento imediato de programas de monitoramento e manejo dessas espécies, às vezes com reconhecida vulnerabilidade diante às transformações nos ecossistemas.

A obtenção de mais dados sobre a biodiversidade é, sem dúvida, um aspecto capital no estabelecimento de estratégias eficientes para a conservação. Apesar dos avanços no conhecimento científico sobre a distribuição geográfica e o status taxonômico de algumas espécies animais e vegetais, ainda é necessário ampliar consideravelmente as pesquisas de campo para aumentar nosso conhecimento sobre a diversidade biológica da Mata Atlântica e 
de outros biomas do País (Lewinsohn \& Prado 2002). Áreas sujeitas a inventários biológicos mais intensivos na Mata Atlântica seguem confirmando o seu alto grau de riqueza e endemismo e registrando novas espécies para a ciência (p. ex. Projeto Biota/FAPESP/Hymenoptera e Isoptera - E. M. Cancello, com. pess.; ver também Cancello et al. 2014), mesmo em grupos taxonômicos bem conhecidos como é o caso das aves (Silva et al. 2003) e dos primatas (Lorini \& Persson 1990; Pontes et al. 2006).

Os inventários da diversidade biológica, em geral, são realizados com o objetivo principal de documentar a distribuição espacial das espécies (Kremen et al. 1993; Heywood \& Watson 1995; Stork \& Samways 1995). Para Longino \& Colwell (1997), esses inventários são necessários também para a caracterização de comunidades, visando à amostragem estruturada da fauna e/ou flora como forma de se estimar a distribuição de abundância, a riqueza de espécies e a complementaridade com outras comunidades (sensu Colwell \& Coddington 1994). Podem ainda fornecer dados para análise de relação evolutiva entre grupos de organismos (ver Balke et al. 2008). Entre as aplicações dessa caracterização está o estabelecimento de prioridades para os programas de monitoramento e conservação, com base em alguns parâmetros de diversidade de comunidades (p. ex. riqueza de espécies e uniformidade).

Inventários são urgentemente necessários para os grupos megadiversos pouco estudados no Brasil. Entre eles estão os artrópodes cuja importância em inventários da biodiversidade tem sido destacada ao longo das duas últimas décadas (Longino \& Colwell 1997). Esse destaque deve principalmente ao fato de: (i) os artrópodes desempenharem importantes funções na manutenção de ecossistemas, (ii) compreenderem cerca de $80 \%$ de todas as espécies de animais, (iii) responderem rapidamente às mudanças em seus microambientes, e (iv) serem pequenos e abundantes em praticamente todos os habitats.

\subsection{A Estação Biológica de Boraceia}

A Estação Biológica de Boraceia (EBB) (Figs. 1-7) representa uma pequena porção da Mata Atlântica, distante aproximadamente $110 \mathrm{~km}$ da cidade de São Paulo e está localizada no Município de Salesópolis, São Paulo ( $23^{\circ} 39^{\prime} \mathrm{S}, 45^{\circ} 53^{\prime} \mathrm{W}-850 \mathrm{~m}$ de altitude). Possui cerca de 40 alqueires (96 ha), e está inserida em uma área de preservação de 6.800 alqueires (16.450 ha), a qual por sua vez estende-se pelas adjacências do Parque Estadual da Serra do Mar (Travassos \& Camargo 1958; Custodio Filho 1989) (Fig. 1). A EBB foi inaugurada em 1940 com o nome de Estação Experimental de Quina da Secretaria de Agricultura do Estado de São Paulo. No 
entanto, graças a sua localização e área de abrangência, a EBB sempre foi considerada um ponto interessante para estudos da fauna da Mata Atlântica, em especial insetos noturnos, e assim, em 1953, a Estação Experimental de Quina foi transferida para o Departamento de Zoologia, sob o nome de Estação Biológica de Boraceia (Travassos Filho \& Camargo 1958).

De acordo com Setzer (1946), Boraceia está entre as áreas mais úmidas do Brasil, entre 1925-1944 apresentou média anual de pluviosidade de $3.058 \mathrm{~mm}$. Posteriormente, Custodio Filho (1989) registrou média de 2.018,84 mm de pluviosidade entre 1970-1986 e umidade relativa nunca menor que $83 \%$. A vegetação que cobre a área da floresta compreende palmeiras (especialmente Euterpe edulis Mart.), samambaias e grandes bambus. Há riachos ao longo da mata onde são encontradas plantas do gênero Heliconia L. que são bem características da região (Bertoluci \& Rodrigues 2002). Grande quantidade de epífitas, em especial da família Bromeliaceae, estão presentes ao longo dos troncos de boa parte das árvores.

Dentre as instalações locais estão os alojamentos, os quais são constantemente utilizados para o desenvolvimento de pesquisas na reserva ou no seu entorno, e para receber grupos relacionados a disciplinas de campo. A primeira listagem da fauna local referiu-se aos mamíferos e foi timidamente apresentada por Carvalho (1965) como adendo da respectiva publicação sobre "bionomia de pequenos mamíferos em Boraceia". Posteriormente, foi divulgado um inventário dedicado aos anuros em um extenso trabalho de Heyer et al. (1990). O conhecimento da avifauna local tem sido registrado há décadas e recentemente foi sumarizado por Cavarzere et al. (2010). O primeiro inventário de artrópodes ocorreu em 2004 com a listagem dos Plecoptera do gênero Anacroneura Klapálek, 1909 realizado por Froehlich (2004). Passados alguns anos, Ferro \& Diniz (2007) apresentaram a lista das espécies de Arctiidae (Lepidoptera) com base nos exemplares depositados em quatro coleções científicas do Brasil. Logo em seguida, Duarte et al. (2008) apresentaram a lista das espécies de Sphingidae noturnos atraídos por armadilhas luminosas, com base no material depositado no Museu de Zoologia da Universidade de São Paulo (MZSP) e no material de coletas contemporâneas ao trabalho; e recentemente Viviani \& Santos (2012) publicaram uma lista de Coleoptera bioluminescentes da EBB. Além desses inventários, a EBB tem sido de grande relevância para o conhecimento da biodiversidade de insetos relacionados à Mata Atlântica, como se pode perceber pelas inúmeras publicações pertinentes à história natural de espécies de Coleoptera desenvolvidas por Cleide Costa, Sergio A. Vanin e Sônia A. Casari, e muitas vezes incluindo outros colaboradores (ver Costa et al. 1988). 
Em abril de 1942 ocorreu a primeira campanha para observação e coleta de insetos noturnos na EBB. Desde então até setembro de 1968, os entomólogos Lauro Travassos Filho, Romualdo Ferreira D’Almeida, Ernesto Xavier Rabello e outros colaboradores continuaram a coletar periodicamente na Estação, especialmente insetos da ordem Lepidoptera (Travassos \& Camargo 1958; dados não publicados). Em consequência dessas campanhas o MZSP conta com um acervo muito bem representado de mariposas da região atlântica do estado, incluindo os saturniídeos. 

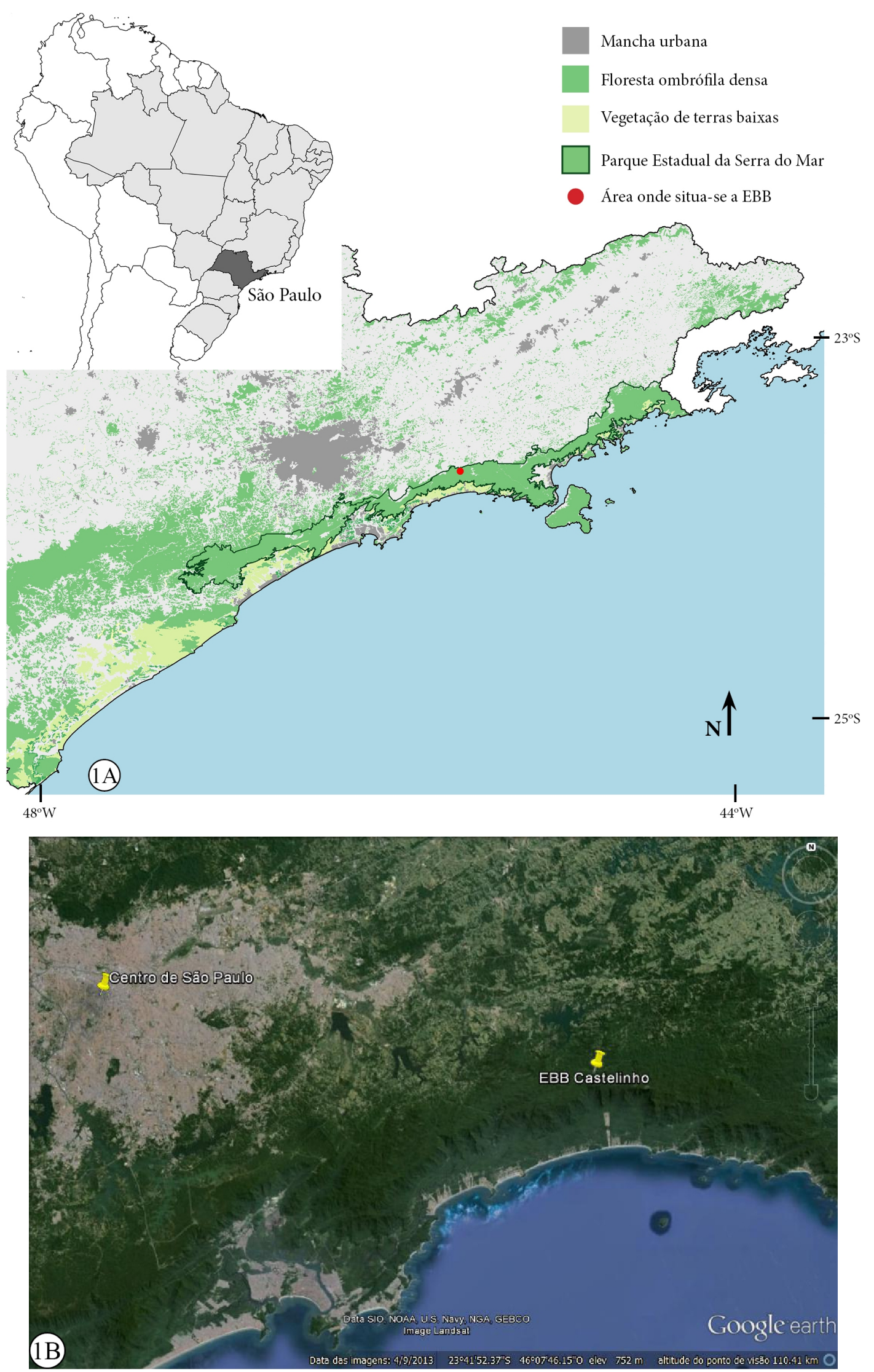

Figuras 1. Localização da área de coleta, Estação Biológica de Boraceia, Salesópolis, SP, Brasil. (A) Mapa do Brasil com o Estado de São Paulo destacado com cinza escuro; (B) Imagem de satélite com a área de coletada (EBB Castelinho) e arredores. 

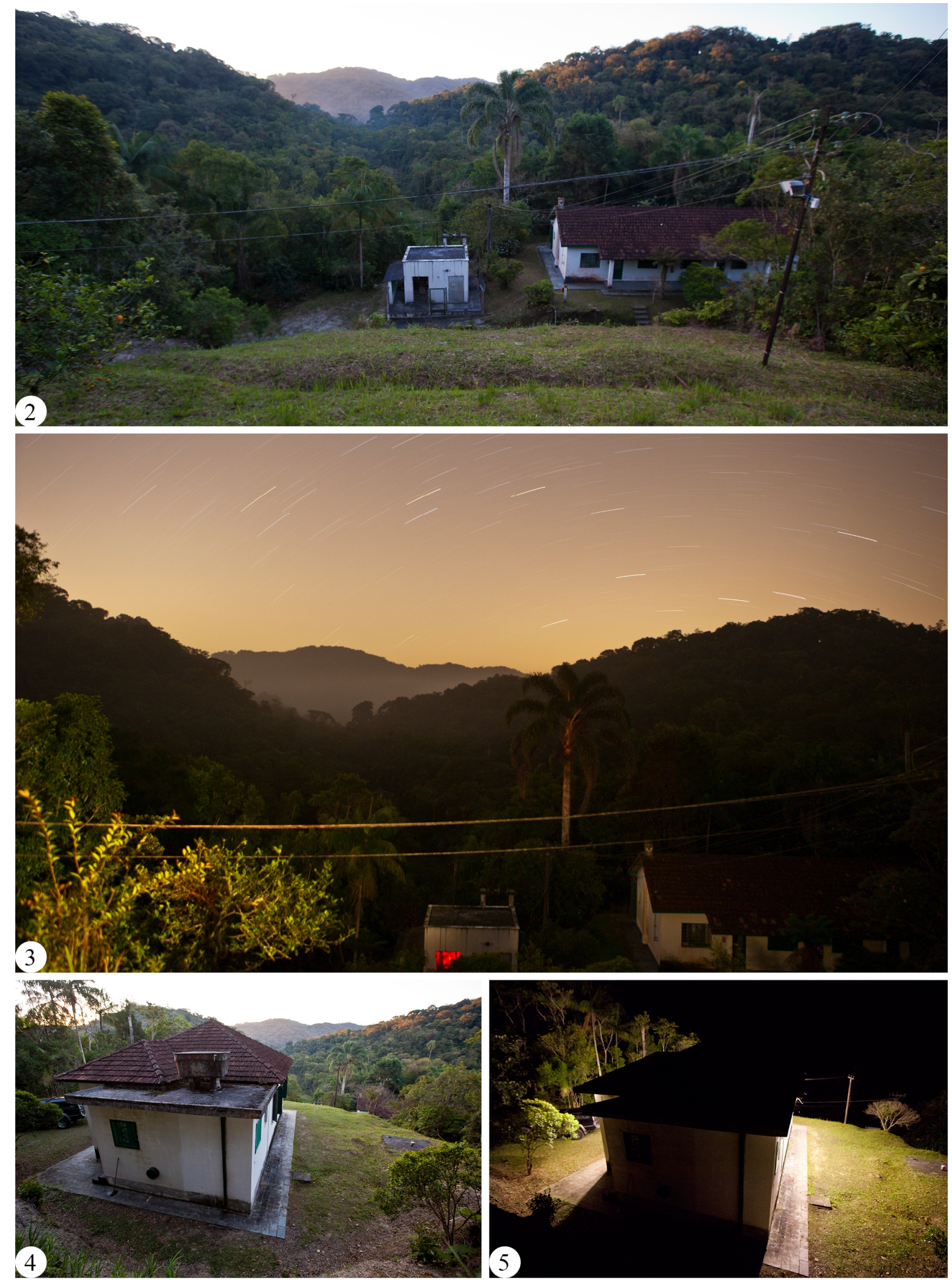

Figuras 2-5. Estação Biológica de Boraceia, Salesópolis, SP, Brasil: Entorno da "Casa dos Biologistas" (sensu Travassos \& Camargo 1958) ou "Castelinho", trata-se de uma das casas de alojamento dos pesquisadores que tem sido historicamente utilizada para coleta de insetos noturnos atraídos por armadilhas luminosas. (2) Vista do fim de tarde a partir do "Castelinho"; (3) mesma vista à noite com lâmpadas utilizadas para coleta desligadas; (4) vista do fim de tarde, foto tirada do fundo da casa ("Castelinho"); (5) mesma vista à noite com lâmpadas utilizadas para coleta ligadas. Fotos: Fabiano F. Albertoni. 

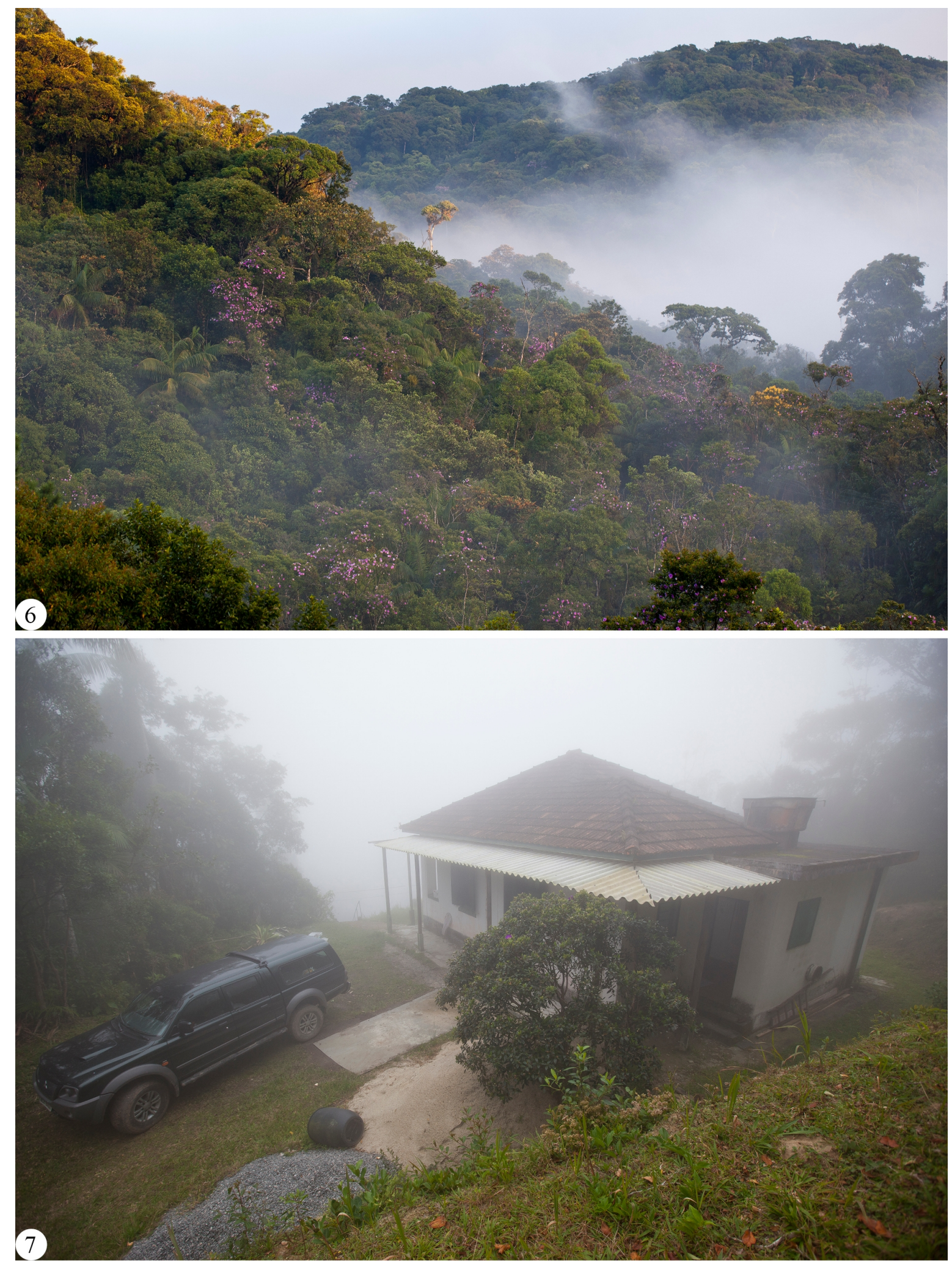

Figuras 6-7. Estação Biológica de Boraceia, Salesópolis, SP, Brasil: Entorno da "Casa dos Biologistas" ou "Castelinho". (6) Vista do fim de tarde da floresta em frente ao "Castelinho" com nevoeiro típico da região; (7) vista a partir da parte de trás do "castelinho" em um momento de intenso nevoeiro. Fotos: Fabiano F. Albertoni. 


\subsection{Ordem Lepidoptera}

Lepidoptera é a segunda maior Ordem da Classe Insecta e do Reino Animalia. Compreende aproximadamente 160.000 espécies descritas de mariposas e borboletas (Kristensen et al. 2007). Alguns autores afirmam que a maioria das estimativas sobre a diversidade destes insetos, em geral, expressam números muito aquém da realidade. Acreditase que se houver uma intensificação de levantamentos faunísticos e de estudos taxonômicos para inúmeras famílias pouco estudadas, é possível que se tenha algo em torno de 500.000 espécies de Lepidoptera em todo mundo (Gaston 1991; Kristensen et al. 2007). Essa estimativa demonstra o tanto que se desconhece sobre um dos principais grupos de insetos que, reconhecidamente, auxiliam na manutenção de vários ecossistemas.

No Brasil, são conhecidas mais de 25.000 espécies de Lepidoptera, mais da metade das espécies da região neotropical (Heppner 1998). Das 122 famílias reconhecidas por Kristensen et al. (2007), 71 ocorrem no Brasil (Duarte et al. 2012).

Como os lepidópteros são importantes em ecossistemas tropicais devido às suas interações com a vegetação e a fauna de invertebrados e vertebrados (Gilbert 1984; Otero \& Marigo 1990; Miller 1993; Góes 2004), e são facilmente amostrados para estudos de comunidades, vários autores têm sugerido estes insetos como indicadores para o monitoramento da diversidade biológica, integridade de paisagens e uso sustentável de recursos naturais (Brown 1991, 1992; Kremen et al. 1993; Sparrow et al. 1994; Brown 1996a, b; Brown \& Freitas 2000a, b) e dentre alguns grupos de Lepidoptera que podem ser adequadamente utilizados para monitoramentos ambientais encontra-se Saturniidae (Brown \& Freitas 1999).

\subsection{Família Saturniidae}

Atualmente a família Saturniidae está dividida em nove subfamílias e é a família com maior número de espécies dentro de Bombycoidea, apresentando distribuição quase em todo mundo, não ocorrendo apenas nos extemos norte (North Cape, Escandinávia) e sul (Ushuaia, Terra del Fuego) do planeta (Lemaire \& Minet 1998). Está representada por 2.349 espécies e 169 gêneros (van Nieukerken 2011), e a maior diversidade do grupo concentra-se na região Neotropical (Lemaire \& Minet 1998), onde são estimadas cerca de 900 espécies. No Brasil, são conhecidas aproximadamente 400 espécies (Duarte et al. 2012).

Recentemente, a família foi figurada como grupo monofilético em Bombycoidea (Zwick et al. 2011), corroborando a hipótese anterior de Regier et al. (2008), na qual a monofilia de 
Saturniidae foi fortemente sustentada com relação ao grupo externo, sendo este representado por 30 espécies pertencentes às demais famílias/subfamílias de Bombycoidea.

Lemaire \& Minet (1998) dividiram os saturniídeos em nove subfamílias: Oxyteninae, Cercophaninae, Arsenurinae, Ceratocampinae, Hemileucinae, Agliinae, Salassinae, Ludiinae e Saturniinae. As subfamílias Oxyteninae e Arsenurinae ocorrem apenas no neotrópico e possuem, respectivamente, 35 espécies em três gêneros e 60 espécies em 10 gêneros. Cercophaninae, com aproximadamente 10 espécies em quatro gêneros, Ceratocampinae com aproximadamente 170 espécies em 27 gêneros e Hemileucinae, a subfamília com maior número de espécies, aproximadamente 630 distribuídas em 51 gêneros, ocorrem no Novo Mundo. Apenas Saturniinae possui representantes em todo mundo, sendo esta a segunda subfamília com maior diversidade contendo aproximadamente 480 espécies e 59 gêneros. As subfamílias Agliinae, com três espécies em um gênero, Salassinae, com 12 espécies e um gênero e Ludiinae, com 80 espécies em oito gêneros ocorrem exclusivamente no Paleártico, na Ásia e na África, respectivamente. Das subfamílias enquadradas na classificação acima, cinco encontram-se representadas na fauna brasileira: Oxyteninae, Arsenurinae, Ceratocampinae, Hemileucinae e Saturniinae (Duarte et al. 2012).

Os saturiniideos adultos compreendem mariposas de pequeno a grande porte, medindo entre 30 e $250 \mathrm{~mm}$ de envergadura alar. São de cores bastante variáveis havendo, no entanto, em um grande número de espécies, predominância de alguns tons de castanho. Podem ser diagnosticados por uma série de características. Diferentemente das outras famílias de Bombycoidea, não possuem frênulo, as antenas dos adultos apresentam flagelômero distal em forma de cone sensorial e o quarto tarsômero das pernas anteriores dos machos é sexualmente dimórfico. Em muitos casos apresentam significativa variação intraespecífica; apresentam aparelho bucal rudimentar e possivelmente não se alimentam em sua curta vida, a qual varia de cinco a 12 dias (Janzen 1984); o dimorfismo sexual é evidente nas espécies de Ceratocampinae, Hemileucinae e Oxyteninae, cujas fêmeas podem pesar mais que o dobro dos machos, possuem antenas geralmente filiformes (pectinada nos machos), asas maiores que os machos e de bordas arredondadas (Janzen 1984); são predominantemente de hábito noturno, excetuando algumas espécies de Agliinae (não registrada para o Brasil), Saturniinae e Hemileucinae (Lemaire \& Minet 1998).

Apesar de haver algumas espécies de importância econômica devido aos danos que suas larvas causam à agricultura, em especial da subfamília Hemileucinae (Specht et al. 2008), na natureza os dados sobre plantas hospedeiras e biologia de Saturniidae são muito pouco 
conhecidos para as espécies neotropicais (Lemaire 2002). Na subfamília Hemileucinae também estão incluídas algumas espécies de importância médica, especialmente na fase de larva. As larvas de Hemileucinae possuem escolos com "espinhos" capazes de injetar substâncias urticantes e até hemorrágicas (Specht et al. 2008), destacando-se o gênero Lonomia Walker, 1855, cuja toxina pode levar o organismo que entrou em contato à morte. Lagartas de Automeris também são de importância médica e econômica para agricultura, pois assim como outros Hemileucinae alimentam-se de diversas plantas cultivadas, especialmente as frutíferas (Specht et al. 2008) como abacate - Persea americana Mill (Lauraceae), goiabeira - Psidium guajava Linn. (Myrtaceae), laranjeiras - Citrus spp. (Rutaceae), macieiras - Malus spp. Rosaceae) e outras (ver lista para plantas hospedeiras de Hemileucinae do Rio Grande do Sul em Specht et al. 2008).

Os imaturos de Saturniidae historicamente incluem-se como importantes semaforontes no suporte à classificação da família, destacando-se os trabalhos de Mosher $(1914,1916)$ sobre morfologia das pupas de Hemileucinae, Saturniinae e Ceratocampinae (Hemileucidae, Saturniidae e Caratocampidae sensu Mosher 1914, 1916); Balcázar-Lara \& Wolfe (1997) e Peigler (1993), nos quais os caracteres de imaturos são usados para análise cladística de Ceratocampinae e Arsenurinae, respectivamente; e mais recentemente Rougerie \& Estradel (2008) descrevendo a importância de caracteres de imaturos para o tratamento filogenético dentro de Saturniinae.

\subsection{Saturniidae do Brasil (estado-da-arte)}

No Brasil e em toda América do Sul ocorrem cinco das nove subfamílias de Saturniidae: Arsenurinae, Ceratocampinae, Hemileucinae, Oxyteninae e Saturniinae, não ocorrendo Agliinae, Cercophaninae, Ludiinae e Salassinae. Para o país, são registradas aproximadamente 400 espécies distribuídas nas cinco subfamílias (Duarte et al. 2012). Estima-se que haja aproximadamente 280 espécies no Estado de São Paulo (Brown \& Freitas 1999), no entanto, apesar de a fauna local ser relativamente bem representada em coleções entomológicas, a dificuldade no gerenciamento do grande volume de informações, (determinação taxonômica e dados de etiquetas) não permitiu até o momento a divulgação de dados aprofundados sobre a diversidade da família para o Estado, sendo este número uma aproximação especulativa relativamente embasada. O Estado de São Paulo conta apenas com um levantamento não publicado realizado na Estação Biológica de Boraceia entre os anos de 2000 e 2003, no qual, 
com auxílio de lâmpadas de vapor de mercúrio para atrair os adultos, foram coletadas 62 espécies em nove saídas de campo (Luiz Carlos de S. Ferreira, dados não publicados).

Os únicos Estados do país que constam com listagem de espécies relativamente bem documentadas são o Paraná e o Rio Grande do Sul. Para o segundo, são listadas 113 espécies de todas as subfamílias, excetuando-se Oxyteninae ainda sem registro para região. Ocorrem 61 espécies de Hemileucinae, 30 de Ceratocampinae, 12 de Arsenurinae e 10 de Saturniinae (Nunes 2004; Specht et al. 2005; Prestes et al. 2009; Corseuil 2013). O projeto de levantamento da entomofauna do Paraná em oito localidades do Estado, entre 1986 e 1987, obteve como um dos resultados uma lista de 83 espécies de Saturniidae (Marinoni et al. 1997). Mais recentemente, entre 2010 e 2011, para uma dissertação de mestrado ainda não publicada, foram amostrados 856 exemplares atraídos por luz, de 89 espécies e 33 gêneros, sendo todos amostrados em um único ponto de coleta (Santos 2012). Muitas espécies são as mesmas das listadas por Marinoni et al. (1997), porém há diversos novos registros para o Estado do Paraná.

O único bioma (ou ecótono) brasileiro cuja fauna de Saturniidae foi documentada é o cerrado (Camargo \& Becker 1999; Camargo et al. 2008). Em um extenso trabalho envolvendo 74 localidades, 10 Estados mais o Distrito Federal, e levantamentos de dados referentes às diversas coleções brasileiras, foram catalogadas 202 espécies da família (Camargo et al. 2008). Destas, 119 (58,9\%) são de Hemileucinae, 48 (23,7\%) de Ceratocampinae, 20 (10,9\%) de Arsenurinae, 11 (5,4\%) de Saturniinae e 2 (1\%) de Oxyteninae.

Além dos inventários, dezenas de estudos relacionados à história natural de algumas espécies têm sido desenvolvidos, em especial sobre as espécies de Hemileucinae por tratar-se de lagartas e até adultos com importância médica. No entanto, muitas espécies de Arsenurinae e Ceratocampinae que ocorrem no Brasil também tiveram seus imaturos e biologias descritos.

A fauna de saturniídeos do Estado de São Paulo é ainda pouco conhecida, contando apenas, até onde sabemos, com um levantamento não publicado realizado na Estação Biológica de Boraceia, Salesópolis. Neste levantamento, foram coletadas 62 espécies com auxílio de lâmpadas de vapor de mercúrio para atrair os adultos. Ao todo foram nove visitas entre setembro de 2000 e abril de 2003 (Luiz Carlos de S. Ferreira, dados não publicados).

Tendo em vista a eficiência de coletas noturnas utilizando-se armadilhas luminosas para amostrar exemplares adultos de Saturniidae; a posição estratégica da EBB para o cenário da Mata Atlântica; e sendo a fauna do Estado de São Paulo ainda pouco documentada. O presente estudo reporta o que é, até o momento, a primeira análise que utiliza dados de longo prazo 
(quase 70 anos) da fauna de Saturniidae da Mata Atlântica. E neste contexto, remete-se aos dados históricos concernentes às espécies coletadas e depositadas no acervo do Museu de Zoologia da Universidade de São Paulo entre 1942 até 2013, para gerar uma lista de espécies, e revelar informações sobre riqueza, composição das espécies e abundância dos exemplares coletados, tanto em todo período mencionado, como em um compartivo entre dois anos consecutivos de coletas, entre 1948 e 1950, com as coletas recentes, entre 2012 e 2013. Além disso, o presente estudo avalia as distribuições sazonais e circadianas das espécies coletadas entre 2012 e 2013. 


\section{OBJETIVOS}

\subsection{Objetivo geral}

Contribuir para o conhecimento da fauna de Saturniidae (Lepidoptera) da Mata Atlântica e do Estado de São Paulo.

\subsection{Objetivos específicos}

- Realizar o levantamento dos Saturniidae coletados na Estação Biológica de Boraceia;

- Analisar, ao longo de um ano, a abundância relativa, a riqueza de espécies, a diversidade e a uniformidade de Saturniidae da Estação Biológica de Boraceia e comparar com os dados disponíveis amostrados em 1948 e 1950;

- Analisar, ao longo de um ano, a sazonalidade das espécies mais abundantes e a frequência de determinadas espécies de acordo com a variação temporal ao longo de cada noite de coleta (distribuição circadiana), dos Saturniidae da Estação Biológica de Boraceia. 


\section{MATERIAL E MÉTODOS}

\section{1 Área de Estudo (Figs. 1-7)}

A parte de campo do presente estudo foi realizada na EBB (detalhes sobre a área de estudo estão no tópico “A Estação Biológica de Boraceia”, p. 2).

Os dados de pluviosidade média mensal e os valores de temperaturas mínima e máxima foram obtidos pelo radar meteorológico do DAEE (Departamento de Águas e Energia Elétrica), instalado no Município de Salesópolis, cerca de $80 \mathrm{~km}$ da capital e pela própria base da SABESP - Casa Grande. Esse radar cobre um raio de $240 \mathrm{~km}$, a partir de Salesópolis e mede a intensidade de chuvas potenciais a uma altitude de aproximadamente $3.000 \mathrm{~m}$ (dados extraídos da página eletrônica do Departamento de Águas e Energia Elétrica http://www.daee.sp.gov.br). Os dados climáticos para 1948 e 1950 estão disponíveis em Leemans \& Cramer (1991).

Os dados de vegetação presente no mapa (Fig. 1) foram obtidos diretamente do Atlas de Remanescentes da SOS Mata Atlântica (SOS Mata Atlântica 2012).

\subsection{Metodologia de coleta e identificação das espécies}

As amostragens dos saturniídeos foram realizadas seguindo o mesmo plano básico da metodologia empregada em 1948 e 1950. Os saturniídeos foram atraídos com lâmpadas de vapor de mercúrio instaladas em uma das casas-alojamento da EBB (casa dos biologistas sensu Travassos Filho \& Camargo 1958; atualmente conhecida como castelinho) que por estar localizado em um ponto elevado, tem sido bastante utilizado para coleta de insetos noturnos (Duarte et al. 2008). As paredes brancas do alojamento servem para reforçar a luminosidade e atrair uma quantidade maior de lepidópteros (Travassos Filho \& Camargo 1958). As coletas para este trabalho foram realizadas uma vez por mês, em quatro noites consecutivas, no período de março de 2012 a abril de 2013 (Figs. 8-10).

As amostragens foram realizadas em noites de lua nova para que a luz lunar não interferisse na atratividade dos saturniídeos pela luz artificial (Yela \& Holyoak 1997). Os saturniídeos foram amostrados do crepúsculo (18:00h) ao amanhecer (6:00h), gerando 12 horas de esforço por noite de coleta - o "horário de verão" adotado por alguns Estados do Brasil, incluindo São Paulo, não foi considerado. Estas 12 horas foram divididas em 24 intervalos de 
tempo, de 30 minutos cada, e grupos de exemplares foram arrolados de acordo com o intervalo de tempo em que foram coletados. Foram utilizados recipientes plásticos para individualizar as amostras durante o fluxo de trabalho de campo (anotações de protocolo, "envelopagem" e coleta de exemplares) (Figs. 11-13).

Duas folhas por noite compunham os protocolos de coleta, uma com o número de exemplares, a temperatura, a umidade média registrada e as observações para cada período; e a outra folha para o registro do número de exemplares de cada espécie (Fig. 11; Anexos A, B). Esta segunda folha do protocolo foi muito importante para assegurar o atrelamento dos exemplares de cada intervalo de tempo a seus respectivos intervalos de tempo durante todo o procedimento laboratorial, da coleta até a identificação de cada exemplar. A possibilidade de haver desligamento das informações atreladas a cada exemplar durante os eventos (coleta, montagem, desmontagem, inserção na gaveta de entrada, rotulagem, tombo e identificação) é proporcional ao número de eventos e de exemplares processados. A existência da segunda página de protocolo nos permitiu solucionar alguns casos de perda de referência do exemplar com sua origem ou mesmo corrigir referências cruzadas. 

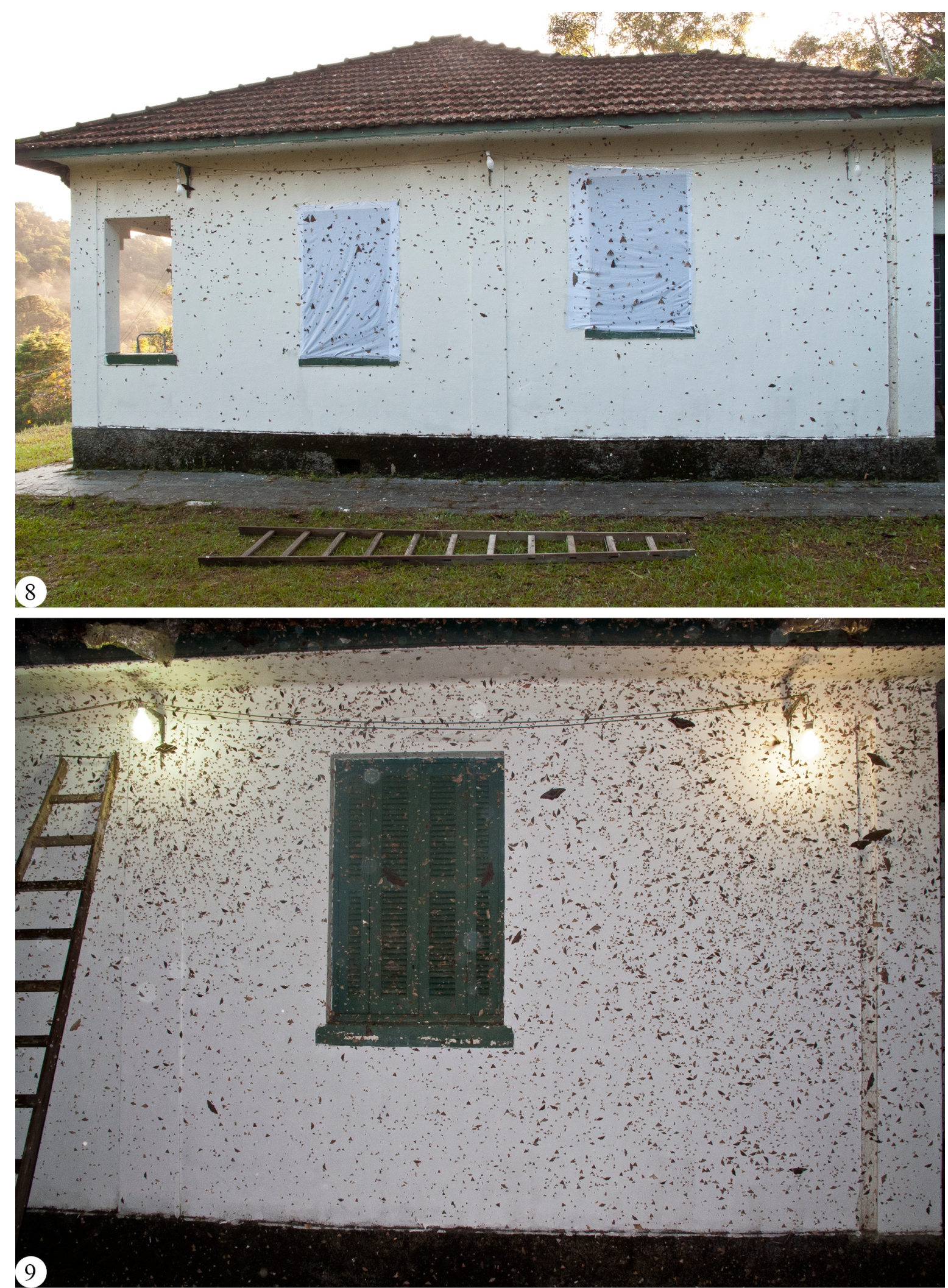

Figuras 8-9. Estação Biológica de Boraceia, Salesópolis, SP, Brasil: Amostragem de Saturniidae na "Casa dos Biologistas" (sensu Travassos \& Camargo 1958) ou "Castelinho". (8) Coleta de 25 de março de 2012, às 7:00h; (9) coleta de 22 de abril de 2012, às 23:10h. Fotos: Fabiano F. Albertoni. 

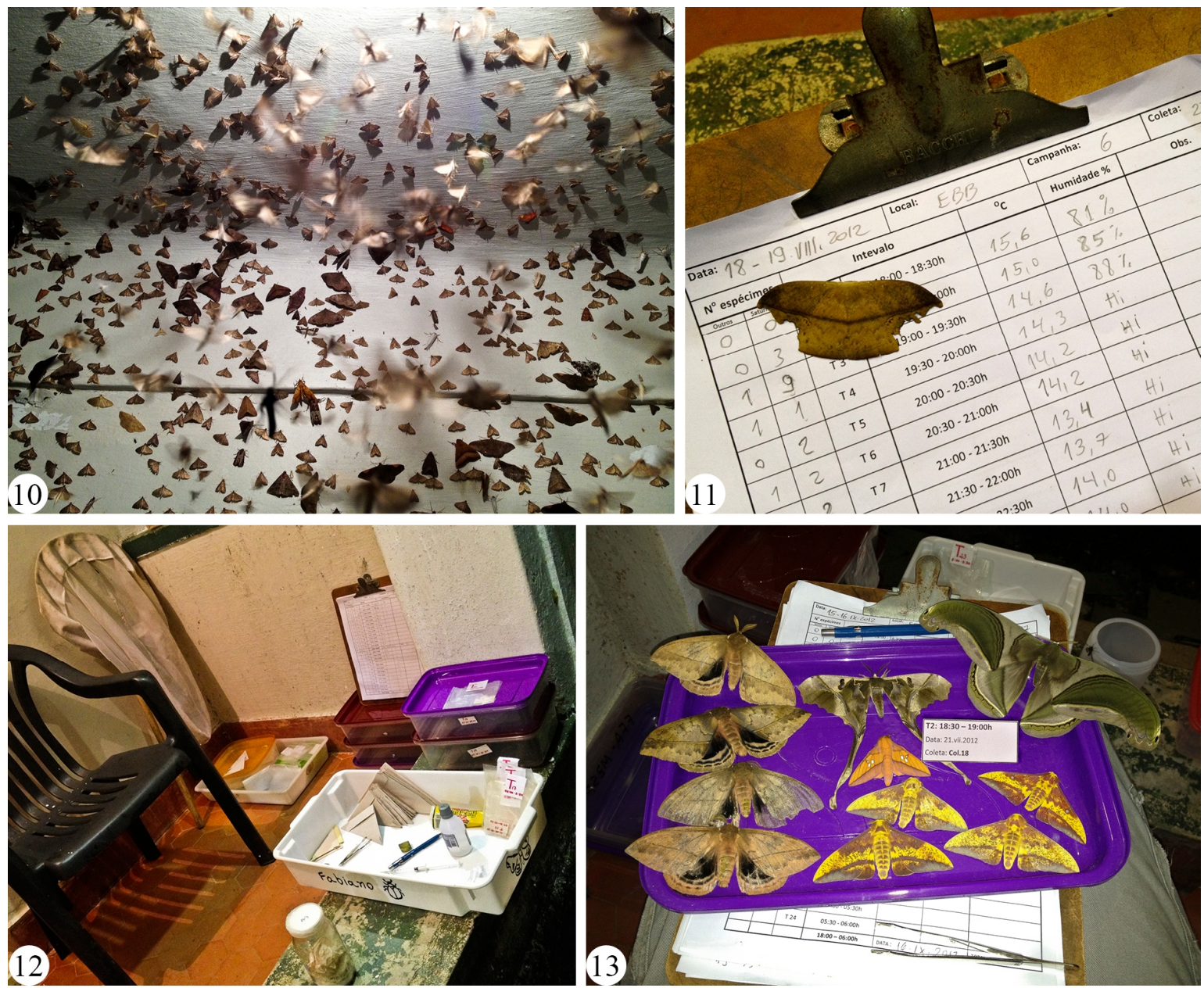

Figuras 10-13. Estação Biológica de Boraceia, Salesópolis, SP, Brasil: Amostragem de Saturniidae. (10) Mariposas atraídas pela lâmpada da varanda da casa; (11) protocolo de coleta com preenchimento iniciado e uma Oxytenis bicornis pousada sobre ele; (12) sistema de organização e materiais utilizados nas coletas para amostrar os Saturniidae a cada intervalo de 30 minutos; (13) saturniídeos referentes a uma unidade de amostra de 30 minutos. Fotos: Fabiano F. Albertoni.

Os exemplares foram sacrificados com injeção de amônia no tórax (Duarte et al. 2008), agrupados pelos respectivos intervalos de tempo e levados para o laboratório onde foram acondicionados em freezers. Posteriormente, foram montados, rotulados e tombados (com número de tombo) ou mantidos individualizados em envelopes contendo os dados de origem e nome da espécie (Figs. 14, 19), e depositados no acervo do MZSP; os dados pertinentes a todos os exemplares foram digitalizados. Para rotulagem foram utilizadas etiquetas tradicionais (local, data e coletor) e etiquetas referentes à amostragem do projeto aqui desenvolvido, contendo o código do intervalo de tempo (IT.01-24), seguido pelo intervalo por extenso (p. ex. 18:00-18:30h), o código da coleta (Col.01-51) e o código da campanha (Camp.01-13) em que 
o exemplar foi coletado. Outras etiquetas para objetivos específicos, como de genitália e de exemplar fotografado será exposto adiante.
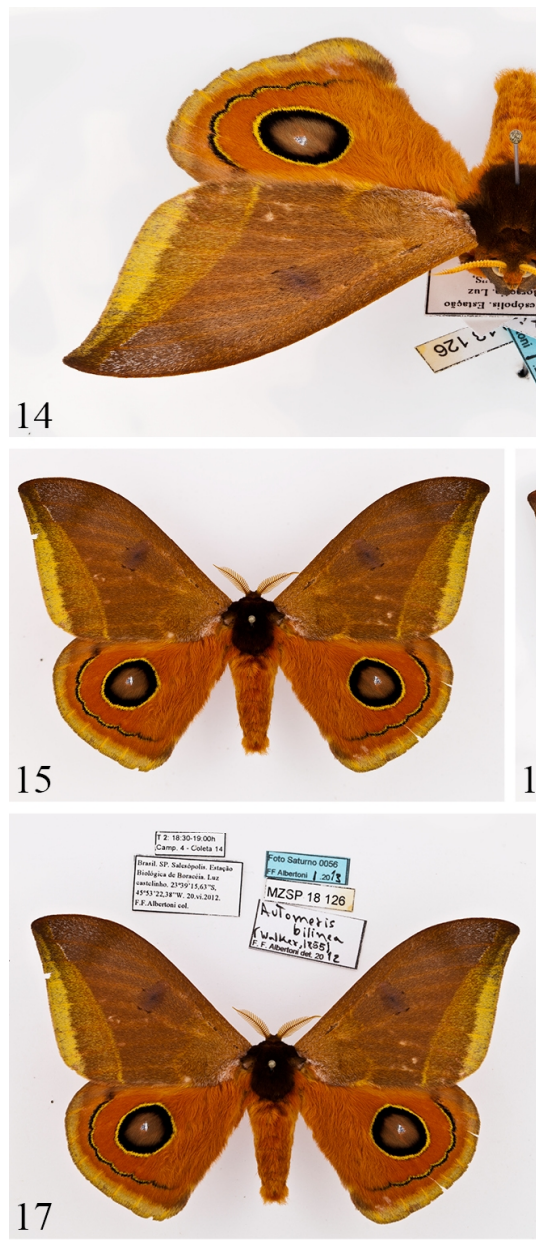
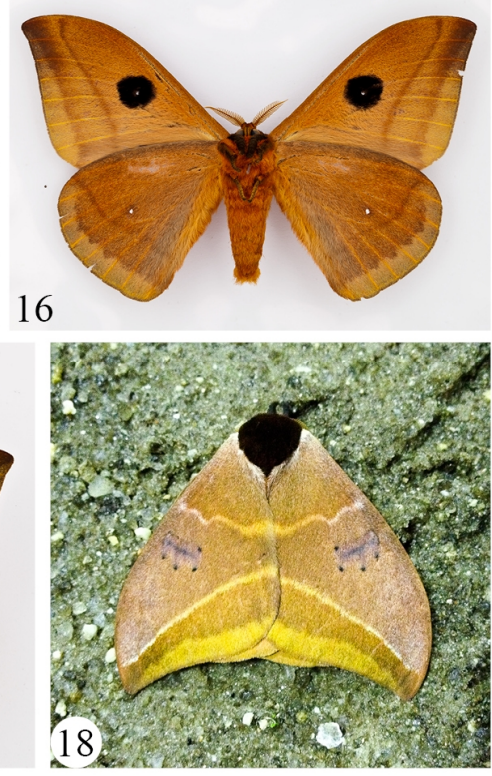

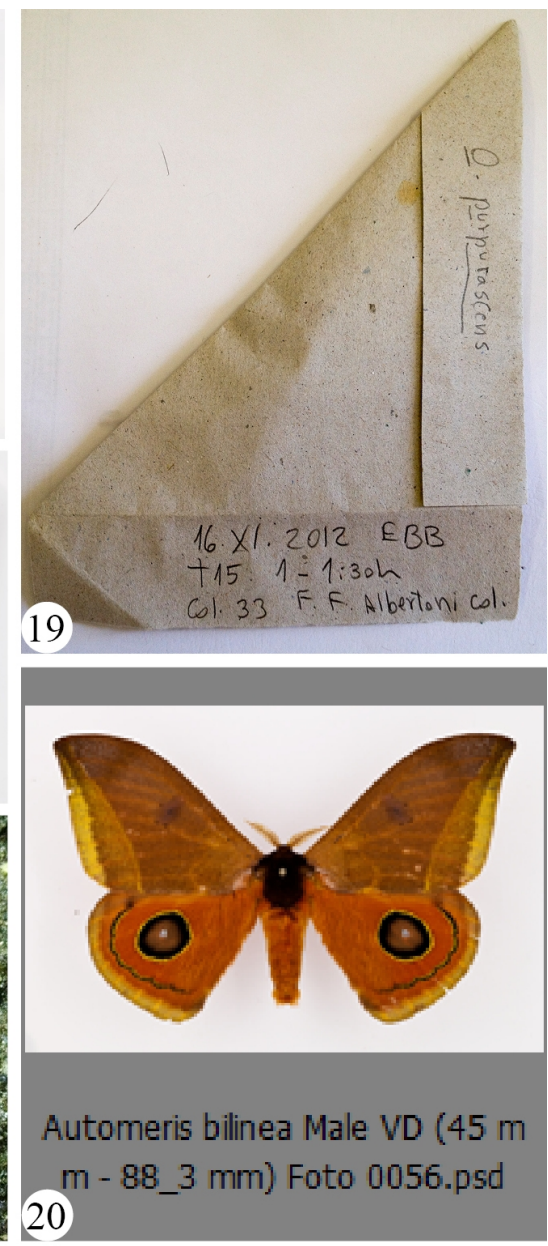

20

Figuras 14-20. Tratamento físico dado ao material inserido na coleção e registro fotográfico, exemplares de Automeris bilinea (Walker). Amostragem de Saturniidae. (14) Mariposa alfinetada com suas respectivas etiquetas; (15) vista dorsal; (16) vista ventral; (17) vista dorsal com as respectivas etiquetas do exemplar; (18) exemplar em campo pousado em posição de descanso; (19) envelope com dados de coleta e contendo exemplar de Othorene purpurascens (Schaus); (20) thumbnail do arquivo referente à vista dorsal do exemplar com respectivo nome do arquivo. Fotos: Fabiano F. Albertoni.

Os exemplares montados e os envelopados foram identificados baseados na literatura disponível: Lemaire $(1978,1980,1988,2002)$, D’Abrera $(1995,1998)$ para a família em geral; Mielke et al. (2005), Wolfe (2005), Specht et al. (2006), Brechlin \& Meister (2011) para atualização dos trabalhos anteriormente citados; além dessa literatura foram utilizados os exemplares previamente identificados da coleção do MZSP e as imagens e os dados associados disponíveis na área restrita a membros da página http://www.silkmoths.bizland.com/indexos.htm. Em alguns casos, foi necessária a dissecção 
dos exemplares para confirmar a identificação, especialmente exemplares do gênero Hylesia Hübner, [1920] e de espécies com grande variação intraespecífica, como Dirphia muscosa Schaus, 1898. Para isso, o abdômen foi cortado aproximadamente entre os segmentos IV-V, inserido em um frasco com $\mathrm{KOH} 10 \%$ e fervido em banho-maria por aproximadamente 10 minutos. Posteriormente, o abdômen foi limpo interna- e externamente com auxílio de pinças e pinceis, e mantido em solução de Chlorazol black (corante azulado para as partes membranosas) por aproximadamente dois minutos; a genitália foi separada dos segmentos abdominais, mas, juntamente com o tegumento do abdômen, foram individualmente acondicionados em frascos com glicerina, contendo os números de série de material dissecado, número o qual também acompanhou o exemplar dissecado. Uma etiqueta idêntica a dos frascos foi fixada no exemplar montado e dissecado.

Para cada primeira citação do nome de uma espécie ou gênero no texto, o nome foi seguido do autor e data da descrição.

\subsection{Fotografia dos exemplares montados}

Para fotografar as mariposas montadas foi utilizado uma máquina Canon EOS 5D Mark II acoplada a uma estativa e à lente Canon EF 100mm Macro f/2.8 L IS USM ou Canon EF 24$70 \mathrm{~mm} \mathrm{f} / 2.8 \mathrm{~L}$ USM, acionada por disparador remoto RS-80N3 e com iluminação continua proveniente de duas lâmpadas MEDALight Ra90 5200K de 25W/120V com difusor.

Foi dada prioridade para exemplares mais frescos e bem preservados; na ausência destes, foram fotografados exemplares previamente existentes e mais bem preservados do acervo de Lepidoptera do MZSP.

Os exemplares foram fotografados em vista dorsal juntamente com suas respectivas etiquetas e sozinhos em vistas dorsal e ventral. Para cada uma das três vistas foram feitas aproximadamente entre duas e oito fotos, gerando um total de 2.547 fotografias. Para o melhor desempenho do fluxo de trabalho com o volume de arquivos "raw", as imagens foram importadas e ajustadas pelo programa Adobe Photoshop Lightroom 3.4, no qual foram reveladas em arquivos de extensão "psd". Posteriormente, as fotografias relativas a cada vista foram combinadas no programa Helicon Focus 5.3 gerando um arquivo também de extensão "psd". Os arquivos receberam a seguinte identificação: o nome da espécie correspondente ao exemplar fotografado, seguido da palavra "etiqueta", ou das abreviações "VD" (vista dorsal) ou "VV" (vista ventral), dependendo do tipo da vista que se referia ao arquivo, sendo estas: 
vista dorsal com as etiquetas, apenas $\mathrm{VD}$ ou $\mathrm{VV}$, mais as medidas da asa direita e da envergadura do exemplar, e o código da etiqueta de exemplar fotografado com seu respectivo número (Figs. 14-17, 20).

Em campo, sempre que possível, exemplares pousados foram fotografados com celular iPhone 4S ou com a máquina fotográfica referida anteriormente (Fig. 18) gerando um banco de imagens dos representantes de várias espécies em posição de descanso ou de aposematismo. Ovos, larvas e pupas das espécies criadas também foram fotografados.

\subsection{Espécies criadas em laboratório}

Buscando obter informações sobre o ciclo biológico de algumas espécies de Saturniidae e ampliar a coleção de imaturos de Lepidoptera do MZSP, fêmeas adultas coletadas foram mantidas vivas para oviposição.

Nestas ocasiões, as fêmeas foram acondicionadas individualmente em recipientes plásticos de aproximadamente $32 \times 21 \times 15 \mathrm{~cm}$ para obtenção de ovos. Uma lâmpada de 60 watts foi colocada junto ao recipiente para aumentar a temperatura interna e estimular a oviposição.

As larvas foram criadas em um recipiente tampado com tecido voil. Assim que eclodiam, uma variedade de espécies de plantas era oferecida, geralmente buscando espécies vegetais próximas às já conhecidas para os grupos de mariposas relacionados disponíveis em Gardiner (1982), Stone (1991), Specht et al. (2008), Janzen \& Hallwachs (2009).

Ovos, larvas e pupas foram fixados com água fervendo e posteriormente preservados em duplo álcool 80\%. Vouchers estão depositados na coleção de Imaturos de Lepidoptera do MZSP.

\subsection{Procedimentos gerais para análise dos dados}

O levantamento e digitalização dos dados relativos aos exemplares previamente depoisitados na coleção de Saturniidae do Museu de Zoologia da Universidade de São Paulo foi concluida ${ }^{1}$. Os dados referentes aos exemplares deste acervo, não relacionados às coletas realizadas durante o presente estudo, foram organizados em planilhas do programa Microsoft Excel. Cada exemplar ocupando uma linha e seus dados distribuídos nas respectivas colunas:

\footnotetext{
${ }^{1}$ Os dados de parte da coleção Saturniidae foram digitalizados em 2009.
} 
Código de tombo, Ordem, Família, Subfamília, Tribo, Subtribo, Gênero, Epíteto, Epíteto subespecífico, Espécie, Autor, Espécie e autor, Sexo, Coletor, Data, Mês, Ano, Década, País, Estado, Cidade, Complemento (do local), Alt(m), Longitude, Latitude, Dissecado, Fotografado, Ex-coleção (a que pertencia), Quantidade e Observação. Para os dados inexistentes os campos foram preenchidos com a abreviatura NA (Not Available); para exemplares tombados, mas que não possuíam rótulo algum foi atribuído o termo "sem procedência" no campo "País". Exemplares envelopados não foram tombados.

Os exemplares de Hylesia não identificados e não categorizados em nenhuma das três morfoespécies do gênero não foram tratados como espécies e assim não entraram em nenhum resultado ou análise envolvendo o número de espécies coletadas. Neste caso, os exemplares participaram apenas de análises de abundância, qualquer exceção será mencionada na legenda da figura gerada pela respectiva análise. Para as curvas de rarefação, nas quais são exigidas as espécies e suas respectivas abundâncias, os 40 exemplares de Hylesia sp. não foram considerados.

Para os dados oriundos das coletas realizadas durante este estudo foi elaborado um banco de dados no programa Microsoft Access, conforme demonstrado na Fig. 21.

Informações mais detalhadas pertinentes ao material e aos métodos de cada seção serão aprofundadas nos dois tópicos a seguir. 


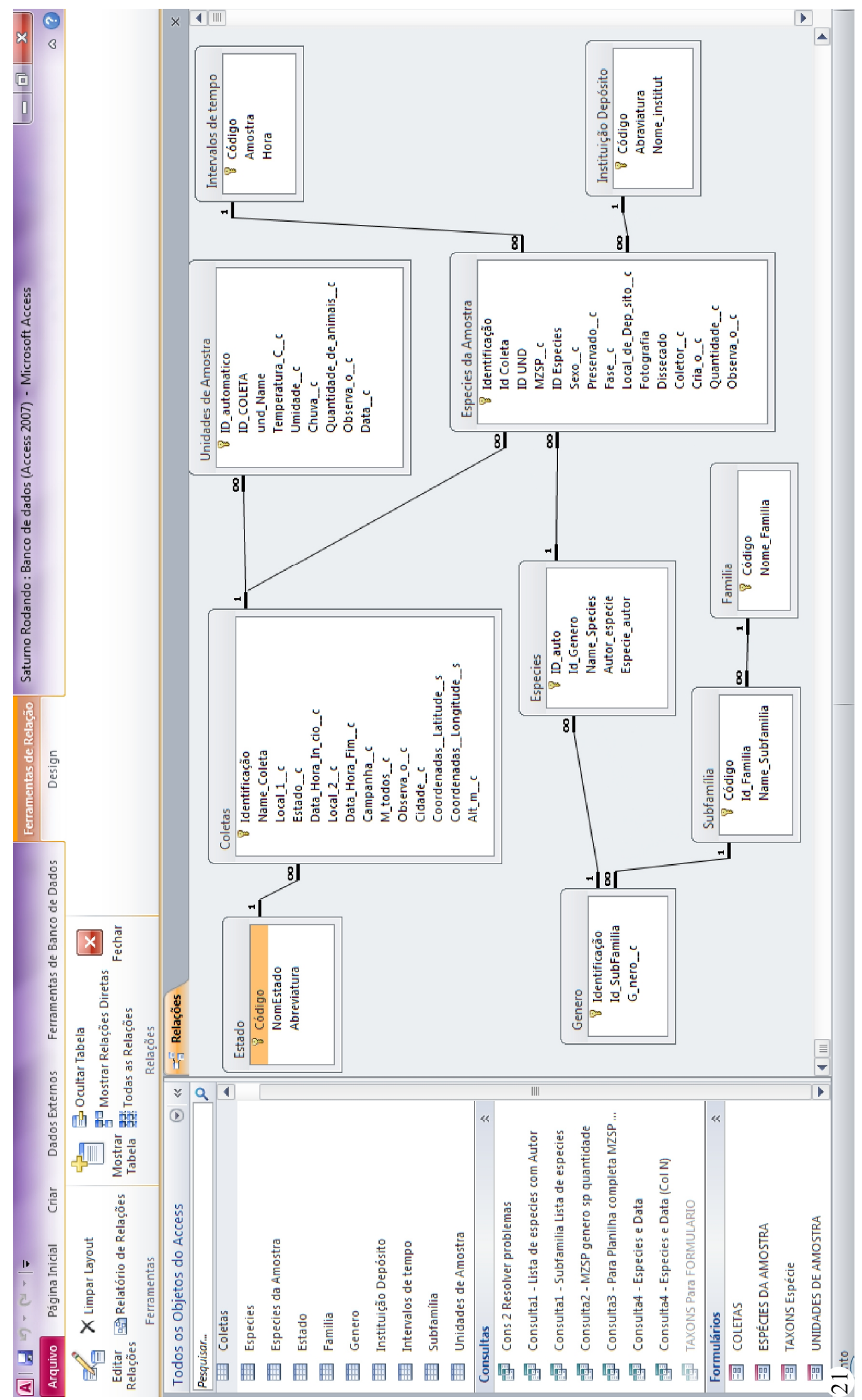

Figura 21. Print screen da página do banco de dados do Access ilustrando relacionamentos e campos das tabelas. 


\subsubsection{Levantamento de Saturniidae (Insecta, Lepidoptera) atraídos por luz da Estação}

Biológica de Boraceia. A fauna atual e uma retrospectiva de quase 70 anos

Para os dados comparativos entre as coletas atuais (2012-2013) e os dados históricos foram utilizados os dados referentes a 25 meses consecutivos de coleta ente 1948 e 1950, sendo o primeiro mês março de 1948 e o último março de 1950 (Tab. 1).

Para categorização de abundância das espécies, cinco classes de abundância foram definidas arbitrariamente de acordo com as respectivas abundâncias relativas de cada espécie, desta forma tem-se: raras se $\mathrm{X} \leq 0,1$; incomuns se $0,1<\mathrm{X} \leq 0,5$; comuns se $0,5<\mathrm{X} \leq 1$; abundantes se $1<X \leq 3$; muito abundantes se $X>3$; onde $X$ é a abundância relativa de cada espécie em $\%$.

Para análise dos dados de riqueza de espécies foi utilizado o programa EstimateS 9.1.0 (Colwell 2013). As curvas de rarefação foram feitas de acordo com dois parâmetros: com base nas unidades amostrais (“sample-based rarefaction”) e com base no número de exemplares das amostras ("individual-based rarefaction"). Para o primeiro caso, a unidade de amostra foi considerada o mês de coleta no seu respectivo ano, sendo os exemplares amostrados em cada unidade aqueles coletados neste período, em um total de 176 unidades amostrais. Para o segundo caso, os exemplares não morfoespeciados de Hylesia e exemplares previamente pertencentes ao acervo do MZSP, mas sem referência de datas, foram excluídos da análise com base no número de exemplares. 
Tabela 1. Anos e meses em que exemplares de Saturniidae (Lepidoptera) foram amostrados na Estação Biológica de Boraceia, Salesópolis, SP, Brasil entre 1942 e 2013.

\begin{tabular}{|c|c|c|c|c|c|c|c|c|c|c|c|c|}
\hline ANO & Jan & Fev & Mar & Abr & Mai & Jun & Jul & Ago & Set & Out & Nov & Dez \\
\hline 1942 & & $\mathrm{x}$ & & $\mathrm{x}$ & & & & & $\mathrm{x}$ & & $\mathrm{x}$ & $\mathrm{x}$ \\
\hline 1943 & & & & & & & & & & & & $\mathrm{x}$ \\
\hline 1946 & & & & & & & $\mathrm{x}$ & & & & & \\
\hline 1947 & & & & & & & & & $\mathrm{x}$ & & $\mathrm{x}$ & $\mathrm{x}$ \\
\hline 1948 & $\mathrm{x}$ & $\mathrm{x}$ & $\mathrm{x}$ & $\mathrm{x}$ & $\mathrm{x}$ & $\mathrm{x}$ & $\mathrm{x}$ & $\mathrm{x}$ & $\mathrm{x}$ & $\mathrm{x}$ & $\mathrm{x}$ & $\mathrm{x}$ \\
\hline 1949 & $\mathrm{x}$ & $\mathrm{x}$ & $\mathrm{x}$ & $\mathrm{x}$ & $\mathrm{x}$ & $\mathrm{x}$ & $\mathrm{x}$ & $\mathrm{x}$ & $\mathrm{x}$ & $\mathrm{x}$ & $\mathrm{x}$ & $\mathrm{x}$ \\
\hline 1950 & $\mathrm{x}$ & $\mathrm{x}$ & $\mathrm{x}$ & & & & & $\mathrm{x}$ & $\mathrm{x}$ & & & \\
\hline 1951 & & & $\mathrm{x}$ & & & & & & & & $\mathrm{x}$ & \\
\hline 1952 & $\mathrm{x}$ & & & & $\mathrm{x}$ & $\mathrm{x}$ & & & & & $\mathrm{x}$ & \\
\hline 1953 & & & & & & & & & & $\mathrm{x}$ & & \\
\hline 1954 & & $\mathrm{x}$ & & $\mathrm{x}$ & & $\mathrm{x}$ & $\mathrm{x}$ & $\mathrm{x}$ & $\mathrm{x}$ & $\mathrm{x}$ & & \\
\hline 1956 & & & & & & & & & $\mathrm{x}$ & $\mathrm{x}$ & & \\
\hline 1957 & $\mathrm{x}$ & & $\mathrm{x}$ & $\mathrm{x}$ & & & & & & $x$ & $\mathrm{x}$ & \\
\hline 1958 & & & $\mathrm{x}$ & & & & & & $x$ & & $\mathrm{x}$ & $\mathrm{x}$ \\
\hline 1959 & & $\mathrm{x}$ & $\mathrm{x}$ & & & $\mathrm{x}$ & $\mathrm{x}$ & & $\mathrm{x}$ & & $\mathrm{x}$ & \\
\hline 1960 & & & & & & & & & & $\mathrm{x}$ & & \\
\hline 1961 & & & & & & & & $\mathrm{x}$ & & & & \\
\hline 1962 & $\mathrm{x}$ & & & $\mathrm{x}$ & & & $\mathrm{x}$ & $\mathrm{x}$ & $\mathrm{x}$ & $\mathrm{x}$ & $\mathrm{x}$ & $\mathrm{x}$ \\
\hline 1963 & & $\mathrm{x}$ & $\mathrm{x}$ & & & $\mathrm{x}$ & & & $\mathrm{x}$ & & & \\
\hline 1964 & $\mathrm{x}$ & $\mathrm{x}$ & & & & & & & & $\mathrm{x}$ & $\mathrm{x}$ & $\mathrm{X}$ \\
\hline 1965 & $x$ & $\mathrm{x}$ & $\mathrm{x}$ & $\mathrm{x}$ & $\mathrm{x}$ & $\mathrm{x}$ & $\mathrm{x}$ & $\mathrm{x}$ & $\mathrm{x}$ & $\mathrm{x}$ & $\mathrm{x}$ & $\mathrm{x}$ \\
\hline 1966 & $\mathrm{x}$ & $\mathrm{x}$ & $\mathrm{x}$ & & $\mathrm{x}$ & $\mathrm{x}$ & $\mathrm{x}$ & $\mathrm{x}$ & $x$ & $\mathrm{x}$ & $\mathrm{x}$ & $x$ \\
\hline 1967 & & $\mathrm{x}$ & $\mathrm{x}$ & $x$ & & & $\mathrm{x}$ & $\mathrm{x}$ & $x$ & $x$ & $\mathrm{x}$ & $x$ \\
\hline 1968 & $\mathrm{x}$ & $\mathrm{x}$ & $\mathrm{x}$ & $x$ & $\mathrm{x}$ & & & $\mathrm{x}$ & $\mathrm{x}$ & $\mathrm{x}$ & $\mathrm{x}$ & $x$ \\
\hline 1969 & $\mathrm{x}$ & $\mathrm{x}$ & & $x$ & & & $\mathrm{x}$ & $\mathrm{x}$ & & & & \\
\hline 1970 & & & & & & & & & & $\mathrm{x}$ & & \\
\hline 1983 & & & & & & & & & & $\mathrm{x}$ & & \\
\hline 1985 & $\mathrm{x}$ & & & & & & & & & $\mathrm{x}$ & & \\
\hline 1987 & & & & & & & & & & $\mathrm{x}$ & & \\
\hline 1989 & & & & & & & & & & $\mathrm{x}$ & & \\
\hline 1991 & & & & & & & & & & $\mathrm{x}$ & & \\
\hline 1995 & & & & & & & & & & $\mathrm{x}$ & & \\
\hline 1997 & & & & $\mathrm{x}$ & & & & & & & & \\
\hline 1999 & & & & $\mathrm{x}$ & & & & & & & & \\
\hline 2000 & & & & & & & & & $\mathrm{x}$ & $\mathrm{x}$ & $\mathrm{x}$ & \\
\hline 2001 & & $\mathrm{x}$ & & $\mathrm{x}$ & & & & $\mathrm{x}$ & $\mathrm{x}$ & $x$ & & \\
\hline 2002 & & & $\mathrm{x}$ & & & & & & & $\mathrm{x}$ & & \\
\hline 2003 & & & & $\mathrm{x}$ & & & & & & & & \\
\hline 2004 & & & & $\mathrm{x}$ & $\mathrm{x}$ & & & & & & & \\
\hline 2008 & & & & & & & & & $\mathrm{x}$ & & & \\
\hline 2010 & & & & & & & & & $\mathrm{x}$ & & & \\
\hline 2012 & & $\mathrm{x}$ & $\mathrm{x}$ & $\mathrm{x}$ & $\mathrm{x}$ & $\mathrm{x}$ & $\mathrm{x}$ & $\mathrm{x}$ & $\mathrm{x}$ & $\mathrm{x}$ & $\mathrm{x}$ & $\mathrm{x}$ \\
\hline 2013 & $\mathrm{X}$ & $\mathrm{x}$ & $\mathrm{x}$ & & & $\mathrm{x}$ & & & & & & \\
\hline Total & 13 & 16 & 15 & 16 & 8 & 10 & 11 & 13 & 20 & 24 & 17 & 13 \\
\hline
\end{tabular}


Seguindo os parâmetros do parágrafo anterior, as curvas de rarefação foram utilizadas para avaliar a riqueza de espécies da Estação Biológica de Boraceia; comparar esta riqueza com a de outros possíveis trabalhos; avaliar a arbitrariedade dos coletores ao coletarem Saturniidae entre 1948 e 1950; avaliar o grau de heterogeneidade na estruturação da assembleia local dentro dos parâmetros espaço-tempo, e para comparar a riqueza de espécies entre as diferentes épocas coletadas (1948-1950 e 2012-2013) (Hurlbert 1971; Gotelli \& Colwell 2001; Colwell et al. 2004, 2012). Extrapolações da curva de rarefação para os períodos em questão e o estimador de riqueza Chao 1 (modo não clássico) foram utilizados para avaliar e estimar riqueza local de acordo com as atualizações de Colwell et al. (2012) e presentes na versão atual do EtimateS 9.1.0 (Colwell 2013).

Para comparar a estrutura das comunidades originárias das coletadas recentes e históricas, foi realizada uma análise de ordenação indireta por Escalonamento Multidimensional Não-métrico (NMDS) em duas dimensões. Nesta análise, foram agrupadas em unidades amostrais (amostras da comunidade), os resultados de coleta de cada mês e as frequências das espécies convertidas em frequências relativas por unidade amostral (dividindo a abundância de cada espécie pelo total de mariposas coletadas no respectivo mês). A transformação da frequência absoluta para frequência relativa teve o intuito de diminuir o efeito da abundância de exemplares na comparação entre unidades amostrais.

A ordenação das unidades amostrais foi baseada em uma matriz de similaridade de Bray-Curtis criada a partir da matriz de abundância relativa das espécies por unidade amostral. A variância captada pela ordenação foi medida através de uma regressão linear entre as distâncias das amostras no espaço da ordenação e as distâncias originais de Bray-Curtis. O NMDS foi gerado através do software R 3.1.1 (R Development Core Team, 2014) com a função metaMDS (pacote vegan 2.0.1), com 100 inícios randômicos de ajuste do melhor padrão, parâmetro Autotransform $=F A L S E$ e demais parâmetros mantidos na programação padrão.

A diferença estatística entre as unidades amostrais, referentes ao presente trabalho e às coletas históricas, foi verificada através de uma Análise de Variância Multivariada Permutacional (PERMANOVA, Anderson 2001), uma versão não paramétrica para Análise de Variância Multivariada. A mesma foi executada com a função adonis do pacote vegan 2.0.1, com 10.000 randomizações. 


\subsubsection{Atividade temporal de 96 espécies de Saturniidae ao longo de 51 noites de coleta na}

Estação Biológica de Boraceia (Salesópolis, SP, Brasil)

Para estabelecer relações entre os exemplares de Saturniidae coletados e as variações de temperatura foi estabelecido um ranque com 17 categorias para as variações de temperaturas registradas ao longo dos 1.220 intervalos de coleta (cinco intervalos não foram contabilizados devido à falta de energia na $\mathrm{EBB}$ ), sendo eles: onde, $\mathrm{T}^{\circ}$, é o indicativo da categoria do ranque de temperaturas em ${ }^{\circ} \mathrm{C}$. $\left(\mathrm{T}^{\circ} 1\right) \leq 8,9^{\circ} \mathrm{C} ;\left(\mathrm{T}^{\circ} 2\right)$ entre $9^{\circ}-9,9^{\circ} \mathrm{C} ;\left(\mathrm{T}^{\circ} 3\right)$ entre $10^{\circ}-10,9^{\circ} \mathrm{C} ;\left(\mathrm{T}^{\circ} 4\right)$ entre $11^{\circ}-11,9^{\circ} \mathrm{C}$; $\left(\mathrm{T}^{\circ} 5\right)$ entre $12^{\circ}-12,9^{\circ} \mathrm{C}$; $\left(\mathrm{T}^{\circ} 6\right)$ entre $13^{\circ}-13,9^{\circ} \mathrm{C}$; $\left(\mathrm{T}^{\circ} 7\right)$ entre $14^{\circ}-14,9^{\circ} \mathrm{C}$; $\left(\mathrm{T}^{\circ} 8\right)$ entre $15^{\circ}-15,9^{\circ} \mathrm{C} ;\left(\mathrm{T}^{\circ} 9\right)$ entre $16^{\circ}-16,9^{\circ} \mathrm{C} ;\left(\mathrm{T}^{\circ} 10\right)$ entre $17^{\circ}-17,9^{\circ} \mathrm{C} ;\left(\mathrm{T}^{\circ} 11\right)$ entre $18^{\circ}-$ $18,9^{\circ} \mathrm{C} ;\left(\mathrm{T}^{\circ} 12\right)$ entre $19^{\circ}-19,9^{\circ} \mathrm{C} ;\left(\mathrm{T}^{\circ} 13\right)$ entre $20^{\circ}-20,9^{\circ} \mathrm{C}$; $\left(\mathrm{T}^{\circ} 14\right)$ entre $21^{\circ}-21,9^{\circ} \mathrm{C} ;\left(\mathrm{T}^{\circ} 15\right)$ entre $22^{\circ}-22,9^{\circ} \mathrm{C} ;\left(\mathrm{T}^{\circ} 16\right)$ entre $23^{\circ}-23,9^{\circ} \mathrm{C}$ e $\left(\mathrm{T}^{\circ} 17\right) \geq 24^{\circ} \mathrm{C}$. Da mesma forma, para algumas análises foi estabelecido um ranque com seis categorias para os intervalos de tempo (IT) de acordo com o número de exemplares coletados em cada um, sendo eles: (IT 1) nenhum exemplar coletado, (IT 2) com até cinco exemplares coletados, (IT 3) de 6 a 10 exemplares coletados, (IT 4) de 11 a 15 exemplares coletados, (IT 5) de 16 a 20 exemplares coletados e (IT 6) com mais de 20 exemplares coletados.

Alguns gêneros e espécies foram escolhidos para avaliações mais aprofundadas de padrões como da distribuição sazonal e circadiana de abundância e de riqueza das espécies. Para escolha desses táxons, levou-se em conta o número de espécies de cada gênero, a abundância das espécies e a caracterização fenotípica dos complexos de espécies, sendo escolhidas aquelas onde foram observadas variações fenotípicas entre indivíduos da mesma espécie (p. ex. Lonomia obliqua Walker, 1855), e semelhanças fenotípicas entre indivíduos de espécies diferentes (p. ex. Pseudoautomeris Lemaire, 1967).

Para tratamento dos dados através de análise de correspondência (CA) e de componente principal (PCA) foi utilizado o programa PAST (Hammer et al. 2001). Para a CA, os intervalos de tempos foram tomados como os objetos e as espécies com suas respectivas abundâncias as variáveis; as análises de PCA foram geradas no sentido de avaliar a distribuição dos intervalos de tempo de acordo com a temperatura, riqueza e abundância das espécies, além de permitir a avaliação da distribuição das 17 categorias de temperaturas com relação aos intervalos de tempo, a riqueza e à abundância das espécies, e da distribuição das espécies com relação à temperatura, abundância e ao número de intervalos de tempo em que foram coletadas. Para gerar a série de figuras como a Fig. 51 foi utilizada a função para gráfico composto "genérica" criada por Victor Lemes Landeiro, executada no software R 3.1.1 (R Development Core Team 
2014), que categoriza as espécies em um ranque de acordo com suas respectivas distribuições de abundâncias relativas a cada um dos intervalos de tempo durante as noites, ou mês de coleta. A distribuição visual perpendicular das abundâncias é gerada graças ao ranqueamento que multiplica a abundância relativa de determinada espécie por cada intervalo em que a respectiva abundância ocorreu. No entanto, para análise da variável "espécie", os dados relativos à distribuição sazonal das espécies foram achatados, isto é, cada um dos 24 intervalos de tempo foi considerado único, tendo a abundância das suas espécies somadas para todas as 51 noites de coleta. 


\section{RESULTADOS E DISCUSSÃO}

A seção de Resultados e Discussão está divida em três partes relativamente independentes, com seus respectivos resultados e discussões. A primeira fornece resultados gerais, reportando objetivamente o trabalho que foi realizado e discutindo algumas implicações destes resultados. A segunda extrai do acervo de Lepidoptera do MZSP os dados pertinentes aos exemplares da EBB para fazer uma listagem e comparar as comunidades das coletas recentes (2012-2013) com a das coletas históricas (1948-1950); além disso, faz uma avaliação da fauna da EBB comparando com dados publicados de outros levantamentos de Saturniidae realizados no Brasil. A terceira parte trata unicamente dos exemplares amostrados recentemente, nos 13 meses de coleta, de março de 2012 a março de 2013, buscando observar padrões nas distribuições sazonal e circadiana das espécies e táxons supraespecíficos, além de buscar compreender a relação da atividade dos exemplares com as variáveis ambientais.

\subsection{Panorama geral}

Durante as coletas de março de 2012 a março de 2013 foram totalizadas 51 noites de amostragens em 13 campanhas, o equivalente a 612 horas de esforço de campo. Este esforço resultou em 3.286 exemplares de saturniídeos coletados, dos quais, 489 foram identificados e mantidos em envelopes com os dados de origem e nome da espécie (Fig. 19), e 2.797 foram montados, rotulados, identificados e tombados (Fig. 14); as informações pertinentes a todos os exemplares coletados foram inseridas em tabelas do banco de dados Access (Fig. 21).

De todos os exemplares coletados, 3.091 (94,1\%) foram identificados em nível específico, restando 195 (5,9\%) determinados em nível genérico. Estes casos restringem-se a três morfoespécies e a um grupo de exemplares de Hylesia (estes identificados somente pelo nome do gênero) cuja taxonomia é reconhecidamente problemática (Lemaire 2002; M. Duarte com. pes.; obs. pes.); e a uma morfoespécie do gênero Cerodirphia Michener, 1949, possivelmente um fenótipo variante de Cerodirphia opis (Schaus, 1892), o qual necessita de exame mais minucioso. Visando conhecimento mais aprofundado da morfologia de alguns exemplares da assembleia da Estação Biológica de Boraceia, especialmente na busca de identificação precisa, 63 machos foram dissecados. Mesmo assim, os casos citados acima 
permaneceram pendentes. No Anexo C estão disponíveis as listas dos exemplares e espécies dissecados.

Além do material coletado no presente estudo, 8.478 exemplares do acervo do MZSP foram rotulados com número de tombo e os dados de cada exemplar e de seus respectivos rótulos foram digitalizados. Estes saturniídeos dividem-se em cinco subfamílias (Hemileucinae, Ceratocampinae, Arsenurinae, Saturniinae e Oxyteninae), 65 gêneros e 334 espécies.

De todos os exemplares montados pertencentes ao acervo do MZSP, 226, representando 94 espécies, foram fotografados em vistas dorsal e ventral, e em vista dorsal com suas respectivas etiquetas. Para algumas espécies, como Dirphia muscosa, uma série de exemplares foi fotografada com intuito de ilustrar a grande variação intraespecífica. A listagem das espécies, do número de exemplares fotografados de cada espécie e as imagens de vistas dorsal e ventral encontram-se nos Anexos D-F.

Fêmeas de nove espécies de Saturniidae foram coletadas para obtenção de ovos. Destas, obtivemos ovos e larvas de primeiro instar, porém o estudo completo do ciclo de vida só foi viável para quatro espécies: Adeloneivaia fallax (Boisduval, 1872), Adelowalkeria tristygma (Boisduval, 1872) (Ceratocampinae), Automeris bilinea (Walker, 1855) (Hemileucinae) e Copaxa canella Walker, 1855 (Saturniinae). Para imagens dos imaturos cujas espécies foram obtidos ciclo completo ver Anexos $\mathrm{G}$ e $\mathrm{H}$.

No início do século XXI começaram a surgir programas e propostas para indexação online da biodiversidade mundial (Bispy et al. 2002; Gewin 2002; Godfray 2002; Maddisson et al. 2007) com o principal propósito de integrar as aréas de conhecimento sobre taxonomia e das tecnologias emergentes, como computadores cada vez mais potentes, permitindo a criação de grandes bancos de dados e a "World Wide Web" com potencial de atingir toda população do planeta. Exemplos conhecidos que buscam integrar informações de biodiversidade, geralmente não apenas para cidadãos do meio científico, mas para população de forma geral são: “All species fundation", "Global Biodiversity Information Facility", "Integrate Taxonomic Information System", "Species 2000" e "The Tree of Live Web Project". Sob esse prisma, o tombamento seguido da digitalização dos dados de 11.569 exemplares da família Saturniidae vai de encontro com essa nova perspectiva de utilização e de possibilitar a disponibilização da informação taxonômica e da biodiversidade.

O mesmo pode ser dito das fotografias em alta qualidade dos 226 exemplares montados e daqueles in situ. A sistematização de dados visuais relacionados à fauna brasileira de Saturniidae é ainda incipiente, sendo as grandes coletâneas como Lemaire (1978, 1980, 1988, 
2002) e D’Abrera (1995, 1998), ambos não restritivos à fauna brasileira, as maiores referências. A confecção de catálogos foi considerada uma das metas para a Zoologia Brasieira por Marques \& Lamas (2006) e a indexação on-line da informação taxonômica uma ferramenta a ser explorada para divulgação científica. A associação entre um banco de dados eficiente e imagens de exemplares das espécies presentes no banco de dados propicia a organização de catálogos ilustrados, os quais podem ser publicados na internet ou impressos e serão de grande importância para sintetizar o conhecimento taxonômico e de grande utilidade para estudos de biodiversidade.

Estudos que detalham a morfologia dos imaturos e a biologia das espécies brasileiras de Saturniidae são melhor documentados para espécies de importância médica (Lemaire 2002; Specht et al. 2008) havendo muito o que se explorar neste campo. Com o atual discurso de taxonomia integrativa (Wheeler 2008; Schlick-Steiner et al., 2010), estudos envolvendo informações morfológicas de imaturos e biologia das espécies tendem a ser considerados triviais para reconstrução histórica robusta da filogenia de grupos taxonômicos em estudo, e assim, o fortalecimento do acervo da coleção de imaturos de Lepidoptera, com espécies identificadas e criadas em laboratório, torna-se crucial para esse novo modelo de estudos taxonômicos (ver também Meier \& Lim 2009). Além disso, tendo em vista o dimorfismo presente em algumas espécies de Saturniídae e a dificuldade na identificação morfológica de grupos, como do gênero Hylesia, o estudo da biologia de Saturniidae torna-se uma ferramenta elucidativa para definição taxonômica de determinadas espécies.

\subsection{Levantamento de Saturniidae (Insecta, Lepidoptera) atraídos por luz da Estação Biológica de Boraceia. A fauna atual e uma retrospectiva de quase 70 anos}

\subsubsection{A assembleia de Saturniidae da Estação Biológica de Boraceia}

O acervo de Lepidoptera do MZSP conta com 6.288 exemplares de Saturniidae (5.738 machos, 549 fềmeas e um ginandromorfo), coletados na Estação Biológica de Boraceia entre 1942 e 2013. Estes exemplares estão distribuídos entre as cinco subfamílias registradas no Brasil, representando 42 gêneros e 119 espécies. A subfamília que apresentou maior abundância e número de espécies foi Hemileucinae com 3.646 exemplares $(57,98 \%)$ distribuídos em 70 espécies (58,82\%), seguido de Ceratocampinae com 1.297 exemplares (20,63\%) e 24 espécies (19,33\%), Arsenurinae com 659 exemplares (10,48\%) e 14 espécies (11,76\%), Saturniinae com 
557 exemplares $(8,86 \%)$ e 10 espécies $(8,4 \%)$, e Oxyteninae com 129 exemplares $(2,05 \%)$ e duas espécies (1,68\%) (Figs. 22, 23; Tab. 2, 3).
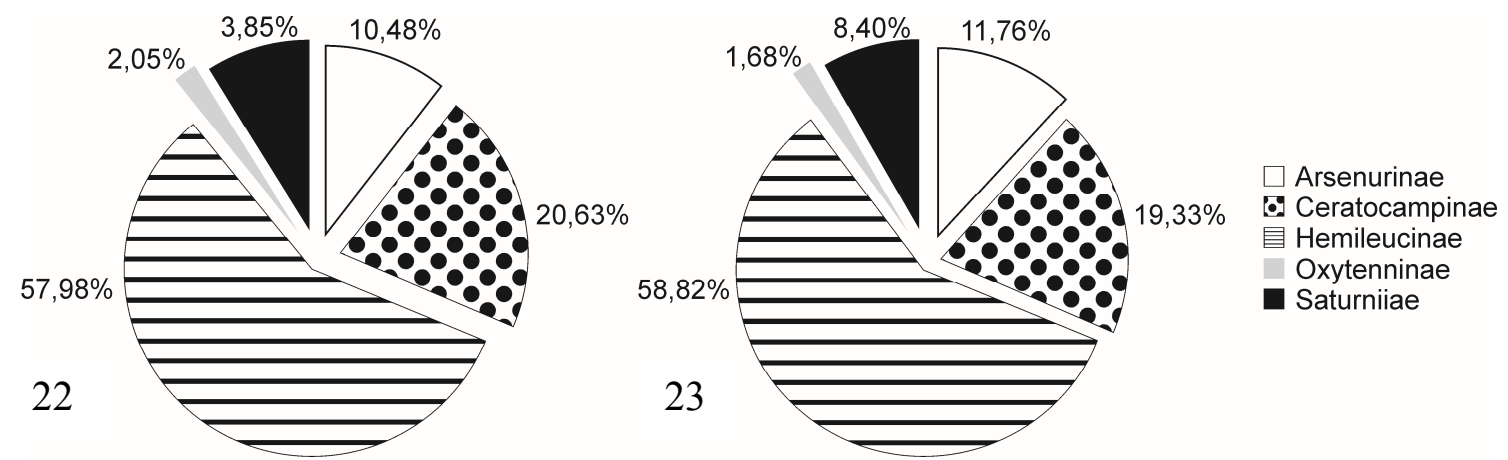

Figuras 22-23. Assembleia de Saturniidae da Estação Biológica de Boraceia, Salesópolis, SP, Brasil. (22) Abundância relativa e (23) riqueza relativa do número de exemplares de cada subfamília de Saturniidae coletados entre 1942 e 2013.

Das 119 espécies representadas na Coleção de Lepidoptera do MZSP, apenas nove possuem um único exemplar coletado na Estação Biológica de Boraceia, duas espécies de Arsenurinae, Arsenura sylla (Cramer, 1779) e Paradaemonia pluto (Westwood, 1854); três de Ceratocampinae, Adeloneivaia catharina (Bouvier, 1927), Cicia nettia (Schaus, 1921) e Neocarnegia basirei (Schaus, 1892); e quatro espécies de Hemileucinae, Automeropsis umbrata (Boisduval, 1875), Cerodirphia apunctata Dias \& Lemaire, 1991, Dirphia araucaria E.D. Jones, 1908 e Pseudodirphia catarinensis (Lemaire, 1975). Destes nove exemplares, três foram coletados entre 2012 e 2013: Automeropsis umbrata (Boisduval, 1875), Dirphia araucariae E.D. Jones, 1908 e Neocarnegia basirei (Schaus, 1892). Dentre as espécies mais abundantes estão Hylesia metaphyrra com 424 exemplares, Hylesia oratex com 265, Dirphia muscosa com 261 (todos Hemileucinae), Copaxa canella (Saturniinae) com 232 e Lonomia obliqua (Hemileucinae) com 189 exemplares; além destas, outras 16 espécies estão representadas por mais de 100 exemplares no acervo do MZSP (Tab. 3). 
Tabela 2. Número de espécies e de exemplares de cada gênero e de cada subfamília de Saturniidae coletados na Estação Biológica de Boraceia, Salesópolis, SP, Brasil de 1942 a 2013 e depositados na coleção de Lepidoptera do MZSP. Ginandro = Ginandromorfo.

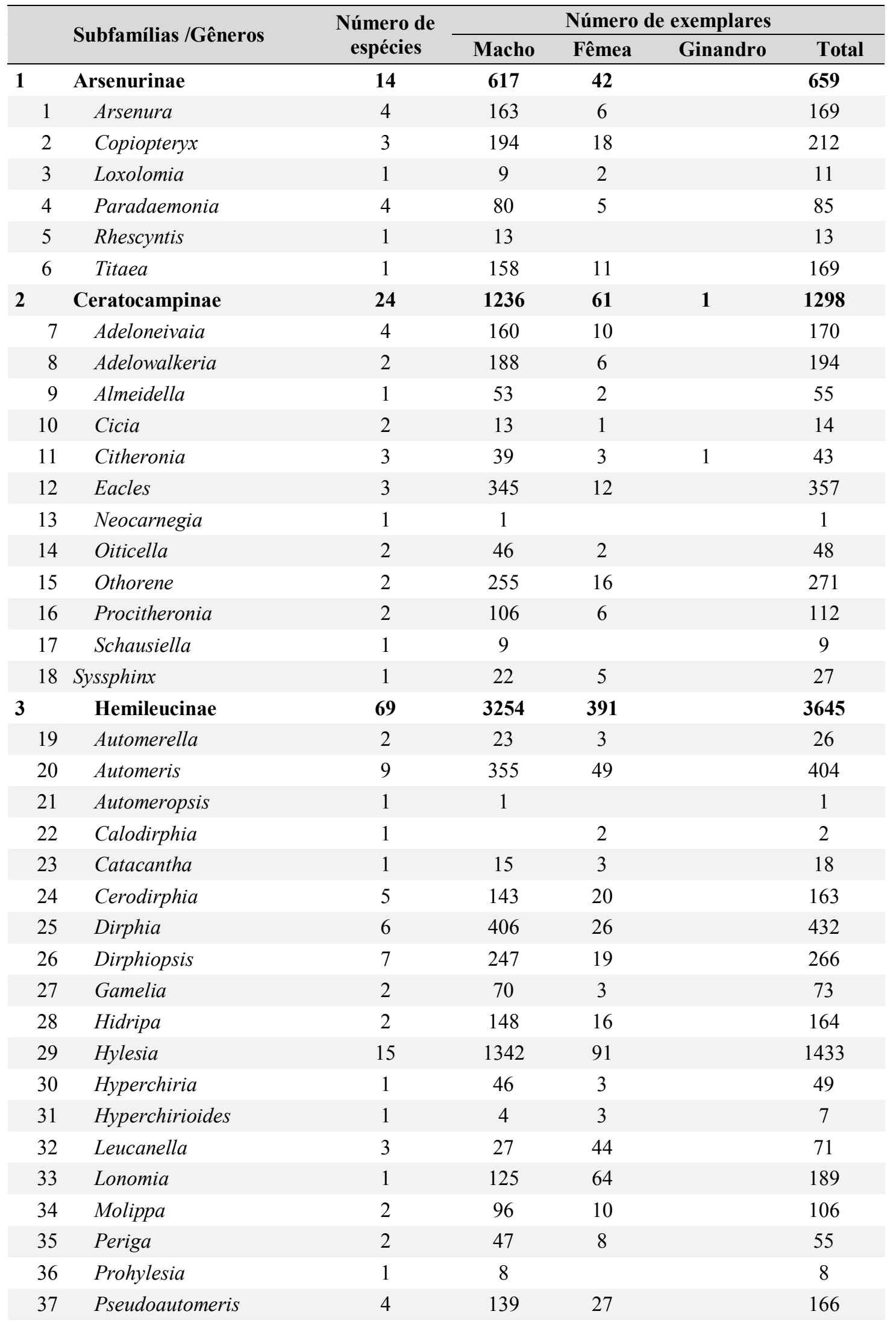




\begin{tabular}{|c|c|c|c|c|c|c|}
\hline & \multirow{2}{*}{ Subfamílias /Gêneros } & \multirow{2}{*}{$\begin{array}{l}\text { Número de } \\
\text { espécies }\end{array}$} & \multicolumn{4}{|c|}{ Número de exemplares } \\
\hline & & & Macho & Fêmea & Ginandro & Total \\
\hline 38 & Pseudodirphia & 1 & 1 & & & 1 \\
\hline 39 & Travassosula & 1 & 11 & & & 11 \\
\hline 4 & Oxyteninae & 2 & 126 & 3 & & 129 \\
\hline 40 & Oxytenis & 2 & 126 & 3 & & 129 \\
\hline 5 & Saturniinae & 10 & 505 & 52 & & 557 \\
\hline 41 & Copaxa & 4 & 305 & 30 & & 335 \\
\hline 42 & Rothschildia & 6 & 203 & 23 & & 226 \\
\hline & Total Geral & 119 & 5738 & 549 & 1 & 6288 \\
\hline
\end{tabular}

Os gêneros mais abundantes e com maior número de espécies da $\mathrm{EBB}$ pertencem à subfamília Hemileucinae. Para o gênero Hylesia foram amostrados 1.433 exemplares pertencentes a 15 espécies, incluindo Hylesia sp.1, sp.2 e sp.3; em seguida, os gêneros com maior quantidade de espécies foram Automeris Hübner, 1819 (Hemileucinae) com 404 exemplares distribuídos em nove espécies e Dirphiopsis Bouvier, 1928 com sete espécies e 266 exemplares amostrados; o gênero Dirphia Hübner, 1819, representado por seis espécies, é o segundo mais abundante com 432 exemplares amostrados. O gênero Rothschildia (Saturniinae) é o único gênero fora de Hemileucinae representado por cinco ou mais espécies, tendo sido coletados 226 exemplares de seis espécies.

Foram plotadas curvas de rarefação com base nos exemplares coletados e com base nas amostras. Na rarefação com base no número de exemplares foi utilizado o método de extrapolação apontado em Colwell et al. (2012), o número de exemplares foi extrapolado em uma vez e meia o seu valor original, sendo que os autores consideram que, dependendo das amostras, extrapolações em até três vezes podem gerar curvas robustas, com intervalos de confiança expandidos em nível tolerável. Nenhuma das curvas estabilizou a assíntota de riqueza de espécies, no entanto, de acordo com as rarefações, apenas entre três e seis espécies a mais do que o amostrado foram estimadas para a área.

Os dados da curva com extrapolação sugerem que aumentado o número de exemplares coletados para 9.360 (uma vez e meia a mais), aproximadamente 122 espécies seriam amostradas (Fig. 24). A curva também nos indica que as primeiras 100 espécies podem ser coletadas com uma amostragem de 1.042 exemplares. Para rarefação baseada nas unidades amostrais, as primeiras 100 espécies podem ser coletadas após o $48^{\circ}$ mês de coleta, quando já teriam sido coletados aproximadamente 1.702 exemplares (Fig. 25). Nesta análise, Chao 1 apresentou uma riqueza estimada em 125 espécies, mas o intervalo inferior, para 95\% de confiança, estimou 120 espécies, sobrepondo-se completamente ao intervalo superior, de 
125,45 espécies da riqueza observada, e praticamente sobrepôs-se à própria riqueza observada de 119 espécies, não havendo assim diferença estatística com relação à curva para as espécies observadas e seus respectivos intervalos de confiança.
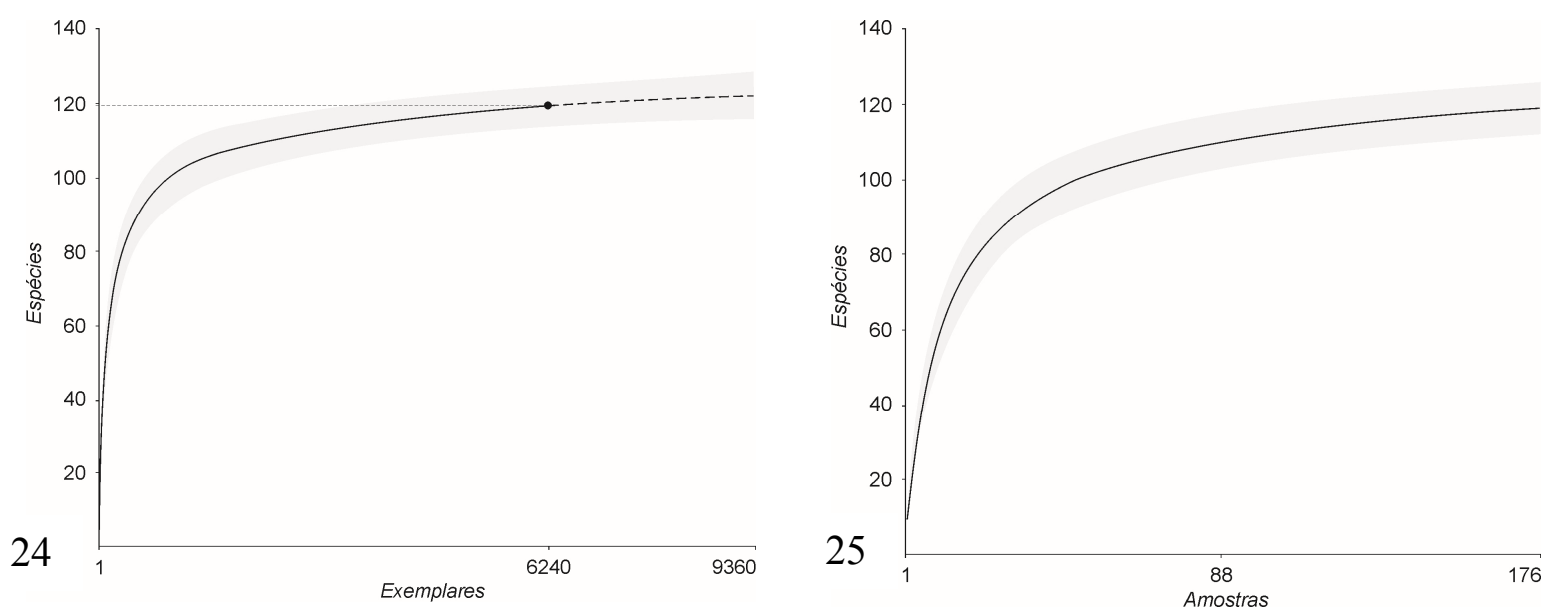

Figuras 24-25. Curvas de rarefação. (24) Curva com extrapolação (de 1,5x=9.360 exemplares) no número de exemplares (extrapolation on individual-based rarefaction), cálculo analítico; a linha pontilhada indica valores extrapolados à partir do número observado de exemplares (6.240) e (25) curva com interpolação randomizada do número de amostras (sample-based rarefaction) dos exemplares de Saturniidae coletados entre 1942 e 2013 na Estação Biológica de Boraceia, Salesópolis, SP, Brasil. Cada mês em que houve coleta representa uma unidade amostral, totalizando 176 unidades. As áreas cinzas correspondem aos intervalos com 95\% de confiança. 
Tabela 3. Lista das espécies de Saturniidae (Lepidoptera) coletados na Estação Biológica de Boraceia, Salesópolis, SP, Brasil entre 1942 e 2013. Gin = Ginandromorfo.

\begin{tabular}{|c|c|c|c|c|c|}
\hline \multirow{2}{*}{ 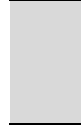 } & \multirow{2}{*}{ Subfamília/Espécies } & \multicolumn{4}{|c|}{ Número de indivíduos } \\
\hline & & Fêmeas & Gin & Machos & Total \\
\hline 1 & Arsenurinae & 42 & & 617 & 659 \\
\hline 1 & Arsenura armida (Cramer, 1779) & 2 & & 50 & 52 \\
\hline 2 & Arsenura biundulata Schaus, 1906 & 4 & & 110 & 114 \\
\hline 3 & Arsenura sylla (Cramer, 1779)** & & & 1 & 1 \\
\hline 4 & Arsenura xanthopus (Walker, 1855)** & & & 2 & 2 \\
\hline 5 & Copiopteryx derceto (Maassen, [1872]) & 2 & & 18 & 20 \\
\hline 6 & Copiopteryx semiramis (Cramer, 1775). & & & 17 & 17 \\
\hline 7 & Copiopteryx sonthonnaxi Ém. André, 1905 & 16 & & 159 & 175 \\
\hline 8 & Loxolomia serpentina Maassen, 1869 & 2 & & 9 & 11 \\
\hline 9 & Paradaemonia mayi (Jordan, 1922) & 4 & & 43 & 47 \\
\hline 10 & Paradaemonia orsilochus (Maassen, 1869) & 1 & & 9 & 10 \\
\hline 11 & Paradaemonia platydesmia (W. Rothschild, 1907) & & & 27 & 27 \\
\hline 12 & Paradaemonia pluto (Westwood, [1854])** & & & 1 & 1 \\
\hline 13 & Rhescyntis pseudomartii Lemaire, 1976 & & & 13 & 13 \\
\hline 14 & Titaea tamerlan (Maassen, 1869) & 11 & & 158 & 169 \\
\hline 2 & Ceratocampinae & 61 & 1 & 1236 & 1298 \\
\hline 15 & Adeloneivaia acuta (Schaus, 1896) & & & 2 & 2 \\
\hline 16 & Adeloneivaia catharina (Bouvier, 1927)** F & 1 & & & 1 \\
\hline 17 & Adeloneivaia fallax (Boisduval, 1872) & 9 & & 153 & 162 \\
\hline 18 & Adeloneivaia subangulata (Herrich Schäffer, [1855]) & & & 5 & 5 \\
\hline 19 & Adelowalkeria flavosignata (Walker, 1865) & & & 34 & 34 \\
\hline 20 & Adelowalkeria tristygma (Boisduval, 1872) & 4 & & 153 & 157 \\
\hline 21 & Almeidella almeidai Oiticica, 1946 & 2 & & 53 & 55 \\
\hline 22 & Cicia crocata (Boisduval, 1872) & 1 & & 12 & 13 \\
\hline 23 & Cicia nettia (Schaus, 1921) & & & 1 & 1 \\
\hline 24 & Citheronia brissotii (Boisduval, 1868) & & & 7 & 7 \\
\hline 25 & Citheronia laocoon (Cramer, 1777) & 1 & 1 & 18 & 20 \\
\hline 26 & Citheronia phoronea (Cramer, 1779) & 2 & & 14 & 16 \\
\hline 27 & Eacles ducalis (Walker, 1855) & 4 & & 123 & 127 \\
\hline 28 & Eacles imperialis (Drury, 1773) & 8 & & 96 & 104 \\
\hline 29 & Eacles mayi Schaus, 1920 & & & 126 & 126 \\
\hline 30 & Neocarnegia basirei (Schaus, 1892) & & & 1 & 1 \\
\hline 31 & Oiticella brevis (Walker, 1855) & 1 & & 41 & 42 \\
\hline 32 & Oiticella convergens Herrich-Schäffer, [1855]) & 1 & & 5 & 6 \\
\hline 33 & Othorene cadmus (Herrich-Schäffer, [1854]) & 13 & & 107 & 120 \\
\hline
\end{tabular}




\begin{tabular}{|c|c|c|c|c|c|}
\hline & \multirow{2}{*}{ Subfamília/Espécies } & \multicolumn{4}{|c|}{ Número de indivíduos } \\
\hline & & Fêmeas & Gin & Machos & Total \\
\hline 34 & Othorene purpurascens (Schaus, 1942) & 3 & & 148 & 151 \\
\hline 35 & Procitheronia principalis (Walker, 1855) & 6 & & 58 & 64 \\
\hline 36 & Procitheronia purpurea (Oiticica, 1930) & & & 48 & 48 \\
\hline 37 & Schausiella arpi (Schaus, 1892) & & & 9 & 9 \\
\hline 38 & Syssphinx molina (Cramer, 1780) & 5 & & 22 & 27 \\
\hline 3 & Hemileucinae & 390 & & 3253 & 3643 \\
\hline 39 & Automerella aurora (Maassen \& Weyding, 1885) & 2 & & 15 & 17 \\
\hline 40 & Automerella flexuosa (R. Felder \& Rogenhofer, 1874) & 1 & & 8 & 9 \\
\hline 41 & Automeris basalis (Walker, 1855) & 7 & & 26 & 33 \\
\hline 42 & Automeris beckeri (Herrich-Schäffer, [1856]) & 9 & & 95 & 104 \\
\hline 43 & Automeris bilinea (Walker, 1855) & 1 & & 44 & 45 \\
\hline 44 & Automeris illustris (Walker, 1855) & 7 & & 131 & 138 \\
\hline 45 & Automeris inornata (Walker, 1855) & 8 & & 50 & 58 \\
\hline 46 & Automeris melanops (Walker, 1865) & & & 7 & 7 \\
\hline 47 & Automeris muscula (Vuillot, 1892) ${ }^{\mathrm{F}}$ & 6 & & & 6 \\
\hline 48 & Automeris nubila (Walker, 1855) ${ }^{\mathrm{F}}$ & 3 & & & 3 \\
\hline 49 & Automeris tristis (Boisduval, 1875) & 8 & & 2 & 10 \\
\hline 50 & Automeropsis umbrata (Boisduval, 1875) & & & 1 & 1 \\
\hline 51 & Calodirphia arpi (Schaus, 1908) ${ }^{\mathrm{F}}$ & 2 & & & 2 \\
\hline 52 & Catacantha ferruginea (Draudt, 1929) & 3 & & 14 & 17 \\
\hline 53 & Cerodirphia apunctata Dias \& Lemaire, 1991 & & & 1 & 1 \\
\hline 54 & Cerodirphia opis (Schaus, 1892) & 9 & & 31 & 40 \\
\hline 55 & Cerodirphia rosacordis (Walker, 1855) & & & 3 & 3 \\
\hline 56 & Cerodirphia sp.1 & & & 26 & 26 \\
\hline 57 & Cerodirphia vagans (Walker, 1855) & 11 & & 66 & 77 \\
\hline 58 & Cerodirphia zikani (Schaus, 1921) & & & 16 & 16 \\
\hline 59 & Dirphia araucariae E.D. Jones, 1908 & & & 1 & 1 \\
\hline 60 & Dirphia baroma (Schaus, 1906) & 16 & & 67 & 83 \\
\hline 61 & Dirphia dolosa Bouvier, 1929 & 1 & & 47 & 48 \\
\hline 62 & Dirphia fornax (Druce, 1903) & 2 & & 35 & 37 \\
\hline 63 & Dirphia muscosa Schaus, 1898 & 7 & & 254 & 261 \\
\hline 64 & Dirphia sombrero Le Cerf, 1934 & & & 2 & 2 \\
\hline 65 & Dirphiopsis delta (Foetterle, 1902) & & & 32 & 32 \\
\hline 66 & Dirphiopsis epiolina (R. Felder \& Rogenhofer, 1874) & 5 & & 90 & 95 \\
\hline 67 & Dirphiopsis multicolor (Walker, 1855) & 6 & & 59 & 65 \\
\hline 68 & Dirphiopsis picturata (Schaus, 1913) & 6 & & 26 & 32 \\
\hline 69 & Dirphiopsis trisignata (R. Felder \& Rogenhofer, 1874) & 1 & & 14 & 15 \\
\hline
\end{tabular}




\begin{tabular}{|c|c|c|c|c|c|}
\hline \multirow{2}{*}{\multicolumn{2}{|c|}{ Subfamília/Espécies }} & \multicolumn{4}{|c|}{ Número de indivíduos } \\
\hline & & \multirow{2}{*}{$\begin{array}{c}\text { Fêmeas } \\
1\end{array}$} & \multirow{2}{*}{ Gin } & \multirow{2}{*}{$\frac{\text { Machos }}{3}$} & \multirow{2}{*}{$\begin{array}{c}\text { Total } \\
4\end{array}$} \\
\hline 70 & Dirphiopsis undulinea (F. Johnson, 1937) & & & & \\
\hline 71 & Dirphiopsis wanderbilti Pearson, 1958 & & & 23 & 23 \\
\hline 72 & Gamelia catharina (Draudt, 1929) & 2 & & 2 & 4 \\
\hline 73 & Gamelia remissoides Lemaire, 1967 & 1 & & 68 & 69 \\
\hline 74 & Hidripa paranensis (Bouvier, 1929) & 16 & & 126 & 142 \\
\hline 75 & Hidripa perdix (Maassen \& Weyding, 1885) & & & 22 & 22 \\
\hline 76 & Hylesia ebalus (Cramer, 1775) & & & 4 & 4 \\
\hline 77 & Hylesia falcifera (Hübner, [1825]) & 5 & & 76 & 81 \\
\hline 78 & Hylesia maurex Draudt, 1929 & 4 & & 44 & 48 \\
\hline 79 & Hylesia metapyrrha (Walker, 1855) & 22 & & 402 & 424 \\
\hline 80 & Hylesia munonia Schaus, 1927 & & & 135 & 135 \\
\hline 81 & Hylesia nanus (Walker, 1855) & 1 & & 46 & 47 \\
\hline 82 & Hylesia nigricans (Berg., 1875) & & & 12 & 12 \\
\hline 83 & Hylesia oratex Dyar, 1913 & 16 & & 249 & 265 \\
\hline 84 & Hylesia paulex Dognin, 1922 & 1 & & 55 & 56 \\
\hline 85 & Hylesia rufex Draudt, 1929 & & & 12 & 12 \\
\hline 86 & Hylesia scortina Draudt, 1929 & 5 & & 111 & 116 \\
\hline * & Hylesia sp. & 29 & & 11 & 40 \\
\hline 87 & Hylesia sp.1 & & & 118 & 118 \\
\hline 88 & Hylesia sp.2 & & & 3 & 3 \\
\hline 89 & Hylesia sp.3 & & & 11 & 11 \\
\hline 90 & Hylesia vindex Dyar, 1913 & 8 & & 53 & 61 \\
\hline 91 & Hyperchiria incisa Walker, 1855 & 3 & & 46 & 49 \\
\hline 92 & Hyperchirioides bulaea (Maassen \& Weyding, 1885) & 3 & & 4 & 7 \\
\hline 93 & Leucanella gibbosa (Conte, 1906) & 21 & & 26 & 47 \\
\hline 94 & Leucanella janeira (Westwood, [1854]) & 8 & & 1 & 9 \\
\hline 95 & Leucanella viridescens (Walker, 1855) ${ }^{\mathrm{F}}$ & 15 & & & 15 \\
\hline 96 & Lonomia obliqua Walker, 1855 & 64 & & 125 & 189 \\
\hline 97 & Molippa cruenta (Walker, 1855) & 6 & & 11 & 17 \\
\hline 98 & Molippa sabina Walker, 1855 & 4 & & 85 & 89 \\
\hline 99 & Periga circumstans Walker, 1855 & 2 & & 18 & 20 \\
\hline 100 & Periga falcata (Walker, 1855) & 6 & & 29 & 35 \\
\hline 101 & Prohylesia zikani Draudt, 1929 & & & 8 & 8 \\
\hline 102 & Pseudoautomeris brasiliensis (Walker, 1855) & 10 & & 38 & 48 \\
\hline 103 & Pseudautomeris coronis (Schaus, 1913) & 9 & & 56 & 65 \\
\hline 104 & Pseudautomeris grammivora (Jones, 1908)** F & 2 & & & 2 \\
\hline 105 & Pseudautomeris hubneri (Boisduval, 1875) & 6 & & 45 & 51 \\
\hline
\end{tabular}




\begin{tabular}{llcccc}
\hline \multirow{2}{*}{ Subfamília/Espécies } & \multicolumn{3}{c}{ Número de indivíduos } \\
\cline { 3 - 6 } & Fêmeas & Gin & Machos & Total \\
\hline 106 & Pseudodirphia catarinensis (Lemaire, 1975) & & 1 & 1 \\
107 & Travassosula subfumata (Schaus, 1921) & & 11 & 11 \\
$\mathbf{4}$ & Oxyteninae & $\mathbf{3}$ & $\mathbf{1 2 6}$ & $\mathbf{1 2 9}$ \\
108 & Oxytenis bicornis Jordan, 1924 & 3 & 85 & 88 \\
109 & Oxytenis modestia (Cramer, 1780) & & 41 & 41 \\
$\mathbf{5}$ & Saturniinae & $\mathbf{5 2}$ & $\mathbf{5 0 5}$ & $\mathbf{5 5 7}$ \\
110 & Copaxa canella Walker, 1855 & 23 & 209 & 232 \\
111 & Copaxa decrescens Walker, 1855 & & 35 & 35 \\
112 & Copaxa joinvillea Schaus, 1921 & 5 & & 21 & 26 \\
113 & Copaxa satellita Walker, 1865 & 1 & 37 & 38 \\
114 & Rothschildia arethusa (Walker, 1855) & 1 & & 19 & 20 \\
115 & Rothschildia aurota (Cramer, 1775) & 3 & & 47 & 50 \\
116 & Rothschildia belus (Maassen, [1873]) & & 5 & 5 \\
117 & Rothschildia hesperus (Linnaeus, 1758) & 13 & & 39 & 52 \\
118 & Rothschildia hopfferi (C. Felder \& R. Felder, 1859) & 2 & & 63 & 65 \\
119 & Rothschildia jacobaeae (Walker, 1855) & 4 & & 30 & 34 \\
& Número de exemplares & $\mathbf{5 4 8}$ & $\mathbf{1}$ & $\mathbf{5 7 3 8}$ & $\mathbf{6 2 8 7}$ \\
& Número de espécies & $\mathbf{8 0}$ & $\mathbf{1}$ & $\mathbf{1 1 3}$ & $\mathbf{1 1 9}$ \\
& Número de espécies sem representantes do sexo & $\mathbf{3 9}$ & $\mathbf{1 1 8}$ & $\mathbf{6}$ & \\
\hline
\end{tabular}

* Fêmeas e machos de Hylesia que não puderam ser identificados e nem categorizados em morfoespécies, não sendo assim contabilizadas no total do número de espécies.

** Espécies não coletadas em nenhum dos 25 meses, entre março de 1948 e março de 1950, nem entre os 13 meses de março de 2012 a março de 2013.

${ }^{\mathrm{F}}$ Espécie representada apenas por exemplares fêmeas.

4.2.2 Avaliação histórica das espécies de Saturniidae registradas entre 1948 e 1950 e entre 2012 e 2013

No total dos 38 meses analisados, 4.157 exemplares de 114 espécies, considerando três morfoespécies do gênero Hylesia, foram capturados. As cinco espécies registradas fora desse período foram Adeloneivaia catharina (Bouvier, 1927) (Ceratocampinae), Arsenura sylla (Cramer, 1779), Arsenura xanthopus (Walker, 1855), Paradaemonia pluto (Westwood, 1854) (Arsenurinae) e Pseudoautomeris grammivora (Jones, 1908) (Hemileucinae). Excetuando-se a última espécie, todas estão representadas por apenas um exemplar. 


\section{Dados Históricos (1948-1950)}

Durante as campanhas realizadas entre os 25 meses, de março de 1948 a março de 1950, foram capturados 926 exemplares pertencentes a 97 espécies. Hemileucinae figurou como a subfamília de maior número de espécies, 55, e com mais exemplares coletados, 479, seguida de Ceratocampinae com 19 espécies e 172 exemplares, Arsenurinae com 11 espécies e 149 exemplares, Saturniinae com 10 espécies e 108 exemplares e Oxyteninae com duas espécies e 18 exemplares coletados (Fig. 26). Destas, 18 espécies foram coletadas apenas neste período dos 25 meses analisados (Tab. 4), três delas foram representadas por apenas um exemplar, os hemileucíneos Calodirphia arpi (Schaus, 1908) e Pseudodirphia catharinensis (Lemaire, 1975), além de Cicia nettia (Schaus, 1921) (Ceratocampinae). Outras três espécies chamam a atenção por ocorrerem em seis, sete e oito amostras, respectivamente: Molipa cruenta (Walker, 1855) (Hemileucinae), Rothschildia jacobaeae (Walker, 1855) (Saturniinae) e Syssphynx molina (Cramer, 1780) (Ceratocampinae) e pela abundância relativa dos exemplares capturados.

Para avaliar a hierarquia de abundância das espécies, o conjunto de dados históricos incluiu 33 espécies com até dez exemplares coletados. Os representantes mais amostrados foram Copaxa canella (Saturniinae) e Copiopteryx sonthonnaxi Ém. André, 1905 (Arsenurinae), com 48 exemplares coletados cada; Dirphia muscosa (Hemileucinae) foi a $5^{\text {a }}$ mais abundante com 38 exemplares coletados, sendo todas as três espécies classificadas como muito abundantes; e Hylesia metapyrrha Walker, 1855 a $10^{\text {a }}$ com 24 exemplares, classificada como abundante (Fig. 28). A distribuição dos exemplares nas amostras revelou 12 espécies coletadas apenas em uma amostra ("uniques") e 21 apenas em duas (“duplicates"). A espécie com maior número de réplicas entre as amostras foi Hidripa paranensis Bouvier, 1929 (Hemileucinae), presente em 16 amostras (Tab. 5). As espécies mais abundantes deste período, C. sonthonnaxi e C. canella, foram capturadas em 15 e 14 amostras, respectivamente (Tab. 5). 


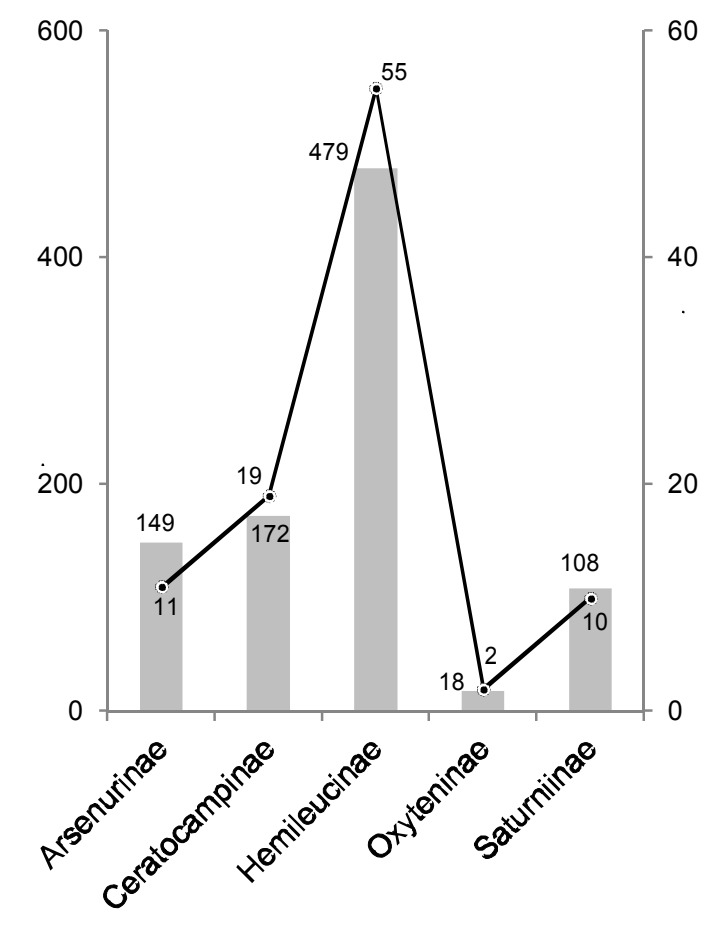

26

6 Abundância —-Número de espécies

60

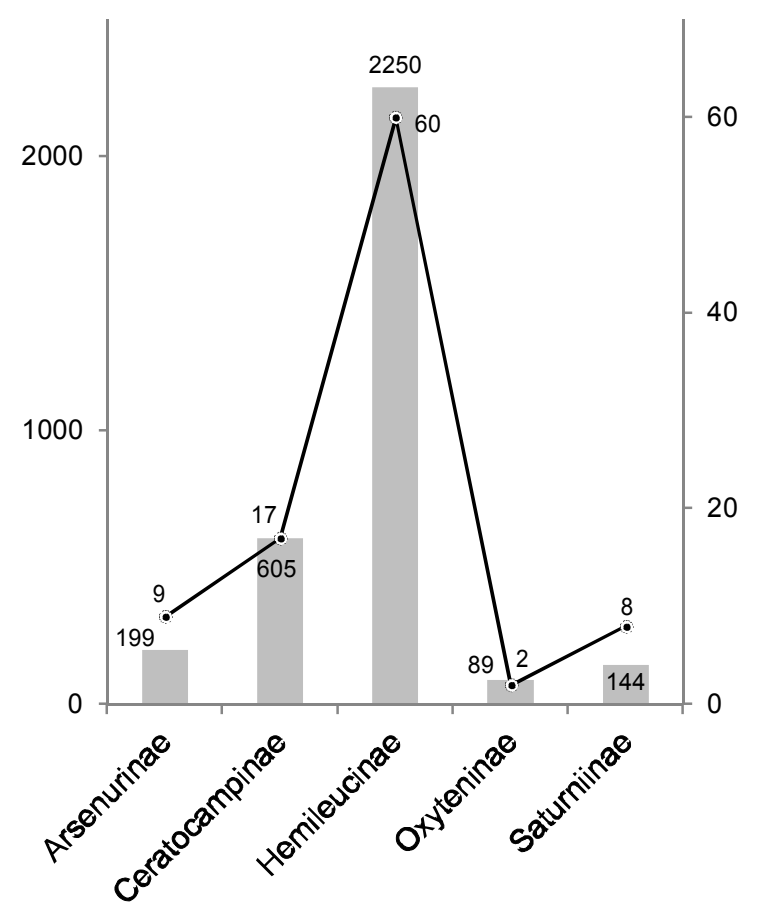

27 Abundância -_-Número de espécies

Figuras 26-27. Abundância e número de espécies de Saturniidae, na Estação Biológica de Boraceia, Salesópolis, SP, Brasil. (26) Abundância e riqueza de espécies coletadas para cada uma das subfamílias durante os 25 meses de campanha entre 1948 e 1950; (27) abundância e número de espécies coletadas para cada uma das subfamílias durante os 13 meses de campanha entre 2012 e 2013.

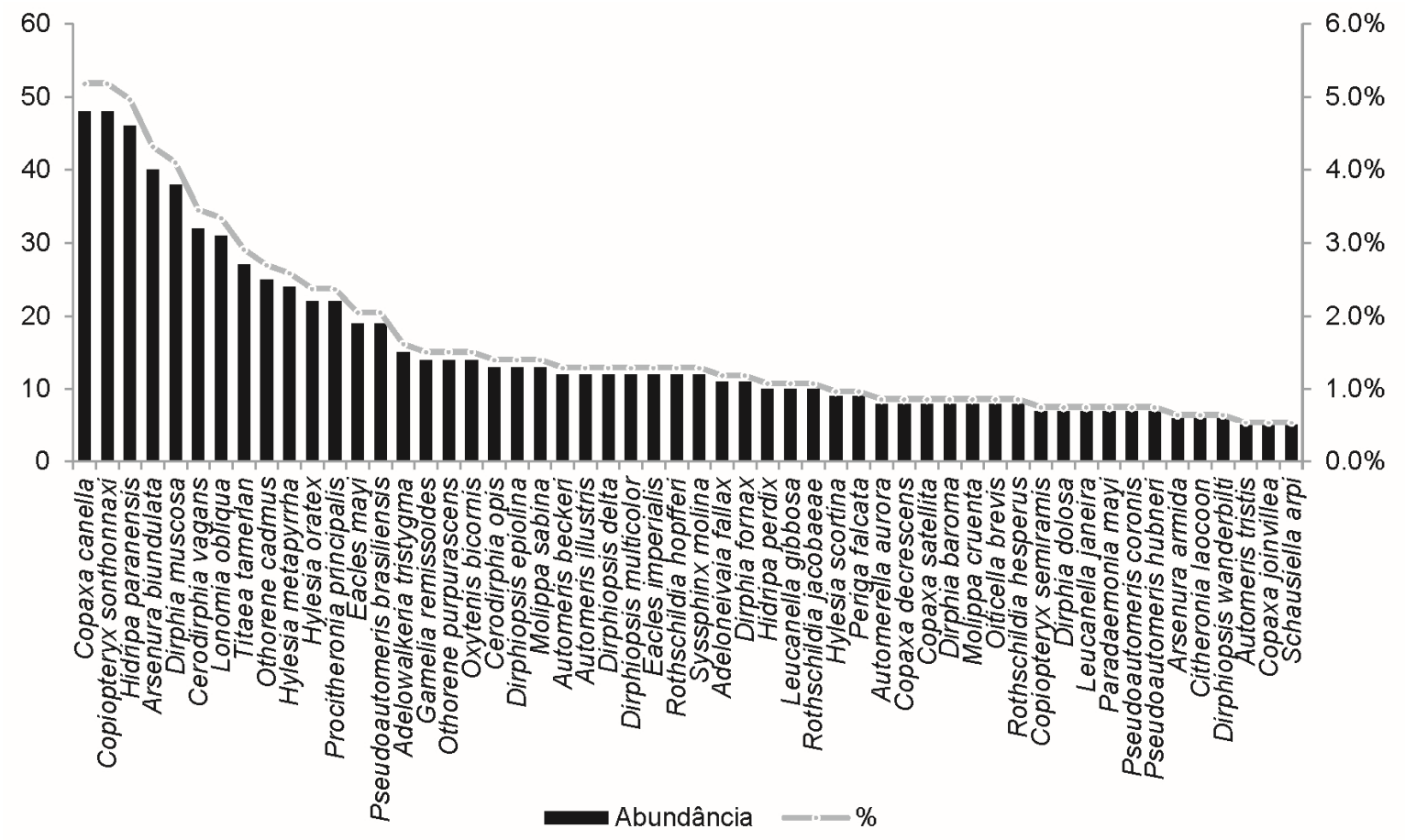

Figura 28. Abundância absoluta e relativa das espécies classificadas como comuns (abundância relativa entre 0,5\% e 1\%) ou mais abundantes coletados em 25 meses entre 1948 e 1950, na Estação Biológica de Boraceia, SP, Brasil. No gráfico foram representadas 33 espécies. 
Tabela 4. Listagem das 35 espécies coletadas na Estação Biológica de Boraceia, Salesópolis, SP, Brasil que ocorreram apenas em um dos dois períodos analisados, 1948-1950 ou 2012-2013, estando discriminados o número de amostras (data de referência) e o número de exemplares (n) em que cada espécie foi coletada.

\begin{tabular}{rcc|cll}
\hline Espécies & $\mathbf{n}$ & $\mathbf{2 0 1 2 - 2 0 1 3}$ & $\mathbf{1 9 4 8 - 1 9 5 0}$ & $\mathbf{n}$ & Espécies \\
\hline Adeloneivaia acuta & 2 & $\mathbf{1}$ & $\mathbf{1}$ & 1 & Automeris nubila \\
Adeloneivaia subangulata & 5 & $\mathbf{1}$ & $\mathbf{1}$ & 1 & Calodirphia arpi \\
Automeropsis umbrata & 1 & $\mathbf{1}$ & $\mathbf{1}$ & 1 & Cicia nettia \\
Cerodirphia apunctata & 1 & $\mathbf{1}$ & $\mathbf{1}$ & 3 & Citheronia phoronea \\
Dirphia araucariae & 1 & $\mathbf{1}$ & $\mathbf{1}$ & 3 & Dirphiopsis undulinea \\
Hylesia sp.3 & 11 & $\mathbf{1}$ & $\mathbf{1}$ & 2 & Hylesia nigricans \\
Neocarnegia basirei & 1 & $\mathbf{1}$ & $\mathbf{1}$ & 1 & Pseudodirphia catarinensis \\
Prohylesia zikani & 6 & $\mathbf{1}$ & $\mathbf{2}$ & 2 & Dirphia sombrero \\
Cerodirphia zikani & 15 & $\mathbf{2}$ & $\mathbf{2}$ & 2 & Paradaemonia orsilochus \\
Hylesia rufex & 5 & $\mathbf{2}$ & $\mathbf{2}$ & 5 & Schausiella arpi \\
Hylesia sp. 2 & 3 & $\mathbf{2}$ & $\mathbf{3}$ & 4 & Automeris muscula \\
Automeris inornata & 45 & $\mathbf{3}$ & $\mathbf{3}$ & 7 & Copiopteryx semiramis \\
Citheronia brissotii & 7 & $\mathbf{3}$ & $\mathbf{3}$ & 3 & Leucanella viridescens \\
Gamelia catharina & 4 & $\mathbf{3}$ & $\mathbf{3}$ & 4 & Rothschildia arethusa \\
Hylesia sp. ${ }^{*}$ & 37 & $\mathbf{3}$ & $\mathbf{4}$ & 4 & Oiticella convergens \\
Cerodirphia sp.1 & 26 & $\mathbf{4}$ & $\mathbf{6}$ & 8 & Molippa cruenta \\
Hylesia sp.1 118 & $\mathbf{4}$ & $\mathbf{7}$ & 10 Rothschildia jacobaeae \\
Hylesia falcifera & 78 & $\mathbf{7}$ & $\mathbf{8}$ & 12 & Syssphinx molina \\
\hline
\end{tabular}

* Táxon cujos machos e fêmeas não foram morfoespeciados.

Marcações em cinza-claro indicam espécies com apenas um exemplar coletado. Áreas em cinza mais escuro indicam espécies com significativa expressão em um ou outro período amostrado.

As curvas de rarefação com base nos exemplares e com base nas amostras não estabilizaram a assíntota de riqueza dentro da amostragem observada. Na rarefação com base no número de exemplares (Fig. 29), com extrapolação de três vezes o número de exemplares ( $\mathrm{n}=2.778)$, o número estimado de espécies foi de 100,55, com estabilização da assíntota para os 177 últimos exemplares, sendo que para os 1.246 últimos exemplares o número de espécies aumentou de 100 para 100.55 (Fig. 29). Para a rarefação com base nas amostras Chao 1 estimou em 100 espécies a riqueza local, contudo o valor não tem relevância estatística uma vez que o limite superior do intervalo com 95\% de confiança das espécies observadas foi de 101 espécies, maior que o estimado por Chao 1 (Fig. 30). 

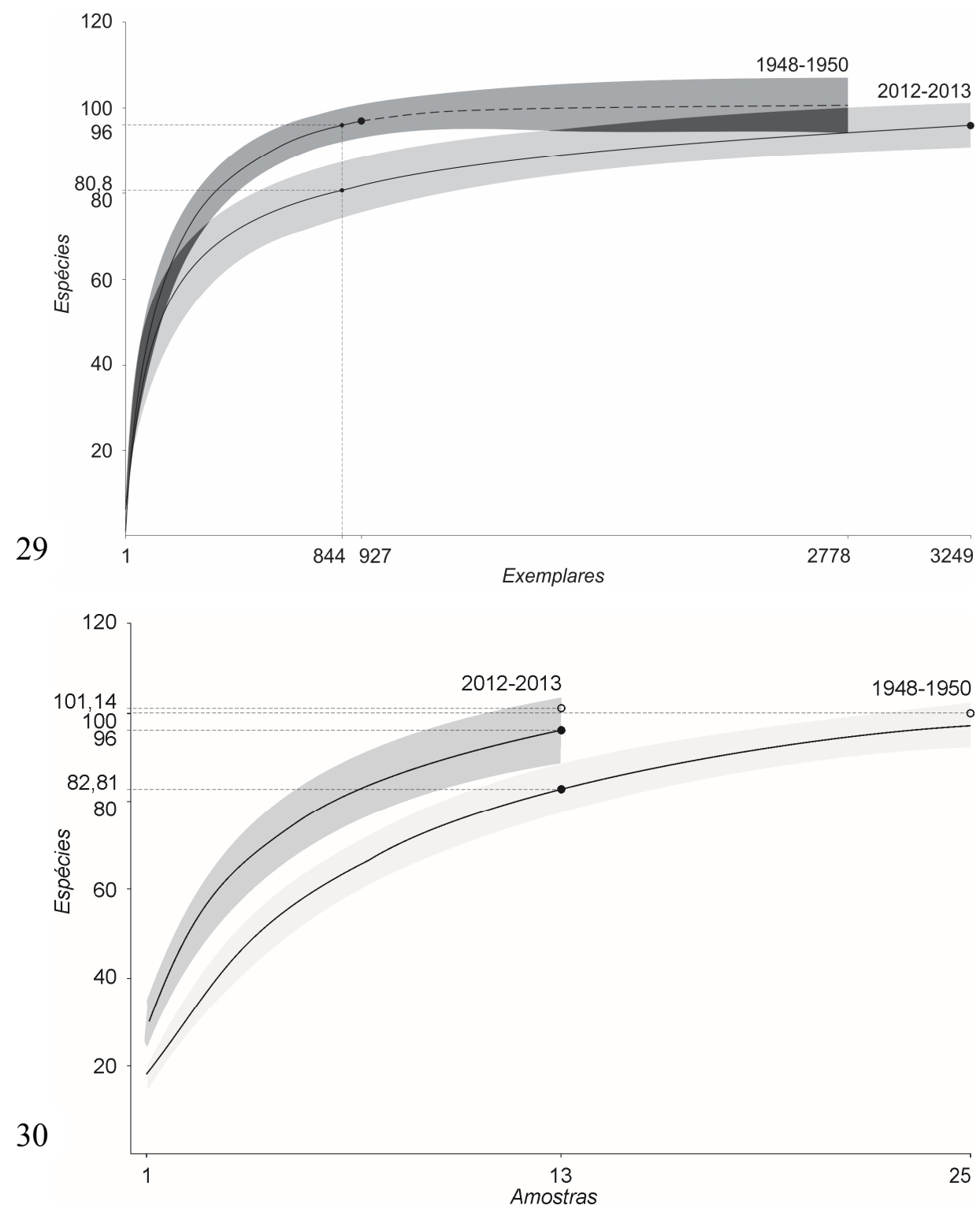

Figuras 29-30. Curvas de rarefação. (29) Rarefação com base nos exemplares (individual-based rarefaction); linhas pontilhadas indicam extrapolação do número de exemplares observados para as coletas históricas; (30) rarefação com base nas amostras (sample-based rarefaction); círculos abertos correspondem aos valores gerados pelo estimador de riqueza Chao 1. Áreas cinza correspondem aos interevalos com 95\% de confiança. Coletas realizadas entre 1948-1950 e 2012-2013 na Estação Biológica de Boraceia, SP, Brasil sendo que para as coletas entre 1948-1950 o número de exemplares foi extrapolado em três vezes.

Dados Recentes (2012-2013)

Nos 13 meses de coletas entre março de 2012 e março de 2013 foram capturados 3.287 exemplares e 96 espécies. Dentre as subfamílias, Hemileucinae foi a mais representativa com 60 espécies e 2.251 exemplares coletados, seguida de Ceratocampinae com 17 espécies e 605 exemplares, Arsenurinae com nove espécies e 199 exemplares, Saturniinae com oito espécies e 144 exemplares e Oxyteninae com duas espécies e 89 exemplares. Um total de 17 espécies foi 
amostrado apenas nas campanhas recentes, quatro delas representadas por um único exemplar, Automeropsis umbrata, Cerodirphia apunctata, Dirphia araucaria e Neocarnegia basirei (Fig. 27; Tab. 4).

Um conjunto de 54 espécies foi avaliado quanto à hierarquia de abundância de até dez exemplares coletados (Fig. 31). As espécies mais abundantes pertencem ao gênero Hylesia, sendo $H$. metapyrrha a mais abundante com 322 exemplares, seguido por $H$. oratex com 230 . Dirphia muscosa aparece em terceiro lugar com 153 exemplares e Copiopteryx sonthonnaxi em décimo sétimo, com 67 exemplares. Um total de 20 espécies foi coletado em apenas uma amostra ("uniques") e 12 foram coletadas em apenas duas amostras (“duplicates"). Dentre as espécies com maior distribuição amostral estão C. canella, Othorene cadmus (Herrich-Schäffer, [1854]) e Oxytenis bicornis Jordan, 1924 capturadas em 12 das 13 amostras referentes a este período (Tab. 5).

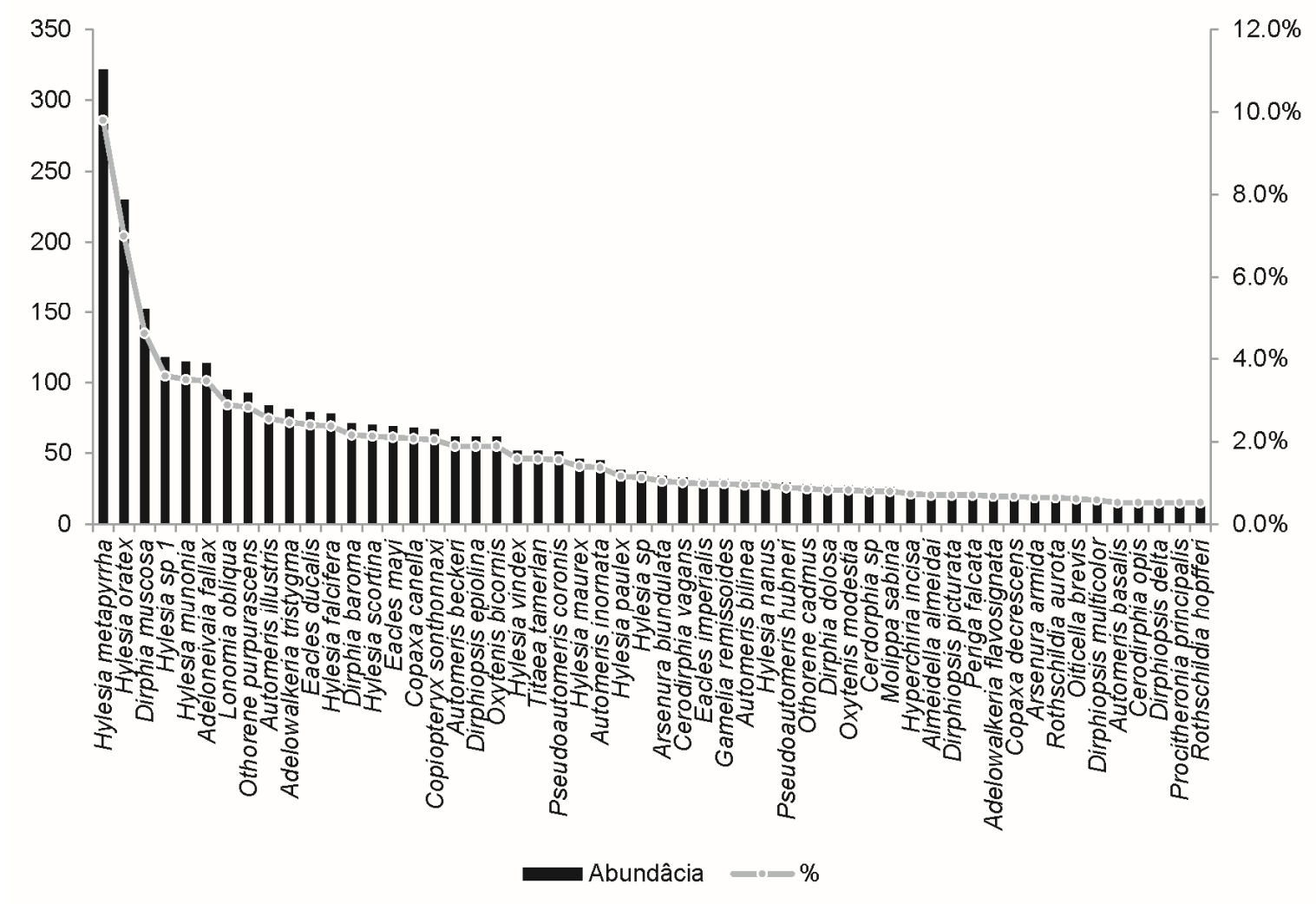

Figura 31. Abundância absoluta e relativa das espécies classificadas como comuns (abundância relativa entre 0,5\% e 1\%) ou mais abundantes, coletadas nos 13 meses entre 2012 e 2013, na Estação Biológica de Boraceia, SP, Brasil. No gráfico foram representadas 54 das 96 espécies.

As curvas de rarefação não apresentaram estabilização da assíntota de riqueza observada, a não ser para valores extrapolados na rarefação com base no número de exemplares. Para este caso, o número de exemplares foi extrapolado em três vezes $(n=9.750)$, estabilizando 
a assíntota com 102,28 espécies nos 25 últimos exemplares extrapolados, porém o intervalo para $95 \%$ de confiança passa a aumentar de forma exponencial a partir de aproximadamente 6.000 exemplares. Para a rarefação com base no número de amostras (Fig. 30), o estimador de riqueza Chao 1 estimou 101,14 espécies, e o intervalo superior com 95\% de confiança da riqueza observada apresentou a possibilidade de variação para até 103,14 espécies (Fig. 30).

Tabela 5. Lista das 96 espécies coletadas na Estação Biológica de Boraceia, Salesópolis, SP, Brasil que ocorreram nos períodos analisados, 1948-1950 e 2012-2013, estando discriminados o número de amostras (data de referência) e o número de exemplares (n) em que cada espécie foi coletada.

\begin{tabular}{|c|c|c|c|c|c|}
\hline Espécies & $2012-2013$ & $\mathbf{n}$ & Espécies & 1948-1950 & $\mathbf{n}$ \\
\hline Adeloneivaia acuta & 1 & 2 & Automerella flexuosa & 1 & 2 \\
\hline Adeloneivaia subangulata & 1 & 5 & Automeris nubila & 1 & 1 \\
\hline Automerella flexuosa & 1 & 1 & Calodirphia arpi & 1 & 1 \\
\hline Automeris melanops & 1 & 4 & Cerodirphia rosacordis & 1 & 1 \\
\hline Automeropsis umbrata & 1 & 1 & Cicia nettia & 1 & 1 \\
\hline Cerodirphia apunctata & 1 & 1 & Citheronia phoronea & 1 & 3 \\
\hline Cerodirphia rosacordis & 1 & 1 & Dirphiopsis picturata & 1 & 1 \\
\hline Cicia crocata & 1 & 2 & Dirphiopsis undulinea & 1 & 3 \\
\hline Citheronia laocoon & 1 & 1 & Hylesia ebalus & 1 & 1 \\
\hline Copaxa joinvillea & 1 & 2 & Hylesia maurex & 1 & 1 \\
\hline Copiopteryx derceto & 1 & 4 & Hylesia nigricans & 1 & 2 \\
\hline Dirphia araucariae & 1 & 1 & Hylesia vindex & 1 & 2 \\
\hline Dirphiopsis trisignata & 1 & 5 & Hyperchiria incisa & 1 & 1 \\
\hline Hylesia ebalus & 1 & 2 & Leucanella gibbosa & 1 & 10 \\
\hline Hylesia sp. 3 & 1 & 11 & Pseudodirphia catarinensis & 1 & 1 \\
\hline Leucanella janeira & 1 & 1 & Rothschildia belus & 1 & 1 \\
\hline Neocarnegia basirei & 1 & 1 & Adelowalkeria flavosignata & 2 & 3 \\
\hline Procitheronia purpurea & 1 & 10 & Almeidella almeidai & 2 & 3 \\
\hline Prohylesia zikani & 1 & 6 & Automeris basalis & 2 & 2 \\
\hline Rothschildia belus & 1 & 1 & Automeris bilinea & 2 & 2 \\
\hline Almeidella almeidai & 2 & 23 & Automeris melanops & 2 & 2 \\
\hline Automerella aurora & 2 & 3 & Catacantha ferruginea & 2 & 2 \\
\hline Automeris tristis & 2 & 2 & Cicia crocata & 2 & 4 \\
\hline Cerodirphia opis & 2 & 17 & Copaxa joinvillea & 2 & 5 \\
\hline Cerodirphia zikani & 2 & 15 & Copiopteryx derceto & 2 & 2 \\
\hline Copaxa satellita & 2 & 7 & Dirphia sombrero & 2 & 2 \\
\hline Hylesia rufex & 2 & 5 & Dirphiopsis trisignata & 2 & 4 \\
\hline Hylesia sp. 2 & 2 & 3 & Eacles ducalis & 2 & 3 \\
\hline Hyperchirioides bulaea & 2 & 2 & Hylesia paulex & 2 & 2 \\
\hline Paradaemonia mayi & 2 & 10 & Hyperchirioides bulaea & 2 & 2 \\
\hline Paradaemonia platydesmia & 2 & 5 & Loxolomia serpentina & 2 & 3 \\
\hline Pseudoautomeris brasiliensis & 2 & 4 & Paradaemonia orsilochus & 2 & 2 \\
\hline Arsenura biundulata & 3 & 34 & Periga circumstans & 2 & 3 \\
\hline Automeris basalis & 3 & 17 & Procitheronia purpurea & 2 & 2 \\
\hline
\end{tabular}




\begin{tabular}{|c|c|c|c|c|c|}
\hline Espécies & 2012-2013 & $\mathbf{n}$ & Espécies & 1948-1950 & $\mathbf{n}$ \\
\hline Automeris beckeri & 3 & 62 & Pseudoautomeris coronis & 2 & 7 \\
\hline Automeris inornata & 3 & 45 & Schausiella arpi & 2 & 5 \\
\hline Citheronia brissotii & 3 & 7 & Travassosula subfumata & 2 & 2 \\
\hline Dirphia baroma & 3 & 71 & Automeris muscula & 3 & 4 \\
\hline Dirphia fornax & 3 & 12 & Copaxa satellita & 3 & 8 \\
\hline Dirphiopsis wanderbilti & 3 & 10 & Copiopteryx semiramis & 3 & 7 \\
\hline Eacles mayi & 3 & 69 & Dirphia fornax & 3 & 11 \\
\hline Gamelia catharina & 3 & 4 & Dirphiopsis epiolina & 3 & 13 \\
\hline Hidripa perdix & 3 & 8 & Eacles mayi & 3 & 19 \\
\hline Hylesia oratex & 3 & 230 & Hylesia munonia & 3 & 4 \\
\hline Hylesia paulex & 3 & 38 & Hylesia nanus & 3 & 3 \\
\hline Hylesia sp. & 3 & 37 & Leucanella janeira & 3 & 7 \\
\hline Hylesia vindex & 3 & 52 & Leucanella viridescens & 3 & 3 \\
\hline Leucanella gibbosa & 3 & 5 & Paradaemonia mayi & 3 & 7 \\
\hline Loxolomia serpentina & 3 & 3 & Paradaemonia platydesmia & 3 & 4 \\
\hline Pseudoautomeris coronis & 3 & 51 & Rhescyntis pseudomartii & 3 & 3 \\
\hline Rhescyntis pseudomartii & 3 & 3 & Rothschildia arethusa & 3 & 4 \\
\hline Rothschildia hesperus & 3 & 5 & Arsenura armida & 4 & 6 \\
\hline Travassosula subfumata & 3 & 8 & Automerella aurora & 4 & 8 \\
\hline Automeris bilinea & 4 & 31 & Automeris tristis & 4 & 5 \\
\hline Catacantha ferruginea & 4 & 9 & Cerodirphia opis & 4 & 13 \\
\hline Cerodirphia sp.1 & 4 & 26 & Citheronia laocoon & 4 & 6 \\
\hline Dirphia dolosa & 4 & 27 & Dirphia baroma & 4 & 8 \\
\hline Dirphiopsis delta & 4 & 17 & Dirphiopsis wanderbilti & 4 & 6 \\
\hline Dirphiopsis epiolina & 4 & 62 & Oiticella convergens & 4 & 4 \\
\hline Dirphiopsis picturata & 4 & 23 & Oxytenis modestia & 4 & 4 \\
\hline Eacles ducalis & 4 & 79 & Rothschildia aurota & 4 & 4 \\
\hline Hylesia sp. 1 & 4 & 118 & Automeris beckeri & 5 & 12 \\
\hline Molippa sabina & 4 & 26 & Copaxa decrescens & 5 & 8 \\
\hline Adelowalkeria flavosignata & 5 & 22 & Dirphia dolosa & 5 & 7 \\
\hline Copaxa decrescens & 5 & 22 & Dirphiopsis multicolor & 5 & 12 \\
\hline Eacles imperialis & 5 & 32 & Hidripa perdix & 5 & 10 \\
\hline Hylesia maurex & 5 & 46 & Othorene purpurascens & 5 & 14 \\
\hline Hylesia munonia & 5 & 115 & Pseudoautomeris hubneri & 5 & 7 \\
\hline Hyperchiria incisa & 5 & 24 & Dirphiopsis delta & 6 & 12 \\
\hline Periga circumstans & 5 & 6 & Hylesia oratex & 6 & 22 \\
\hline Procitheronia principalis & 5 & 17 & Molippa cruenta & 6 & 8 \\
\hline Arsenura armida & 6 & 21 & Molippa sabina & 6 & 13 \\
\hline Hidripa paranensis & 6 & 16 & Oiticella brevis & 6 & 8 \\
\hline Oiticella brevis & 6 & 20 & Periga falcata & 6 & 9 \\
\hline Oxytenis modestia & 6 & 27 & Rothschildia hesperus & 6 & 8 \\
\hline Periga falcata & 6 & 23 & Rothschildia hopfferi & 6 & 12 \\
\hline Rothschildia aurota & 6 & 21 & Adeloneivaia fallax & 7 & 11 \\
\hline Rothschildia hopfferi & 6 & 17 & Arsenura biundulata & 7 & 40 \\
\hline Adelowalkeria tristygma & 7 & 81 & Eacles imperialis & 7 & 12 \\
\hline Dirphia muscosa & 7 & 152 & Gamelia remissoides & 7 & 14 \\
\hline
\end{tabular}




\begin{tabular}{lcc|lcc}
\hline Espécies & $\mathbf{2 0 1 2 - 2 0 1 3}$ & $\mathbf{n}$ & Espécies & $\mathbf{1 9 4 8 - 1 9 5 0}$ & $\mathbf{n}$ \\
\hline Hylesia falcifera & 7 & 78 & Hylesia scortina & 7 & 9 \\
Hylesia nanus & 7 & 31 & Pseudoautomeris brasiliensis & 7 & 19 \\
Hylesia scortina & 7 & 70 & Rothschildia jacobaeae & 7 & 10 \\
Othorene purpurascens & 7 & 93 & Syssphinx molina & 8 & 12 \\
Pseudoautomeris hubneri & 7 & 29 & Oxytenis bicornis & 9 & 14 \\
Cerodirphia vagans & 8 & 33 & Procitheronia principalis & 10 & 22 \\
Copiopteryx sonthonnaxi & 8 & 67 & Titaea tamerlan & 10 & 27 \\
Dirphiopsis multicolor & 8 & 19 & Automeris illustris & 11 & 12 \\
Hylesia metapyrrha & 9 & 322 & Dirphia muscosa & 11 & 38 \\
Lonomia obliqua & 9 & 95 & Hylesia metapyrrha & 11 & 24 \\
Titaea tamerlan & 9 & 52 & Adelowalkeria tristygma & 12 & 15 \\
Adeloneivaia fallax & 11 & 114 & Cerodirphia vagans & 12 & 32 \\
Automeris illustris & 11 & 84 & Lonomia obliqua & 13 & 31 \\
Gamelia remissoides & 11 & 32 & Othorene cadmus & 13 & 25 \\
Copaxa canella & 12 & 68 & Copaxa canella & 14 & 48 \\
Othorene cadmus & 12 & 28 & Copiopteryx sonthonnaxi & 15 & 48 \\
Oxytenis bicornis & 12 & 62 & Hidripa paranensis & 16 & 46 \\
\hline
\end{tabular}

O padrão geral descrito pelo NMDS entre as espécies das comunidades de 1948-1950 e da atual com suas abundâncias relativizadas apresentou alto stress $(>0,15)$ e a variância captada de $63 \%\left(\mathrm{r}^{2}=0,63, \mathrm{p}<0,01\right)$. O NMDS é uma análise de ordenação por similaridae e assim, apresenta visualmente a relação de similaridade entre as amostras ordenadas em $\mathrm{n}$ dimenções. A Fig. 32 apresenta as amostras ordenadas em duas dimeções. $\mathrm{O}$ alto stress resultante indica que o gráfico demonstra fracamente a relação de similaridade encontrada pela análise. Visualmente o padrão parece sugerir alta sobreposição das amostras dos dois trabalhos (19481950 e 2012-2013) (Fig. 32), porém a PERMANOVA indicou haver diferença significativa entre as coletas históricas e do presente trabalho. No entanto, a análise de correspondência (CA) feita com presença e ausência das espécies nos respectivos meses entre as duas épocas, apresentou valores bastante semelhantes para ambas comunidades (Fig. 33). Uma análise de correlação par-a-par para os mesmos dados utilizados na CA demonstrou que $45,8 \%$ das relações da composição das espécies dos meses de 1948-1950 em contraste com a composição das espécies dos meses de 2012-2013 apresentaram correlação significativa $(p<0,05)$ e ainda $100 \%$ da correlação entre os respectivos meses de cada época (ex. março de 1948-1950 com março de 2012-2013, abril de 1948-1950 com abril de 2012-2013 e assim sucessivamente) mostrou-se significativa. 


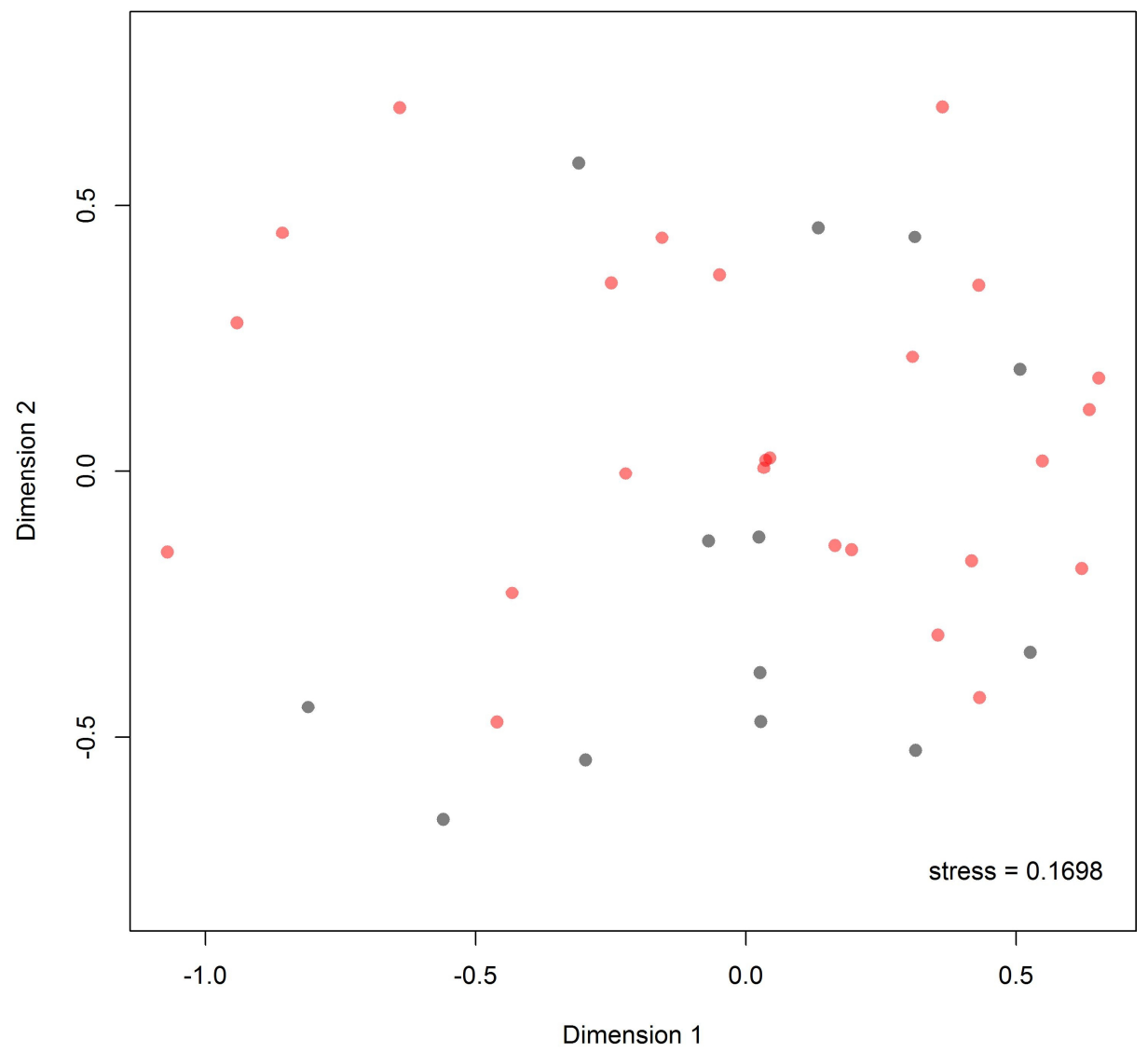

Figura 32. Diagrama da análise por Escalonamento Multidimensional Não-métrico (NMDS) das comunidades representadas pelos 25 meses de 1948-1950 (pontos vermelhos) e pelos 13 meses de 2012-2013 (pontos cinzas), da Estação Biológica de Boraceia, Salesópolis, SP, Brasil.

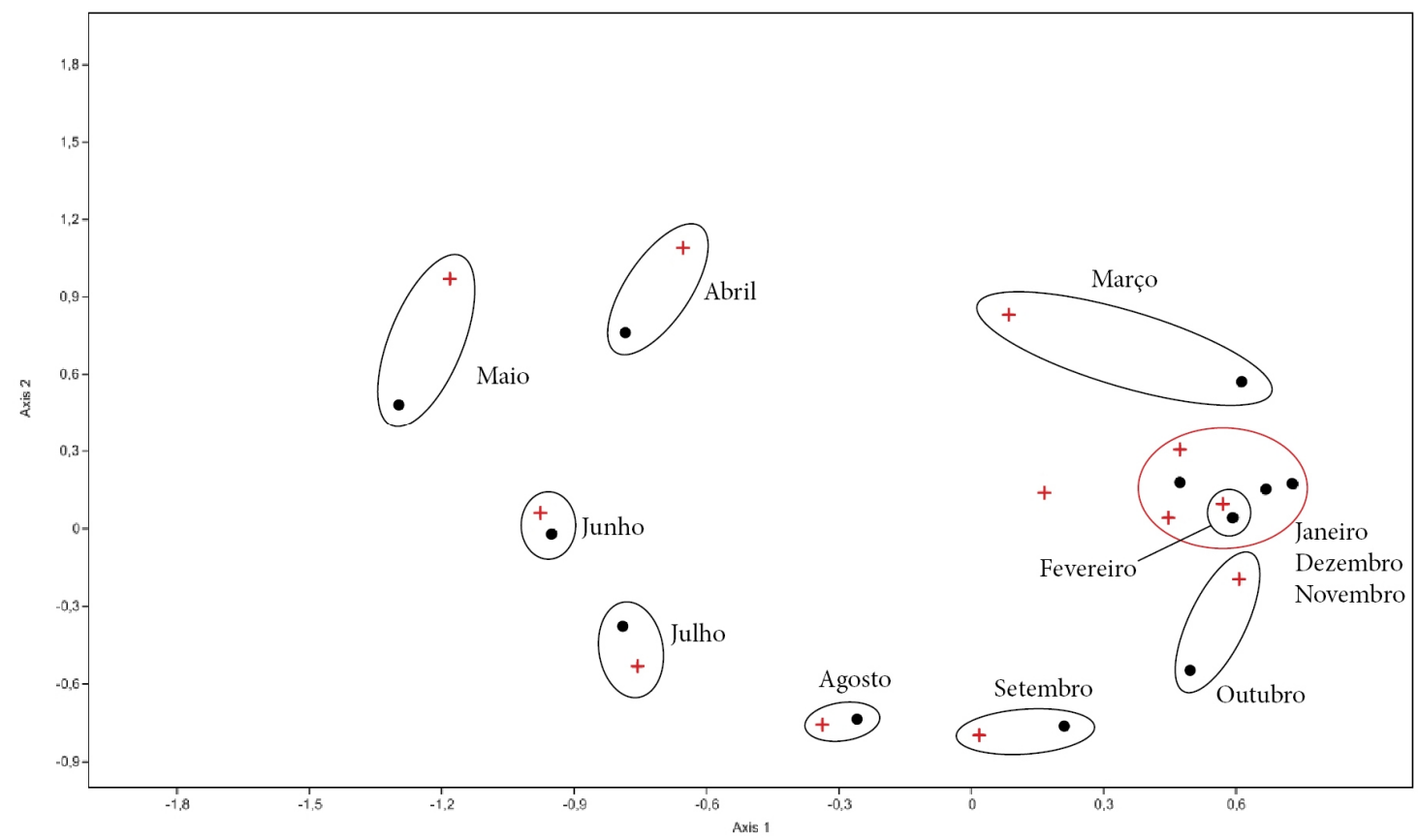

Figura 33. Diagrama da Análise de Correspondência (CA) entre as comunidades de 1948-1950 (pontos pretos) e de 2012-2013 (cruzes vermelhas) da Estação Biológica de Boraceia, Salesópolis, SP, Brasil. A comparação foi feita com os 12 meses do ano para cada época de coleta e assim, os dados dos meses com repetição (por exemplo, março de 2012 e março de 2013) foram somados. 


\subsubsection{As espécies de Saturniidae da Estação Biológica de Boraceia e outros levantamentos}

A distribuição das espécies entre as subfamílias de Saturniidae na Estação Biológica de Boraceia segue o mesmo padrão observado em todas as localidades estudadas no Brasil: o Estado do Paraná (Marinoni et al. 1997) e do Rio Grande do Sul (Nunes 2004; Specht et al. 2005; Prestes et al. 2009; Corseuil 2013), e o bioma Cerrado (Camargo \& Becker 1999; Camargo et al. 2008), como pode ser observado na Fig. 34. Em outros países da América do Sul, a distribuição das espécies entre as subfamílias parece seguir a mesma tendência (p. ex. dados de Equador, ver Racheli \& Racheli 2005, 2006), ou seja, Hemileucinae é a subfamília de maior riqueza seguida por Ceratocampinae, Arsenurinae, Saturniinae e Oxyteninae. No mundo, Hemileucinae é a subfamília com maior número de espécies, porém, Saturniinae, única subfamília distribuída mundialmente, é a segunda com maior riqueza (Lemaire \& Minet 1998; Lemaire 2002).

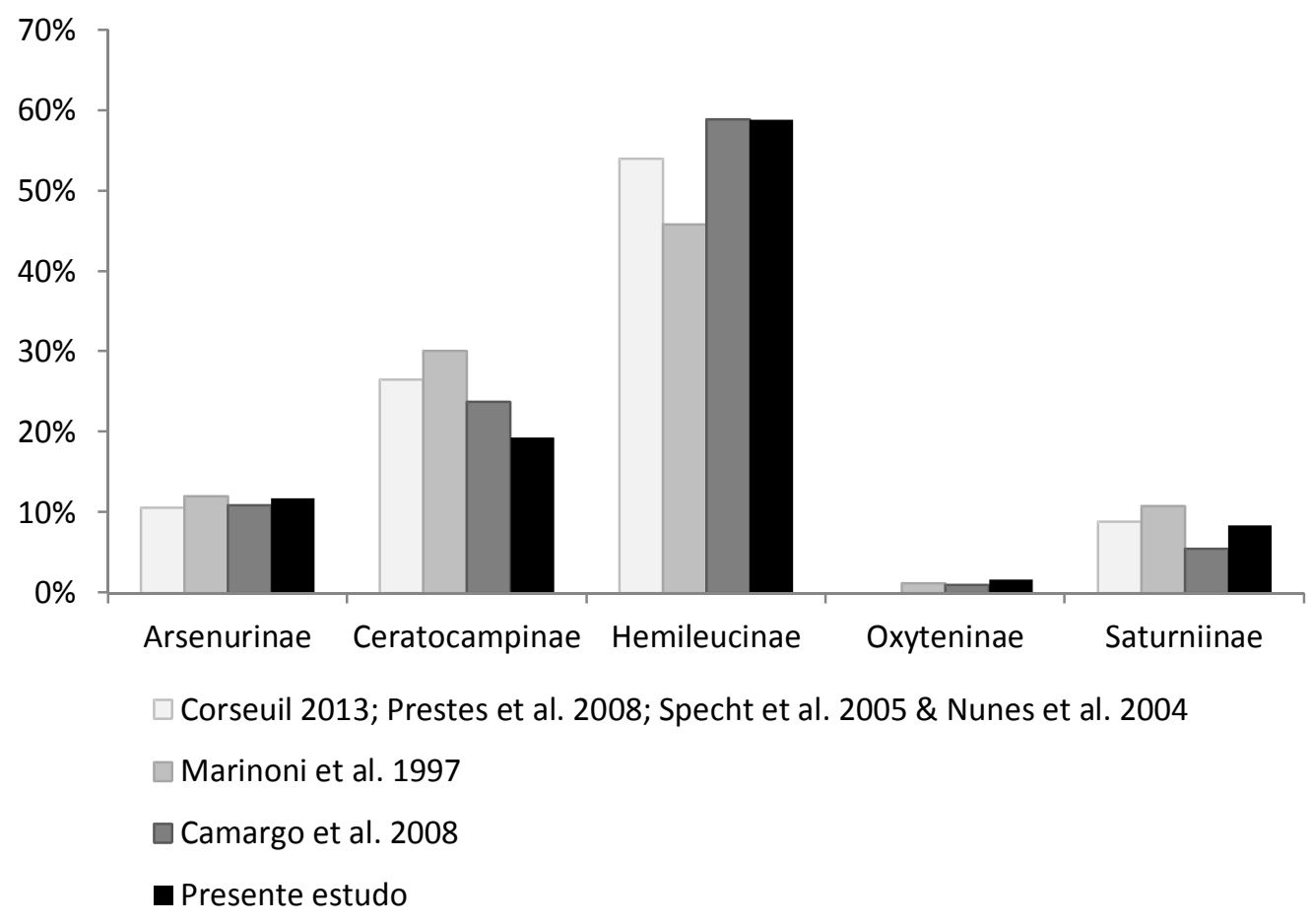

Figura 34. Proporção do número de espécies de todas as subfamílias em três listas de espécies de Saturniidae do Brasil e das espécies coletadas na Estação Biológica de Boraceia (1942-2013). Paraná (Marinoni et al. 1997), Rio Grande do Sul (Nunes et al. 2004; Specht et al. 2005; Prestes et al. 2008; Corseuil 2013), Bioma Cerrado (Camargo et al. 2008).

O levantamento de 119 espécies (Tab. 3) em um único ponto da Estação Biológica de Boraceia demonstra como a área tem relevância pra a amostragem da família no Brasil. Para o 
Estado do Rio Grande do Sul foram registradas 113 espécies (Nunes 2004; Specht et al. 2005; Prestes et al. 2009; Corseuil 2013), para o Paraná, em uma lista que em breve deverá ser atualizada, foram registradas 83 espécies (Marinoni et al. 1997), sendo que os dois Estados juntos somam 140 espécies distintas. Entendemos que essa grande riqueza de espécies está relacionada à localização estratégica da Estação Biológica de Boraceia, inserida dentro de uma faixa contínua de floresta atlântica (floresta ombrófila densa) que abrange praticamente todo litoral e fragmentos não costeiros do Estado de São Paulo, estendendo-se desde o sul do estado nas proximidades de Peruíbe ( $\left.24^{\circ} 11^{\prime} \mathrm{S}, 47^{\circ} 17^{\prime} \mathrm{W}\right)$, até o sul do estado do Rio de Janeiro, na região de Angra dos Reis (22 $\left.51^{\prime} \mathrm{S}, 4^{\circ} 14^{\prime} \mathrm{W}\right)$ (Fig. 1).

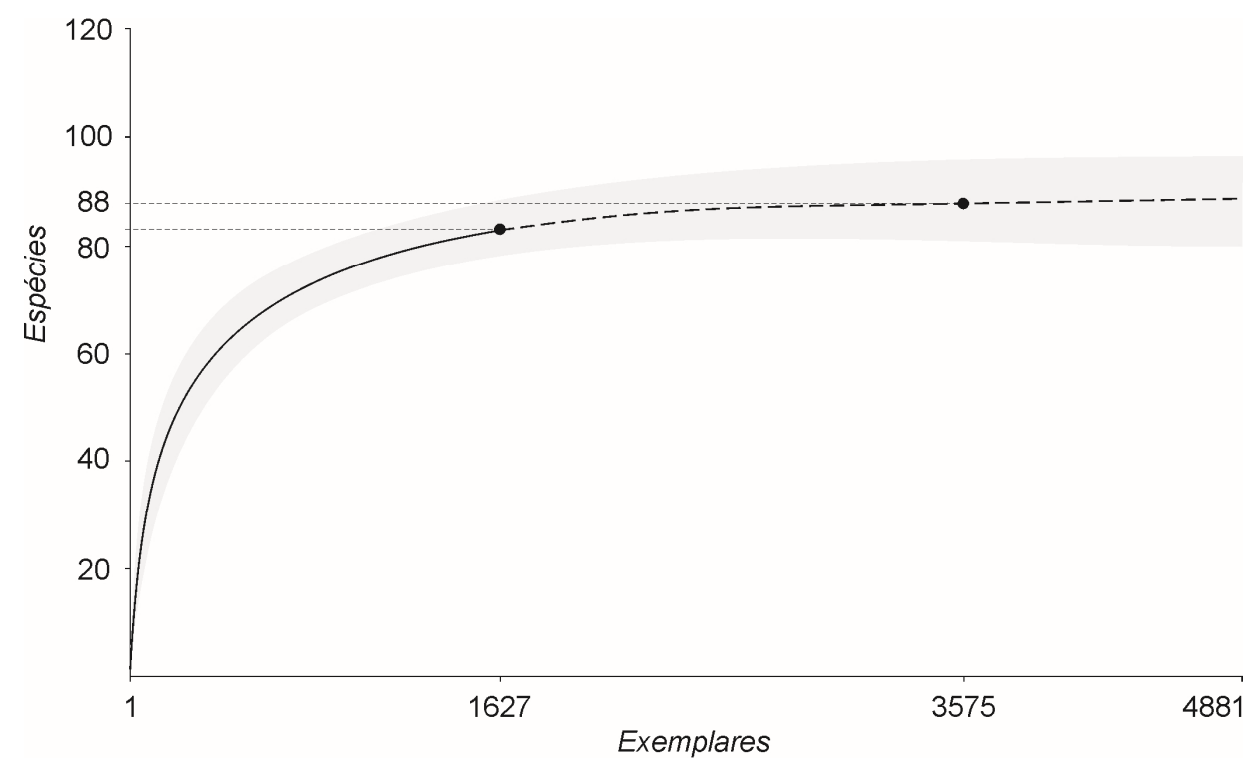

Figura 35. Curva de rarefação com extrapolação (para 4.881 exemplares) no número de exemplares (extrapolation on individual-based rarefaction), coletados entre 1986 e 1987 em oito localidades do Estado do Paraná, Brasil (Marinoni et al. 1997). A rarefação atinge 88 espécies com 3.575 exemplares e fixou seu valor máximo de 88,4 espécies nos últimos 8 exemplares, de um total de 4.88, sendo que 88,39 espécies foi atingido com 4.798 exemplares , permanecendo assim nos 76 "penúltimos” exemplares.

Comparando as curvas de rarefação dos exemplares coletados entre 1942 e 2013 em um único ponto de coleta na Estação Biológica de Boraceia, com os dados obtidos por Marinoni et al. (1997) para o Estado do Paraná, percebe-se que a riqueza de espécies é bastante distinta. De acordo com Colwell et al. (2012), extrapolações para curvas de rarefação com base no número de exemplares mantem-se robustas com até três vezes o tamanho da amostra. Neste caso, a curva de rarefação com base no número de exemplares extrapolada em três vezes $(n=4.881$ exemplares) para os dados de Marinoni et al. (1997) gerou uma estimativa de riqueza de aproximadamente 88 espécies a partir de 3.575 exemplares coletados, sendo que para Estação 
Biológica de Boraceia o mesmo número de espécies deve ser obtido com a coleta de aproximadamente 513 exemplares (rarefação) (Figs. 24, 35).

A dominância do gênero Hylesia na Estação Biológica de Boraceia é expressiva. Para o Rio Grande do Sul estão registradas nove espécies deste gênero, Hylesia dircifex Draudt, 1929, H. metapyrrha (Walker, 1855), H. nigricans (Berg., 1875), H. oratex Dyar, 1913, H. paulex Dognin, 1922, H. remex Dryar, 1913, H. rufex Draudt, 1929, H. scortina Draudt, 1929 e H. vindex Dryar, 1913. Para a EBB. foram registradas 15 espécies, incluindo três morfoespécies e um conjunto de exemplares cuja identificação em nível específico não foi possível (ver Tab. 3: * Hylesia sp.). Das espécies citadas para o Rio Grande do Sul, apenas H. dircifex, H. nigricans e H. remex não foram coletadas na EBB. Este gênero é um dos mais bem representados em número de espécies para a subfamília Hemileucinae, contendo 111 espécies (Lemaire 2002; Camargo 2007), ficando atrás apenas do gênero Automeris Hübner, 1819. É igualmente um dos que apresenta a taxonomia mais complicada, graças à homogeneidade fenotípica e à ampla distribuição geográfica, abrangendo toda região Neotropical, do México até Argentina.

Tendo conhecimento de que o gênero Hylesia figura como um dos mais problemáticos dentro da subfamília Hemileucinae, a notável densidade de espécies e exemplares amostrados na Estação Biológica da Boraceia faz do local um ótimo ponto para estudos mais aprofundados sobre as espécies do gênero. A dissecção de genitálias de 26 exemplares mostrou-se de difícil utilização para separação das espécies. O desenvolvimento de estudos envolvendo diferentes ferramentas para contribuir na delimitação das espécies do gênero (Wheeler 2008; SchlikSteiner et al. 2009) são de extrema importância, tanto para categorização subgenérica da taxonomia tradicional, como para a sistemática e uso deste conhecimento nas relações entre as espécies ou grupos de espécies do gênero.

\subsubsection{A fauna de Saturniidae da Estação Biológica de Boraceia hoje e cerca de 70 anos atrás}

Uma das perguntas que necessitou esclarecimento antes das análises de comparação com os dados históricos foi sobre a arbitrariedade dos coletores à época. Para os dados recentes (2012-2013), todos os exemplares foram amostrados sistematicamente seguindo o protocolo descrito no presente projeto; a hipótese é que os dados históricos (1948-1950) são consequentes de coletas arbitrárias com relação às espécies.

O funcionário da Estação Biológica de Boraceia desde o final de 1972, Sr. Firmino Rodrigues Gomes, nos informou que fomos os primeiros pesquisadores, de que ele tem 
conhecimento, a coletar insetos noturnos no local durante todo o período escuro de cada dia. Essa informação faz com que os dados históricos tenham sido amostrados de maneira distinta dos recentes, havendo restrição do esforço de campo por noite de coleta no primeiro grupo de dados. Percebe-se ainda que há diferença brusca da quantidade de exemplares (926) coletados durante os 25 meses, há mais de 60 anos, e a da quantidade coletada recentemente em 13 meses (3.249 exemplares). As espécies mais abundantes coletadas há 60 anos são prioritariamente espécies representadas em várias amostras (meses) (Figs. 28; Tab. 4 e 5), indicando que suas respectivas abundâncias são advindas da "recoleta" na "próxima" campanha, atitude explicável devido à importância para registro fenológico da espécie. Dessa forma, para cada mês (campanha), coletavam-se exemplares representantes de todas as espécies observadas nas diversas noites do respectivo mês fazendo com que espécies renitentes fossem mais coletadas. Tais fatos indicam que a captura de cada exemplar era arbitrária e não imparcial.

As curvas de rarefação também suportam a hipótese de arbitrariedade das coletas. Duas características podem ser apontadas. A inclinação mais acentuada da curva com base no número de exemplares dos dados de quase 70 anos atrás, comparada à inclinação da mesma curva para os dados atuais (2012-2013) (Figs. 29), indicam que os dados históricos apresentaram maior uniformidade na distribuição das espécies (Gotelli \& Colwell 2001). A agregação natural dos exemplares de um táxon geralmente é variável dentro de variações no espaço ou tempo, o resultado de um padrão de distribuição uniforme das espécies, pode ser um artefato da metodologia utilizada mais do que representar a distribuição natural dos exemplares da comunidade (Gotelli \& Colwell 2001). Observando-se as curvas de cada período com base nos exemplares e as curvas com base nas amostras, nota-se que para o período histórico há pouca distância entre as curvas (Figs. 36, 37), demonstrando que a uniformidade da distribuição das espécies por amostra é semelhante àquela observada para os exemplares como um todo, descaracterizando as amostras como unidades de distribuição randômicas dos exemplares de todas as espécies disponíveis naquele espaço/tempo. Essa distribuição randômica seria mais esperada como reflexo da distribuição natural das espécies da comunidade (Hulbert 1971; Gotelli \& Colwell 2001; Colwell 2004). 

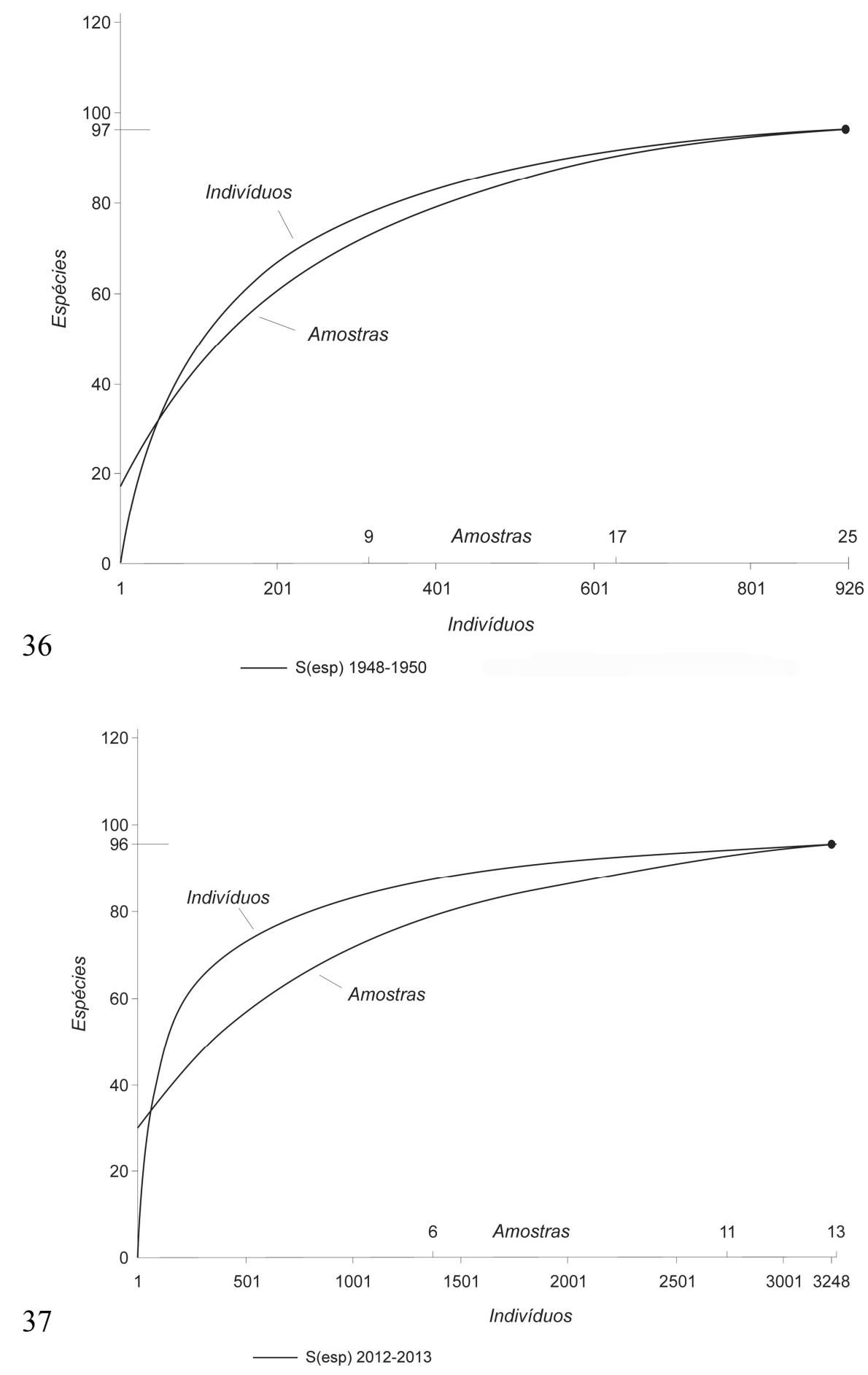

Figuras 36-37. Curvas de rarefação com base nos exemplares e nas amostras para cada período. (36) 1948-1950 e (37) 2012-2013, dos exemplares coletados na Estação Biológica de Boraceia, Salesópolis, SP, Brasil.

Embora haja um abismo no número de exemplares capturados, o número de espécies referentes aos 25 meses analisados das coletas sistemáticas, realizadas entre 1948 e 1950 foi muito semelhante aos 13 meses de coletas, entre 2012 e 2013. Nas coletas históricas (19481950) foram amostradas 97 espécies, enquanto nas coletas recentes foram amostradas 96 
espécies. A distribuição de abundância e número de espécies dentro de cada subfamília, para os dois grupos de dados, seguiu o mesmo padrão observado para o conjunto de dados da Estação Biológica de Boraceia bem como para outras regiões do Brasil e da América do Sul (Marinoni et al., 1997; Lemaire \& Minet 1998; Camargo \& Becker 1999; Lemaire 2002; Nunes 2004; Racheli \& Racheli 2005, 2006; Specht et al. 2005; Camargo et al. 2008; Prestes et al. 2009; Corseuil 2013).

As curvas de rarefação com base no número de exemplares demonstram que, aproximadamente 60 anos atrás, a riqueza de Saturniidae na Estação Biológica de Boraceia era maior que a atual, no entanto, como fora mencionado, este resultado pode ter sido artificialmente obtido devido à arbitrariedade das coletas históricas. Observa-se ainda no mesmo modelo de curva, que a distribuição das espécies entre os indivíduos das coletas recentes apresenta um padrão de menor uniformidade dada a menor inclinação da curva, pois quanto mais íngreme a curva desta rarefação maior a uniformidade da amostra (Gotelli \& Colwell 2001). Por outro lado, as curvas com base no número de amostra (Fig. 13) indicaram que as amostras recentes revelaram densidade de espécies maior que as amostras históricas, mesmo que para muitas espécies haja um número maior de réplicas por unidade de amostra. Para se atingir 96 espécies foram necessários 24 meses de coletas históricas (1948-1950) e 13 meses de coletas recentes (2012-2013). Possivelmente, este fenômeno é consequente do grande esforço de campo realizado em cada noite de coleta. Muitas das espécies de Saturniidae da Estação Biológica de Boraceia apresentam distribuição temporal, ao longo de cada noite, relativamente restrita, com isso ao se reduzir o esforço de campo por noite, aumenta-se a probabilidade de espécies com restrição temporal não serem coletadas e assim a densidade de espécies por amostra é reduzida (dados 1948-1950), ou aumentada quanto maior o esforço contínuo por noite de coleta (dados 2012-2013).

A PERMANOVA da análise multivariada nMDS indicou haver diferença significativa entre as coletas históricas e recentes, no entanto, esta análise levou em consideração a abundância dos indivíduos. A análise de correspondência (CA) na qual foi avaliada apenas a presença e ausência das espécies indicou que não há diferença significativa entre as comunidades, sendo esta análise corroborada pelo teste de correlação entre os meses do período histórico e recente. Observando ambas as análises percebe-se que, de fato, as comunidades alteraram pouco ou quase nada suas estruturas com relação à presença e ausência das espécies, e ainda que houve diferenças metodológicas significativas entre os dois esforços de coleta, uma 
vez que toda diferença observada entre as comunidades está atrelada à distribuição de abundância das espécies para cada uma das épocas.

Dezessete espécies foram coletadas somente nas coletas recentes (2012-2013) e 18 foram coletadas apenas nas amostragens históricas. No entanto, dentre as espécies coletadas apenas recentemente, 11 ocorreram exclusivamente em uma ou duas amostras (uniques e duplicates), e com o número de exemplares relativamente baixo, excetuando-se Cerodirphia zikani (Schaus, 1921) com 15 exemplares e Hylesia sp. 3 com 11, as quais apesar de pertencerem à classe de abundância "incomum", ocorreram com significativo número de exemplares quando comparada às outras 9 espécies de uniques e duplicates. O mesmo fenômeno é observado nos dados históricos, para os quais 10 das 18 espécies ocorreram em apenas uma ou duas amostras e em baixa quantidade, mas classificadas como raras, incomuns ou comuns, como Schausiella arpi (Schaus, 1892), que com 5 exemplares foi classificada como "comum," para a assembleia histórica. Entende-se que estas são espécies pouco comuns na região, ou que estão mais concentradas em algum local afastado do entorno da área de coleta, ou ainda, que os coletores tenham tido sorte ao estar em campo durante os poucos dias de vida dos adultos das respectivas espécies. No caso de $S$. arpi, por exemplo, a espécie só foi coletada nos dois meses de janeiro do período histório aqui estudado, de 1949 e de 1950. Por isso se observa que por não ser Saturniidae uma família com espécies tipicamente migratórias, como Sphingidae (Janzen 1984), o feliz acaso de se coletar alguma delas está diretamente relacionado ao grande esforço realizado em todas essas décadas.

Ainda sobre as espécies coletadas exclusivamente em um ou outro período, chamam atenção aquelas das coletas atuais classificadas como "abundantes", Automeris inornata (Walker, 1855) e Hylesia falcifera (Hübner, 1825), ou "comuns" como Cerodirphia sp.1. Automeris inornata foi coletada em três das campanhas recentes e em cinco outras campanhas fora do período de análise, entre março de 1948 e março de 1950. A primeira foi em setembro de 1950, e a última em setembro de 1968. Já H. falcifera e Cerodirphia sp.1 nunca haviam sido capturadas na Estação Biológica de Boraceia, mesmo assim $H$. falcifera foi novamente coletada após o período sistemático de coleta realizado pelos autores do presente estudo. No concernente as espécies mais abundantes e únicas do período histórico, Molippa cruenta (Walker, 1855) “comum”, Rothschildia jacobaeae (Walker, 1855) - “abundante” e Syssphinx molina (Cramer, 1780) - "abundante" foi observado que M. cruenta foi coletada na EBB pela primeira vez em setembro de 1942 e continuou sendo coletada até fevereiro de 1968; Rothschildia jacobaeae foi coletada pela primeira vez em novembro de 1947 e depois em mais 22 meses até a última 
amostragem em agosto de 1968; este mesmo padrão ocorreu com S. molina sendo amostrada em 21 meses dos 176 em que houve campanha, o primeiro exemplar foi coletado em dezembro de 1943 e o último em novembro de 2000.

Os dados recentes indicam que a região de abrangência do ponto de coleta mantem o grande número de espécies registrado historicamente. Tendo em vista a biologia de adultos de Saturniidae, cuja vida limita-se a curtos 3 a 10 dias (Janzen 1984), o número de vezes em campo torna-se um fator crucial para amostragem real da assembleia e, portanto, um fator positivo para coleta de 97 espécies em 25 meses, em contraste aos 13 meses de coletas recentes. Adicionado ao viés biológico dos saturniídeos, há as espécies raras ou incomuns na região, para as quais ambos os períodos amostraram número semelhante de espécies, 17 únicas em 2012-2013 e 18 únicas em 1948-1950. Estes são fatores que contribuem para o resultado das comunidades atuais e históricas serem distintos (Fig. 32) e são fatores intrínsecos às comunidades de insetos as quais podem nunca atingirem a assíntota de riqueza justamente porque espécies raras estarão constantemente sendo coletadas à medida que mais esforço amostral é realizado (Fisher 1999; Novotný \& Basset 2000; Bebber et al. 2007). Entendemos que a maior riqueza observada para comunidade de mais de seis décadas atrás com relação à atual seja fruto do ruído gerado pela diferença metodológica da época e não por diferença na estrutura das comunidades, e assim, ambas as comunidades devem apresentar riqueza muito aproximada.

A importância da Estação Biológica de Boraceia para a assembleia de Saturniidae da região Atlântica do Estado de São Paulo deve-se especialmente à sua localização, inserida em um contexto de floresta atlântica bem preservada que se estende linearmente da costa norte à costa sul do estado, incluindo o Parque Estadual da Serra do Mar (Fig. 1). Por este motivo, o local e suas instalações situam-se em uma posição estratégica e por isso são muito interessantes para o conhecimento da biodiversidade da mata atlântica do Estado e de todo bioma. Não é coincidência que há mais de 70 anos, no início dos anos 1940, José Pinto da Fonseca, então chefe da divisão de Entomologia do Instituto Biológico (São Paulo, SP) fizera diversas referências à importância da EBB para conhecimento da fauna local e do seu entorno (Travassos \& Camargo 1958). 


\subsection{Potencial dos dados coletados para avaliação da relação das espécies da Estação Biológica de Boraceia com variáveis temporais e ambientais}

Durante as 51 noites dos 13 meses de campanha (março de 2012 a março de 2013) foram coletados 3.287 indivíduos pertencentes a 96 espécies e às cinco subfamílias de Saturniidae presentes na fauna brasileira. A distribuição das espécies, gêneros e subfamílias apresentaram alguns padrões referentes à distribuição sazonal, circadiana e de correlação com as médias de temperaturas; e algumas espécies demonstraram alto grau de abundância em espaços de tempo relativamente bem definidos durante noite.

\subsubsection{Correlações das distribuições de abundância e do número de espécies e de táxons} supraespecificos com temperatura e número de intervalos de coleta.

Para estabelecer algumas relações entre os exemplares de Saturniidae coletados e as distintas temperaturas registradas nos 1.220 intervalos de tempo, foram estabelecidos dois ranques: o primeiro com 17 categorias referentes às variações de temperaturas, e o segundo com seis categorias relacionadas à abundância das espécies (ver detalhes em Material e Métodos). As médias de temperatura (tm) e pluviosidade (pm) não apresentaram correlação linear com a distribuição de abundâncias (a) e no número de espécies (spp) de Saturniidae. A probabilidade de não haver correlação (p) foi significativa, ficando acima de 0,05 ; os valores do coeficiente de correlação (r) foram baixos, o que sinaliza fraca correlação linear entre as variáveis $\left(r_{t m-a}=-0,21 p=0,48 ; r_{t m-s p p}=0,1 p=0,74 ; r_{p m-a}=-0,14 p=0,64 ; r_{p m-s p p}=0.18 p=0,54\right)$ (Fig. 38). A análise de componente principal (PCA) das espécies classificadas por subfamílias, com relação à abundância, número de intervalos de tempo e às respectivas categorias de temperatura, indicou que as 17 categorias não têm influência na ordenação das abundâncias de Saturniidae ente os intervalos (Fig. 38).

Na comparação entre os dados relativizados da abundância e do número de intervalos de tempo, a porcentagem de intervalos sem exemplares coletados tende a ser maior nos extremos de temperatura, especialmente de $22^{\circ} \mathrm{C}$ ou mais, quando o número de intervalos sem exemplares atingiu 50\%. As categorias de temperatura que abrangeram poucos intervalos de tempo com nenhum exemplar coletado foram aquelas com variações de temperatura entre $15^{\circ} \mathrm{C}$ e $16,9^{\circ} \mathrm{C}$ (categorias $\mathrm{T}^{\circ} 8$ e $\mathrm{T}^{\circ}$, respectivamente). Em todas as categorias de temperatura, os intervalos de tempo em que foram coletados entre um e cinco exemplares foram os mais abundantes; os únicos intervalos em que foram coletados 16 ou mais exemplares obtiveram 
registros de temperaturas entre $15^{\circ} \mathrm{C}$ e $17,9^{\circ} \mathrm{C}\left(\mathrm{T}^{\circ} 8\right.$ a $\left.\mathrm{T}^{\circ} 10\right)$ e entre $19^{\circ} \mathrm{C}$ e $19,9^{\circ} \mathrm{C}\left(\mathrm{T}^{\circ} 12\right)$ (Fig. 39).

Ao se comparar proporcionalmente o número de intervalos de tempo (IT) com o número de indivíduos $(\mathrm{N})$ coletados para cada categoria de temperatura, observa-se que, para algumas variações de temperatura houve correlação linear entre estas variáveis (IT e N). Para as variações de $7,8^{\circ} \mathrm{C}$ a $13,9^{\circ}\left(\mathrm{T}^{\circ} 1\right.$ a $\left.\mathrm{T}^{\circ} 6\right)$ e de $20^{\circ} \mathrm{C}$ a $25,6^{\circ} \mathrm{C}\left(\mathrm{T}^{\circ} 13\right.$ a $\left.\mathrm{T}^{\circ} 17\right)$ quanto mais (ou menos) intervalos de tempo ocorreram em determinada categoria de temperatura, mais (ou menos) exemplares foram coletados. A relação se distancia da linearidade especialmente entre $15^{\circ} \mathrm{C}$ e $17,9^{\circ} \mathrm{C}\left(\mathrm{T}^{\circ} 8\right.$ a $\left.\mathrm{T}^{\circ} 10\right)$, quando o número de exemplares coletados aumenta mesmo com a redução do número de intervalos de tempo pertencentes a estas categorias de temperatura (Fig. 40). Tendência semelhante foi observada quando a curva da porcentagem do número de espécies é comparada ao número de intervalos representados pelas respectivas categorias de temperatura. De modo geral a flutuação no número de espécies acompanha mais a flutuação do número de intervalos de tempo do que a abundância. Apenas entre $15^{\circ} \mathrm{C}$ e $17,9^{\circ} \mathrm{C}$ ela está associada à abundância mais do que ao número de intervalos de tempo.

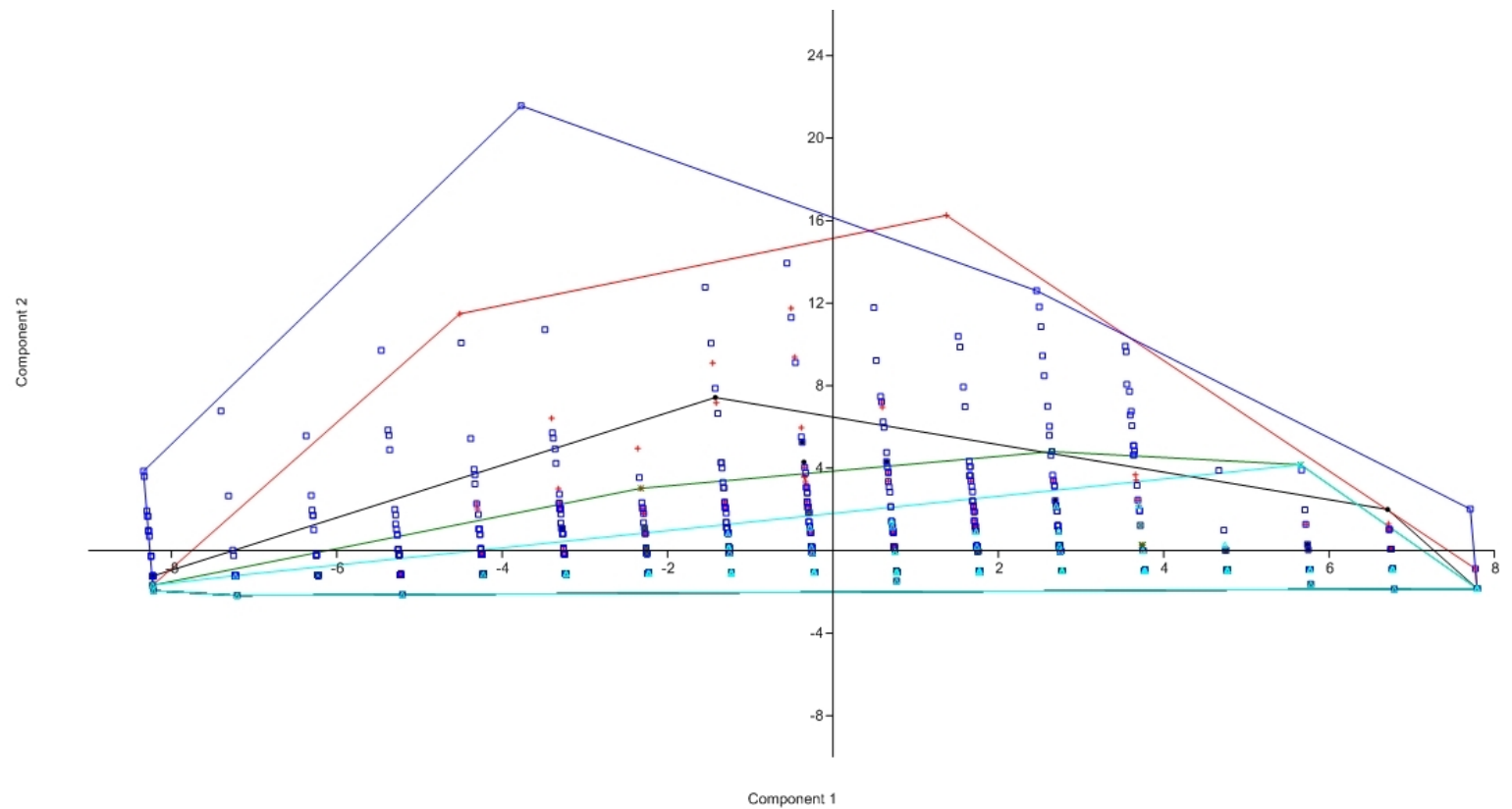

Figura 38. Análise de componente principal (PCA) das subfamílias de acordo com as temperaturas, número de intervalos de tempo referente à determinada temperatura e a abundância pertinente a cada espécie que foi coletada. Os valores das temperaturas foram ranqueados em 17 categorias: $\left(\mathrm{T}^{\circ} 1\right) \leq 8,9^{\circ} \mathrm{C}$; $\left(\mathrm{T}^{\circ} 2\right) 9^{\circ}-9,9^{\circ} ;\left(\mathrm{T}^{\circ} 3\right) 10^{\circ}-10,9^{\circ}$;

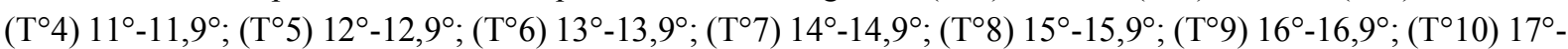

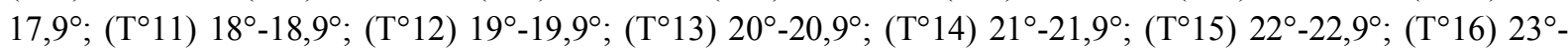
$23,9^{\circ} \mathrm{e}\left(\mathrm{T}^{\circ} 17\right) \geq 24^{\circ}$. As figuras geométricas delimitam os pontos mais externos pertencentes a cada uma das cinco subfamílias de Saturniidae coletadas na Estação Biológica de Boraceia, Salesópolis, SP, Brasil entre março de 2012 e março de 2013. Arsenurinae, linha preta; Ceratocampinae, linha vermelha; Hemileucinae, linha azul; Oxyteninae, linha verde escuro e Saturniinae, linha verde água. 


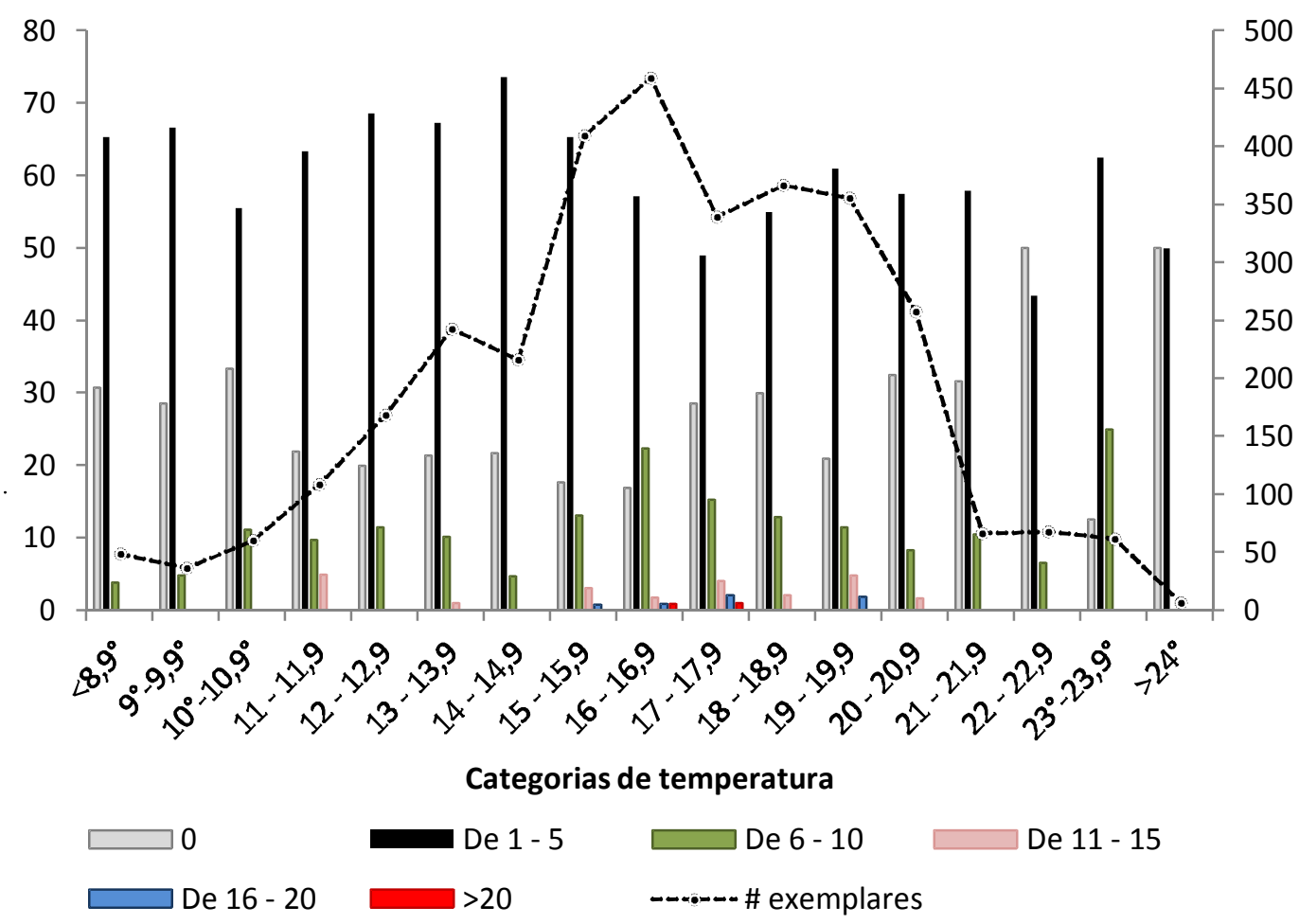

Figura 39. Variação dos intervalos de tempo por ranque de temperatura (barras) e variação do total de indivíduos coletados por ranque de temperatura (linha). Os intervalos de tempo foram ranqueados em seis categorias: nenhum exemplar coletado (barra cinza), com até cinco exemplares coletados (barra preta), de 6 a 10 exemplares coletados (barra verde), de 11 a 15 exemplares coletados (barra rosa), de 16 a 20 exemplares coletados (barra azul) e com mais de 20 exemplares coletados (barra vermelha). Os valores apresentados são porcentagens relativas ao total de intervalos em que cada categoria de temperatura foi registrada.

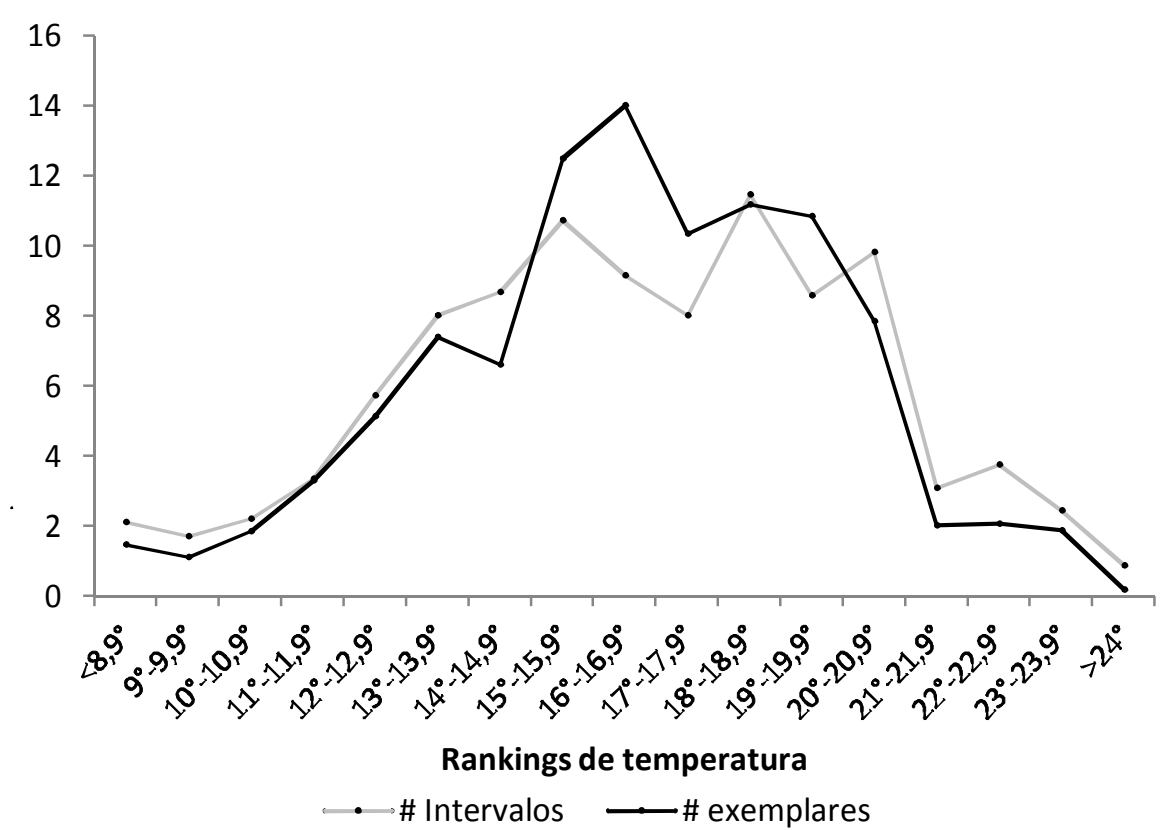

Figura 40. Relação entre a proporção do número de exemplares coletados em cada categoria de temperatura, e a proporção do número de intervalos de tempo em que a variação de temperatura relativa a cada categoria foi registrada. 


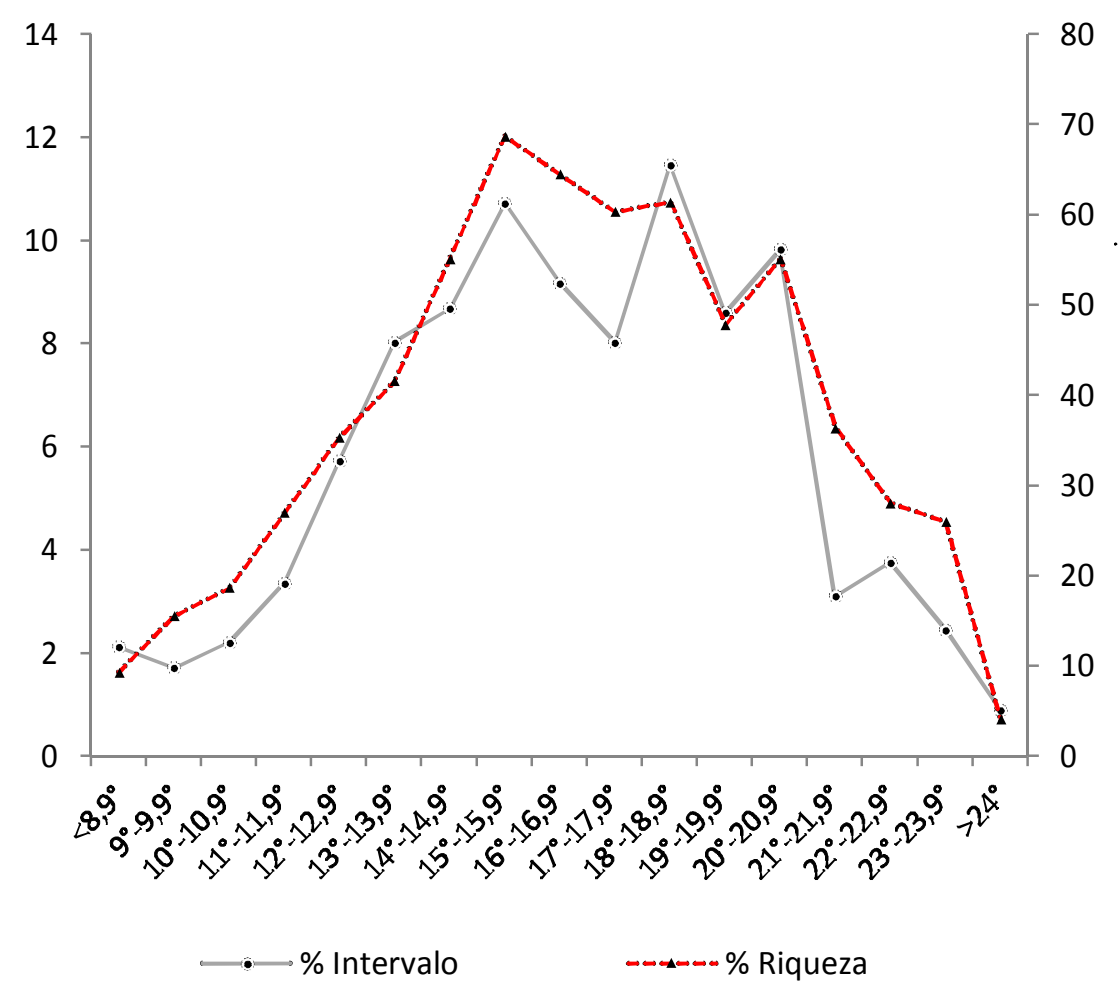

Figura 41. Relação entre a proporção do número de espécies coletados em cada categoria de temperatura, e a proporção do número de intervalos de tempo em que a variação de temperatura relativa a cada categoria foi registrada.

Para compreender melhor a relação entre temperatura, esforço amostral (número de IT), abundância e riqueza foram realizadas mais duas PCA, a primeira referente às distintas temperaturas com relação à abundância, riqueza e numero de intervalos. Tal análise demonstrou que os extremos de temperaturas registrados têm relação negativa com essas três variáveis (pontos acumulados ao lado esquerdo do eixo y - componente 2 e distribuídos relativamente próximos ao eixo $\mathrm{x}$ - componente 1). Além disso, a análise também demonstrou que maior número de intervalos de tempo e altos valores de abundância e riqueza ocorreram em temperaturas medianas dentro do espectro registrado. No mesmo espaço gráfico é possível observar que riqueza de espécies está proximamente relacionada ao número de intervalos de tempo, mais do que está relacionado à abundância. Os dois eixos plotados na análise explicam 98,9\% do arranjo observado (Fig. 42). Na segunda análise de PCA, os intervalos de tempo foram plotados em função de suas respectivas temperaturas, abundância e riqueza, neste caso a temperatura influenciou em $99,5 \%$ da distribuição do eixo x e a abundância e a riqueza em $94 \%$ do eixo y, sendo $90 \%$ e $4 \%$, respectivamente. Nesta figura observa-se que intervalos de tempo com abundâncias e riquezas baixas ou nulas ocorreram em todo gradiente de temperatura 
registrado para os 1220 intervalos de tempo, e que assim, como na figura anterior, apenas em temperaturas medianas, altas abundâncias e riquezas foram amostradas, bem como foi nesta faixa de temperatura onde ocorreu a maior parte da amostragem (Fig. 43).

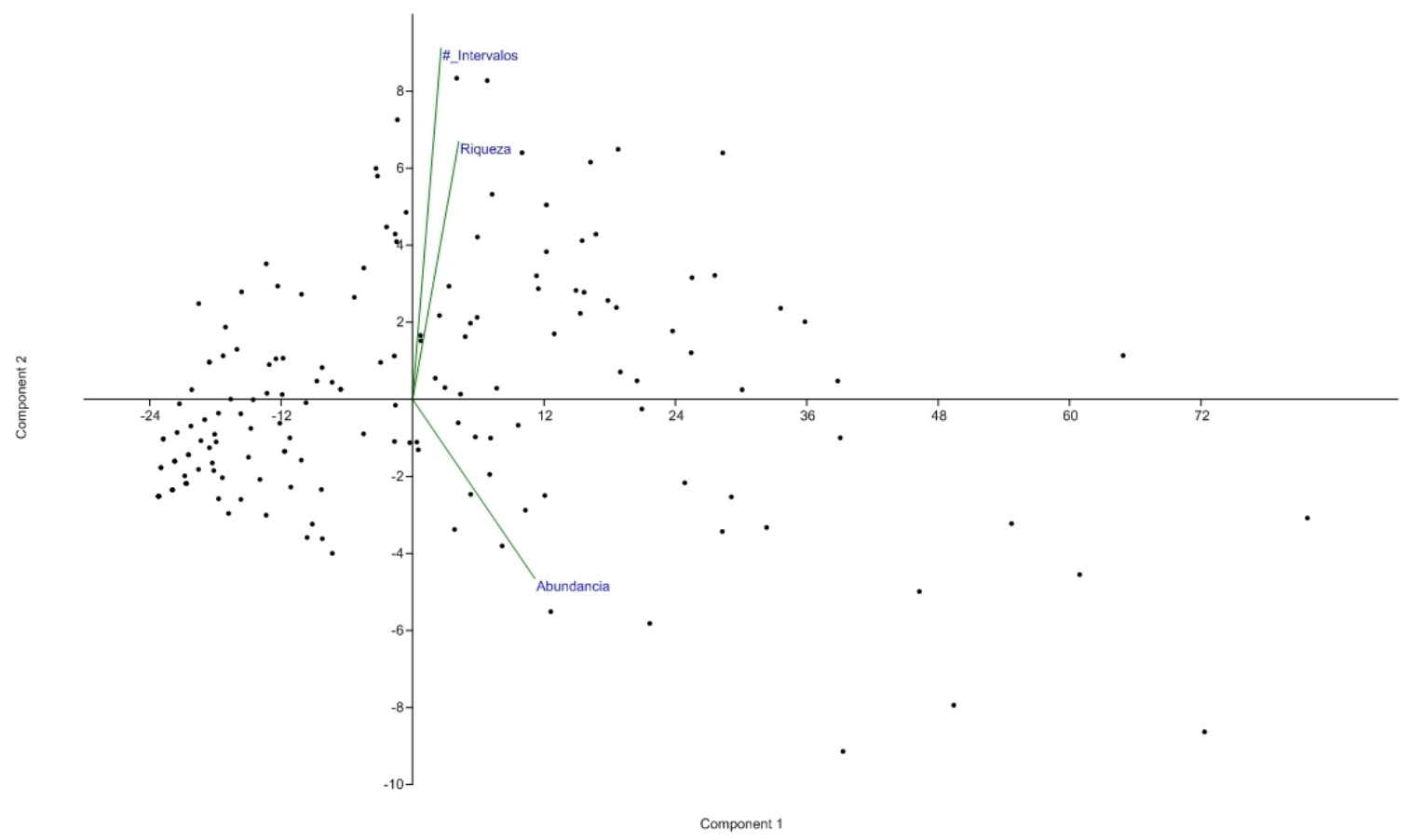

Figura 42. Análise de componente principal (PCA) das médias de temperaturas registradas em cada intervalo de tempo em relação ao número de intervalos, à abundância e ao número de espécies que ocorreram nas respectivas médias de temperatura, das coletas de Saturniidae realizadas na Estação Biológica de Boraceia, Salesópolis, SP, Brasil entre março de 2012 e março de 2013. 


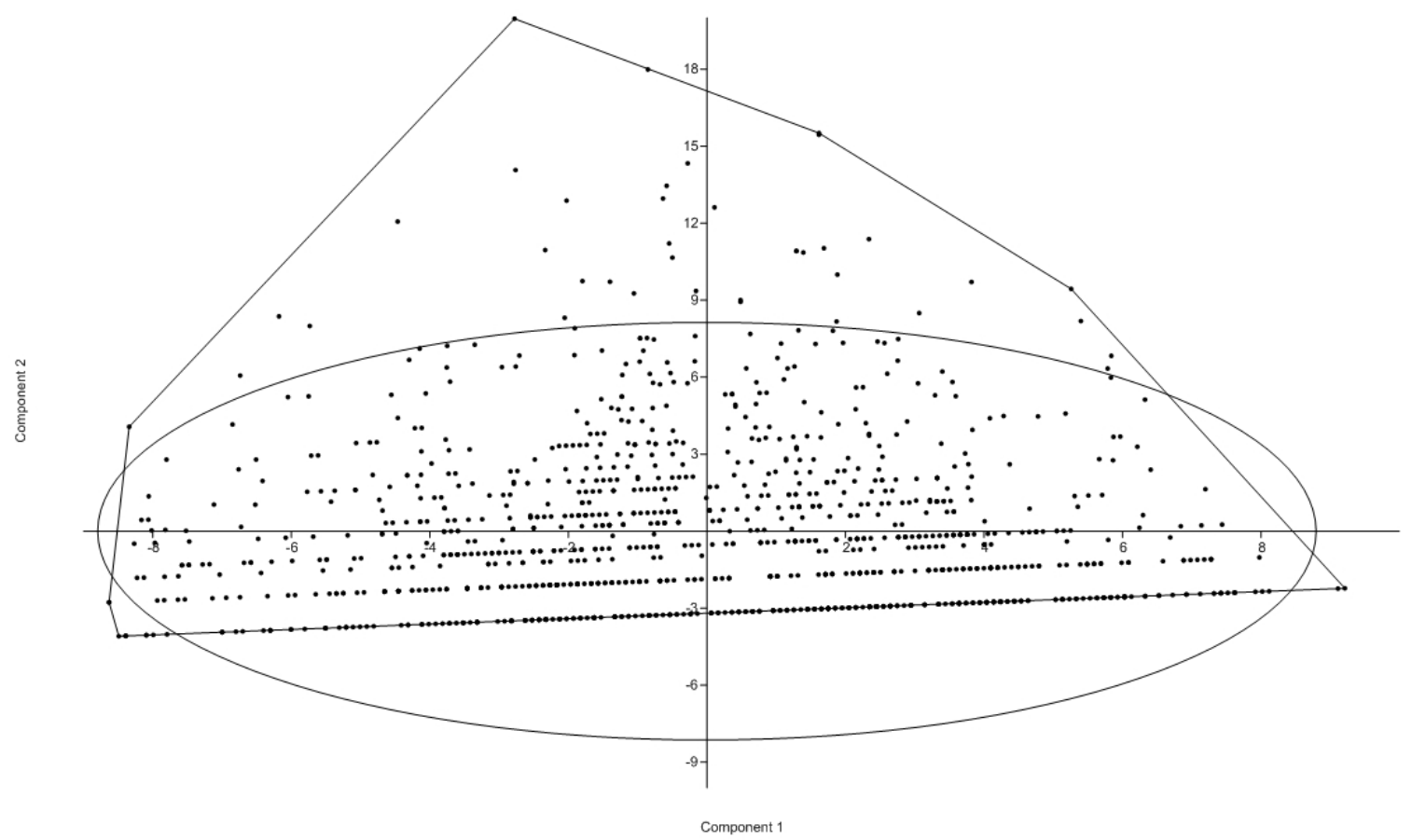

Figura 43. Análise de componente principal (PCA) dos 1.220 intervalos de tempo com suas respectivas médias de temperaturas, abundâncias e número de espécies de Saturniidae coletados na Estação Biológica de Boraceia, Salesópolis, SP, Brasil entre março de 2012 e março de 2013. A elipse representa distribuição de $95 \%$ dos dados e o polígono irregular liga os pontos mais externos.

4.3.2 Correlações das distribuições de abundância e do número de espécies e táxons supraespecificos com variáveis temporais

As subfamílias de Saturniidae apresentaram diferentes distribuições de abundância e número de espécies entre os meses amostrados no presente estudo. Os meses com maior número de exemplares coletados foram abril, março e setembro de 2012 com 440, 367 e 365 exemplares, respectivamente (Fig. 44). As altas abundâncias registradas nos meses de abril e março devem-se especialmente ao número de exemplares do gênero Hylesia coletados nestes períodos; em abril foram coletados 345 exemplares de Hylesia e em março 266. Por outro lado, no mês de setembro o predomínio de abundância deu-se em diferentes gêneros e espécies, especialmente da subfamília Ceratocampinae: Adeloneivaia fallax) (42 exemplares), Almeidella almeidai Oiticica, 1946 (21) e Eacles mayi Schaus, 1920 (64). Automeris beckeri (HerrichSchäffer, [1856]) foi a única espécie não pertencente à Ceratocampinae com mais de 20 exemplares coletados (28 exemplares).

No que se refere à abundância por intervalo de tempo (IT), os momentos com mais indivíduos coletados foram entre 19:00-20:30h e entre 02:00-03:30h, ambos representando três 
intervalos de amostra e sendo os dados do primeiro momento fortemente influenciados pela quantidade de exemplares do gênero Hylesia, contribuindo com aproximadamente metade dos exemplares coletados em cada intervalo. A abundância de exemplares dos intervalos do segundo momento sofreu menor influência das espécies do gênero Hylesia, foram mais influenciados pelas espécies A. fallax, Adelowalkeria tristygma, Othorene purpurascens (Schaus, 1905) e E. mayi, todas da subfamília Ceratocampinae (Fig. 45).

Em média 36,3 espécies $(\mathrm{DP}=8,3)$ foram coletadas por intervalo de amostragem, no total das 51 noites. Os dois últimos intervalos $(05: 00-05: 30 \mathrm{~h}$ e 05:30-06:00h) foram os que apresentaram, individualmente, a menor soma do número de espécies coletadas, com 22 e 12 espécies, respectivamente; seguidos do $1^{\circ}$ intervalo (18:00-18:30h) com 24 espécies e do $22^{\circ}$ (04:30-05:00h) com 29 espécies. Os intervalos que somaram maior número de espécies foram o $5^{\circ}$ (20:00-20:30h) com 50 espécies, o $11^{\circ}$ (23:00-23:30h) com 47, o $4^{\circ}$ (19:30-20:00h) com 45 e o $12^{\circ}$ (23:30-00:00) com 43 (Fig. 45). No entanto, três momentos se destacaram, entre 19:30-21:00h, 23:00-00:30h e 01:30-03:00h, cada um dos momentos representando três intervalos de tempo e sendo para qualquer um deles a soma das espécies coletadas maior que 40 (Fig. 45).

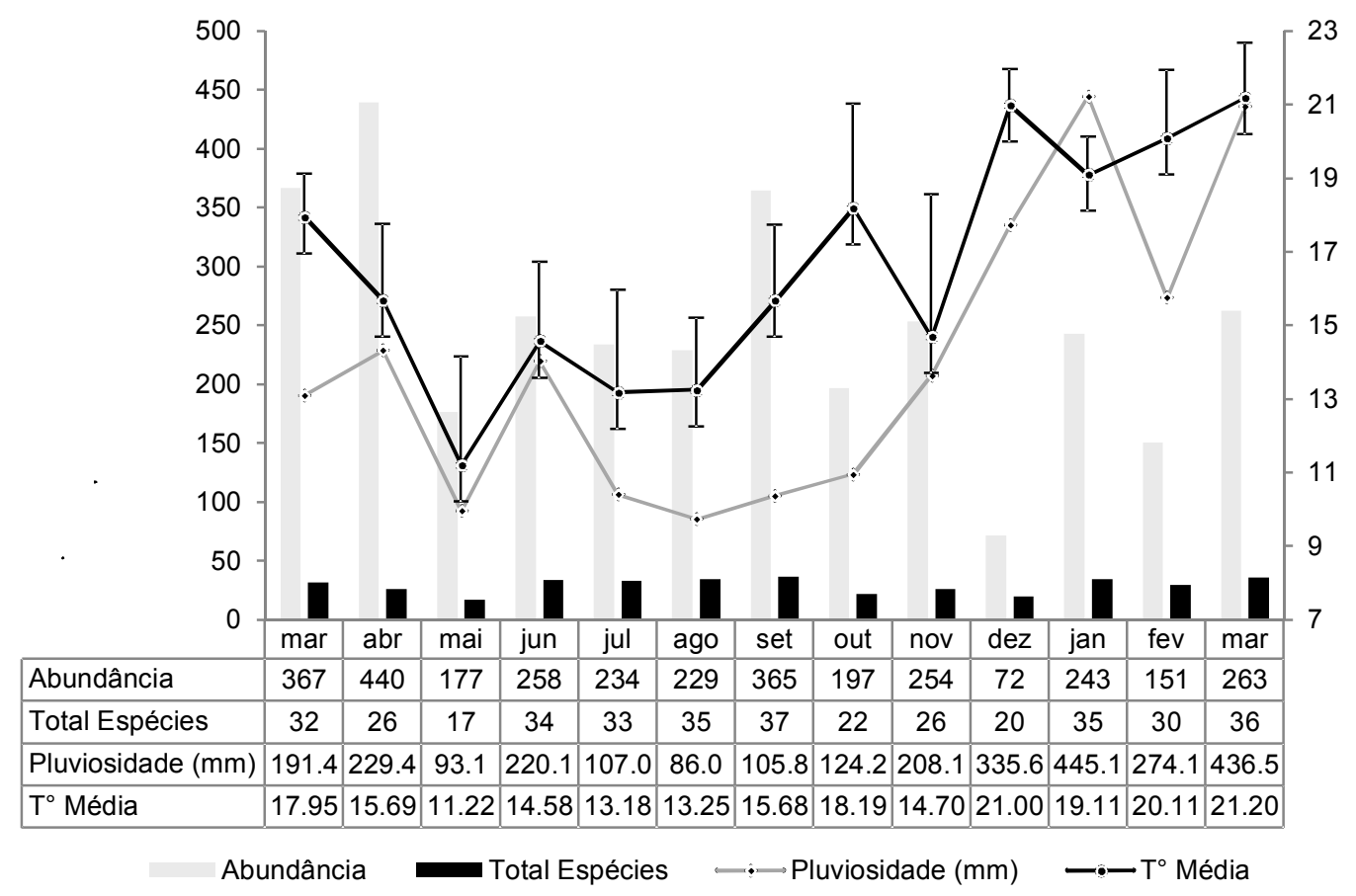

Figura 44. Abundância, número de espécies de Saturniidae e dados climáticos (temperatura e pluviosidade) para cada um dos 13 meses de coleta (março a dezembro de 2012 e janeiro a março de 2013) na Estação Biológica de Boraceia, SP, Brasil. 


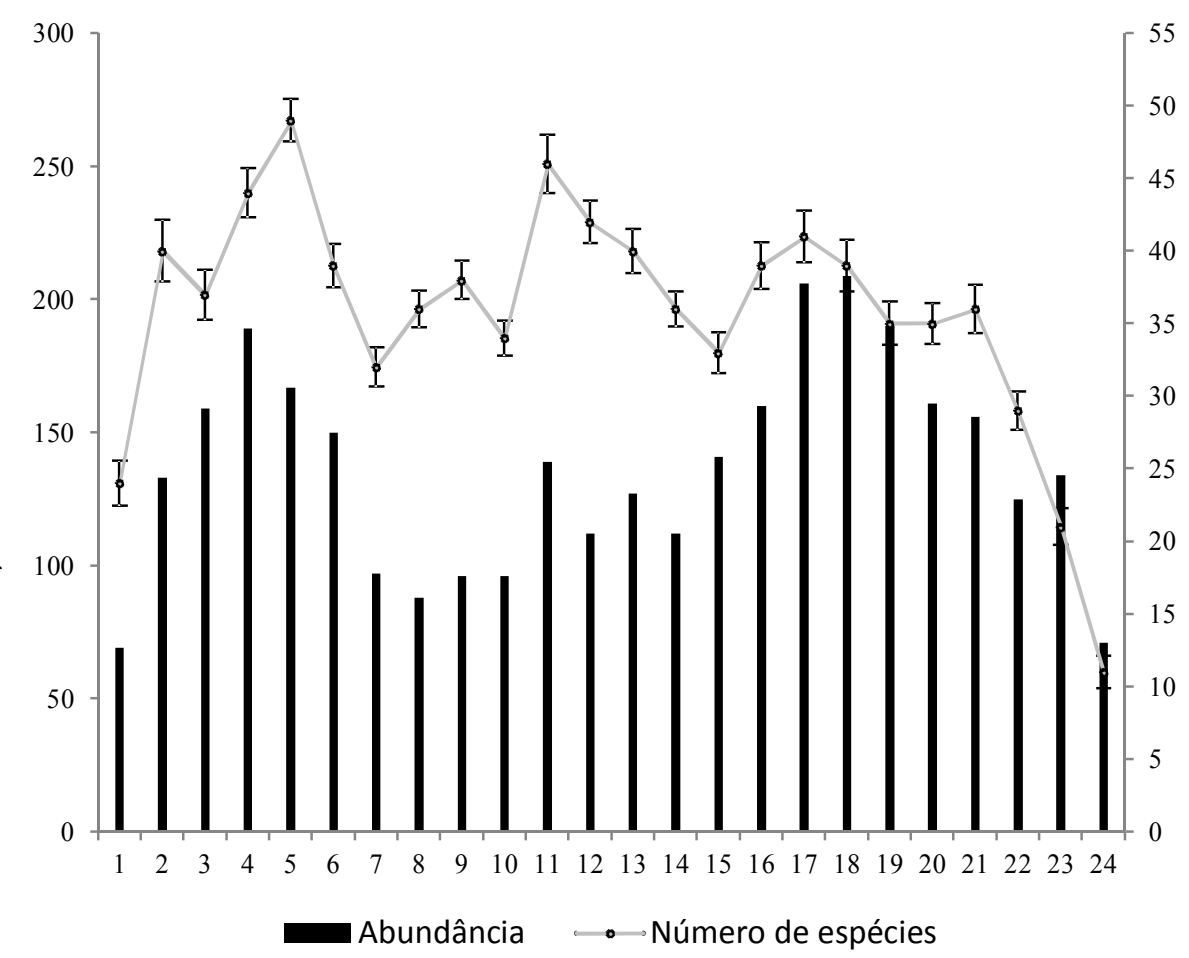

Figura 45. Abundância e número de espécies de Saturniidae para os 24 intervalos $\left(1^{\circ}-12^{\circ}: 18: 00-00: 00 \mathrm{~h}\right.$ e $13^{\circ}$ 24: 00:00-06:00h) das 51 noites de coletas na Estação Biológica de Boraceia, SP, Brasil.

O número de fêmeas coletadas representou $5,05 \%$ de todos os indivíduos, sendo que aproximadamente $80 \%$ das fềmeas foram da subfamília Hemileucinae. A distribuição de abundância das fềmeas variou ao longo do ano, sendo o mês de abril o de maior abundância, para o qual 34 dos 36 exemplares coletados foram do gênero Hylesia (Fig. 46). A distribuição das fêmeas ao longo da noite demonstrou que a abundância e a riqueza de espécies seguem valores absolutos próximos entre si e apresentou uma tendência à redução da abundância e do número de espécies do início para o final da noite. No entanto, valores significativamente altos, para o início da noite, na abundância de fêmeas foi observado para os tempos 17 e 18 (02:0002:30h e 02:30-03:00h, respectivamente) (Fig. 47). Assim, 68,7\% das fềmeas ocorreram até meia noite, de acordo com Janzen (1984) 90\% das fềmeas de Saturniidae do Parque Nacional de Santa Rosa, Costa Rica, chegam na luz nas primeiras quatro horas da noite e fềmeas de nenhuma espécies chega regularmente após á meia noite. Algumas fềmeas de Hylesia, em especial as cinco de $H$. vindex ocorreram exclusivamente após a meia noite. Outras espécies cujas fêmeas foram coletadas somente após 00:00h foram Arsenura biundulata Schaus, 1906, Dirphia dolosa Bouvier, 1929 e Leucanella gibbosa (Conte, 1906), todas com apenas um exemplar cada. 
Os machos representaram 94,95\% dos saturniídeos coletados com distribuição sazonal mais regular que as fêmeas. A mais significativa baixa no número de exemplares ocorreu em dezembro de 2012, mês em que, coincidentemente, as coletas ocorreram por apenas três noites. Com relação à abundância das espécies no decorrer da coleta noturna, os intervalos em que a porcentagem de indivíduos foi igual ou maior que 5\% do total coletado, isto é, os de maior abundância, foram os intervalos quatro (19:30-20:00h) e do 17 ao 20 (02:00-04:00h) (Fig. 48), nos quais aproximadamente $35 \%$ de todos os machos coletados ocorreram. Contrariamente às fêmeas a tendência na abundância dos machos foi de aumentar do início para o final da noite. A riqueza de espécies foi predominante em outros intervalos, sendo os intervalos de tempos 5 (20:00-20:30h), 11 e 12 (23:00-00:00h) e 17 (02:00-02:30h) aqueles com maior somatório de espécies, maior que 40 em cada um deles.

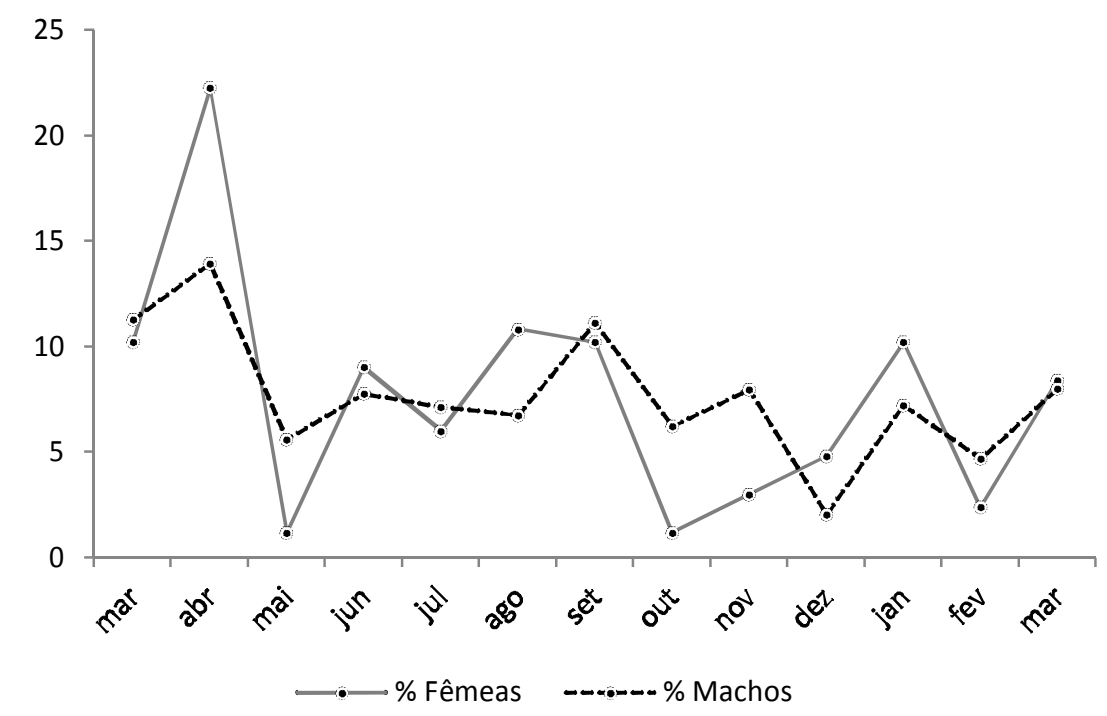

Figura 46. Distribuição da abundância relativa dos exemplares (machos e fêmeas) de Saturniidae amostrados durante os 13 meses de coletas (março de 2012 a março de 2013) na Estação Biológica de Boraceia, SP, Brasil. 


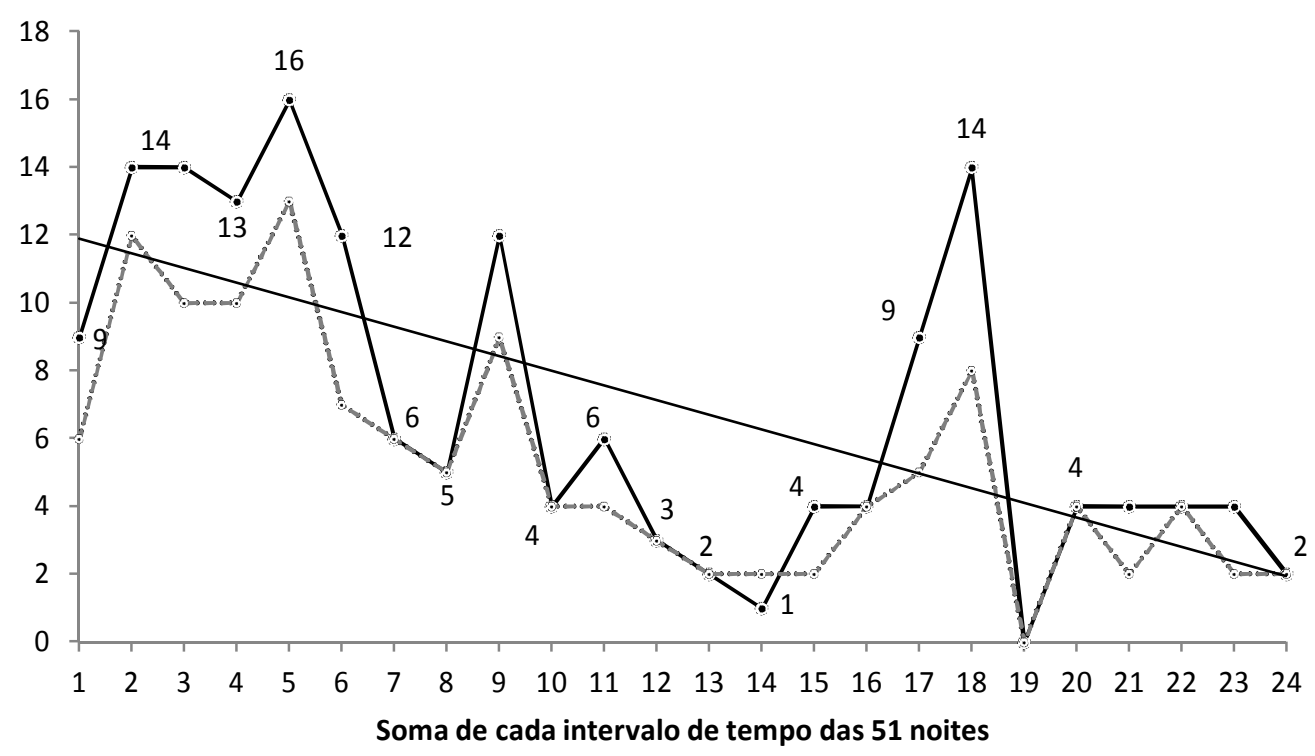

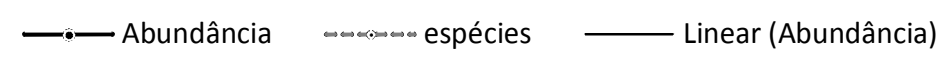

Figura 47. Distribuição da abundância e do número de espécies de Saturniidae (somente fêmeas) nos 24 intervalos de amostra (1-12: 18:00-00:00h e 13-24: 00:00-06:00h) durante as 51 noites de coletas na Estação Biológica de Boraceia, SP, Brasil. Inclui Hylesia sp. para abundância absoluta e como espécie.

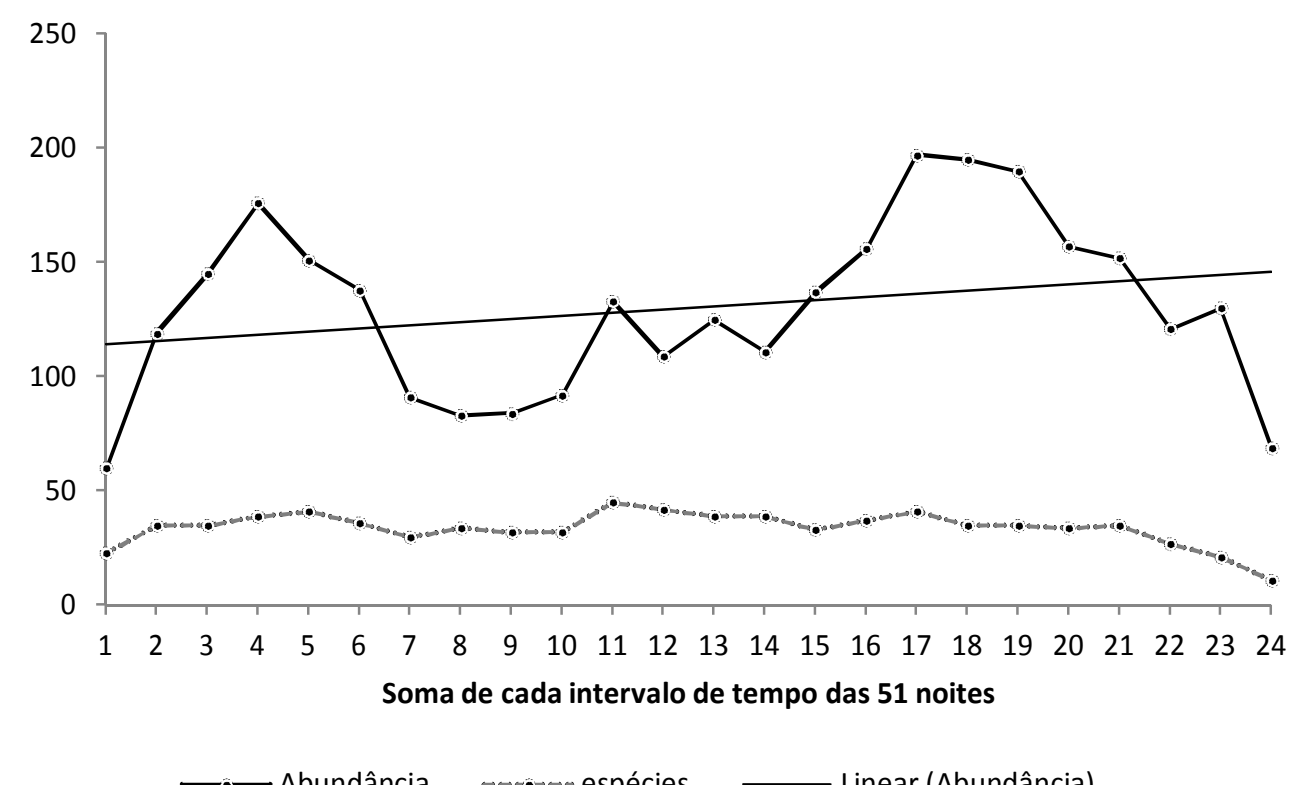

Figura 48. Distribuição da abundância e do número de espécies de Saturniidae (somente machos) nos 24 intervalos de amostra (1-12: 18:00-00:00h e 13-24: 00:00-06:00h) durante as 51 noites de coletas na Estação Biológica de Boraceia, SP, Brasil. Inclui Hylesia sp. para abundância absoluta e como espécie. 
Machos de todas as espécies, excetuando-se Automeris tristes (Boisduval, 1875) e Leucanella janeira (Westwood, [1854]), foram coletados, entretanto, para as 96 espécies, fêmeas de apenas 49 foram representadas. A razão sexual média para as 48 espécies com registro de fềmeas foi de $16,04(\mathrm{DP}=20,26)$ machos para cada fêmea, demonstrando a baixa incidência de fềmeas em armadilhas noturnas. O elevado desvio padrão é reflexo da alta variação no número de fêmeas e machos de espécies "abundantes" ou "muito abundantes". No somatório de cada um dos intervalos de tempo, apenas entre 03:00-03:30h (IT 19) nenhuma fêmea foi coletada. A redução na abundância de fêmeas ao longo da noite contrastada com o aumento dos machos refletiu diretamente no aumento da razão entre os sexos, tornado os intervalos após meia noite com um número relativamente maior de machos por fềmeas do que nos intervalos antes da meia noite.

A análise de correspondência grafada em dois eixos, entre o número de espécies e os intervalos de tempo ao longo do ano, demonstrou que os intervalos ao longo da noite apresentaram significativa variação na composição e equitabilidade das espécies. Especialmente nas seis primeiras horas, a análise apontou que as espécies variaram mais entre estes intervalos do que elas variaram entre os intervalos das seis últimas horas, e ainda que as espécies da segunda metade da noite, intervalo 14 (00:30h) em diante, foram mais distintas daquelas coletadas nos intervalos da primeira metade da noite, quanto mais próximo do início da noite foi o intervalo (Fig. 49). No entanto, os dois eixos explicaram apenas $28,35 \%$ da correspondência entre as espécies dos intervalos. Ao ser considerada a abundância das espécies, a distinção entre os intervalos de tempo em dois eixos, os quais explicam 36\% da relação, é reduzida, mas mantem-se o mesmo padrão de distância entre os intervalos (Fig. 50).

O modelo visual gráfico resultante das análises de categorização por ranque de abundância das espécies ao longo do gradiente temporal em que foram coletadas, os 24 intervalos de tempo e os 13 meses de coleta, demonstram que a distribuição de cada espécie nos 24 intervalos corrobora a análise de correspondência (CA) no sentido de evidenciar a alternância da atividade das espécies ao longo da noite (Fig. 51) e também ao longo dos 13 meses (Fig. 52). 


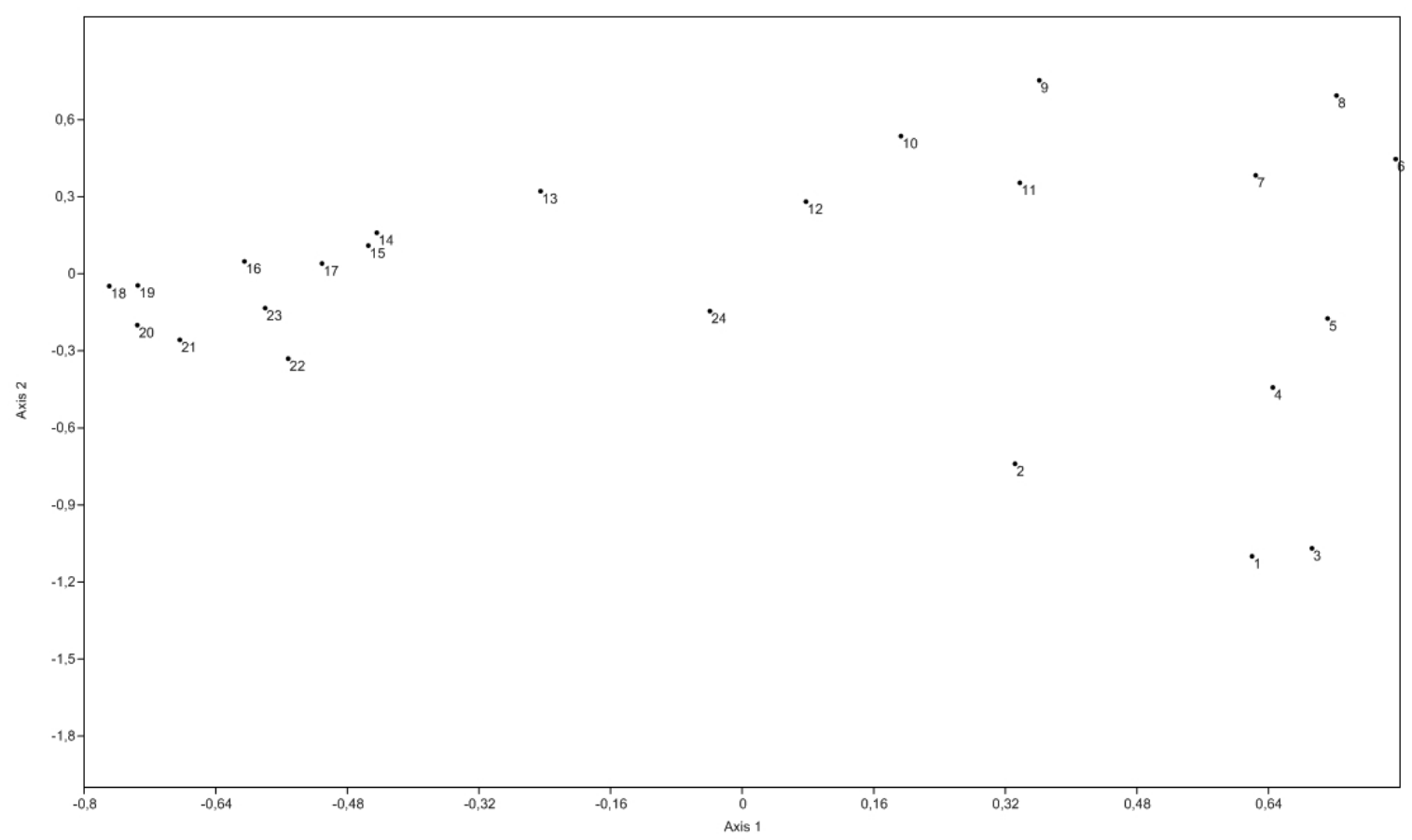

Figura 49. Análise de correspondência (CA) entre presença e ausência de cada espécie de Saturniidae e os 24 intervalos de tempo (1-12: 18:00-00:00h e 13-24: 00:00-06:00h) sendo cada intervalo a soma dos seus respectivos intervalos, nas 51 noites de coleta na Estação Biológica de Boraceia, SP, Brasil.

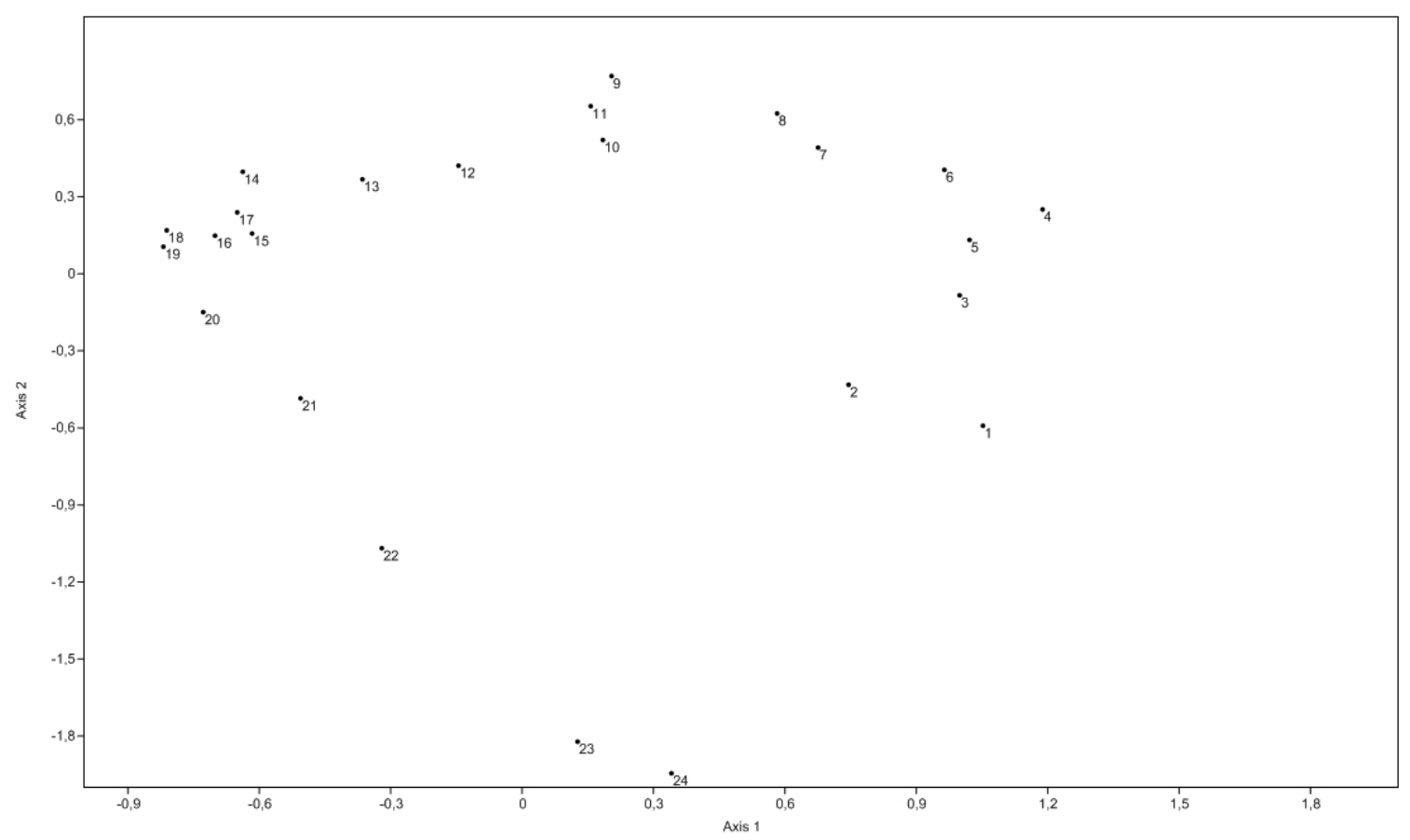

Figura 50. Análise de correspondência (CA) entre abundância de cada espécie de Saturniidae e os 24 intervalos de tempo (1-12: 18:00-00:00h e 13-24: 00:00-06:00h), sendo cada intervalo a soma dos seus respectivos intervalos nas 51 noites de coleta, na Estação Biológica de Boraceia, SP, Brasil. 


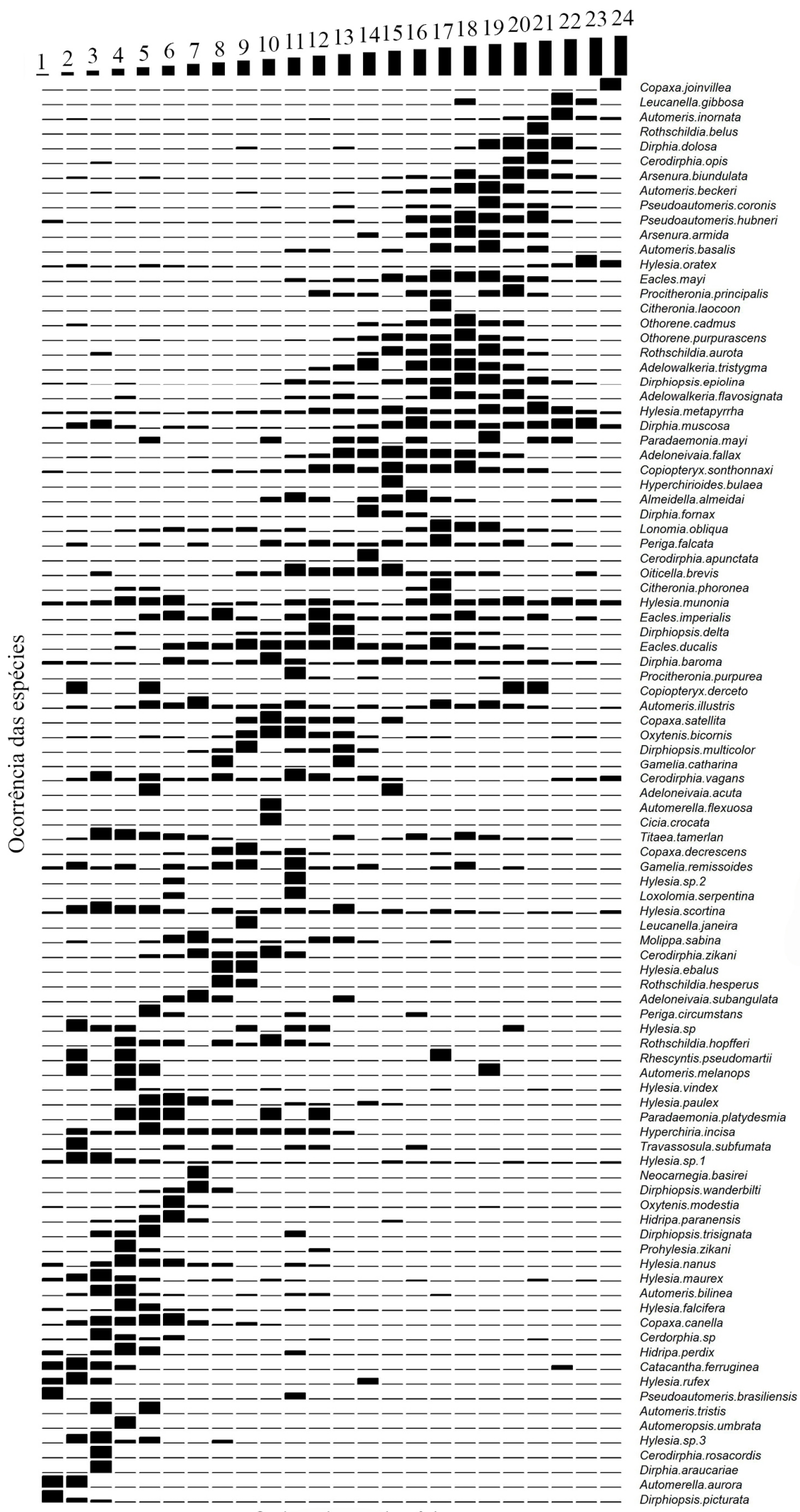

Ordenado por horário

Figura 51. Ranque de abundância dos machos de cada uma das 96 espécies de Saturniidae dos 24 intervalos de tempo (1-2: 18:00-00:00h e 13-24: 00:00- 06:00h), sendo cada intervalo a soma dos seus respectivos intervalos nas 51 noites de coleta na Estação Biológica de Boraceia, SP, Brasil. 


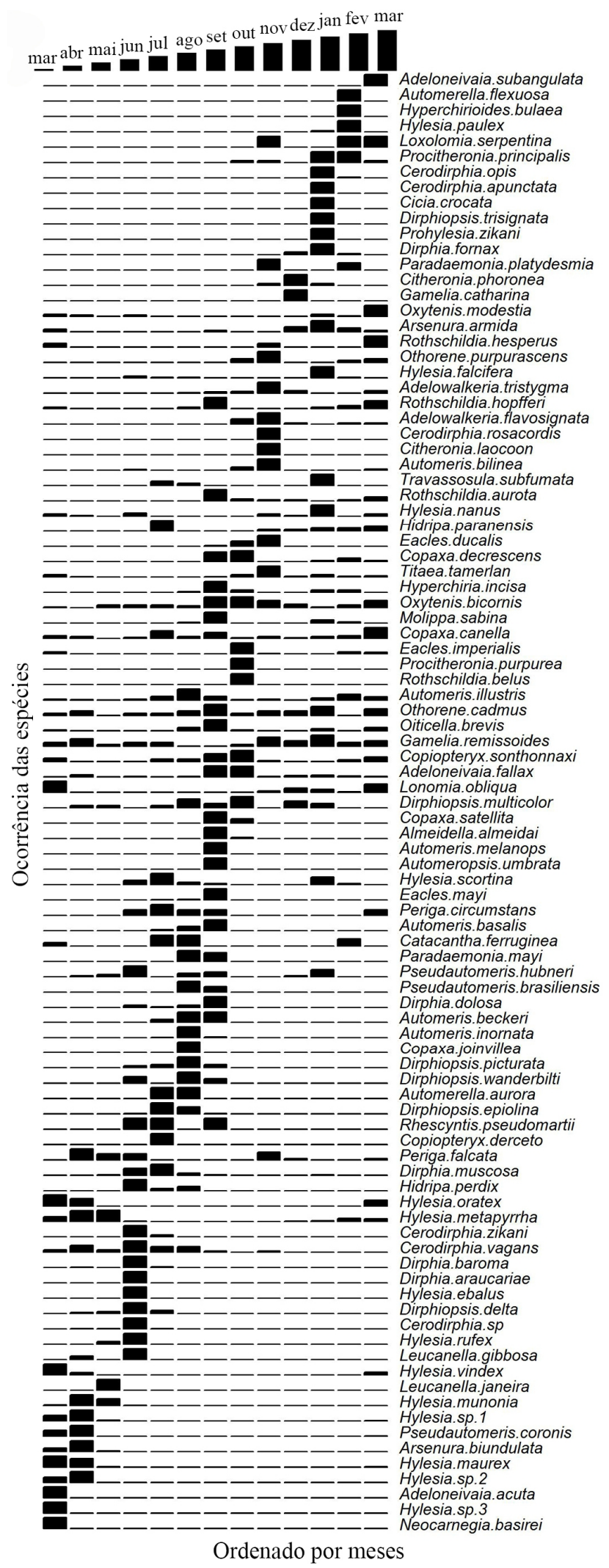

Figura 52. Ranque de abundância dos machos de cada uma das 96 espécies de Saturniidae dos 13 meses (março a dezembro de 2012 e janeiro a março de 2013), de coleta, na Estação Biológica de Boraceia, SP, Brasil. 


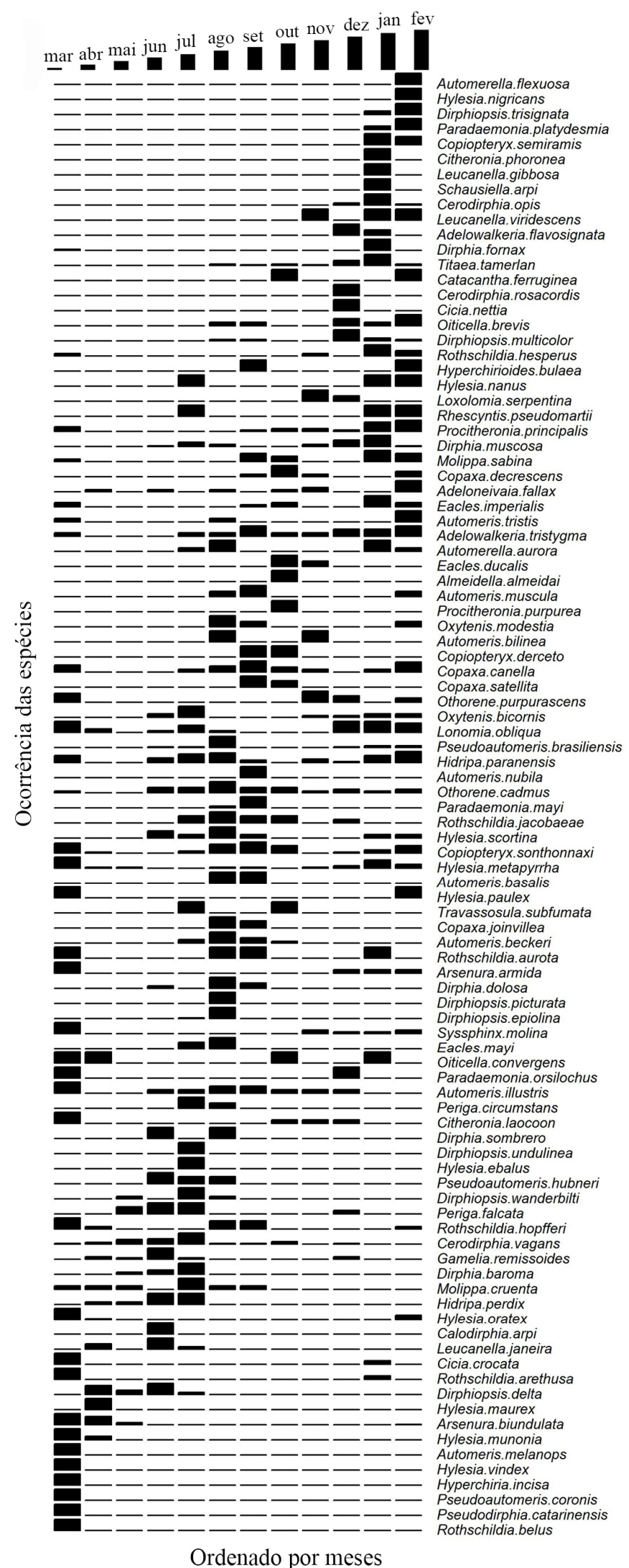

Figura 53. Ranque de abundância dos machos de cada uma das 97 espécies de Saturniidae dos 25 meses (março a dezembro de 1948, março a dezembro de 1949 e janeiro a março de 1950), de coleta, na Estação Biológica de Boraceia, SP, Brasil. 
Estudar a sazonalidade de grupos taxonômicos específicos ou supraespecíficos é adequando quanto maior o período de obtenção dos dados, especialmente com mais de um ano de coleta de dados (Wolda 1988). Portanto, utilizamos os dados históricos dos dois anos de coleta entre 1948 e 1950 para fazer uma avaliação da robustez dos dados referente à sazonalidade dos exemplares coletados recentemente (2012-2013). O que foi observado foram muitas espécies mantendo os padrões de sazonalidade bastante semelhantes entre os anos 19481950 e atualmente (Fig. 53). Os dados coletados recentemente em apenas um ano de campanha podem ser considerados robustos para avaliações de ciclos sazonais das espécies.

A formação de um padrão diagonal de distribuição, conforme demonstrado nas Figs. 51 e 52, em um gradiente temporal, define pontos de ocorrência alternantes entre as espécies, ao longo da noite (Fig. 51) e ao longo do ano (Fig. 52). Com isso, entendemos que para uma amostragem representativa da fauna de Saturniidae de uma determinada localidade é fundamental coletar durante todo o período noturno, conforme realizado no presente estudo, e ao longo de todo ano, caso contrário pode não ser possível coletar espécies com picos sazonais restritos como Automeris inornata, Automerella flexuosa (R. Felder \& Rogenhofer, 1874), Cerodirphia opis, Hylesia paulex, Pseudautomeris coronis (Schaus, 1913) (todas Hemileucinae), Eacles mayi, Procitheronia purpurea (Oiticica, 1930), (todas Ceratocampinae) e Arsenura biundulata (Arsenurniae), entre outras (ver Fig. 52). Os picos restritos de abundância de muitas espécies em determinados períodos do ano podem ser explicados pela biologia dos saturniídeos que, em geral, não se alimentam e são de vida curta (Janzen 1984). Neste caso, espera-se que espécies univoltinas (com apenas uma geração por ano) apresentem padrão sazonal com curtos picos de abundância e que aquelas espécies que apresentam padrão mais bem distribuído ao longo do ano sejam bivoltinas ou multivoltinas.

\subsubsection{Arsenurinae}

A subfamília Arsenurinae foi representada por 199 exemplares, nove espécies e seis gêneros. Com o baixo número de espécies, a flutuação sazonal da subfamília sofreu forte influência da abundância de uma ou até três espécies. Dois picos de abundância foram observados, um entre março e abril (outono), especialmente devido à alta ocorrência de Arsenura biundulata a qual representou $68,1 \%$ dos indivíduos deste período, e um na primavera, entre setembro e novembro, especialmente devido às altas ocorrências de Copiopteryx sonthonnaxi e Titaea tamerlan (Maassen, 1869) as quais representaram 46,9\% e 
39,5\% dos exemplares do período, respectivamente (Fig. 54A). O número de espécies e a abundância variaram na mesma direção, as exceções ocorreram no mês de outubro com apenas duas espécies coletadas e alta abundância, e nos meses de fevereiro e março de 2013 com abundâncias relativamente baixas e espécies relativamente bem representadas.

A flutuação circadiana dos machos de Arsenurinae ficou bem distribuída ao longo da noite com leve tendência a aumentar do início para o final dos intervalos de tempo. Os intervalos de tempo de 16 a 21 (01:30-04:30h) foram os que acumularam maior abundância, contribuindo com $48,7 \%$ dos indivíduos coletados. O número de espécies variou ainda mais do que a abundância ao longo da noite, apresentando vários picos de registro com quatro, cinco ou até seis espécies (Fig. 54B).
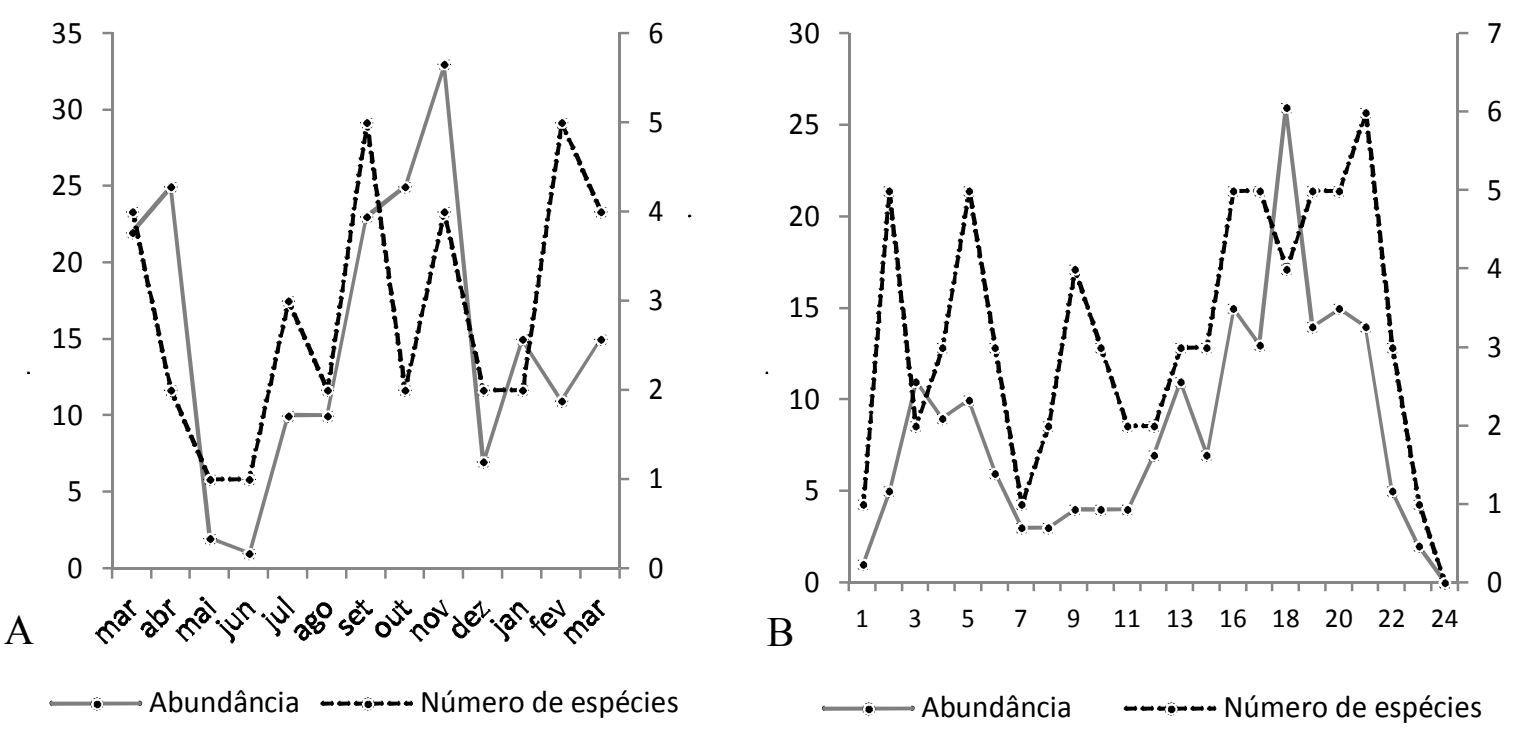

Figura 54. Variação da abundância e do número de espécies de Arsenurinae coletados durante 13 meses (A) e 24 intervalos de tempo das 51 noites de coleta (B) na Estação Biológica de Boraceia, SP, Brasil.

As três espécies mais abundantes da subfamília e cujos exemplares machos foram analisados foram A. biundulata, C. sonthonnaxi e T. tamerlan. A primeira ocorreu apenas de março a maio de 2012, sendo que 69,7\% dos exemplares registrados apenas em abril (Fig. 55A). Os machos de C. sonthonnaxi distribuíram-se bem ao longo do ano, entretanto, ocorreu um pico entre final do inverno e inicio da primavera, em agosto e setembro de 2012, quando foram amostrados 54\% dos machos (Fig. 56A). Os quatro exemplares fêmeas desta espécie distribuíram-se ao longo do ano, ocorrendo nos meses de março, agosto, outubro de 2012 e janeiro de 2013. Os machos de T. tamerlan ocorreram em baixas quantidades (até cinco 
exemplares) em oito meses do ano, entretanto somente em outubro de 2012, 51\% dos exemplares foram coletados (Fig. 57).

Ao longo da noite $A$. biundulata foi a que apresentou distribuição mais agregada, excetuando-se dois exemplares coletados nas primeiras horas, o período de grande atividade da espécie foi crescente após $01: 00 \mathrm{~h}$, e entre $02: 30 \mathrm{~h}$ e $05: 30 \mathrm{~h}, 81,5 \%$ dos machos foram coletados (Fig. 55B). Copiopteryx sonthonnaxi apresentou a distribuição mais ampla entre as três espécies, com a atividade crescente dos machos a partir das $21: 30 \mathrm{~h}$ e com picos entre 00:30h e 03:00h; as quatro fêmeas da espécie, no entanto, ocorreram entre 18:30h e 19:30h (Fig. 56B). A terceira espécie analisada, T. tamerlan, apresentou distribuição circadiana oposta à $A$. biundulata sendo o grande momento de atividade no início da noite, entre 19:00h e 19:30h, quando após uma abrupta elevação no número de machos coletados este número cai gradativamente, intervalo após intervalo, até às 22:00h. Entre 19:00h e 22:00h 57,1\% dos exemplares foram coletados, sendo os demais distribuídos ao longo dos horários mais adiantados (Fig. 57B).

Arsenura biundulata

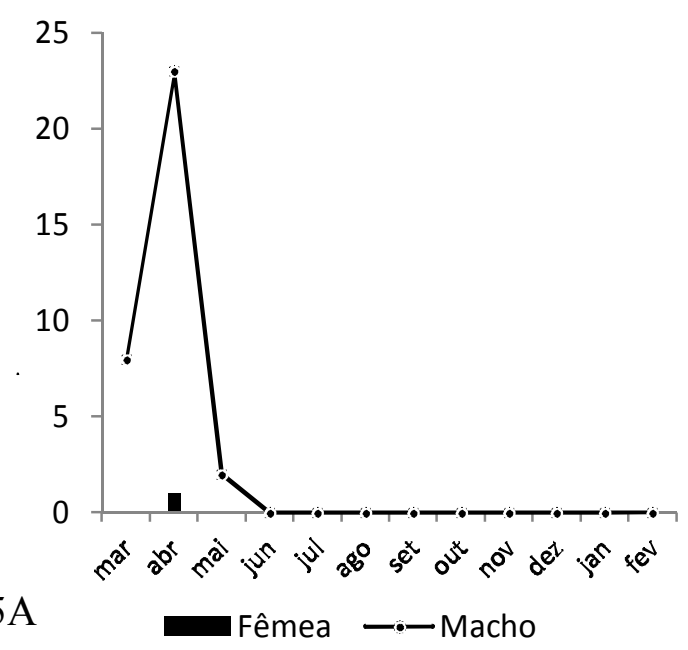

Arsenura biundulata

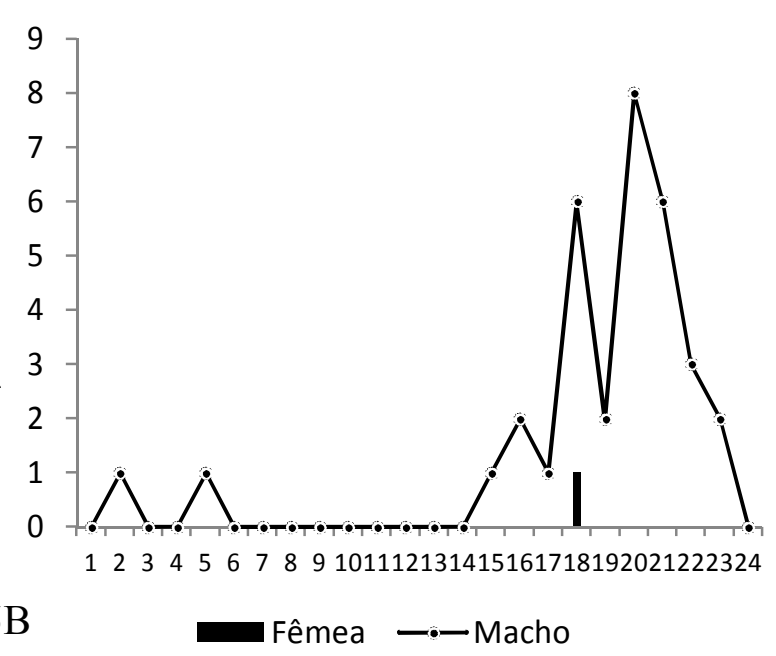


$56 \mathrm{~A}$

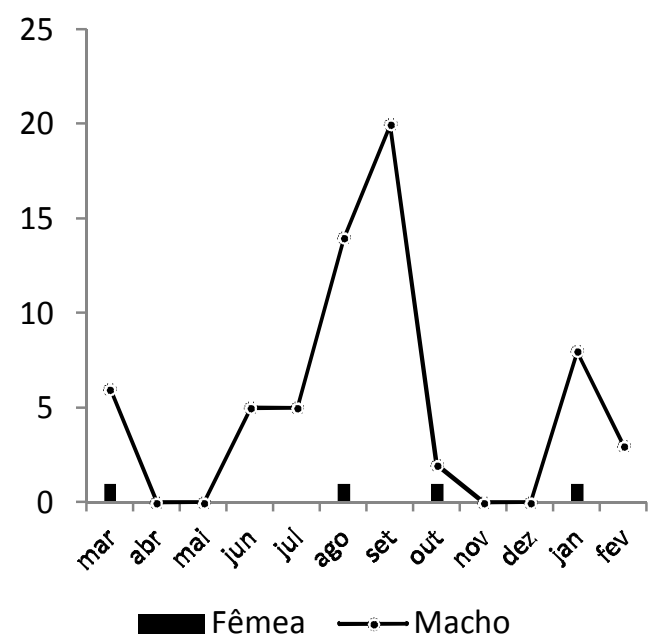

Titaea tamerlan

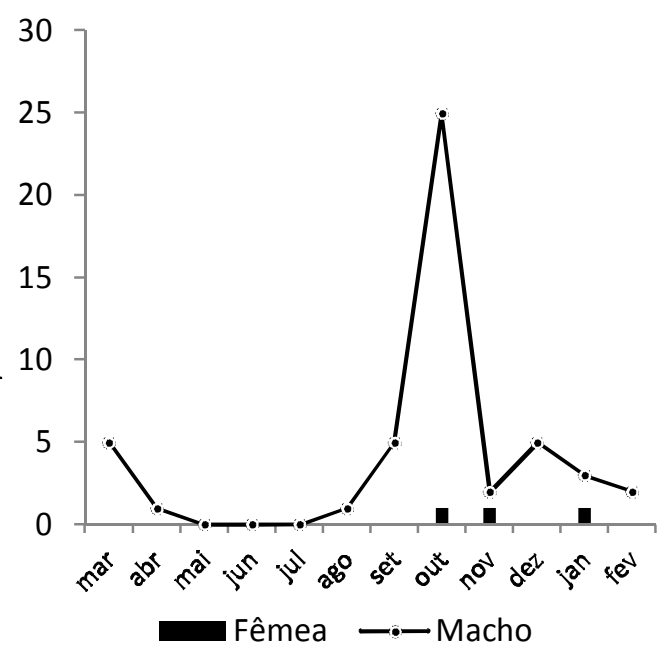

$56 \mathrm{~B}$

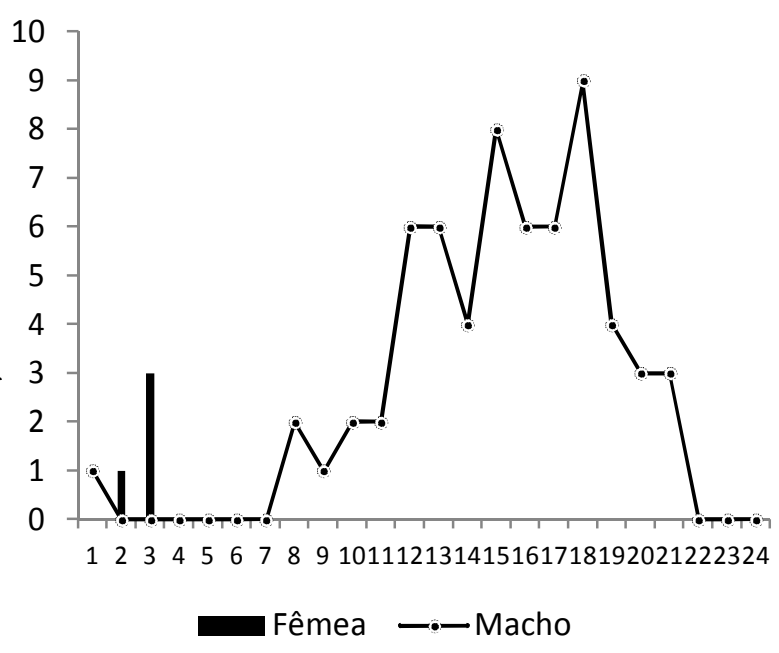

Titaea tamerlan

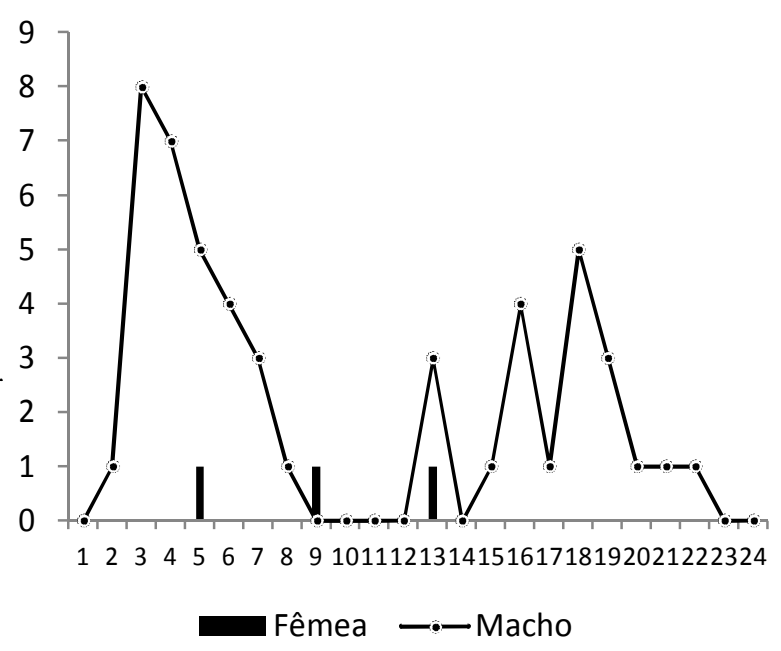

Figuras 55-57. (A) Distribuição sazonal e (B) circadiana de (55) Arsenura biundulata Schaus, 1906; (56) Copipteryx sonthotnnaxi Ém. André, 1905; e (57) Titaea tamerlan (Maassen, 1869) (Arsenurinae), coletadas na Estação Biológica de Boraceia, Salesópolis, SP, Brasil entre março de 2012 e março de 2013.

O baixo número de exemplares coletados para a maioria das espécies de Arsenurinae torna a interpretação dos dados referentes aos ciclos mais cautelosa. A alternância das espécies ao longo da noite foi baixa comparada com a alternância das espécies de outras subfamílias (Fig. 58). Ao longo do ano houve maior alternância (Fig. 59), no entanto, é difícil determinar se este padrão é devido ao ciclo de uma dada espécie ou apenas um artefato metodológico gerado pela baixa representatividade de cada espécie. Espécies mais abundantes como $T$. tamerlan e $C$. sonthonnaxi apresentaram picos sazonais e circadianos menos agudos, indicando que picos agudos nos ciclos de espécies de Arsenurinae podem ser artefato da baixa amostragem de exemplares. 


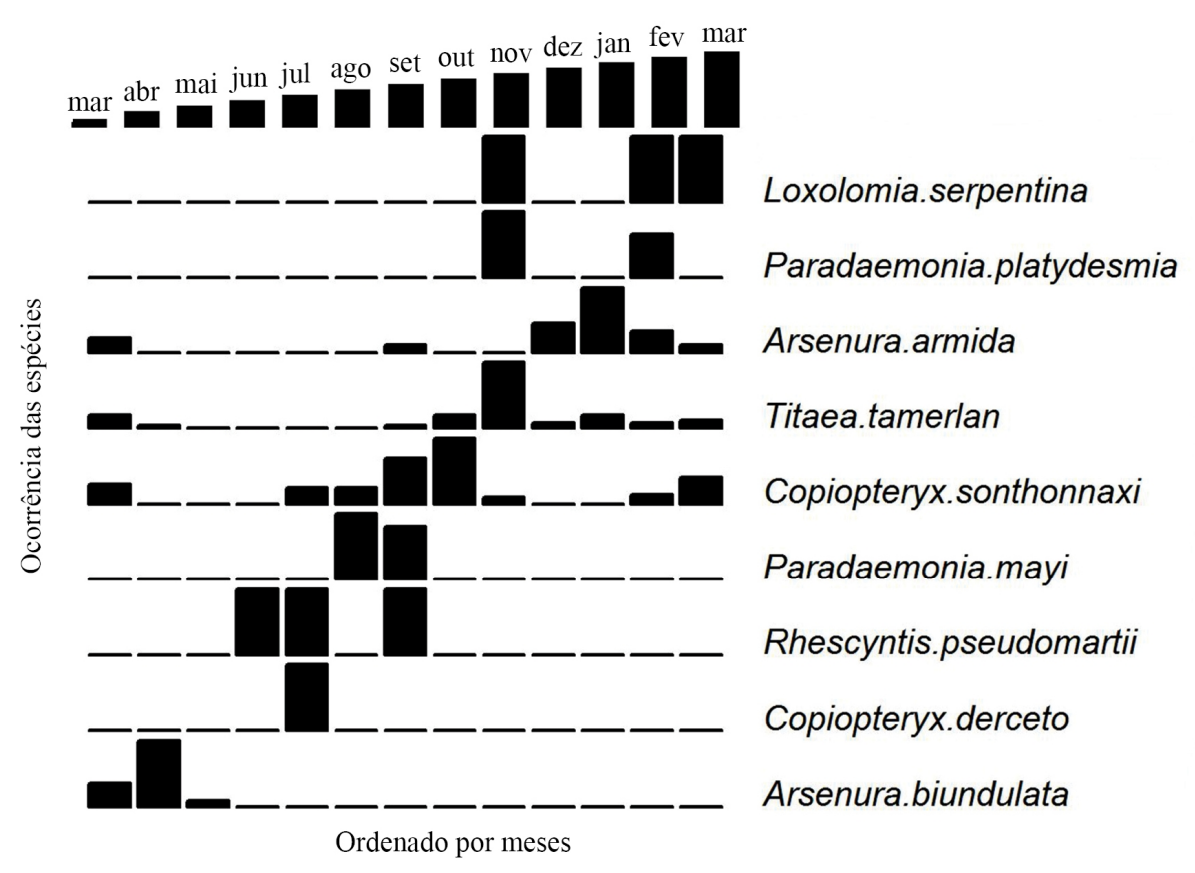

Figura 58. Ranque de abundância dos machos de cada uma das nove espécies de Arsenurniae (199 exemplares) nos 13 meses (março a dezembro de 2012 e janeiro a março de 2013), de coleta, na Estação Biológica de Boraceia, SP, Brasil.

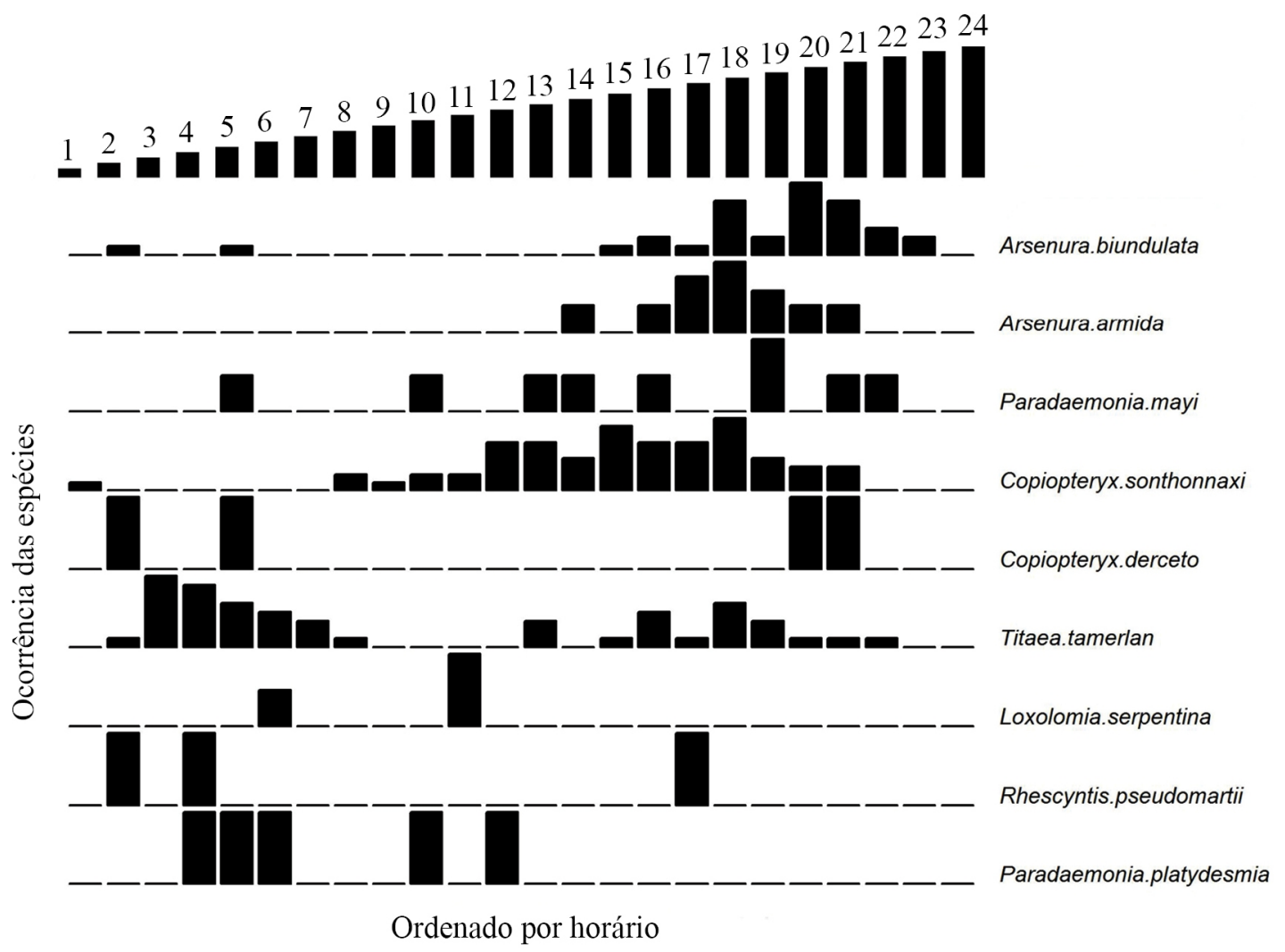

Figura 59. Ranque de abundância dos machos de cada uma das nove espécies de Arsenurniae (199 exemplares) nos 24 intervalos de tempo (1-2: 18:00-00:00h e 13-24: 00:00- 06:00h), sendo cada intervalo a soma dos seus respectivos intervalos nas 51 noites de coleta na Estação Biológica de Boraceia, SP, Brasil. 


\subsubsection{Ceratocampinae}

Ceratocampinae foi a segunda família em número de indivíduos coletados e de riqueza de espécies, com 606 exemplares coletados, representados por 18 espécies e 10 gêneros. A distribuição sazonal dos exemplares da subfamília apresentou amplitude expressiva entre setembro e novembro de 2012 , quando $73,4 \%$ dos exemplares foram coletados, especialmente das espécies Adelowalkeria tristygma, Eacles ducalis Walker, 1855, Eacles mayi e Othorene purpurascens (Schaus, 1905), as quais juntas representaram 59,2\% da abundância de Ceratocampinae nestes meses. A flutuação da riqueza de espécies seguiu o mesmo padrão, porém, com um pico divergindo da relação com a abundância no mês de agosto, quando apenas $2,5 \%$ do total de exemplares foram coletados, representando 35,3\% das espécies (Fig. 60A). O ciclo circadiano dos indivíduos da subfamília também demonstrou padrão de atividade concentrado em algumas horas da noite, $75,1 \%$ dos ceratocampineos ocorreram entre 00:00h e 04:00h da manhã, com uma pequena flutuação não linear entre abundância e riqueza de espécies nos intervalos de 3 a 7 (19:00-21:30h) (Fig. 60). As espécies que mais influenciaram os altos valores registrados nestes intervalos foram Adeloneivaia fallax, A. tristygma e O. purpurascens, representando $57,1 \%$ dos indivíduos.
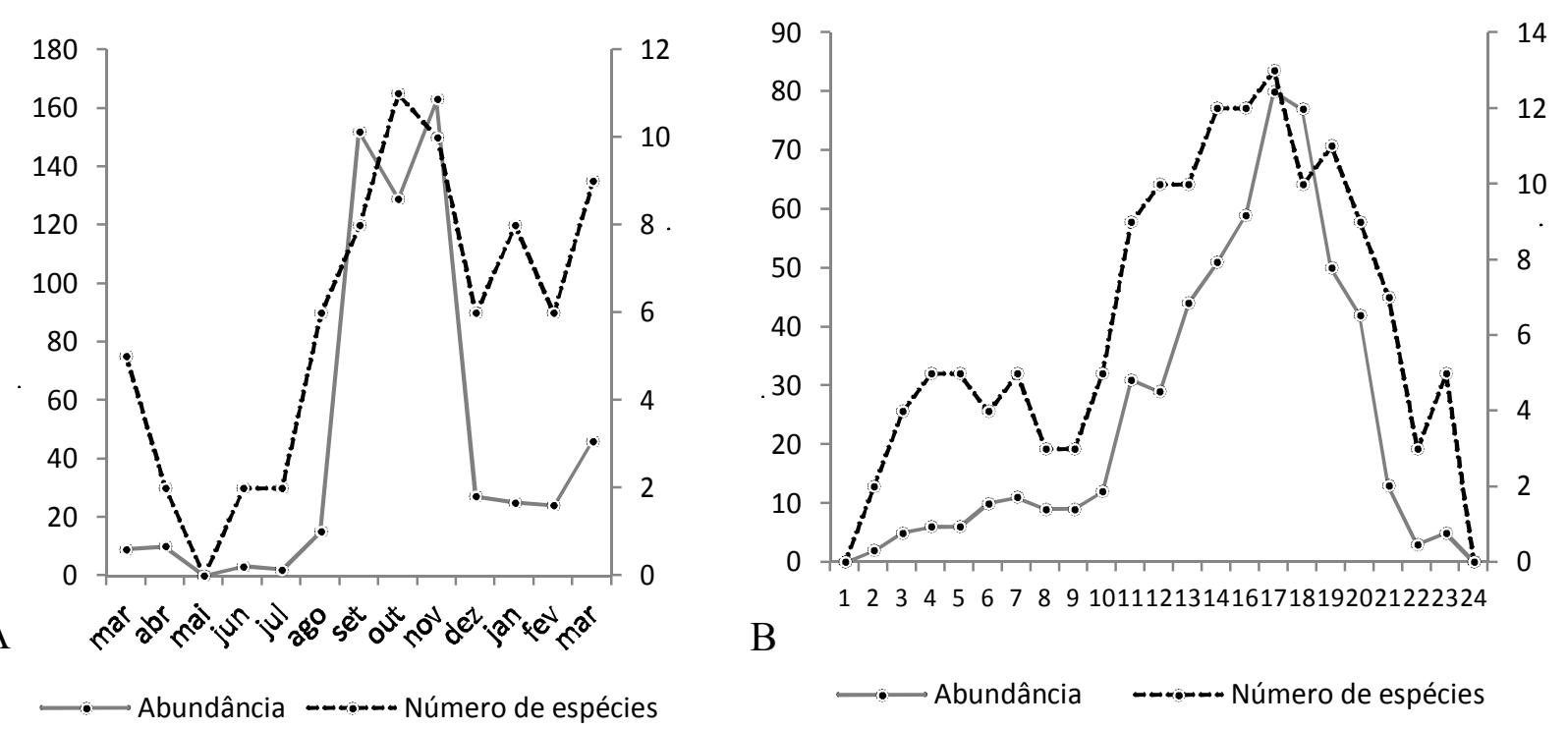

Figura 60. Variação da abundância e do número de espécies de Ceratocampinae coletados durante 13 meses (A) e 24 intervalos de tempo das 51 noites de coleta (B) na Estação Biológica de Boraceia, SP, Brasil.

Para algumas espécies de Ceratocampinae foram feitas análises pontuais quanto à distribuição sazonal e circadiana. Os exemplares machos de A. fallax e de Almeidella almeidai 
ocorreram em grandes quantidades em setembro e outubro de 2012 (primavera), sendo que 71,4\% da abundância da primeira espécie foi amostrada neste período (Figs. 61A, 64A). Almeidella almeidai apresentou distribuição ainda mais concentrada, não ocorrendo fora destes dois meses, sendo 91,3\% delas capturadas apenas em setembro (Fig. 64A). Ao longo das noites ambas as espécies apresentaram a distribuição relativamente ampla, entretanto $75 \%$ dos exemplares de $A$. fallax ocorreram entre 00:00h e 03:00h (Figs. 61B, 64B).

As duas espécies do gênero Adelowalkeria Travassos, 1941 coletadas na EBB apresentaram distribuição sazonais bastante semelhantes, com picos de abundância entre outubro e dezembro de 2012 (Figs. 62A, 63A). A espécie Adelowalkeria falvosignata Walker, 1865 teve o pico de atividade mais concentrado que $A$. tristygma, com 86,4\% dos indivíduos ocorrendo na primavera, em outubro e novembro de 2012; já A. tristygma, apesar da sua distribuição prioritariamente na primavera, estendeu-se de setembro a dezembro quando 83,5\% dos exemplares foram amostrados. A distribuição circadiana de ambas as espécies tendeu aos horários após o meio da noite, sendo A. falvosignata mais amplamente distribuída e $A$. tristygma menos, tendo todos os seus exemplares coletados em dois períodos $(23: 30-01: 00 \mathrm{~h}$ e 01:3004:30h) (Figs. 62B, 63B).

O gênero Othorene Boisduval, 1872 foi representado por duas espécies com distribuições sazonais consideravelmente distintas (Figs. 65A, 66A). Othorene cadmus teve uma das mais amplas distribuições sazonais entre os Saturniidae, ocorrendo praticamente em todos os meses de coleta, exceto em março de 2012 e fevereiro de 2013. A variação circadiana da abundância foi mais restritiva sendo os registros mais altos entre 01:30h e 04:00h da manhã, correspondendo a $83,3 \%$ dos indivíduos. A outra espécie do gênero ocorreu entre outubro e novembro de 2012 , com $69,6 \%$ dos registros e depois voltou a ser coletada em fevereiro e março de 2013 com 27,2\% dos registros. Durante a noite, a distribuição de $O$. purpurascens foi muito semelhante à de $O$. cadmus (Figs. 65B, 66B).

Dentre as espécies de Ceratocampinae com maior convergência nas distribuições sazonais e circadianas estão as três do gênero Eacles Hübner, 1918 (Figs. 67A, 68A,69A). Os machos de Eacles ducalis Walker, 1855, E. imperialis e E. mayi apresentaram picos de atividade praticamente nos mesmos meses. Todos os indivíduos de E. ducalis foram coletados na primavera de 2012, entre setembro e novembro, sendo $64,9 \%$ apenas em novembro; os indivíduos de E. imperialis, apesar de terem sido coletados em outros meses, como fevereiro e março de 2012 e março de 2013, 62,5\% ocorreram apenas em outubro de 2012; e todos os indivíduos de $E$. mayi foram coletados entre julho e setembro de 2012, sendo $92,8 \%$ apenas em 
setembro. A flutuação circadiana de E. ducalis e de E. imperialis foram bastante semelhantes e amplas ao longo da noite, não ocorrendo aproximadamente nas duas primeiras horas e na última hora. Eacles mayi iniciou o ciclo de atividade a partir das 22:30h e parou de ocorrer apenas na última meia hora demonstrando um pico de atividade entre 02:00h e 03:30h com a coleta de 47,8\% dos exemplares (Figs. 67B, 68B, 69B).

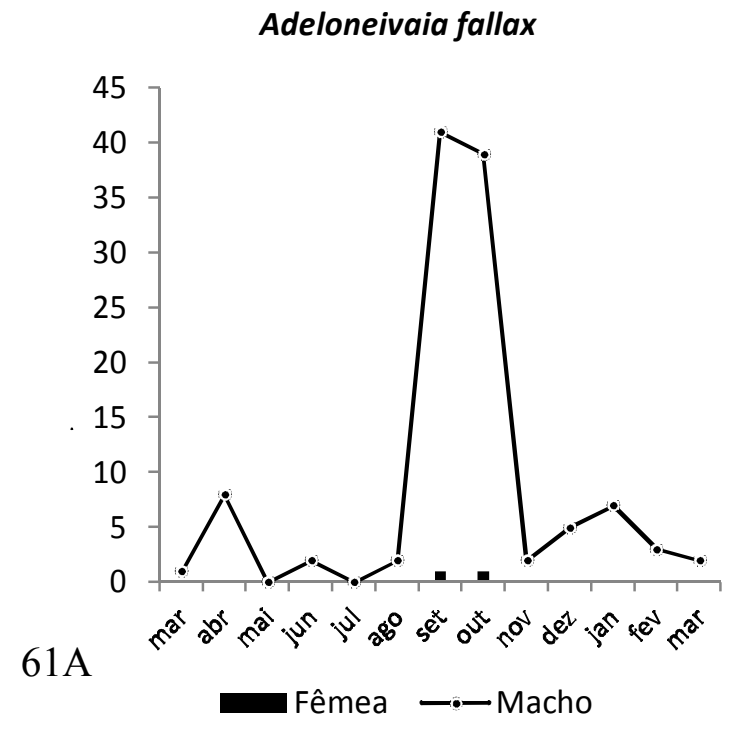

Adelowalkeria flavosignata

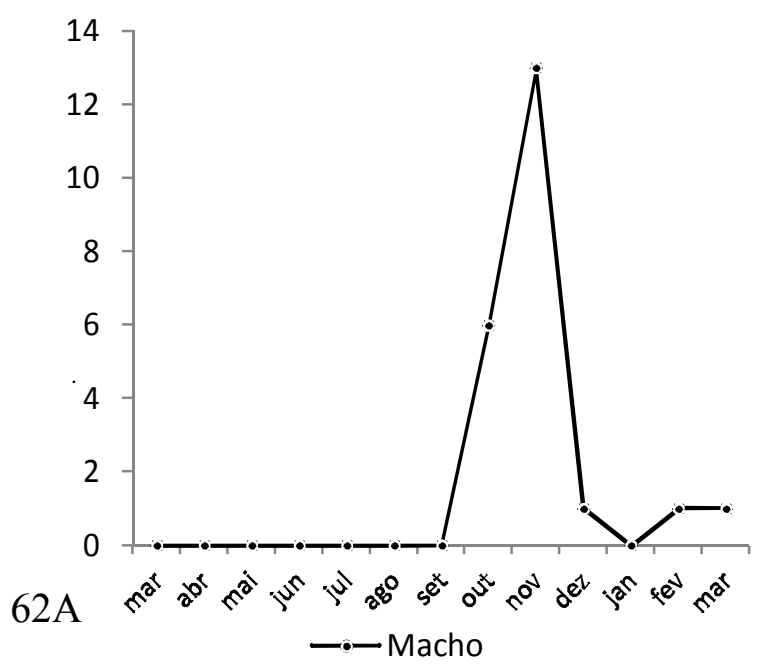

Adeloneivaia fallax

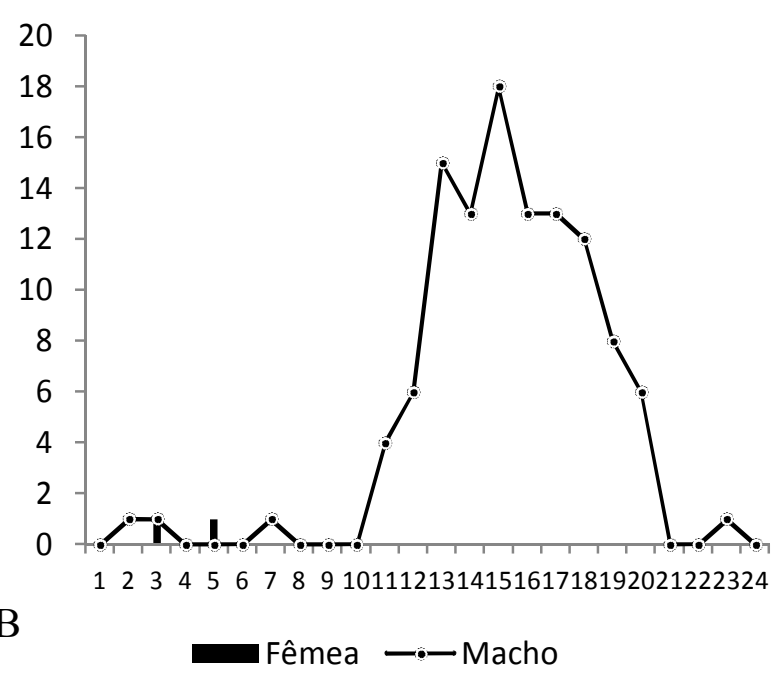

Adelowalkeria flavosignata

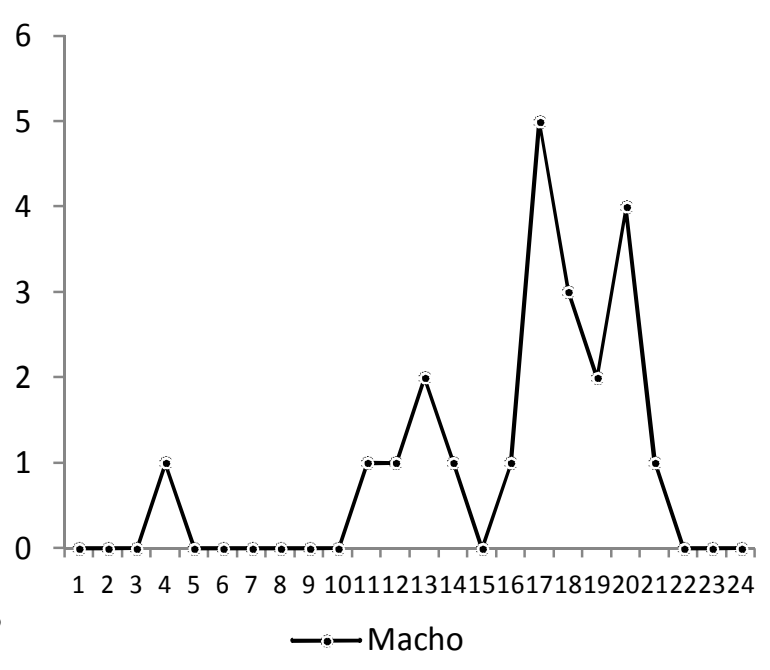


Adelowalkeria tristygma

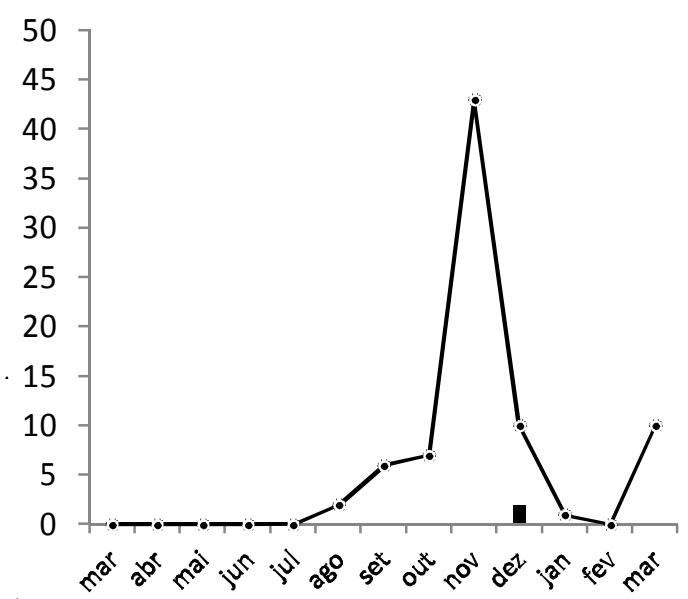
$63 \mathrm{~A}$

Fêmea —-Macho

Almeidella almeidai

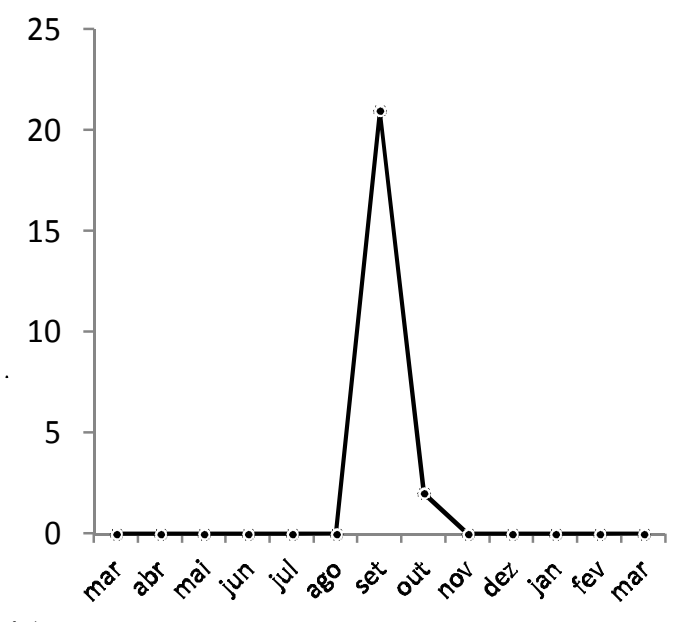

$64 \mathrm{~A}$

-.Macho

Othorene cadmus

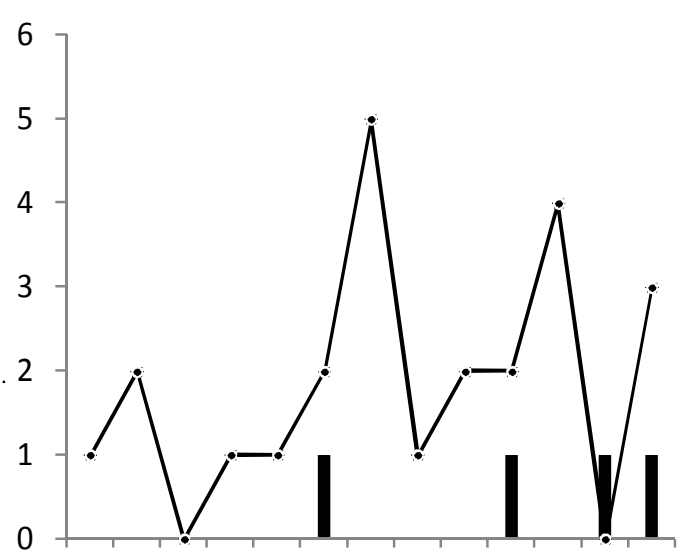

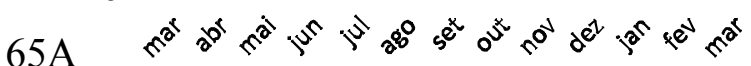

—âmea —-Macho
Adelowalkeria tristygma

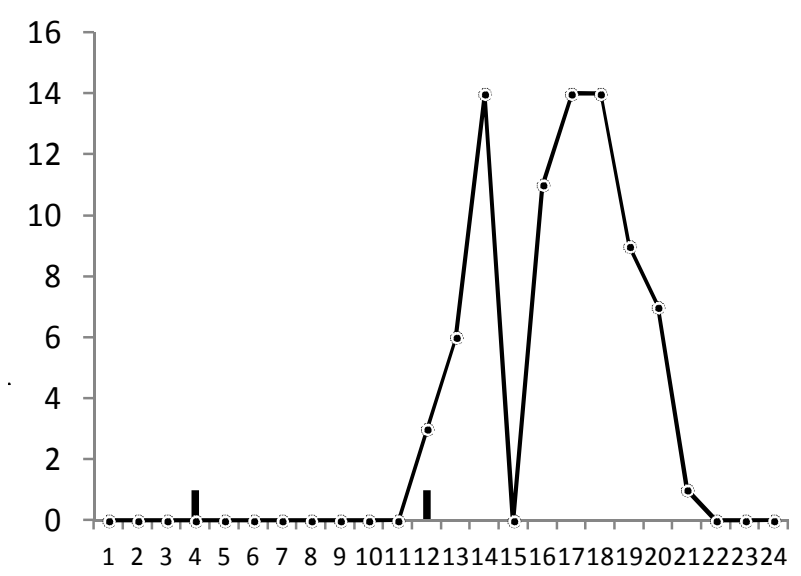
63B

Fêmea —-Macho

Almeidella almeidai

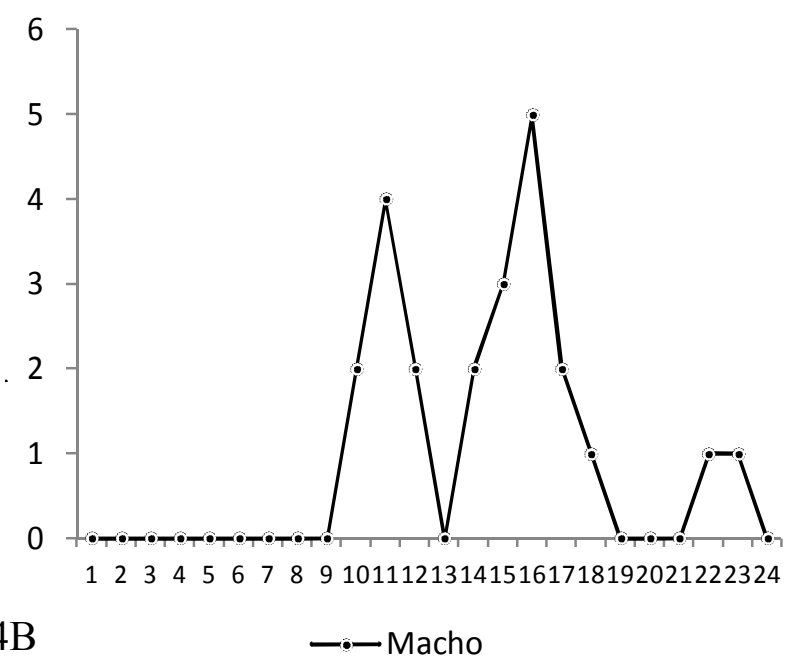

Othorene cadmus

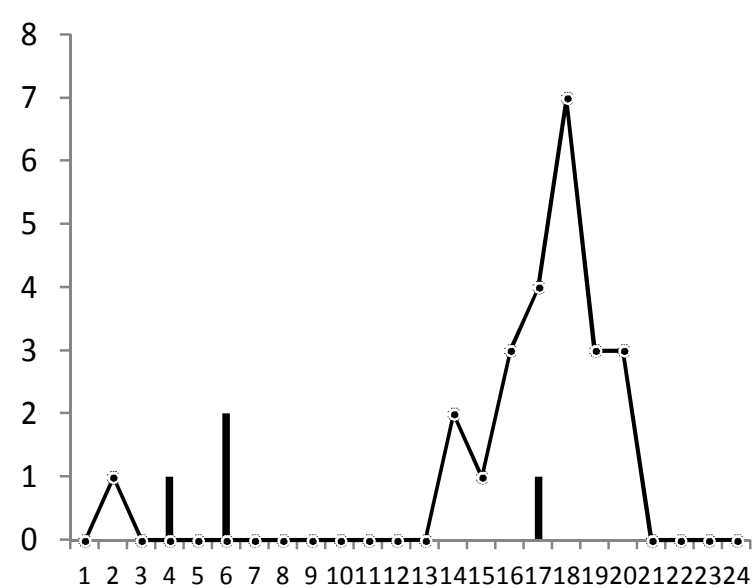
$65 \mathrm{~B}$ 

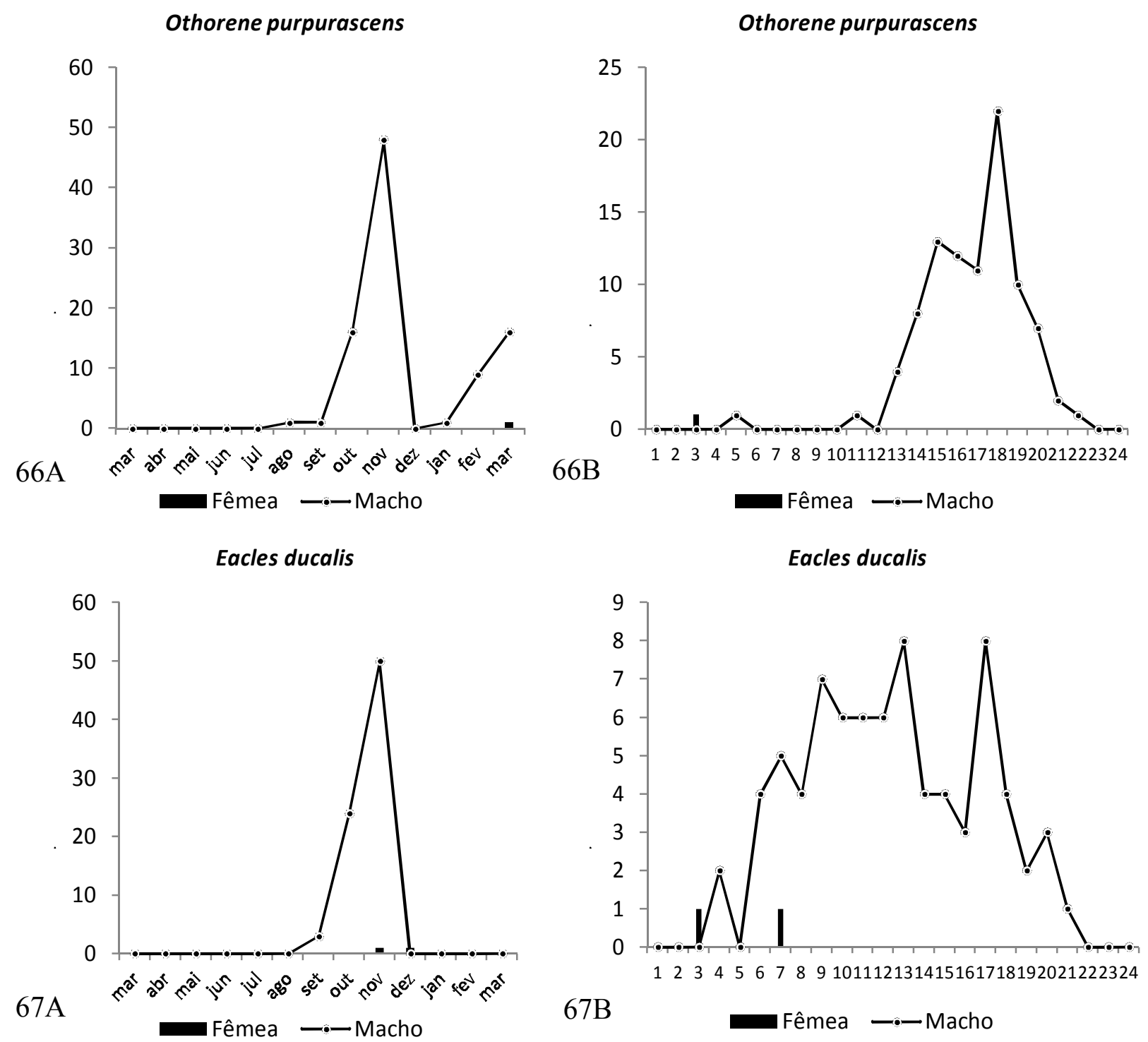

Eacles imperialis

\section{Eacles imperialis}
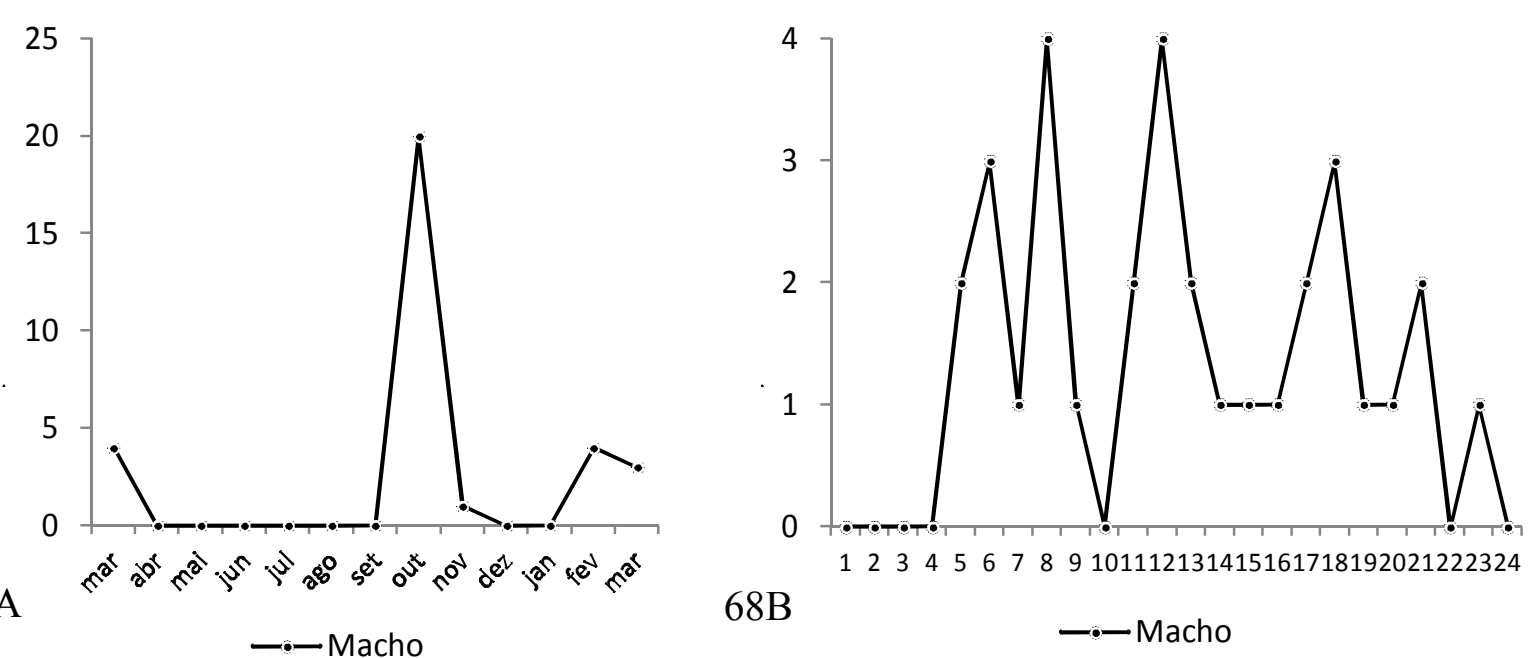


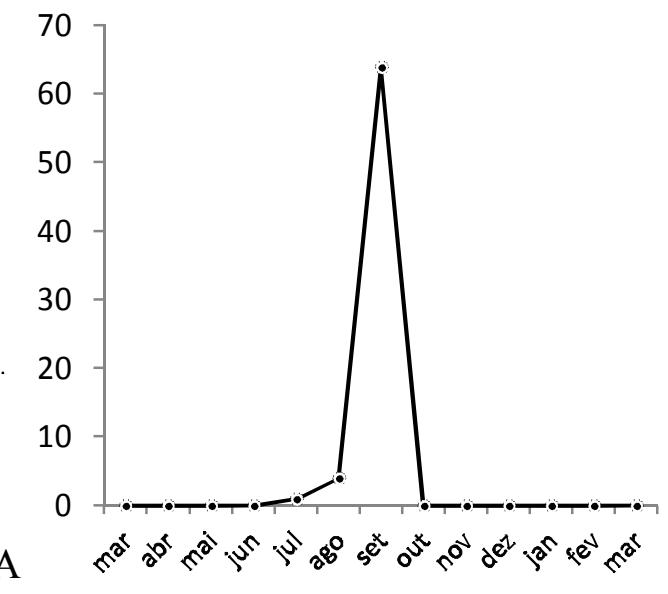

- Macho

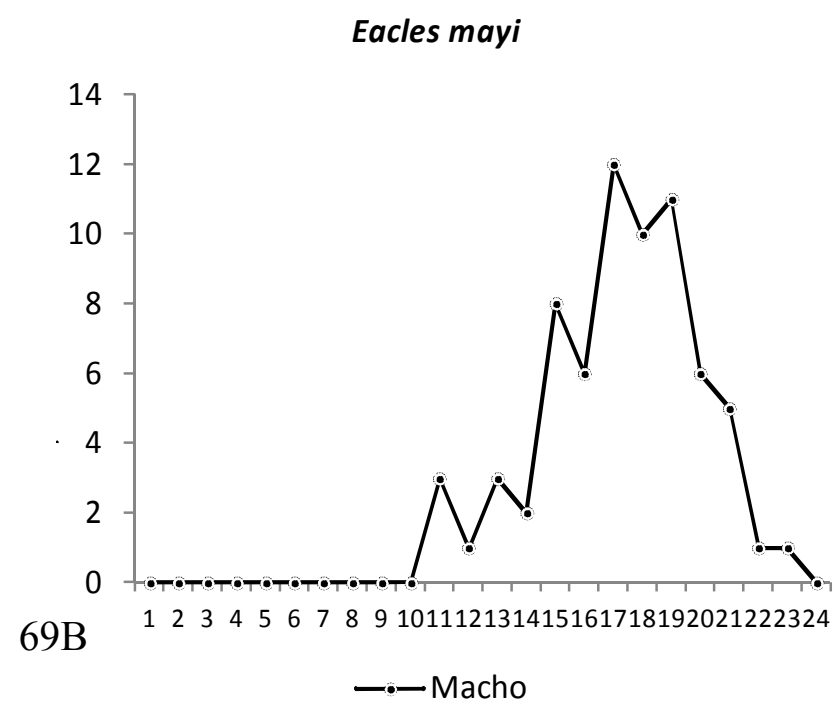

Figuras 61-69. Distribuição (A) sazonal e (B) circadiana de (61) Adeloneivaia fallax (Boisduval, 1872); (62) Adelowalkeria falvosignata Walker, 1865; (63) Adelowalkeria tristygma (Boisduval, 1872); (64) Almeidella almeidai Oiticica, 1946; (65) Othorene cadmus (Herrich-Schäffer, [1854]); (66) Othorene purpurascens (Schaus, 1905); (67) Eacles ducalis Walker; 1855; (68) Eacles imperialis (Drury, 1773); e (69) Eacles mayi Schaus, 1920 (Ceratocampinae), coletadas na Estação Biológica de Boraceia, Salesópolis, SP, Brasil entre março de 2012 e março de 2013.

Como pode ser observado nas Figuras 70 e 71 a alternância entre machos das espécies de Ceratocampinae ao longo dos meses é pequena, poucas espécies ocorreram entre os meses de abril e agosto de 2012; entre setembro de 2012 e março de 2013 algumas espécies alternaram com outras a ocorrência com o passar dos meses. Ao longo da noite a alternância foi igualmente baixa, havendo alta concentração de espécies nos intervalos após o meio da noite, entre 00:30h e 03:30h, quando praticamente todas as espécies puderam ser amostradas. Em geral, espécies que ocorreram em intervalos anteriores ou posteriores a faixa mencionada, como Eacles imperialis (Drury, 1773) e E. ducalis, apresentaram distribuição circadiana de maior amplitude ocorrendo tanto naqueles horários quanto em horários fora da faixa mencionada. 


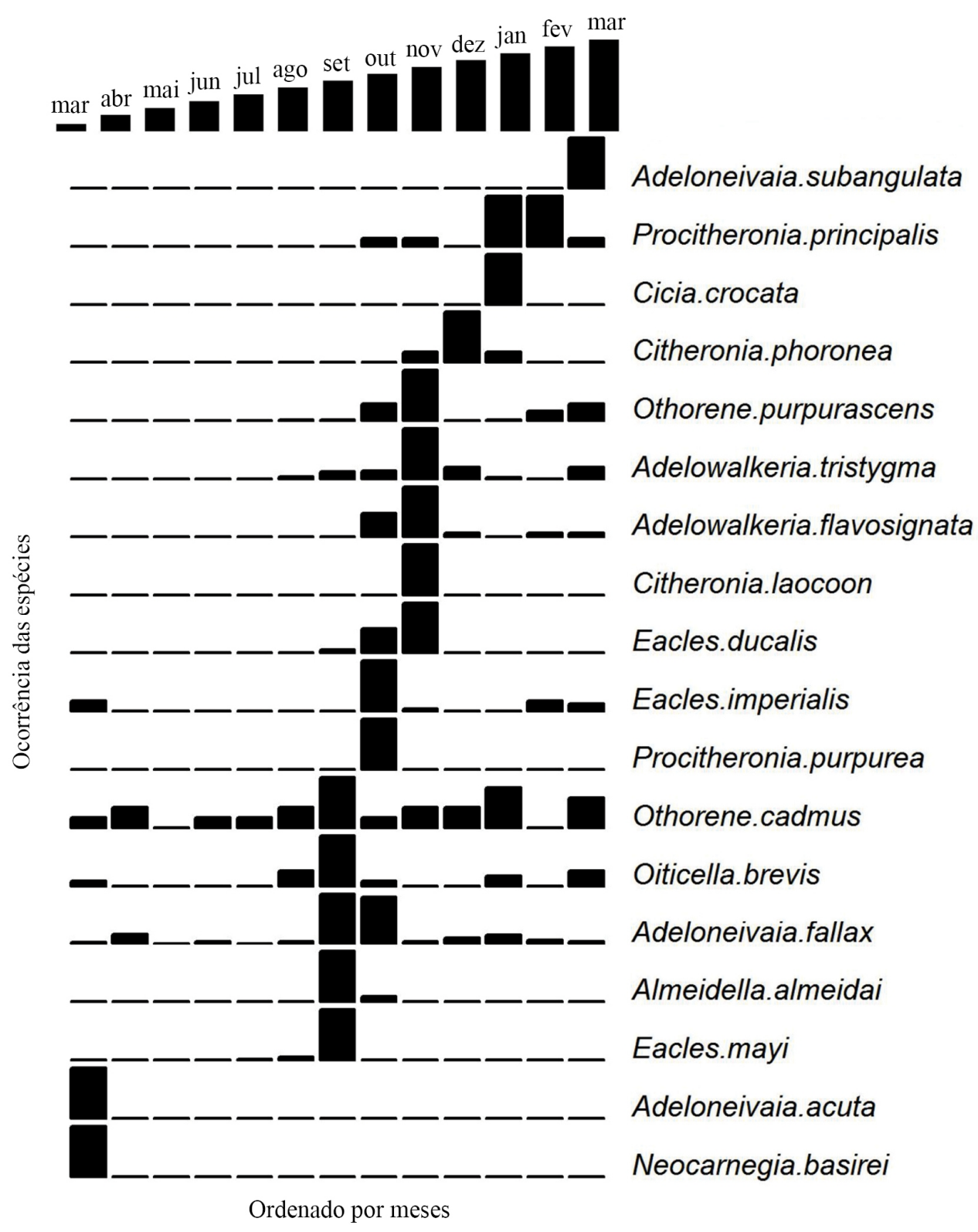

Figura 70. Ranque de abundância dos machos de cada uma das 18 espécies de Ceratocampinae (606 exemplares) nos 13 meses (março de 2012 a março de 2013) de coleta, na Estação Biológica de Boraceia, SP, Brasil. 


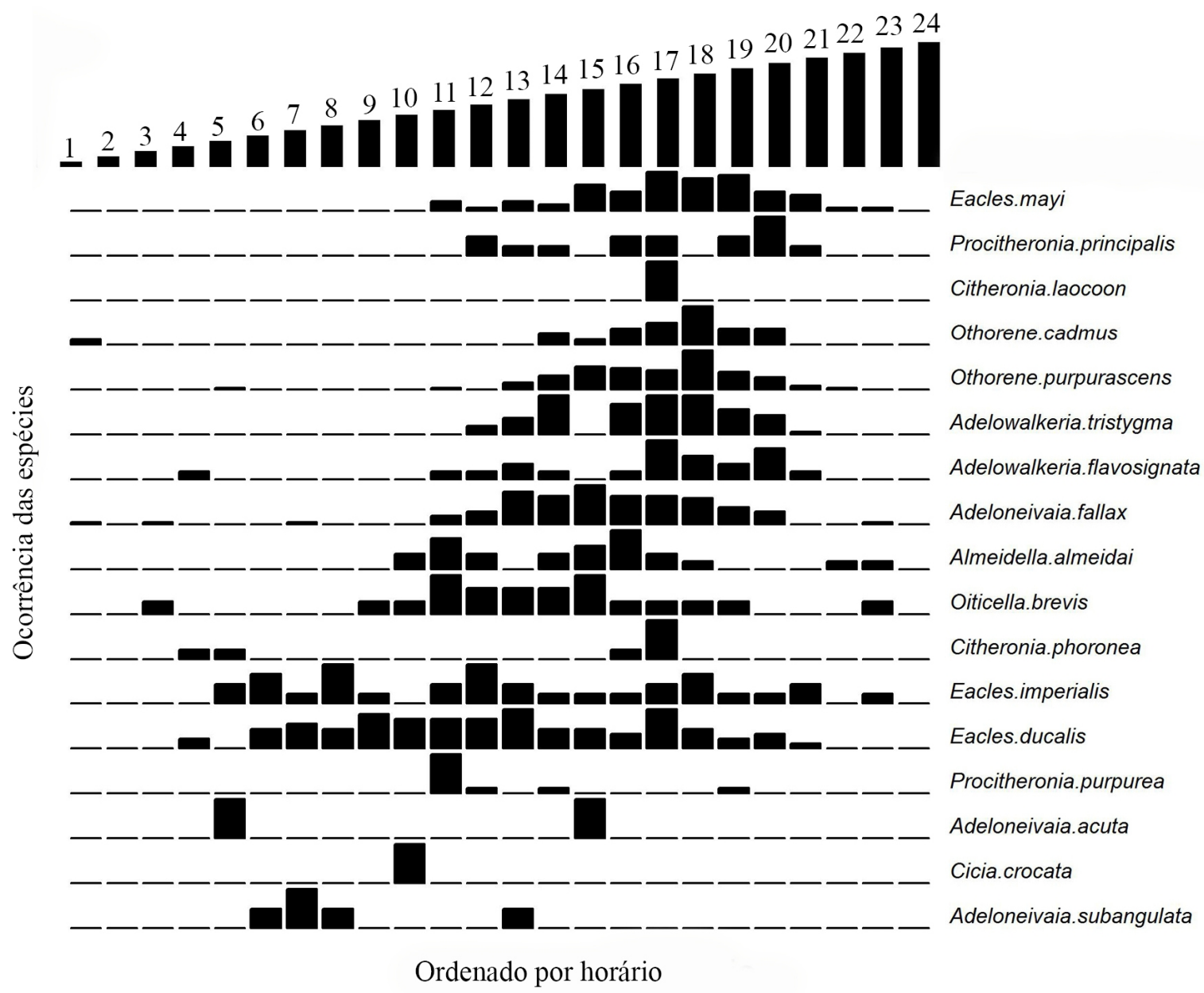

Figura 71. Ranque de abundância dos machos de cada uma das 18 espécies de Ceratocampinae (606 exemplares) nos 24 intervalos de tempo (1-2: 18:00-00:00h e 13-24: 00:00-06:00h) de coleta, na Estação Biológica de Boraceia, SP, Brasil.

\subsubsection{Hemileucinae}

Hemileucinae foi a subfamília mais abundante e com o maior número de espécies coletadas, 2.251 exemplares e 59 espécies (não incluindo Hylesia sp.) distribuídas em 19 gêneros. A distribuição sazonal apresentou grande redução no número de exemplares na primavera, entre outubro e dezembro de 2012, quando apenas 4\% dos exemplares foram amostrados, e alta abundância no outono e início do inverno, em março, abril e junho do mesmo ano. As altas abundâncias destes meses foram influenciadas por espécies do gênero Hylesia, em especial $H$. oratex, $H$. metapyrrha e Hylesia sp.1, as quais representaram, respectivamente $17,5 \%, 15,4 \%$ e $11,1 \%$ da abundância amostrada naqueles meses. Hylesia metapyrrha foi ainda responsável por $61 \%$ dos exemplares em maio de 2012 . Na maioria dos meses a redução na abundância refletiu diretamente no número de espécies amostradas, no entanto para os meses 
de junho a setembro (quase todo inverno e início da primavera), quando a abundância reduziu praticamente à metade da observada nos meses de março e abril, o número de espécies mantevese entre os mais altos $-74,6 \%$ das 59 espécies de Hemileucinae foram coletadas (Fig. 72).

As espécies de Hemileucinae apresentaram maior abundância nas primeiras horas de escuridão, entre $18: 30 \mathrm{~h}$ e $20: 30 \mathrm{~h}$ (24,1\% dos exemplares coletados), e no final da noite entre 03:00h e 05:30h (26,5\%), no entanto houve tendência de redução no número de espécies no decorrer da noite. As maiores riquezas foram observadas nas primeiras horas (18:30-20:30h) e em horários centrais (23:00-00:30h) (Fig. 73), apenas em quatro intervalos de tempo das primeiras horas da noite, nos 13 meses de campanha, foram coletados 86,4\% das 59 espécies e nos três intervalos em horários centrais foram coletados $71,2 \%$ das espécies. Algumas espécies do gênero Hylesia foram as que mais contribuíram para as altas abundâncias em ambos os períodos mencionados, entretanto para o segundo período, no final da noite, exemplares de Automeris beckeri, Automeris inornata, Dirphia muscosa e Pseudoautomeris coronis (Schaus, 1913) tiveram contribuições significativas.
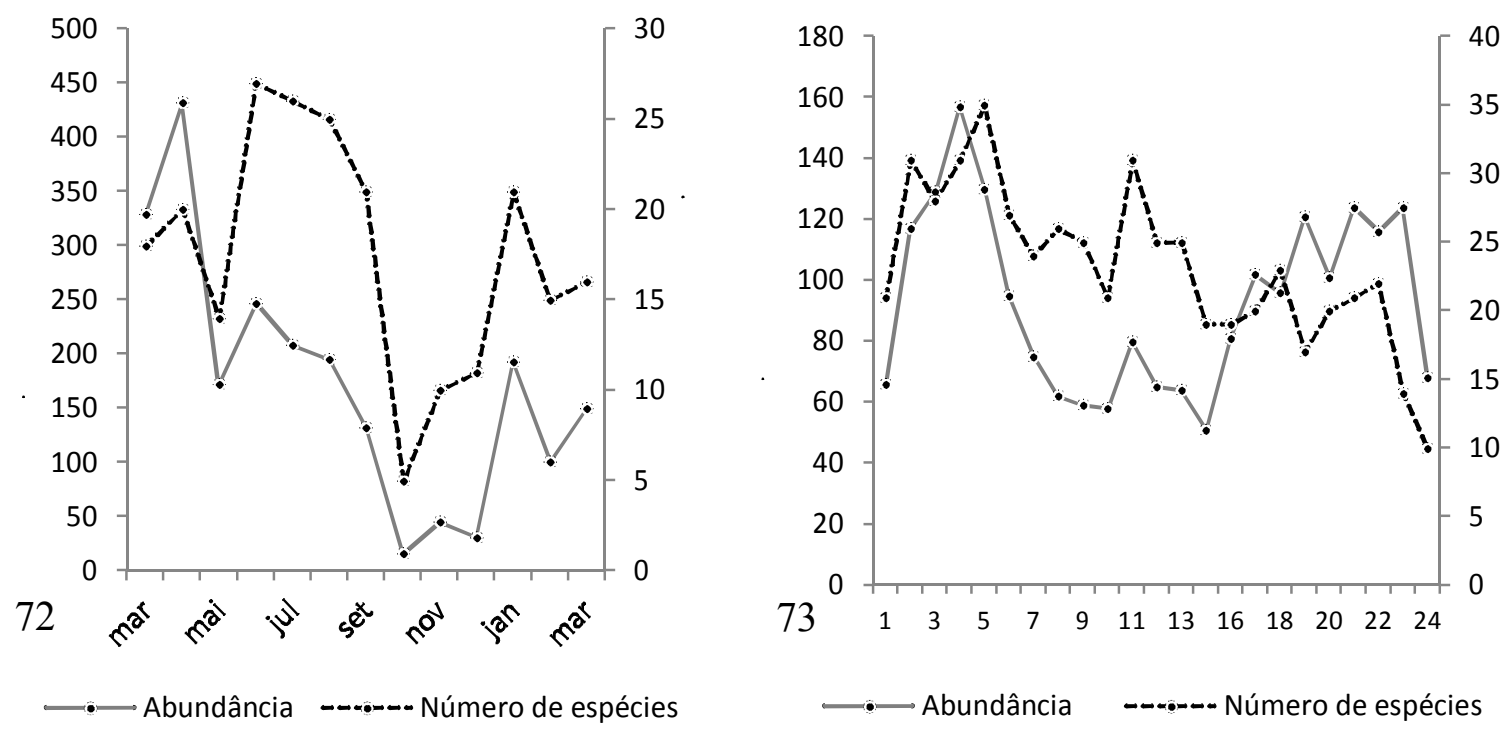

Figuras 72-73. Variação da abundância e do número de espécies de Hemileucinae coletados durante (72) 13 meses e (73) 24 intervalos de tempo das 51 noites de coleta na Estação Biológica de Boraceia, SP, Brasil. Abundância e número de espécies não incluem Hylesia sp.

A distribuição de ocorrência das espécies de Hemileucinae ao longo do gradiente sazonal aponta para relevante alternância das 59 espécies. Geralmente, uma série de espécies tendeu a ocorrer apenas em um, ou poucos meses, e após o fim da atividade dos machos adultos de algumas delas, outras passaram a apresentar atividade, e assim sucessivamente ao longo do 
ano (Fig. 74). As espécies dessa subfamília apresentaram maior alternância sazonal, além de atividade restrita a poucos meses do ano, sendo as espécies com maior distribuição da atividade sazonal A. illustris, C. vagans, Gamelia remissoides Lemaire, 1967, H. nanus, H. scortina e P. hubneri. A distribuição circadiana das espécies da subfamília foi mais dispersa do que a distribuição sazonal. No entanto, apesar do alto agrupamento de espécies em alguns curtos intervalos de tempo, a Fig. 75 demonstra que há alternância das espécies ao longo da noite. Algumas foram coletadas em horários bastante restritos como Automeris inornata, Dirphia fornax (Druce, 1903), Dirphiopsis wanderbilti Pearson, 1958 e Dirphiopsis picturata (Schaus, 1913), outras fugiram de terem sido amostradas em horários restritivos devido a um ou dois exemplares coletados fora dos picos de abundâncias, como Dirphia dolosa, Cerodirphia opis, Pseudautomeris coronis, Hydripa paranensis (Bouvier, 1929) e Catacantha ferruginea (Draudt, 1929). Tal fenômeno pode estar associado à variação circadiana do exemplar ou a falhas de amostragem. Um fato que chama a atenção é a distribuição circadiana das espécies citadas acima como sendo sazonalmente dispersas. Estas espécies também apresentaram ciclo circadiano disperso, sem um pico agudo bem definido.

Importante destacar também os ciclos de atividade de algumas espécies cujo tratamento taxonômico é de difícil resolução ou cujos exemplares apresentam alta taxa de polimorfismo, como por exemplo as espécies dos gêneros Hylesia, Periga e Lonomia. Neste contexto, o uso da atividade sazonal e circadiana das espécies que apresentam atividades bem definidas, pode ser incluído em definições taxonômicas de estudos em sistemática, no suporte da associação entre os machos e fêmeas da mesma espécie, ou mesmo no entendimento das variações polimórficas. 


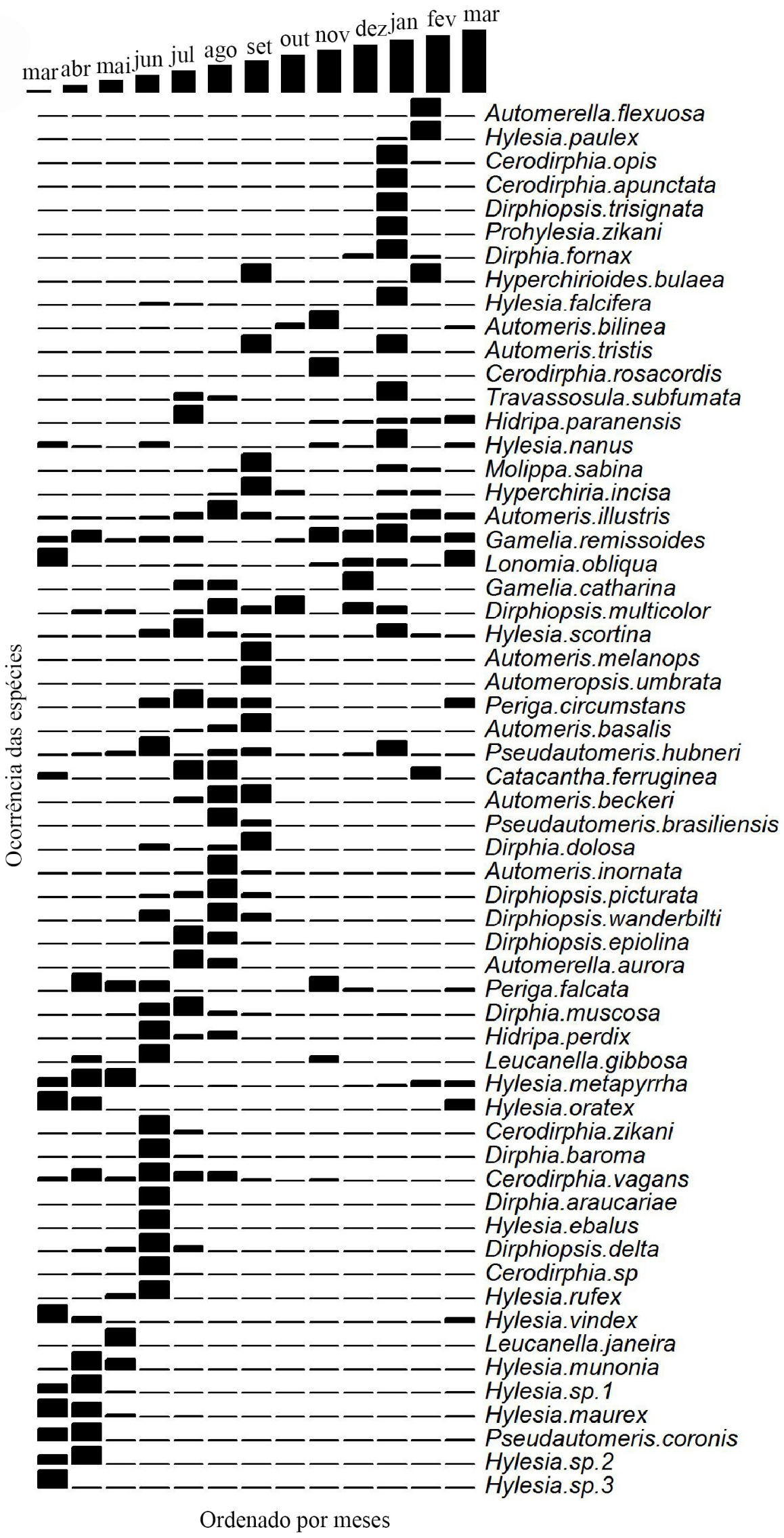

Figura 74. Ranque de abundância dos machos de cada uma das 59 espécies de Hemileucinae nos 13 meses (março a dezembro de 2012 e janeiro a março de 2013) de coleta, na Estação Biológica de Boraceia, SP, Brasil. 


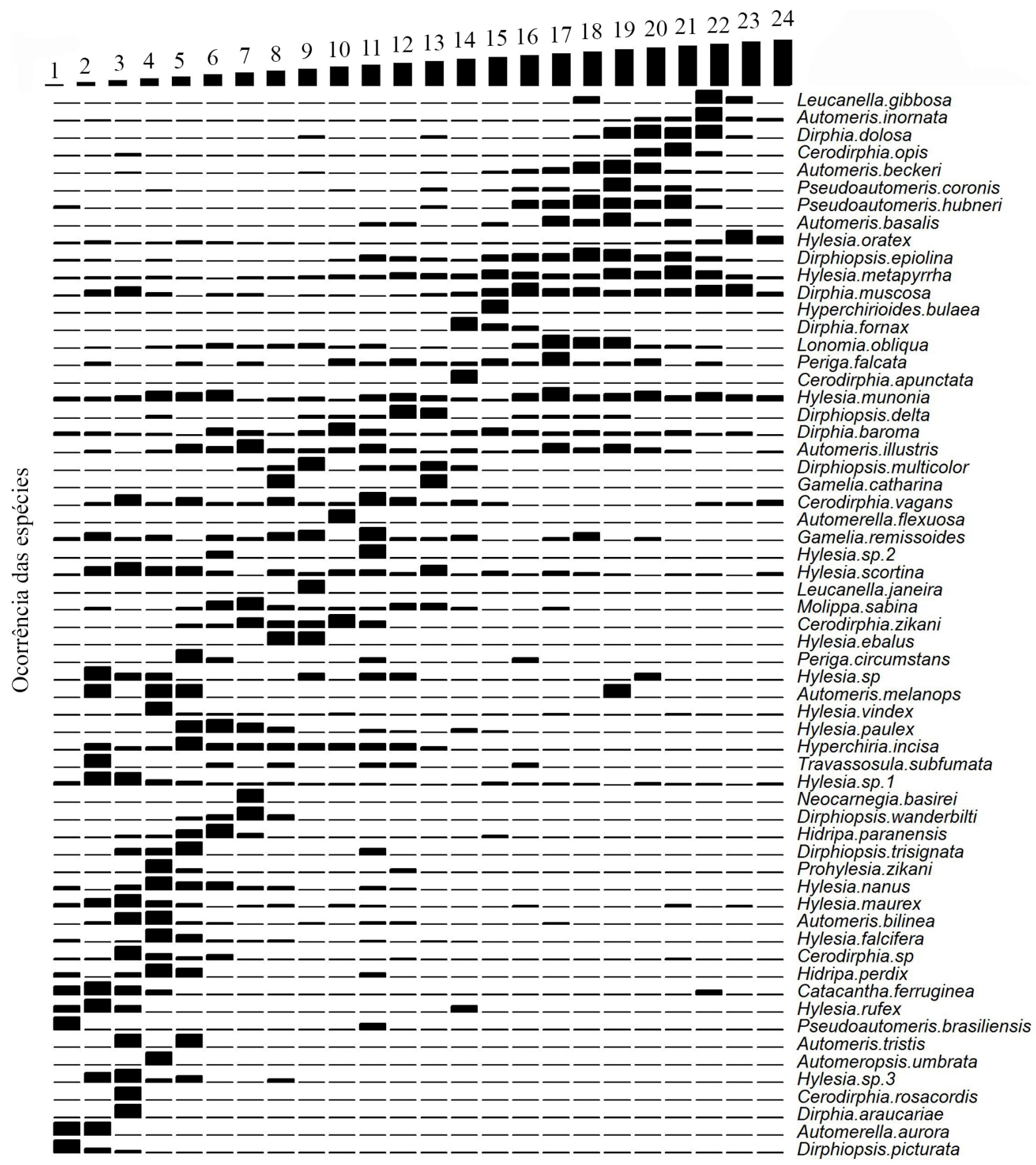

Ordenado por horário

Figura 75. Ranque de abundância dos machos de cada uma das 59 espécies de Hemileucinae nos 13 meses (março a dezembro de 2012 e janeiro a março de 2013), sendo cada um dos 24 intervalos de tempo a soma dos seus respectivos intervalos nas 51 noites de coleta, na Estação Biológica de Boraceia, SP, Brasil. 
Automeris Hübner, 1819 (Figs. 76-80)

As sete espécies do gênero Automeris somaram 245 indivíduos, sendo A. tristes (Boisduval, 1875) e A. melanops (Walker, 1865) representadas por um e quatro indivíduos, respectivamente, dados esses números suas distribuições sazonais e circadianas não foram avaliadas. A espécie com distribuição sazonal mais ampla foi A. illustris (Walker, 1855), amostrada praticamente todos os meses, com exceção de maio e dezembro de 2012. A flutuação circadiana da espécie foi igualmente distribuída em praticamente todos os 24 intervalos de tempo. Automeris bilinea pertencente ao mesmo grupo de A. illustris (ver Lemaire 2002) e apresentou distribuição sazonal restrita a outubro e novembro, porém quatro exemplares, três machos e uma fêmea, foram coletados fora desse período, um em junho de 2012 e três em março de 2013. A distribuição circadiana da espécie ficou concentrada entre 19:00h e 20:00h, com $63,3 \%$ dos indivíduos coletados.

Todos os exemplares de $A$. beckeri e de $A$. basalis ocorreram entre julho e setembro de 2012. Em seu ciclo circadiano, 74,1\% dos exemplares machos de $A$. beckeri ocorreram entre 02:00h e 04:00h da manhã. As fêmeas, por outro lado, ocorreram antes das 20:30h. Automeris basalis apresentou um ciclo circadiano mais bem distribuído com duas fêmeas coletadas entre 20:00h e 21:00h, e os machos com atividade entre 22:30h e 05:00h. A espécie com distribuição sazonal mais restrita foi $A$. inornata, ocorrendo entre julho e setembro de 2012 , mas com $87,5 \%$ dos indivíduos coletados apenas em agosto. A flutuação noturna dos exemplares também foi relativamente concentrada, com $72,5 \%$ deles coletados entre $04: 00 \mathrm{~h}$ e $05: 30 \mathrm{~h}$, e 47,5\% coletados apenas entre 04:30h e 05:00h.

Automeris illustris

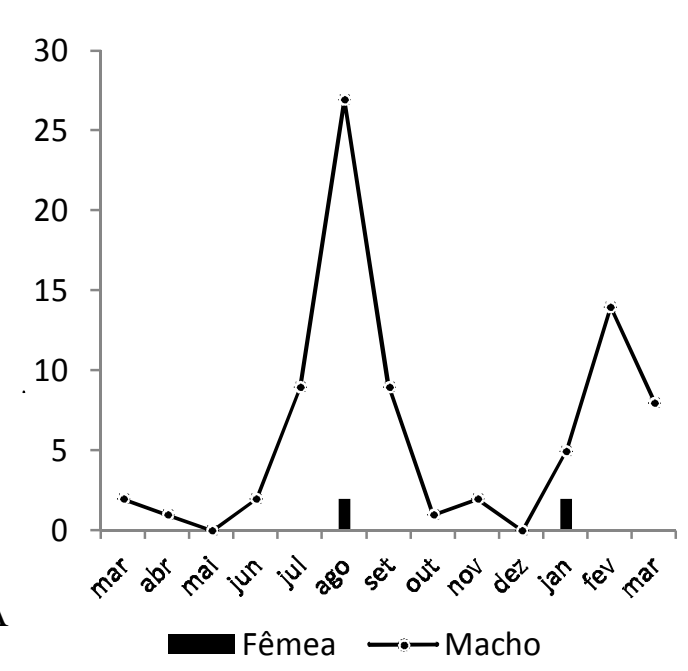

Automeris illustris

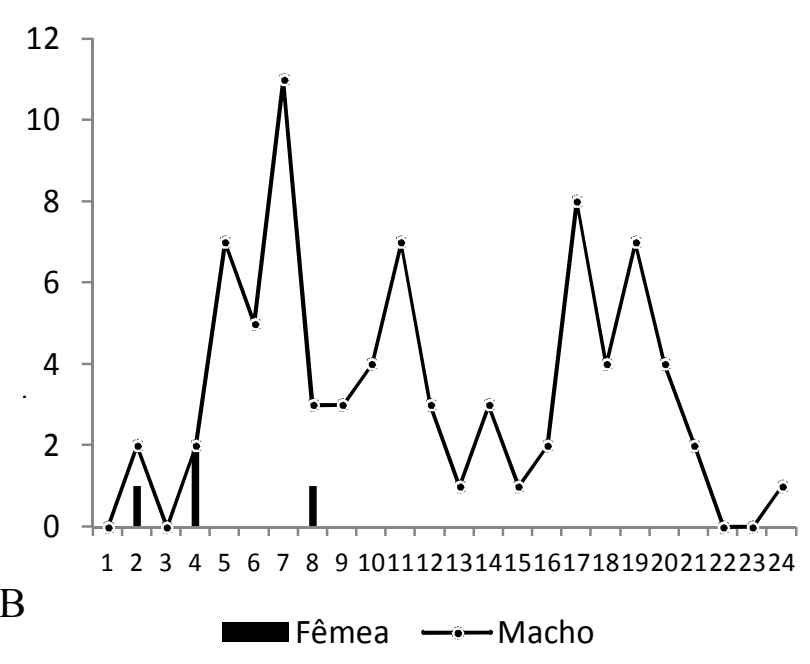


Automeris beckeri

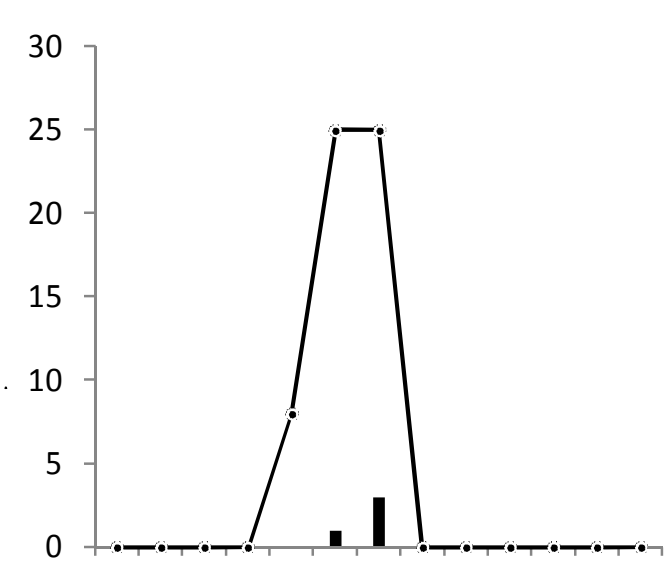

77A

Fêmea - - Macho

Automeris inornata

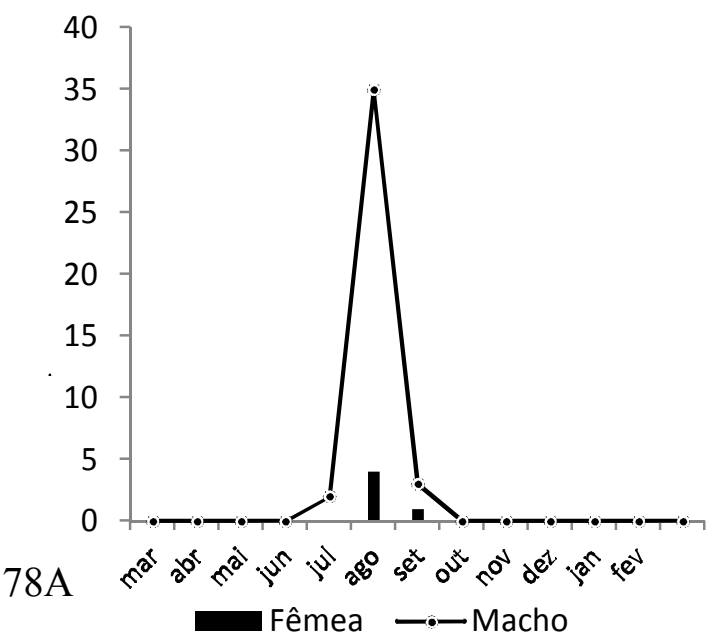

Automeris inornata

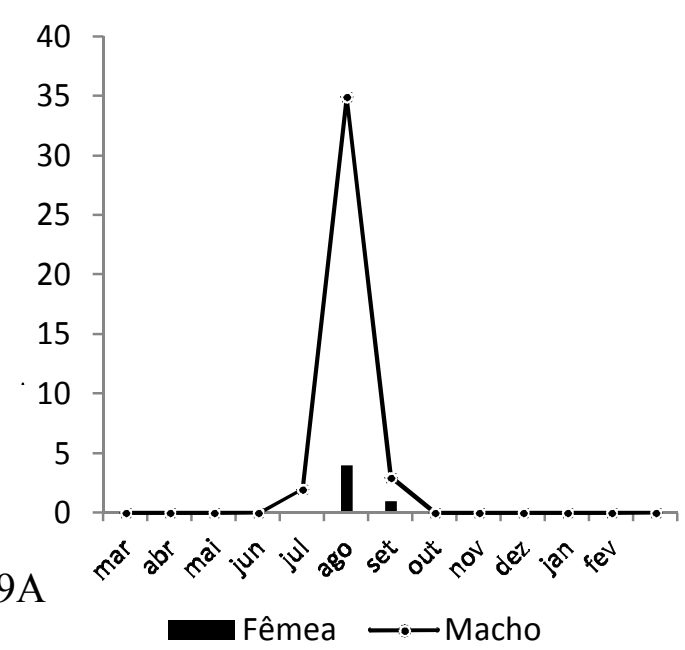

Automeris beckeri

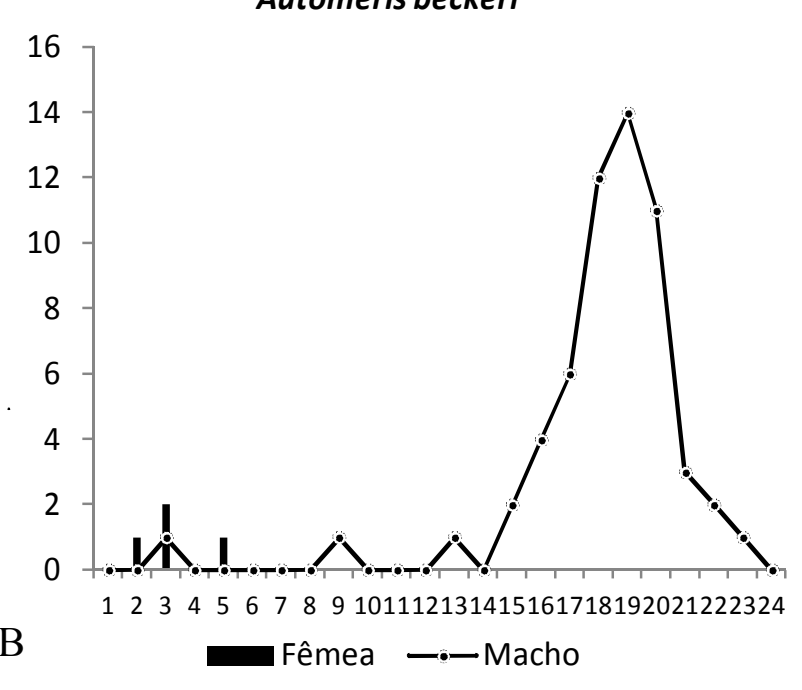

Automeris inornata

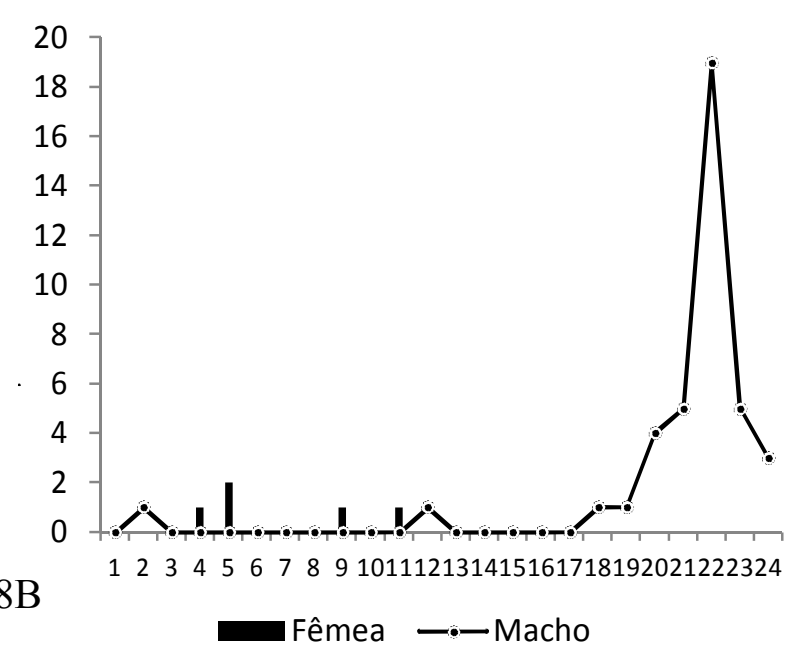

Automeris bilinea

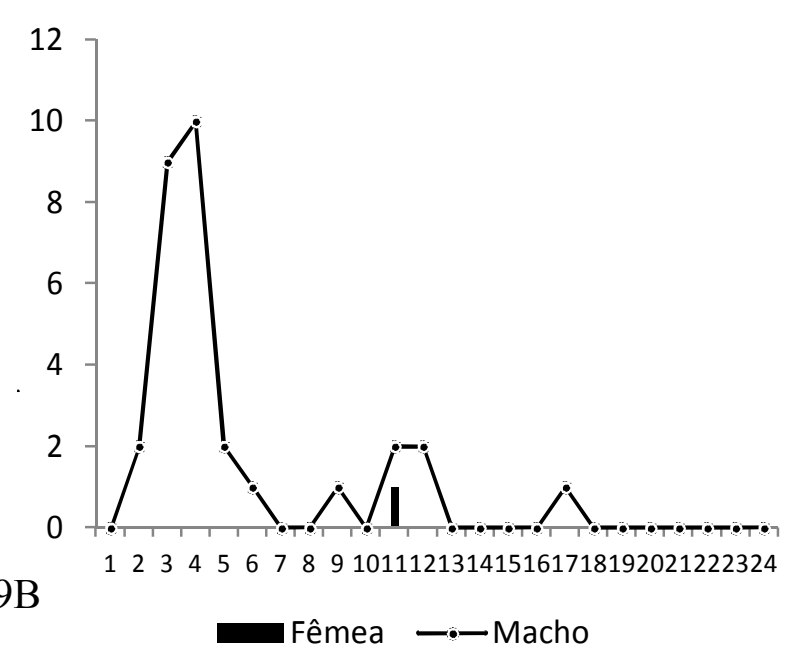



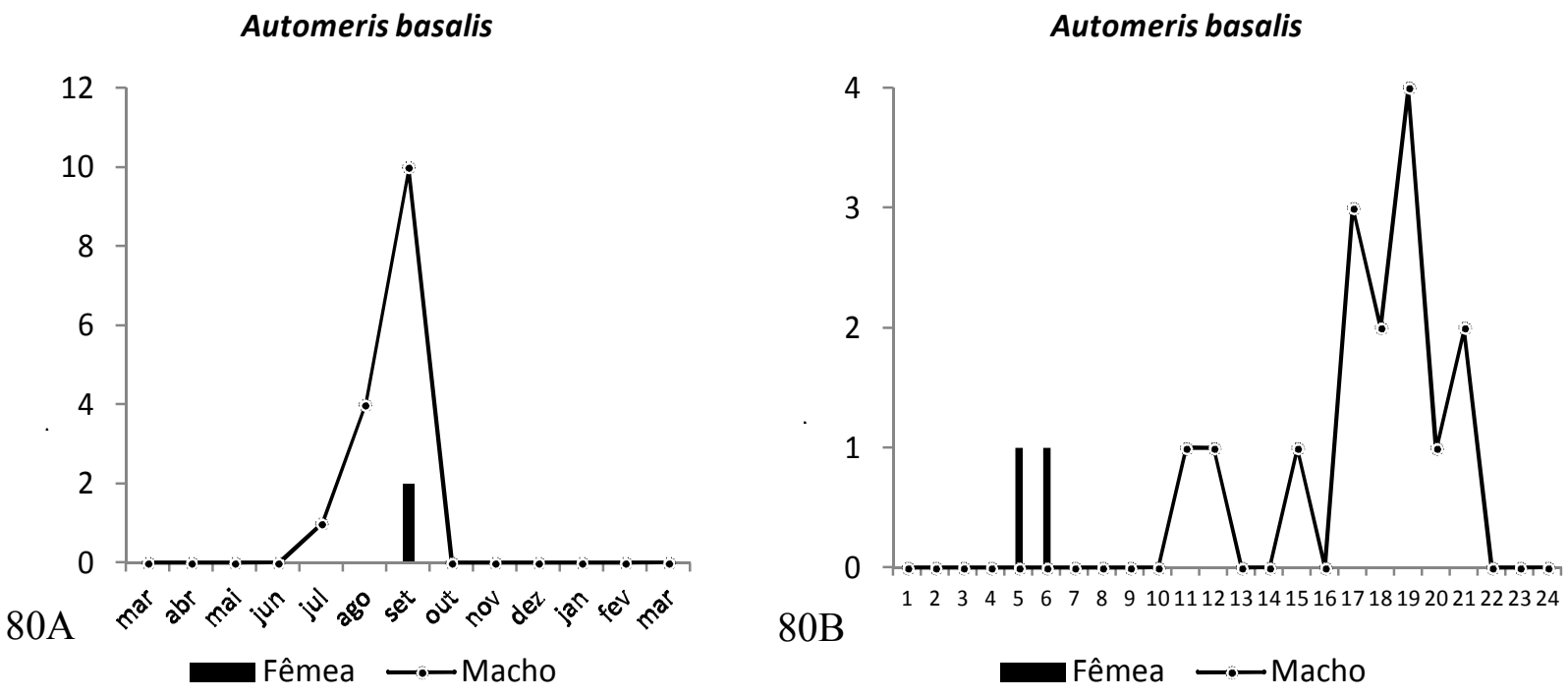

Figuras 76-80. Distribuição sazonal (A) e circadiana (B) de (76) Automeris basalis (Walker, 1855); (77) Automeris beckeri (Herrich-Schäffer, [1856]); (78) Automeris bilinea (Walker, 1855); (79) Automeris illustris (Walker, 1855); e (80) Automeris inornata (Walker, 1855), coletadas na Estação Biológica de Boraceia, Salesópolis, SP, Brasil entre março de 2012 e março de 2013.

\section{Cerodirphia Michener, 1949 (Figs. 81-84)}

O gênero Cerodirphia foi representado por seis espécies e 93 exemplares, sendo que as espécies C. apunctata Dias \& Lemaire, 1991 e C. rosacordis (Walker, 1855) tiveram cada uma apenas um exemplar coletado. Cerodirphia opis, C. zikani (Schaus, 1921) e Cerodirphia sp.1 apresentaram um padrão de distribuição sazonal bastante restrito; C. opis ocorreu apenas entre janeiro e fevereiro de 2013; C. zikani em junho e julho de 2012 e Cerodirphia sp.1 a mais bem distribuída, de abril a julho de 2012.

No entanto, mesmo tratando-se de dois até quatro meses de ocorrência, como para Cerodirphia sp.1, a grande concentração dos indivíduos ocorreu em apenas um dos meses, sendo que $92,9 \%$ dos indivíduos de $C$. opis e de $C$. zikani ocorreram unicamente em janeiro de 2013 e junho de 2012, respectivamente, e 88,5 \% dos indivíduos de Cerodirphia sp.1 ocorreram apenas em junho de 2012. Cerodirphia vagans (Walker, 1855) apresentou a mais ampla distribuição sazonal, não ocorrendo em outubro e dezembro de 2012 e de janeiro a março de 2013, e com o pico da abundância ocorrendo em junho, quando 31,3\% dos exemplares foram coletados.

A distribuição circadiana das quatro espécies analisadas de Cerodirphia apresentou padrão semelhante às respectivas variações de abundância sazonal. Os machos de $C$. opis 
demonstraram maior agregação temporal, sendo prioritariamente coletados entre 03:30h e 05:00h, no entanto as três fềmeas coletadas foram capturadas em horários relativamente distantes entre si (ver Fig. 82B). Os machos de C. zikani ocorreram ao longo de sete intervalos de tempo, entre 20:00h e 23:30h, e os de Cerodirphia sp.1 ocorreram especialmente nos seis primeiros intervalos, entre 18:00h e 21:00h. Cerodirphia vagans apresentou atividade praticamente em todos os intervalos ao longo da noite, não sendo coletada apenas entre 18:00 e $18: 30 \mathrm{~h}$ e entre $01: 30 \mathrm{~h}$ e $04: 30 \mathrm{~h}$.

Cerodirphia sp.1

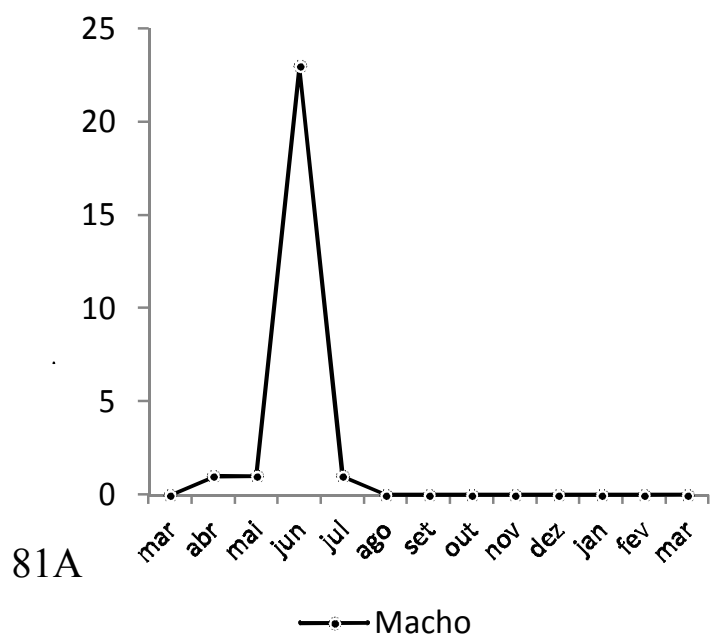

Cerodirphia opis

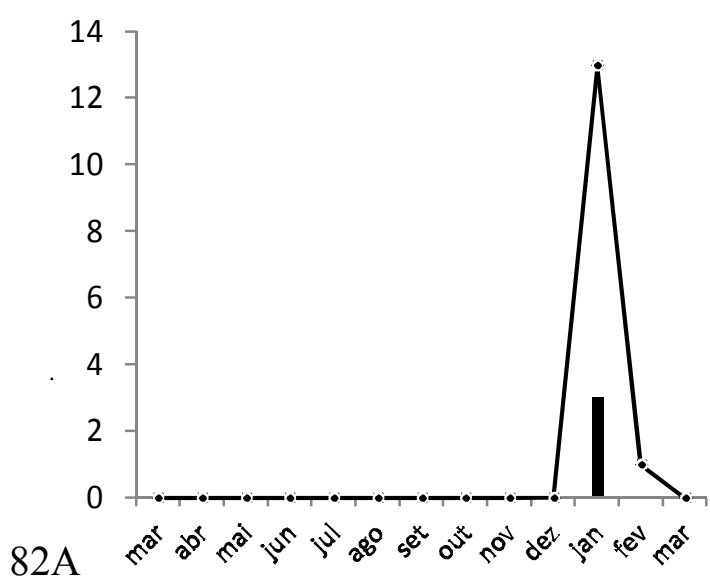

Fêmea -:-Macho
Cerodirphia sp.1

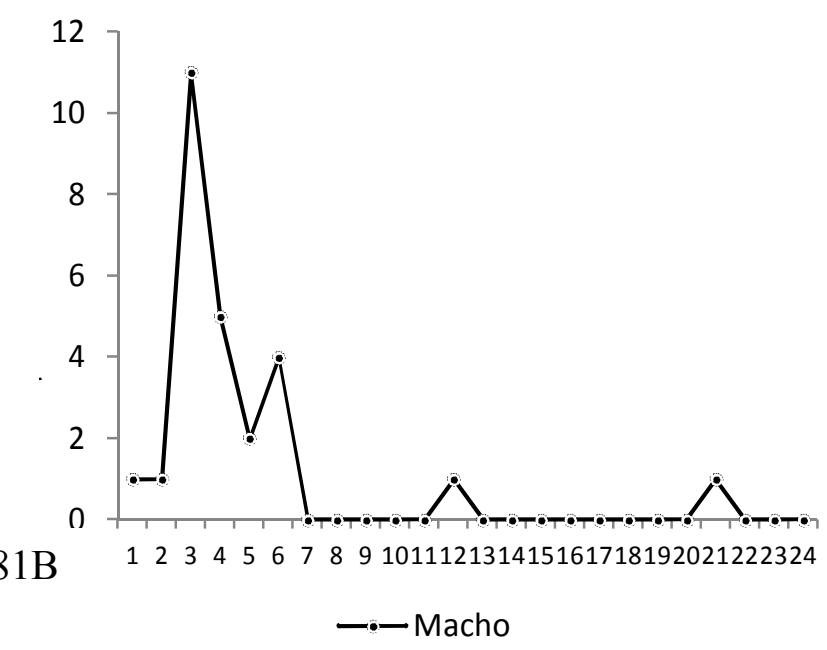

Cerodirphia opis

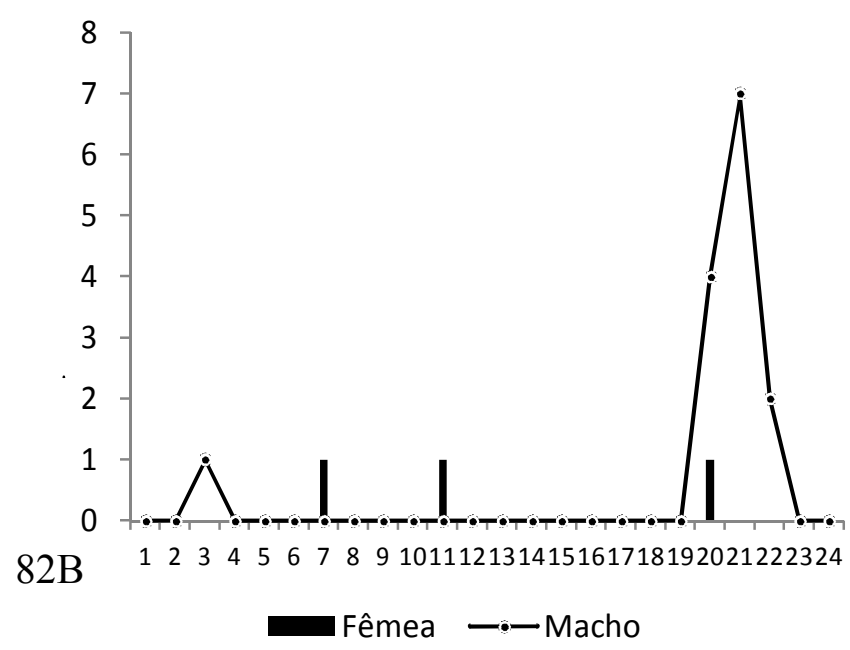




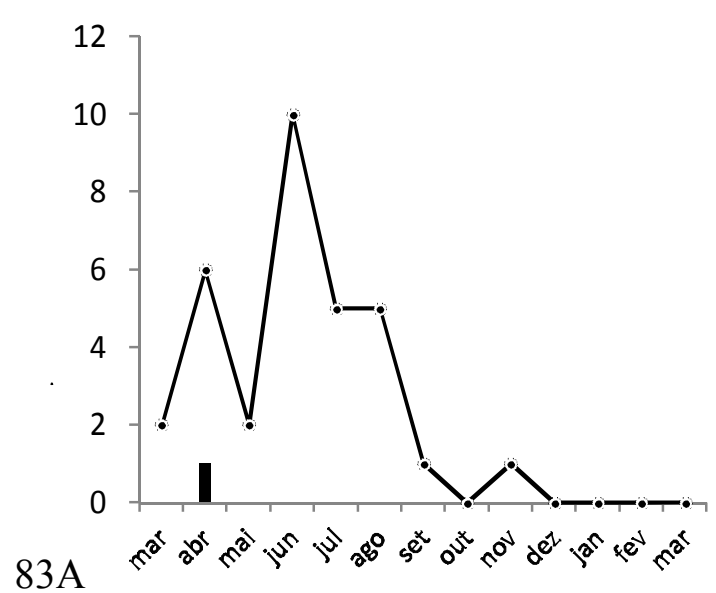

Fêmea - Macho

Cerodirphia zikani

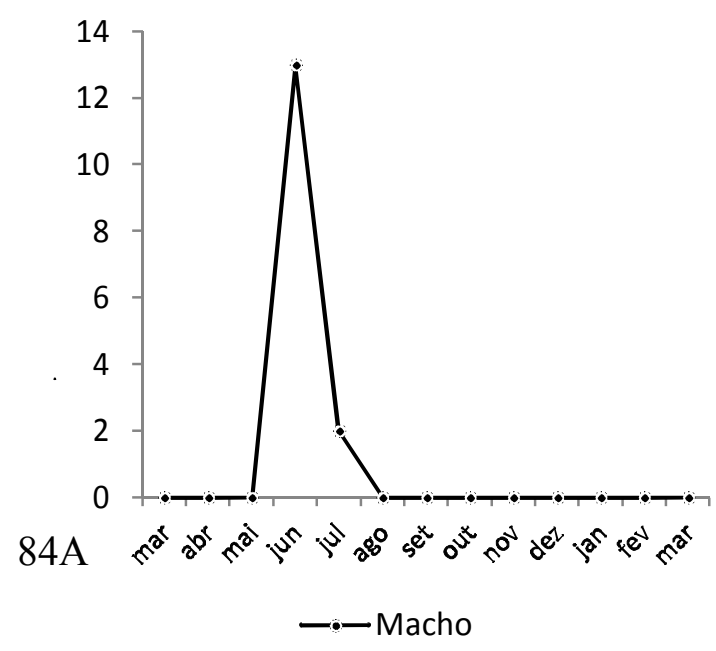

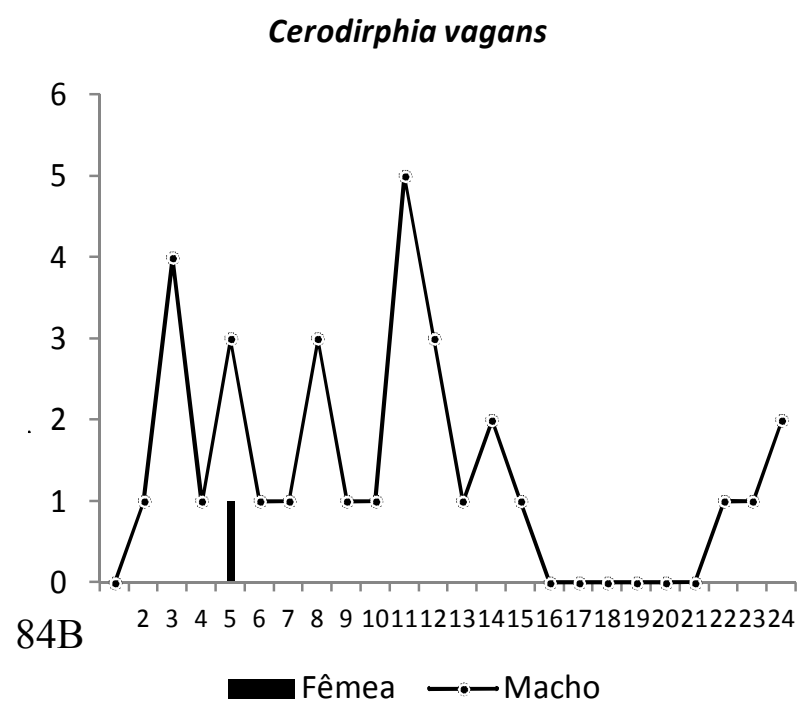

Cerodirphia zikani

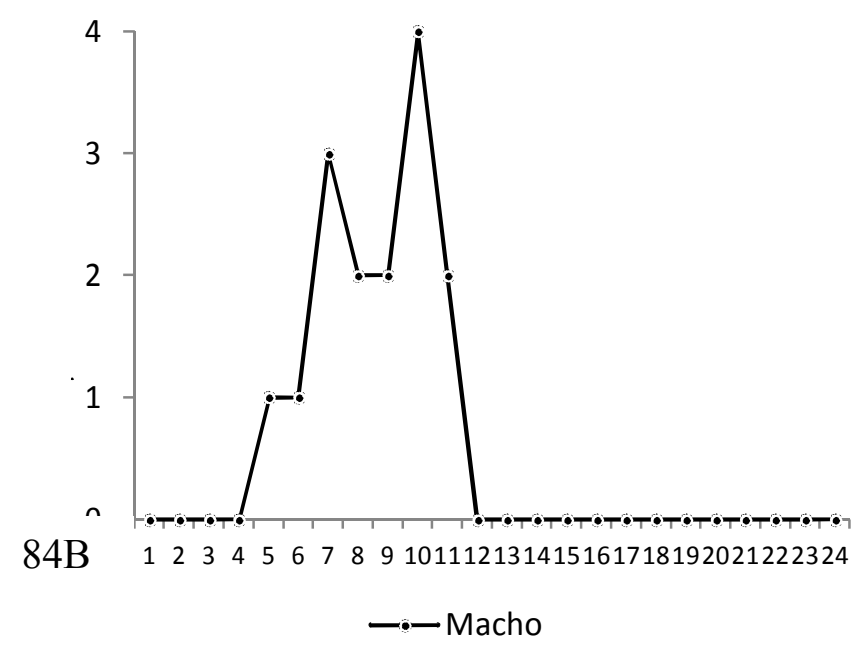

Figuras 81-84. Distribuição sazonal (A) e circadiana (B) de (81) Cerodirphia sp.1; (82) Cerodirphia opis (Schaus, 1892); (83) Cerodirphia vagans (Walker, 1855); e (84) Cerodirphia zikani (Schaus, 1921), coletadas na Estação Biológica de Boraceia, Salesópolis, SP entre março de 2012 e março de 2013.

Dirphia Hübner, [1819] (Figs. 85-87)

As cinco espécies de Dirphia foram representadas por 264 indivíduos, sendo que $D$. araucariae E.D. Jones, 1908 foi representada por apenas um exemplar. Das quatro espécies avaliadas, D. muscosa Schaus, 1898 foi a espécie mais abundante com 150 indivíduos e a que apresentou a distribuição sazonal de machos mais disjunta, tendo sido amostrada em seis dos 13 meses, com o ápice de abundância em julho de 2012 quando 50\% dos exemplares foram 
coletados. Contudo, apesar da espécie ter sido registrada em seis campanhas, 92\% de sua abundância ocorreu no inverno, entre junho e agosto. A flutuação noturna dos machos da espécie foi muito distribuída entre os intervalos, não sendo amostrada apenas em três dos 24 intervalos. Os momentos de maior ocorrência foram no início da noite, entre 18:30h e 19:30h, e após a segunda metade, entre 01:00h e 05:30h. Dirphia baroma (Schaus, 1906) apresentou distribuição sazonal menos disjunta do que D. muscosa, no entanto seus ápices de abundâncias foram sincrônicos, com 98,3\% dos indivíduos machos de D. baroma ocorrendo no inverno, entre junho e julho de 2012, sendo que 91,5\% ocorreram apenas em junho. Também foi a espécie com a segunda maior abundância de fêmeas (12 exemplares), as quais demonstraram maior atividade circadiana no início da noite, antes das 19:30h, mas também ocorrendo em outros horários, incluindo o penúltimo intervalo, entre 05:00h e 05:30h. A distribuição de abundância dos machos ao longo da noite foi significativamente disjunta, não tendo sido coletados apenas em dois intervalos.

As duas espécies menos representadas, D. dolosa e D. fornax, apresentaram ápices de abundância dos machos na primavera e no verão, respectivamente, quando $80,8 \%$ dos indivíduos de $D$. dolosa foram coletados, em agosto e setembro, e 90,9\% dos indivíduos de $D$. fornax foram coletados em dezembro de 2012 e janeiro de 2013. A distribuição circadiana mais concentrada de machos foi de D. fornax, sendo amostrados apenas entre 00:30h e 02:00h. A distribuição dos exemplares de $D$. dolosa ao longo da noite foi mais disjunta com a grande maioria dos espécimes sendo coletados entre 02:30h e 05:30h, incluindo a captura de uma fêmea no intervalo 22 (04:30-05:00h).

Dirphia muscosa

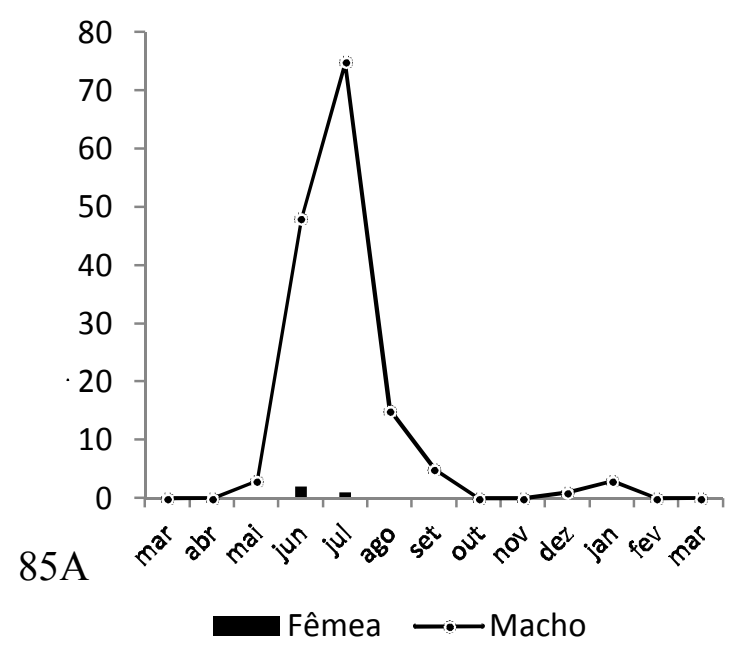

Dirphia muscosa

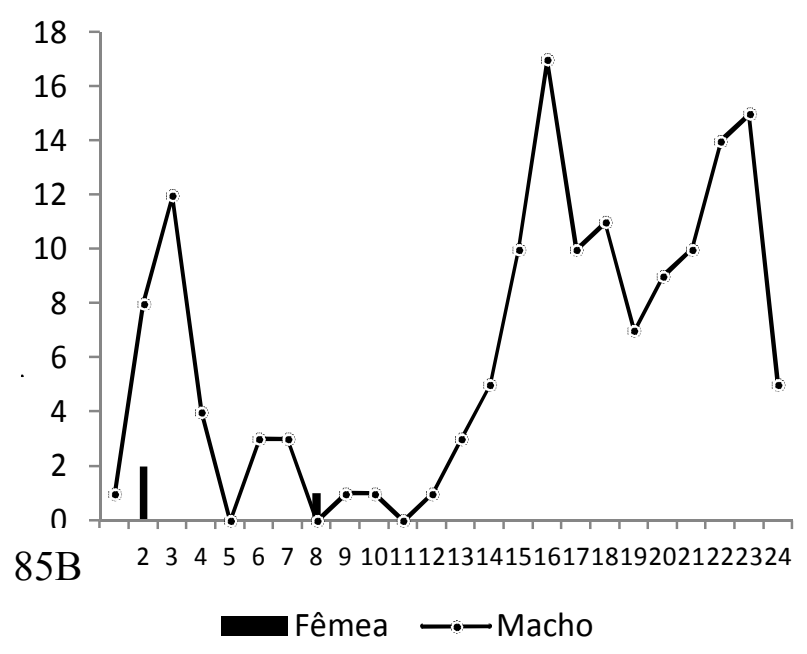




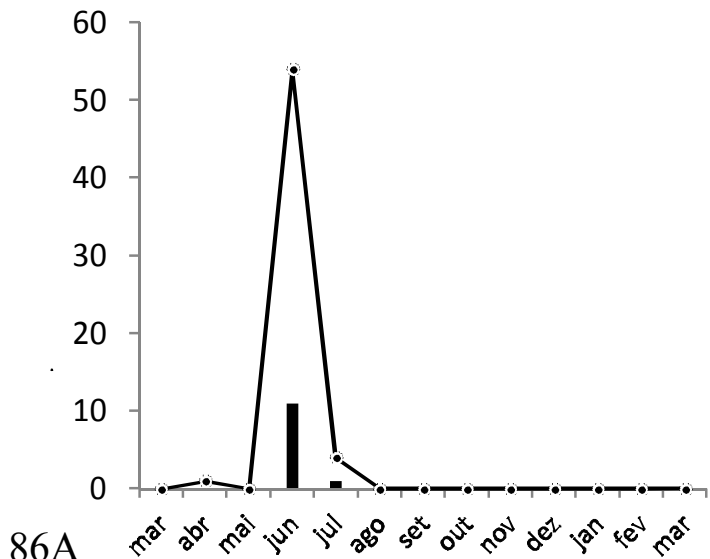

Fêmea —-Macho

\section{Dirphia dolosa}

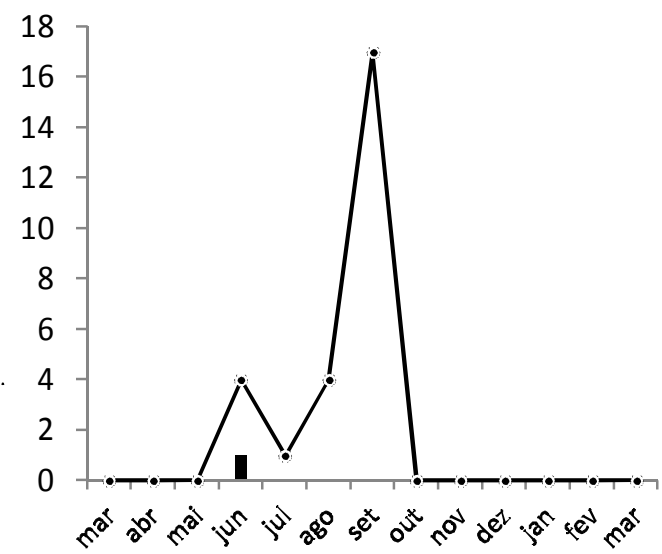

$87 \mathrm{~A}$

Fêmea - - Macho

\section{Dirphia fornax}

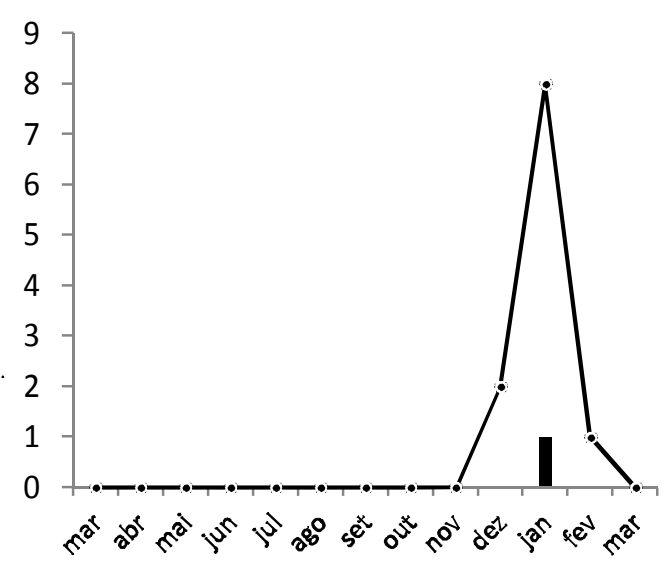

$88 \mathrm{~A}$

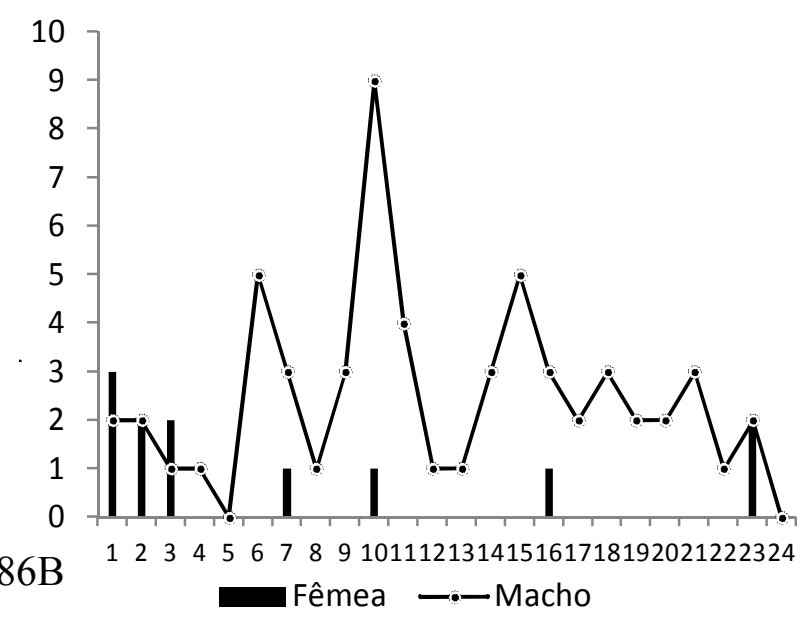

Dirphia dolosa

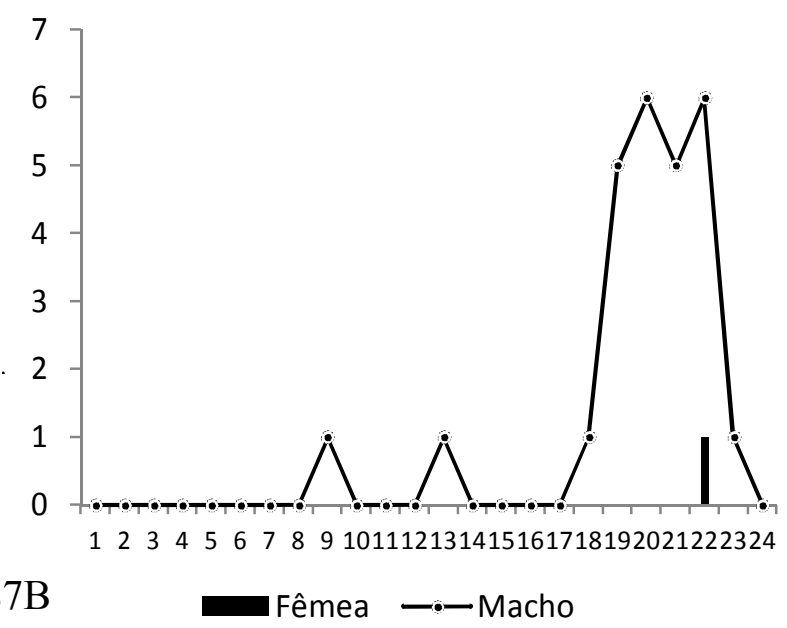

Dirphia fornax

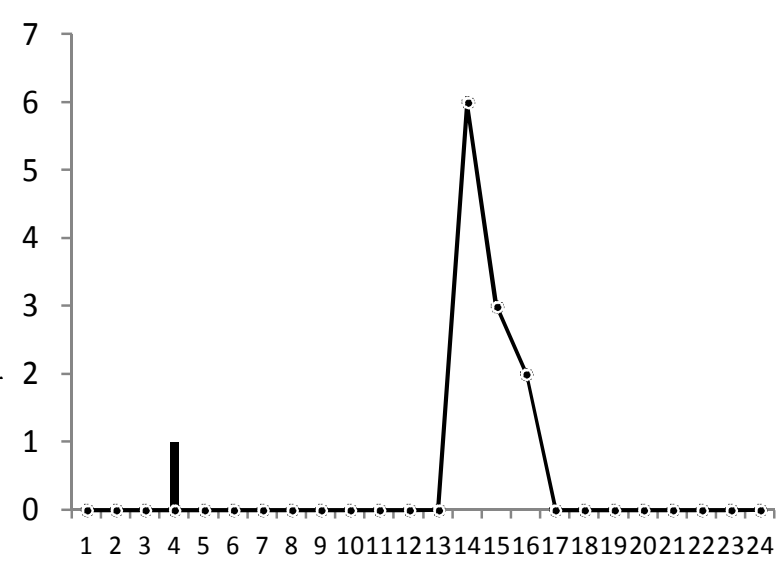

88B

Figuras 85-88. Distribuição sazonal (A) e circadiana (B) de (85) Dirphia muscosa Schaus, 1898; (86) Dirphia baroma (Schaus, 1906); (87) Dirphia dolosa Bouvier, 1929; e (88) Dirphia fornax (Druce, 1903), coletadas na Estação Biológica de Boraceia, Salesópolis, SP, Brasil entre março de 2012 e março de 2013. 
Hylesia Hübner, 1920 (Figs. 89-99)

Hylesia foi o gênero mais abundante e com maior número de espécies, representado por 1.158 indivíduos e 14 espécies. H. metapyrrha ocorreu predominantemente no outono, entre março e maio com $79,6 \%$ dos exemplares machos coletados nestes meses, em dezembro do mesmo ano os machos começaram a reaparecer compondo o total de 314 indivíduos até março do ano seguinte. O ciclo circadiano apresentou tendência de aumento da abundância após 22:00h, atingindo seu pico entre 04:30h e 05:00h, quando passou a cair vertiginosamente. Os machos de H. nanus ocorreram praticamente o ano todo com pico em janeiro de 2013, quando foram capturados $50 \%$ dos exemplares; não foram capturados em parte do inverno e primavera, entre julho a outubro de 2012. Durante o período noturno apresentaram maior concentração no início da noite, entre 19:00h e 22:00, quando 83,3\% dos exemplares foram registrados. A terceira espécie do grupo, $H$. scortina, apresentou um ciclo sazonal aparentemente bianual, com um pico no inverno, entre junho e agosto, e outro no verão entre janeiro e fevereiro de 2013 . O ciclo circadiano foi significativamente distribuído ao longo da noite, não havendo registro somente nos intervalos 7, 20 e 23 .
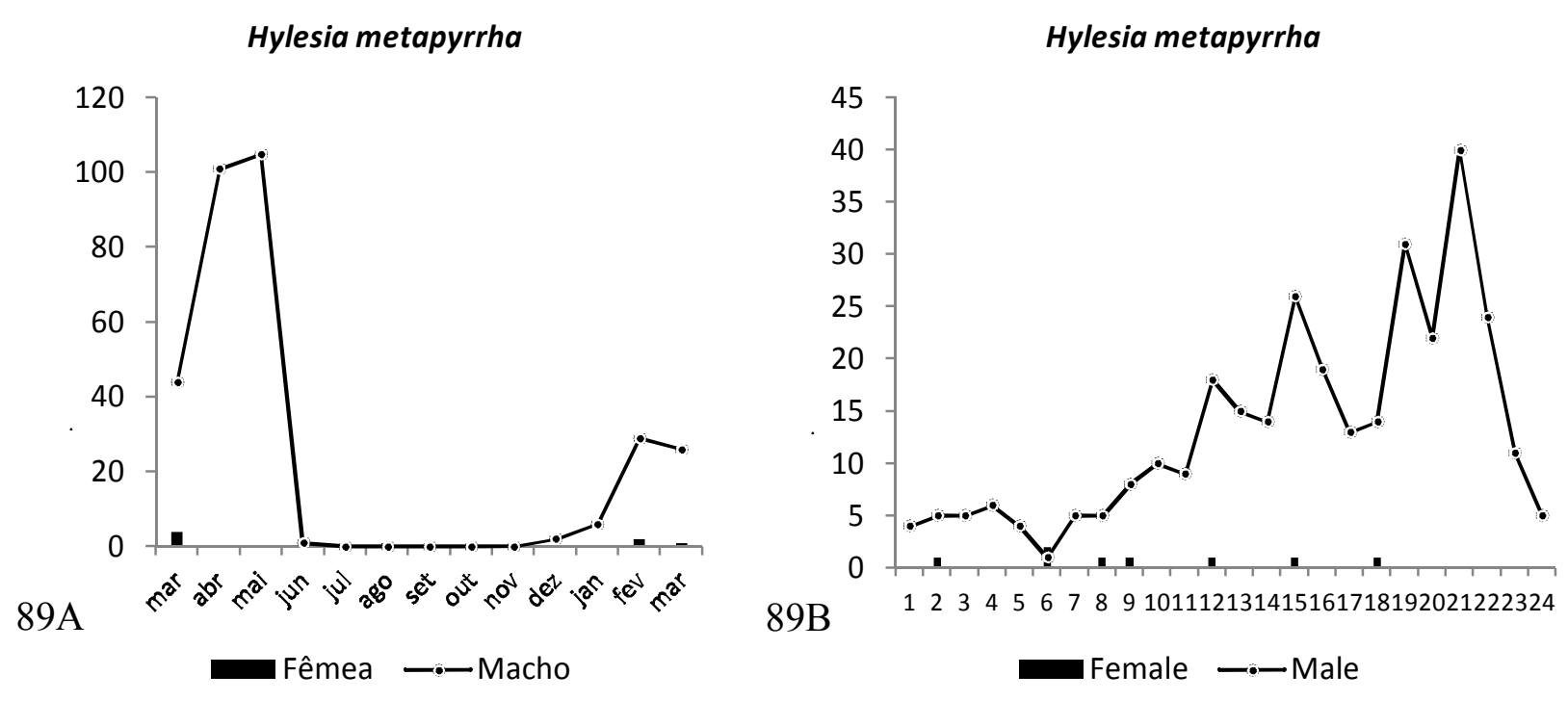


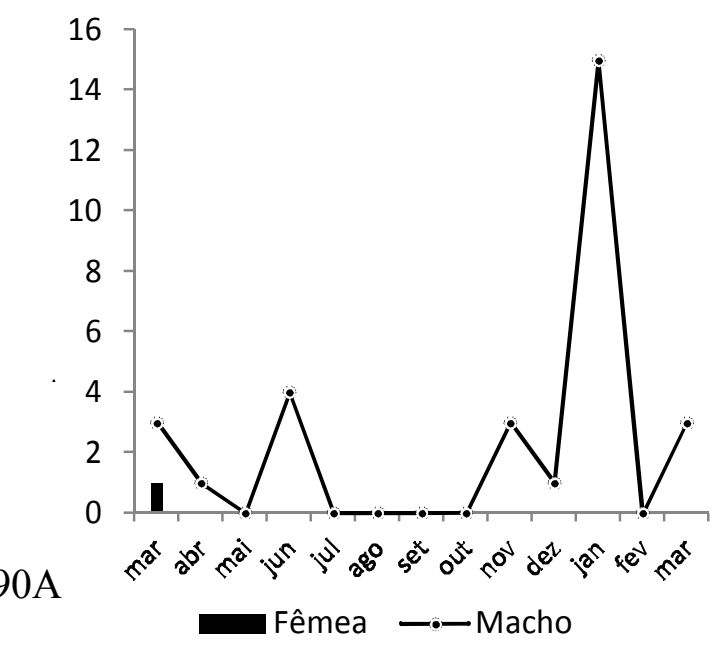

Hylesia scortina

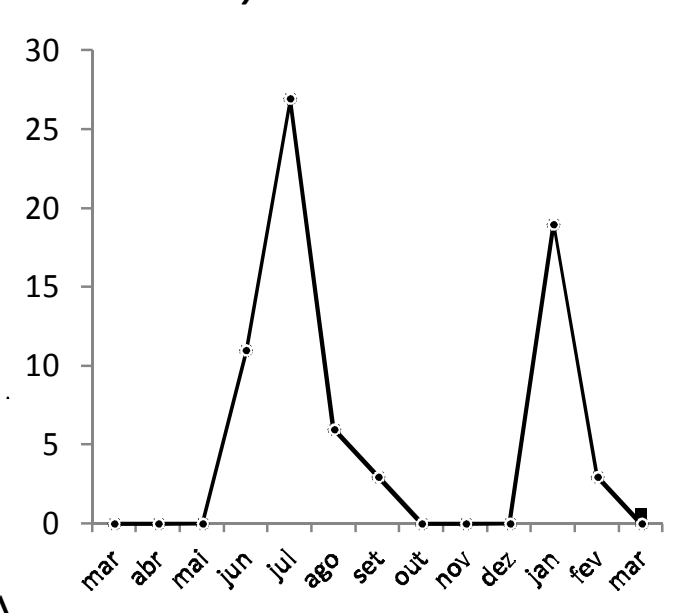

$91 \mathrm{~A}$

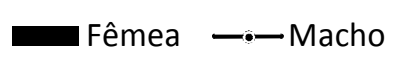

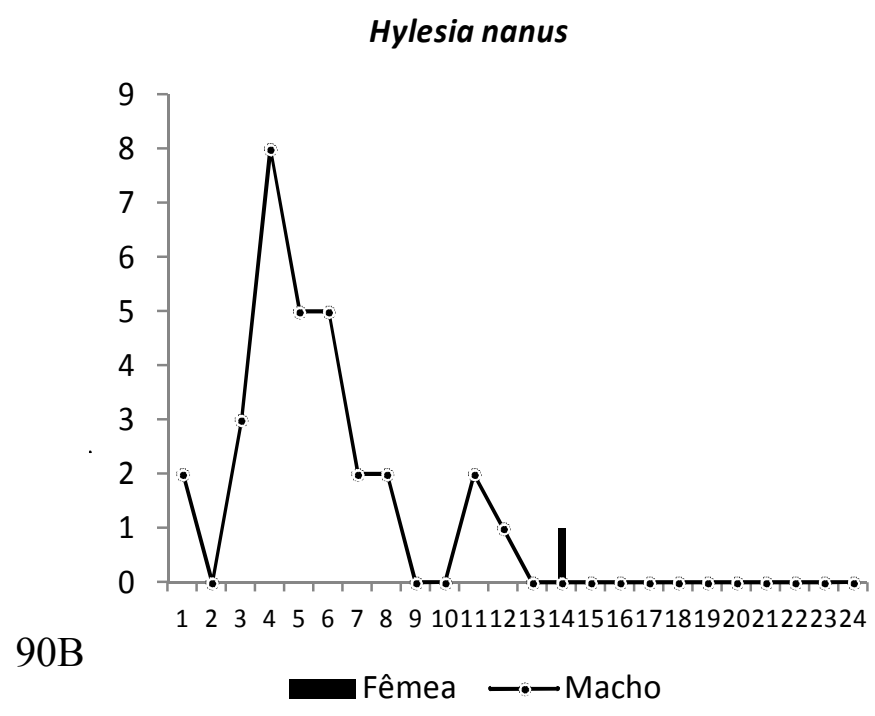

Hylesia scortina

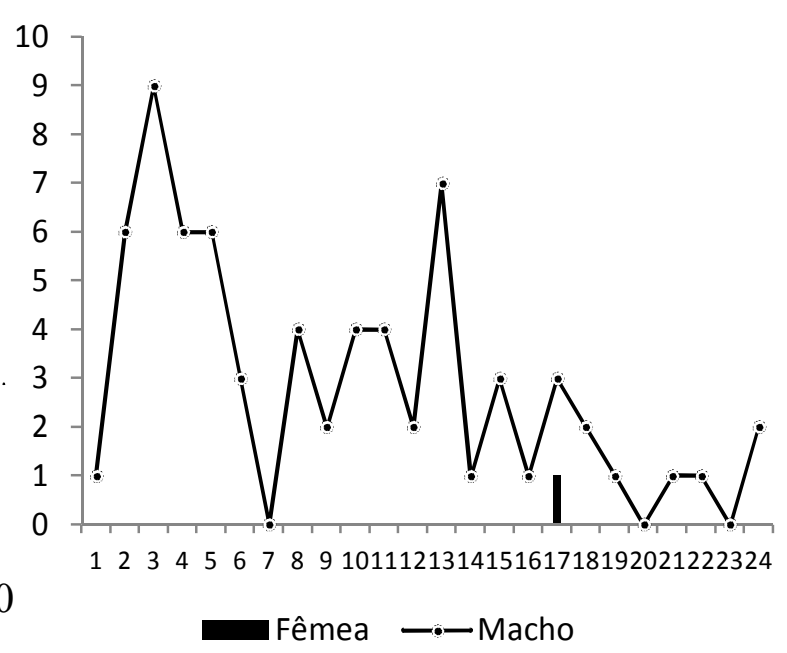

Figuras 89-91. Distribuição sazonal (A) e circadiana (B) de (89) Hylesia metapyrrha (Walker, 1855); (90) Hylesia nanus (Walker, 1855); e (91) Hylesia scortina Draudt, 1929, coletadas na Estação Biológica de Boraceia, Salesópolis, SP, Brasil entre março de 2012 e março de 2013.

Das seis espécies restantes, H. falcifera foi a que apresentou a distribuição anual mais concentrada, com alguns poucos exemplares machos sendo coletados no inverno e um relevante pico em janeiro de 2013 , representado por $78,1 \%$ dos indivíduos. A população de $H$. paulex apresentou pico de distribuição sazonal semelhante, com grande abundância no verão, entre janeiro e fevereiro de 2013, quando todos os indivíduos foram coletados, sendo 91,9\% apenas em fevereiro. A flutuação circadiana da abundância dos machos de $H$. falcifera ficou concentrada no início da noite, especialmente entre $19: 30 \mathrm{~h}$ e $20: 30 \mathrm{~h}$, com $67,1 \%$ dos 
exemplares amostrados neste período. Distribuição igualmente semelhante a $H$. paulex em que $81,1 \%$ dos machos foram amostrados entre $20: 00 \mathrm{~h}$ e $22: 00 \mathrm{~h}$.

As espécies $H$. maurex, $H$. oratex e $H$. vindex são espécies cujos machos demonstraram atividade especialmente no início de outono de 2012 , entre março e abril, quando $95,4 \%$ dos exemplares de $H$. maurex foram capturados; para $H$. oratex e $H$. vindex este número é de $75,3 \%$ e $83 \%$, respectivamente. No entanto, todos os exemplares de $H$. oratex e $H$. vindex foram coletados em março e abril de 2012 e em março de 2013. Com relação aos ciclos circadianos das três espécies, todas apresentaram relativa distribuição ao longo da noite, mas com picos em determinados intervalos. Os machos de $H$. maurex foram predominantes no início da noite, entre $18: 30 \mathrm{~h}$ e $20: 00 \mathrm{~h}$, com $62,8 \%$ de representatividade, bem como os machos de $H$. vindex, $63,8 \%$ dos quais ocorreram entre $19: 30 \mathrm{~h}$ e $21: 00 \mathrm{~h}$, sendo que $53,2 \%$ ocorreram apenas entre 19:30h e 20:00h. Os representantes de $H$. oratex demonstraram o padrão oposto, com $66,5 \%$ dos indivíduos amostrados no final da noite, entre 04:00h e 06:00h da manhã e com alguma representação nos intervalos iniciais da noite, especialmente entre 18:30h e 21:00h (20,3\%).

A distribuição circadiana de $H$. munonia foi a mais disjunta de todos os Saturniidae amostrados no presente estudo, com exemplares machos representados em todos os 24 intervalos de tempo e alguns grupos de intervalos com abundâncias relativamente altas. Sazonalmente a população de H. munonia teve sua distribuição concentrada no outono de 2012 e início de inverno, entre março e junho de 2012 , sendo que $93,9 \%$ dos exemplares ocorreram entre abril e maio.

Dentre as morfoespécies de Hylesia, Hylesia sp.1 demonstrou padrão de distribuição sazonal e circadiano muito semelhante ao observado para $H$. maurex. $\mathrm{O}$ grupo de indivíduos não morfoespeciado, Hylesia sp, o qual 78,4\% (29 de 37) dos exemplares são fềmeas, apresentou distribuição sazonal de fêmeas acumulada em abril de 2012 e grande número de fêmeas coletadas após os 12 primeiros intervalos entre 00:00 e 06:00h da manhã. 
Hylesia falcifera

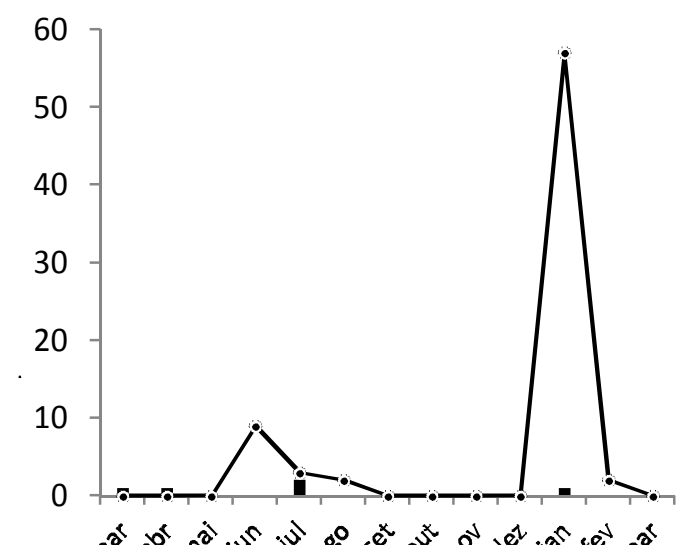

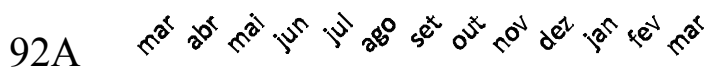

Fêmea —Macho

Hylesia maurex

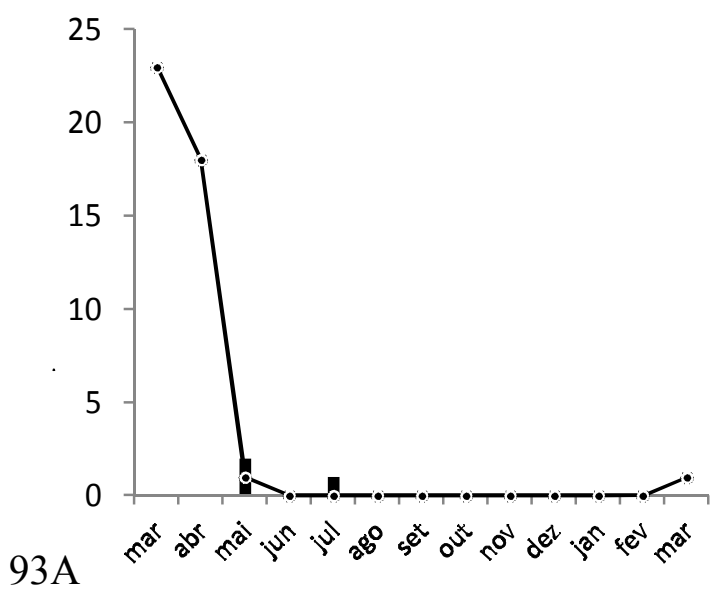

Fêmea —-Macho

Hylesia munonia

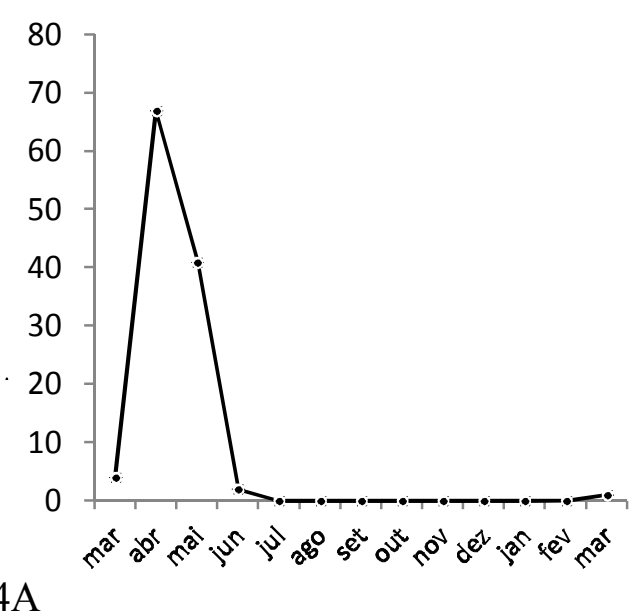

_- Male
Hylesia falcifera

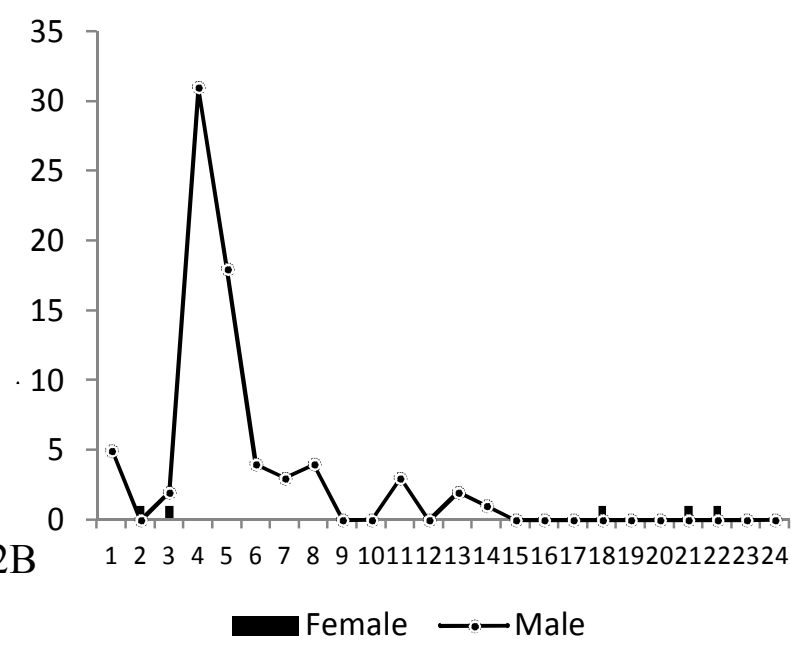

Hylesia maurex

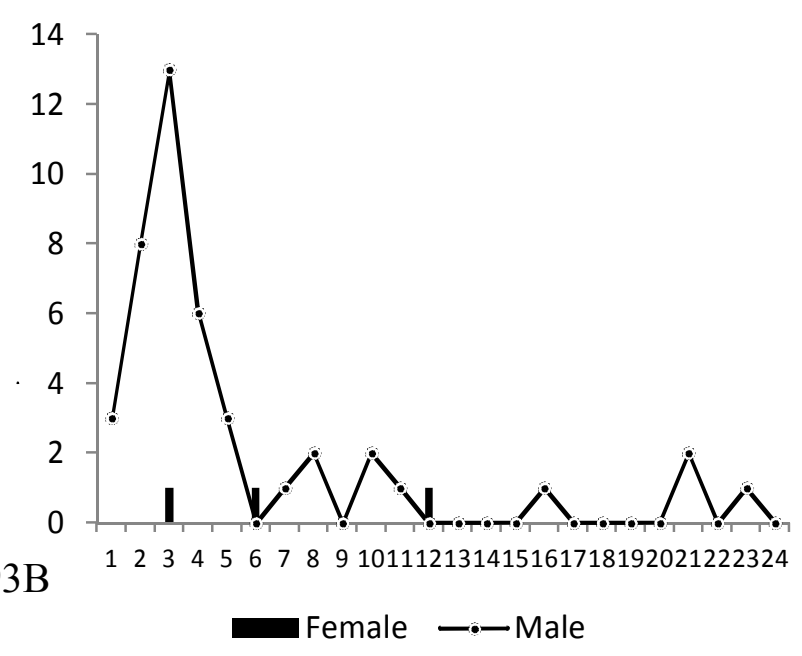

Hylesia munonia

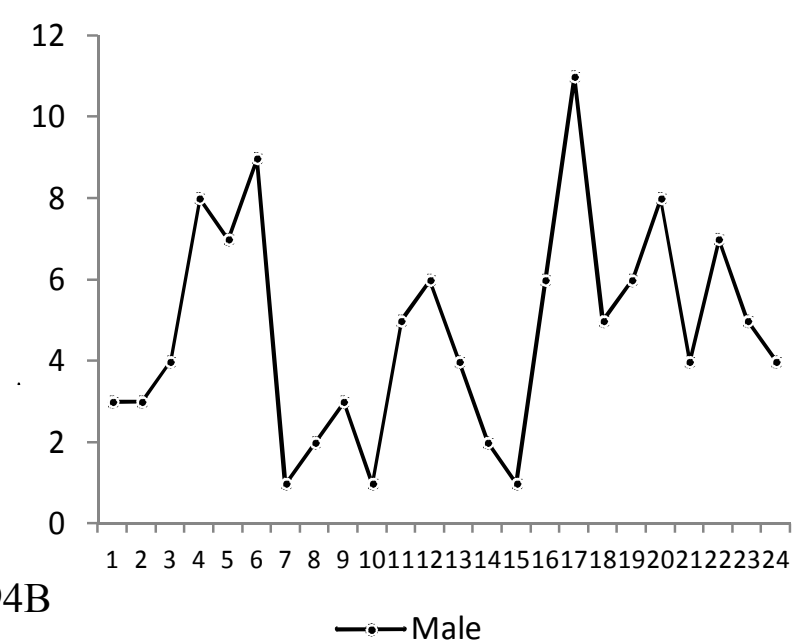


Hylesia oratex

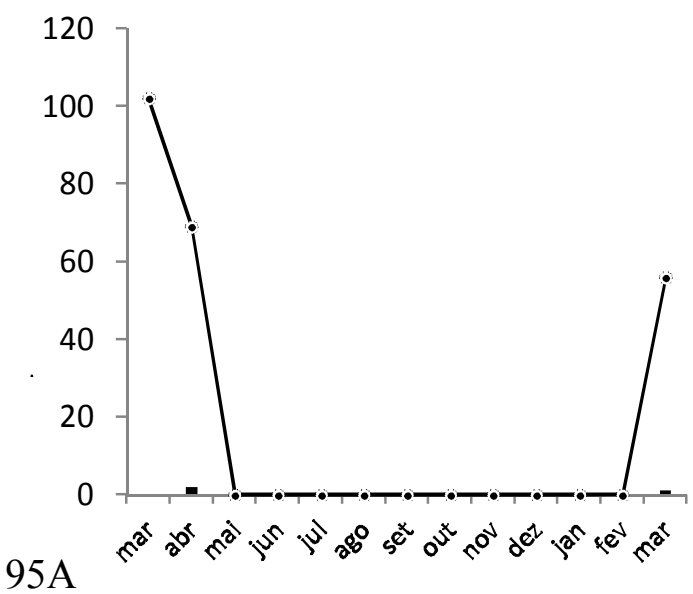

Fêmea —- Macho

Hylesia paulex

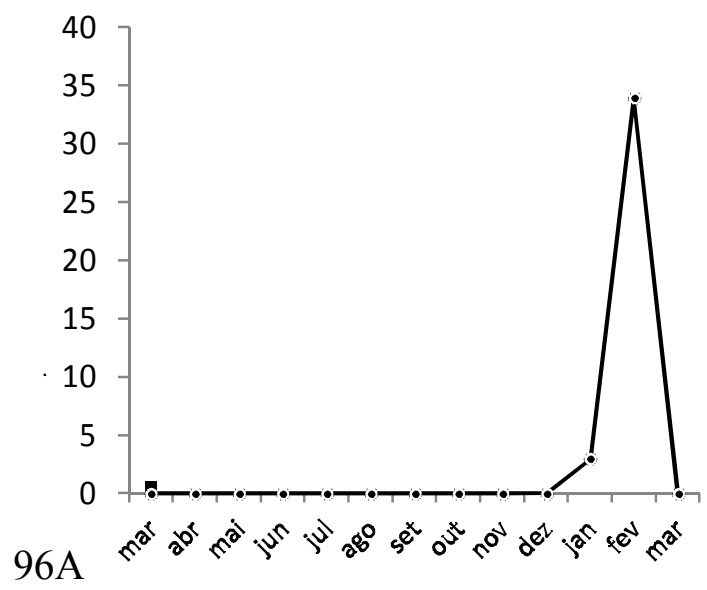

Fêmea - - Macho

\section{Hylesia vindex}

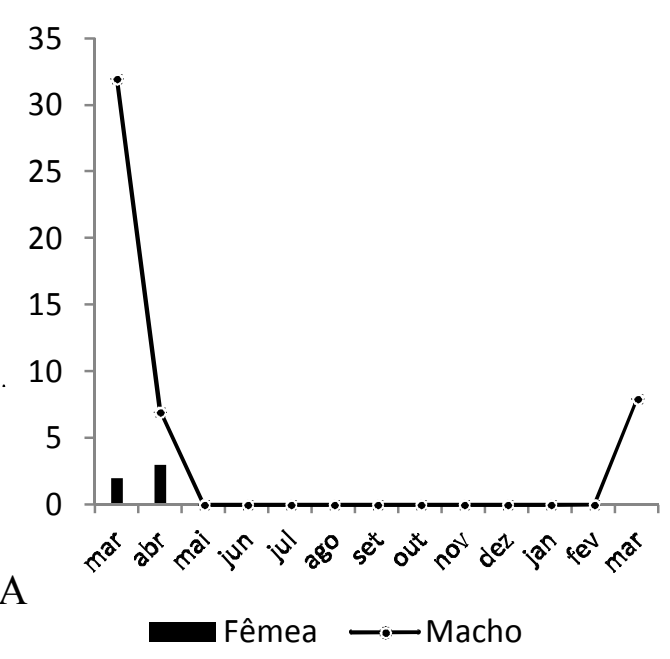

Hylesia oratex

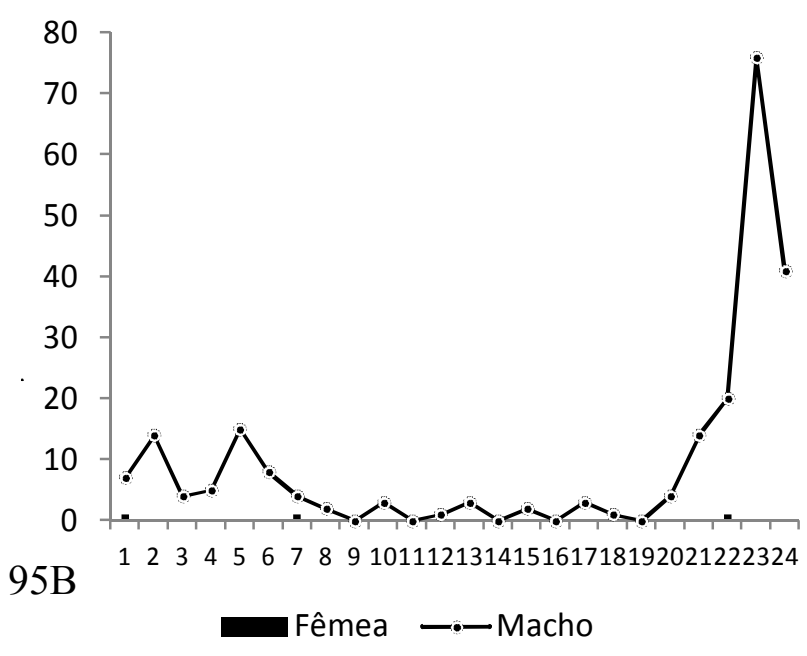

Hylesia paulex

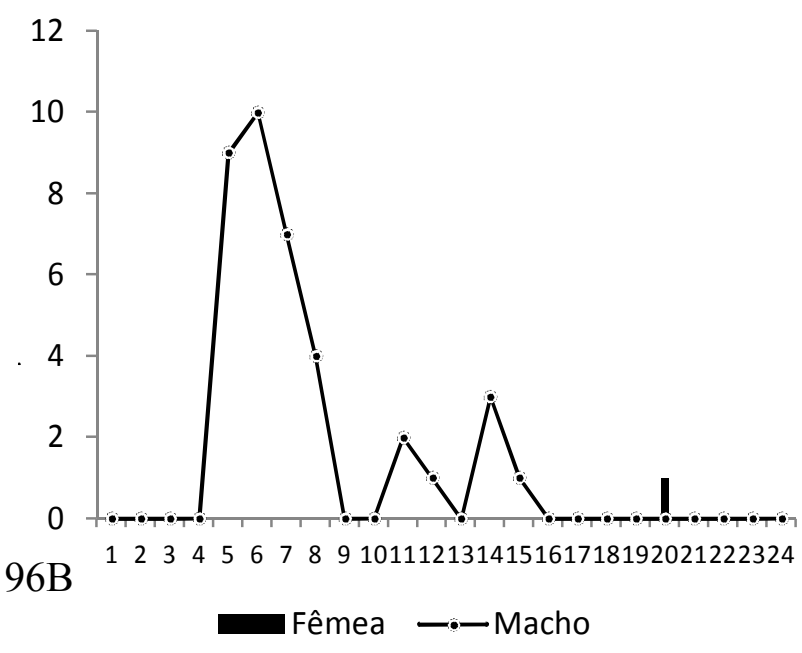

Hylesia vindex

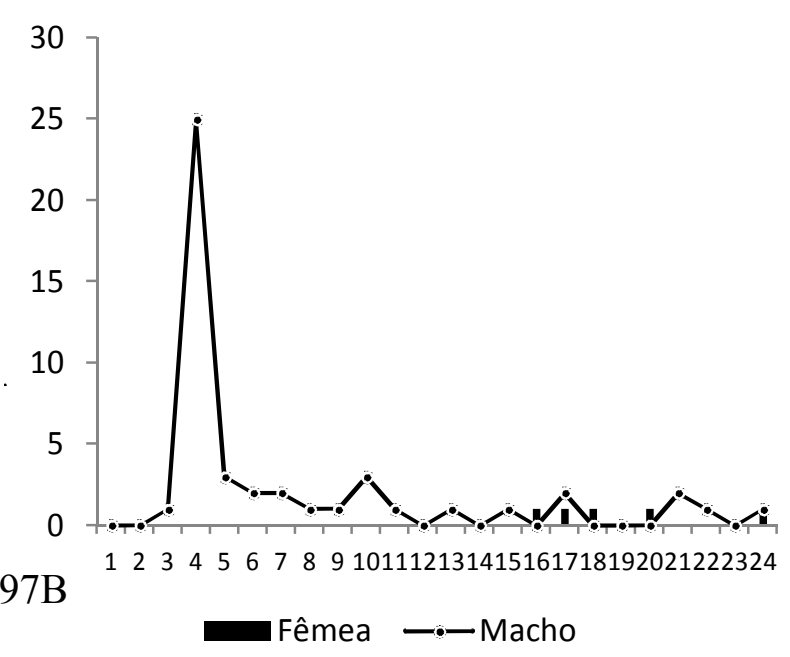


Hylesia sp.1

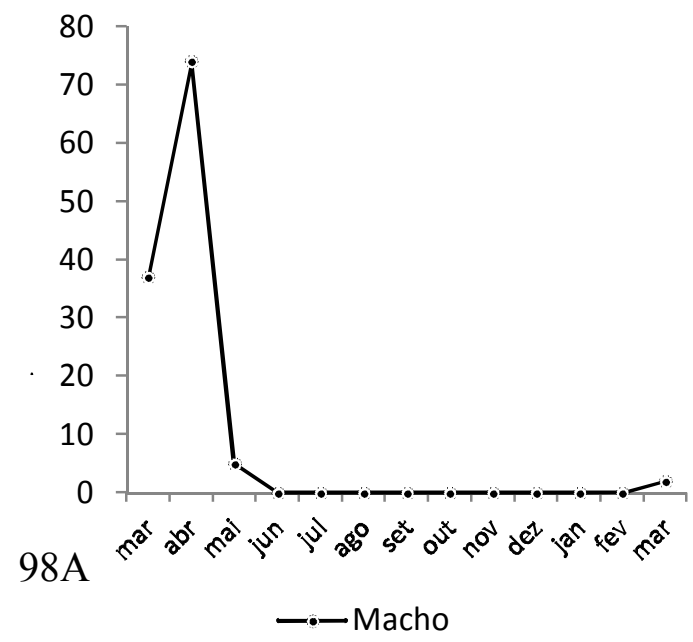

Hylesia sp.

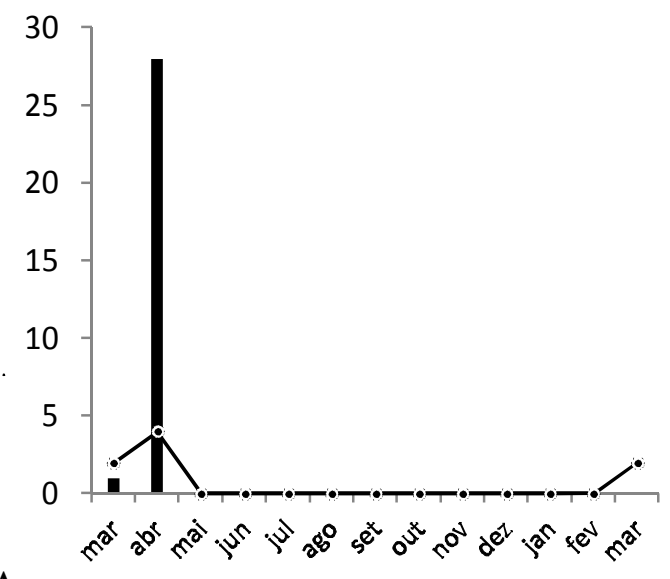

99A
Hylesia sp.1

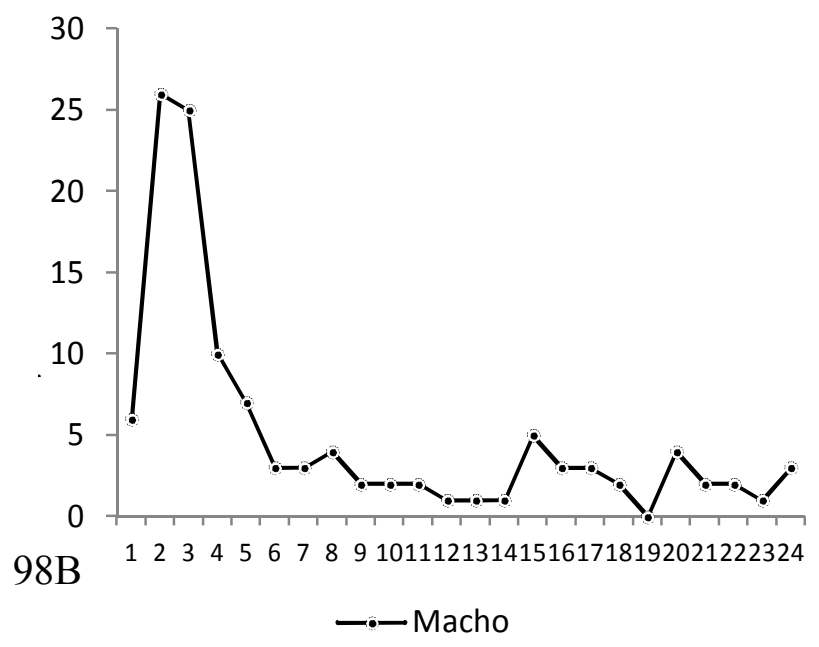

Hylesia sp.

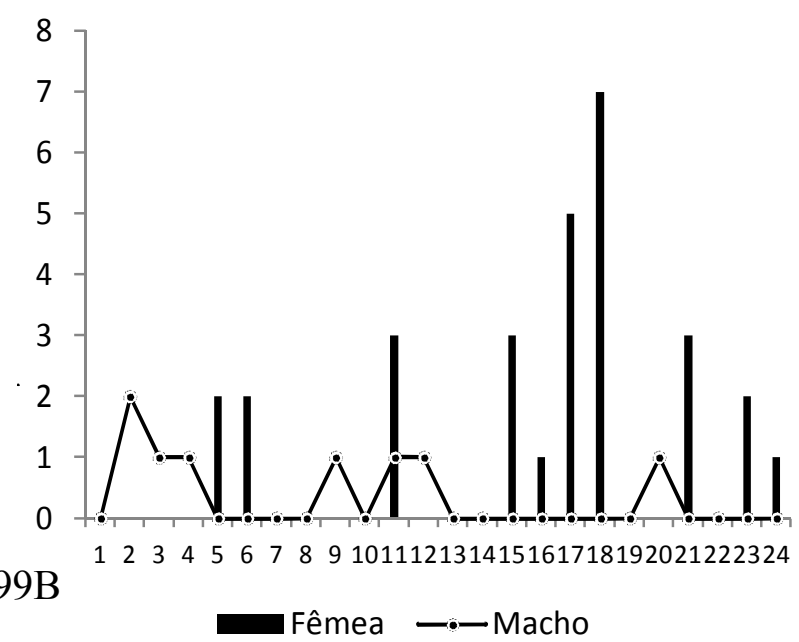

Figuras 92-99. Distribuição sazonal (A) e circadiana (B) de (92) Hylesia falcifera (Hübner, 1825); (93) Hylesia maurex Draudt, 1929; (94) Hylesia munonia Schaus, 1927; (95) Hylesia oratex Dyar, 1913; (96) Hylesia paulex Dognin, 1922; (97) Hylesia vindex Dyar, 1913; (98) Hylesia sp.1; e (99) Hylesia sp., coletadas na Estação Biológica de Boraceia, Salesópolis, SP, Brasil entre março de 2012 e março de 2013.

Pseudautomeris Lemaire, 1967 (Figs. 100-101)

Das três espécies de Pseudautomeris coletadas, duas ocorreram em expressiva abundância, $P$. coronis (51 indivíduos) e P. hubneri (29). Os machos de P. coronis ocorreram agregadamente no início do outono, entre março e abril de 2012 com um único exemplar coletado em março do ano seguinte. Já os machos de P. hubneri ocorreram em sete dos 13 meses amostrados, com três picos esparsos no inverno, primavera de 2012 e verão de 2013 . O ciclo noturno das duas espécies foram semelhantes, com as mais altas abundâncias no final da 
noite, entre $03: 00$ h e $04: 30$ h para $P$. coronis e entre $01: 30$ h e $04: 30$ h para $P$. hubneri, quando foram amostrados $60,9 \%$ e $88,5 \%$ dos exemplares, respectivamente.

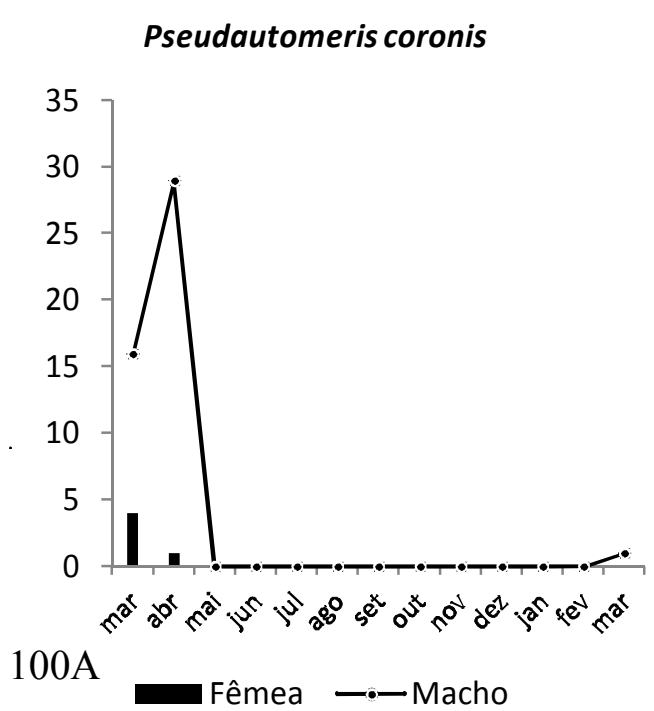

Pseudautomeris hubneri

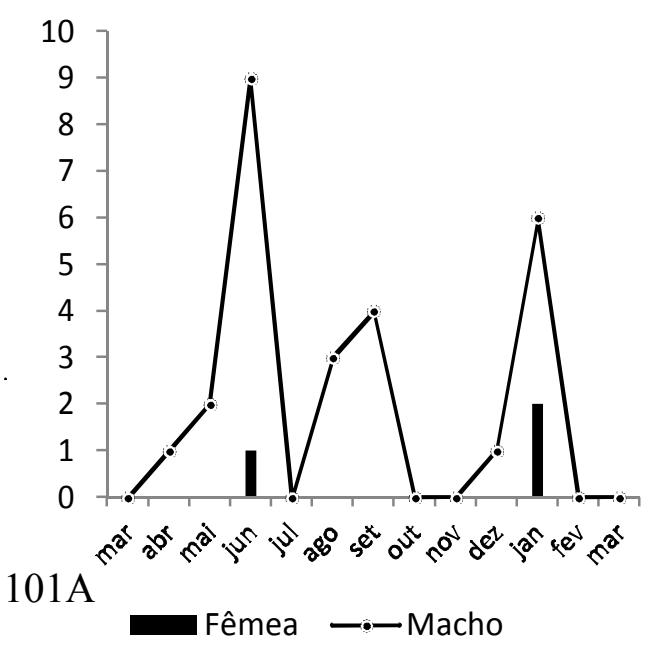

Pseudautomeris coronis

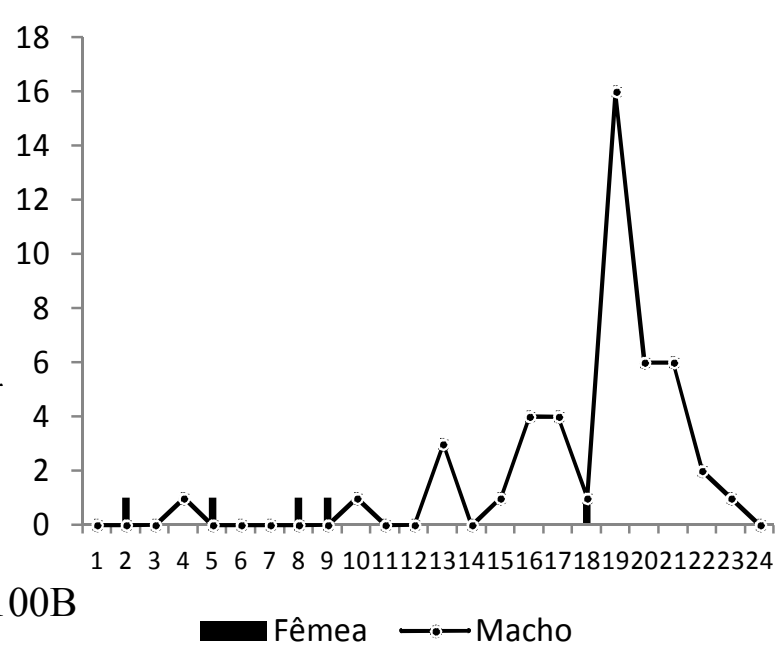

Pseudautomeris hubneri

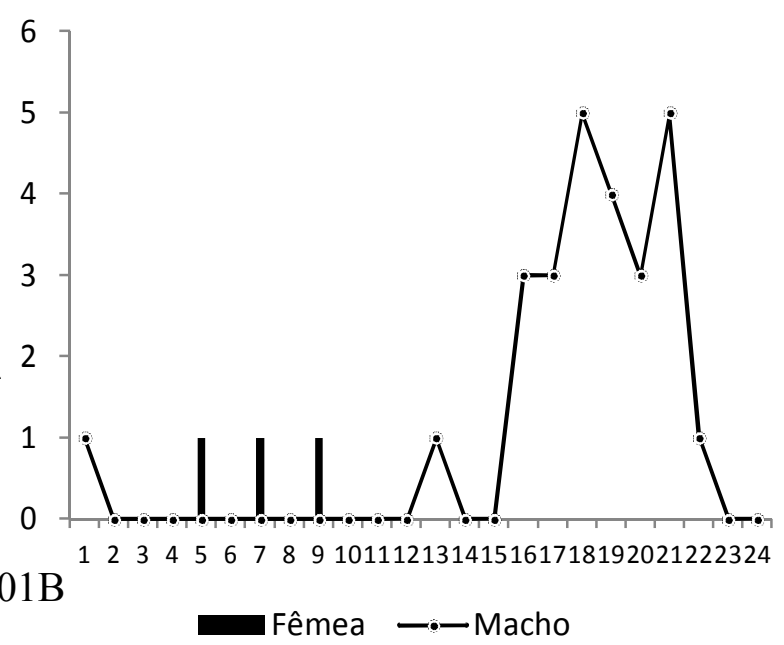

Figuras 100-101. Distribuição sazonal (A) e circadiana (B) de (100) Pseudautomeris coronis (Schaus, 1913); e (101) Pseudautomeris hubneri (Boisduval, 1875), coletadas na Estação Biológica de Boraceia, Salesópolis, SP, Brasil entre março de 2012 e março de 2013.

\section{Outras espécies (Figs. 102-105)}

Algumas outras espécies dos gêneros Dirphiopsis Bouvier, 1928, Lonomia e Periga Walker, 1855 foram escolhidas para análise de sazonalidade e ciclo circadiano. Das cinco espécies de Dirphiopsis duas foram analisadas, D. epiolina com 62 exemplares (59 machos e 3 fêmeas) e $D$. picturata com 23 exemplares (18 machos e 5 fềmeas). A distribuição sazonal de 
abundância dos machos de ambas as espécies foi semelhante estando concentrada no inverno, o pico de D. epiolina foi em julho de 2012 com 57,6\% dos exemplares ocorrendo neste mês e 93,2\% ocorrendo entre julho e agosto; o pico de D. picturata ocorreu em agosto com 55,6\% dos exemplares coletados e $88,9 \%$ nos entre junho e setembro. A atividade da população dos machos de $D$. picturata foi caracterizada pelo voo pontual nos três primeiros intervalos de tempo, entre $18: 00 \mathrm{~h}$ e $19: 30 \mathrm{~h}$, sendo que $66,7 \%$ dos machos ocorreram na primeira meia hora da noite, enquanto que cinco fềmeas foram coletadas em intervalos distantes entre si, sendo a última amostrada entre 04:30h e 05:00h. Os machos de D. epiolina apresentaram um espectro maior de distribuição circadiana com alguns exemplares ativos no início da noite e a maioria concentrada após 22:30h com as mais altas abundâncias entre 02:30h e 03:30h.

A única espécie do gênero Lonomia registrada para EBB é L. obliqua, espécie com maior representatividade de fêmeas entre todos os Saturniidae coletados durante o presente estudo, foram 82 machos e 13 fềmeas. A distribuição sazonal das fêmeas ficou diretamente associada à dos machos e a circadiana ficou relativamente adiantada ao pico de abundância dos machos. As fêmeas ocorreram prioritariamente antes das 23:00h e os machos $(63,4 \%)$ após 01:30h. Os dois mais altos picos de abundância dos machos foram em março de 2012 e de 2013, os quais juntos contribuíram com $64,6 \%$ da abundância.

Do gênero Periga, a espécie P. circumstans foi muito pouco representada e, portanto não foi analisada, a outra espécie amostrada, $P$. falcata, apresentou dois picos de abundância de machos durante o ano, entre o outono e início do inverno, e no final da primavera. Ao longo da noite, os machos apresentaram atividade disjunta, não tendo sido coletados em oito dos 24 intervalos. 
Dirphiopsis epiolina

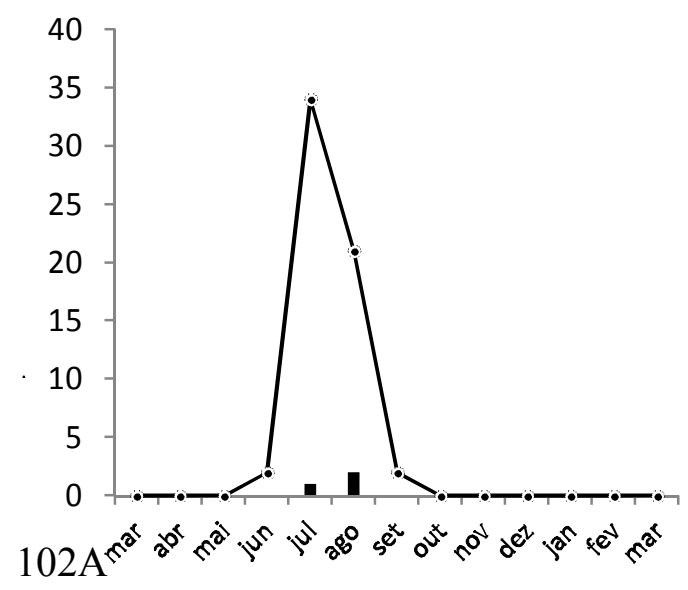

Fêmea —- Macho

Dirphiopsis picturata

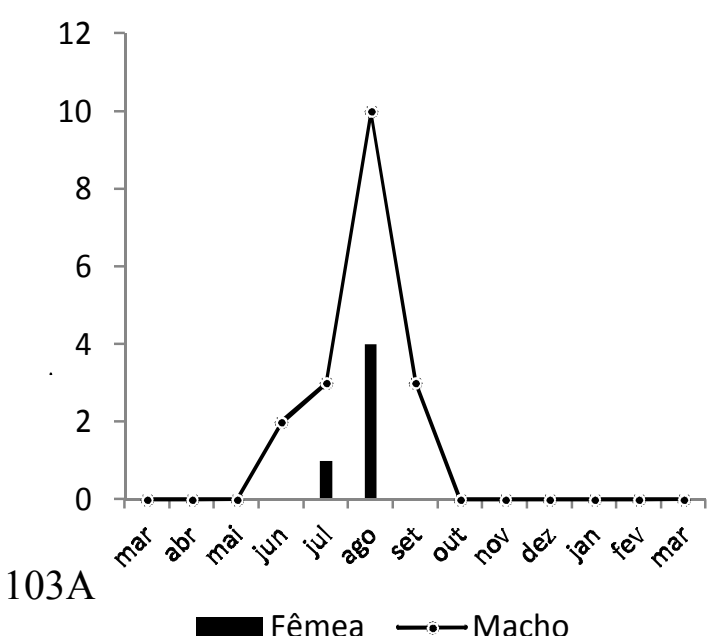

Lonomia obliqua

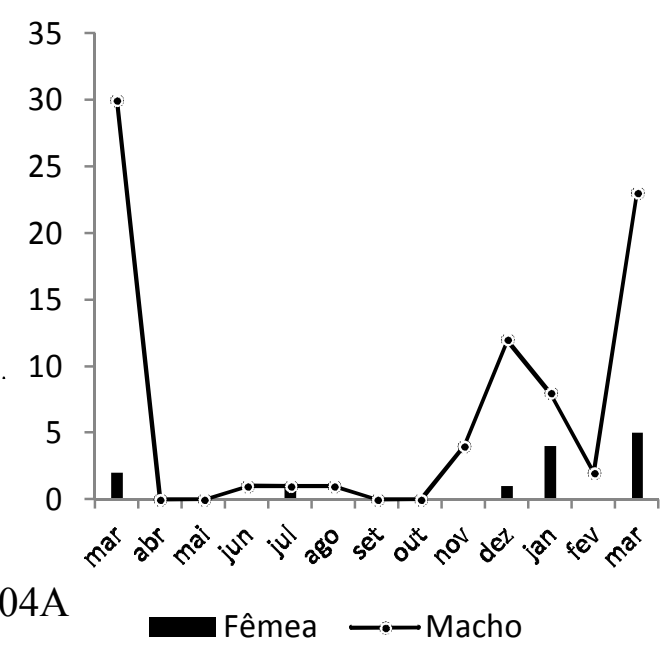

Dirphiopsis epiolina

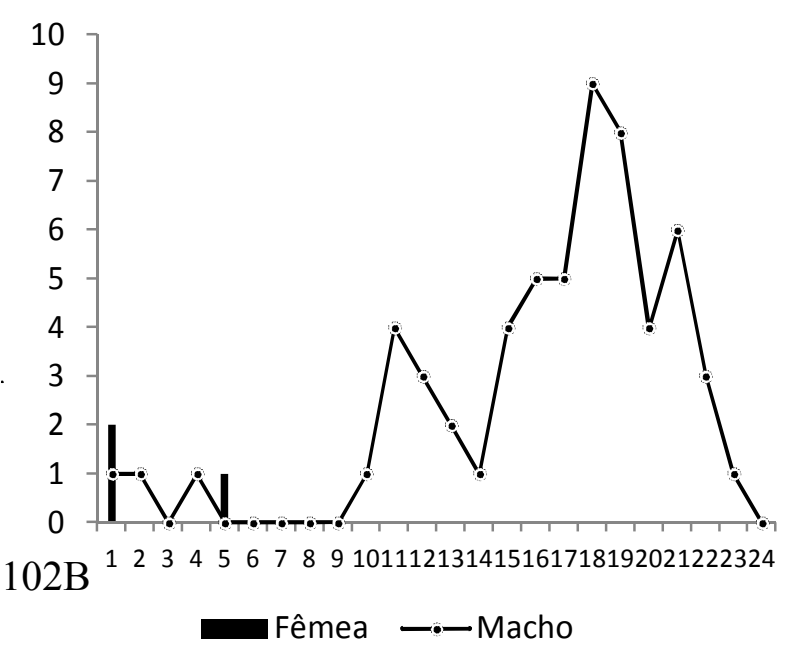

Dirphiopsis picturata

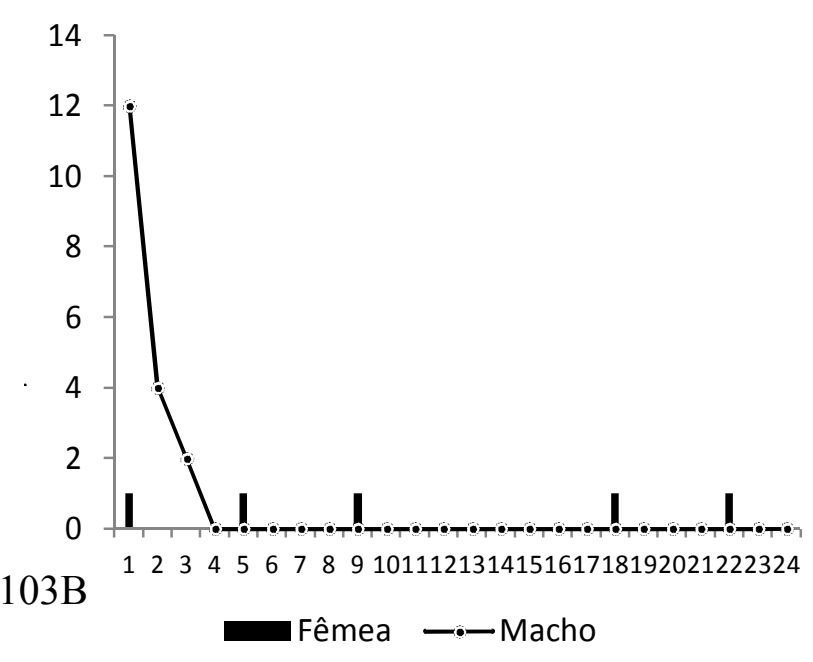

Lonomia obliqua

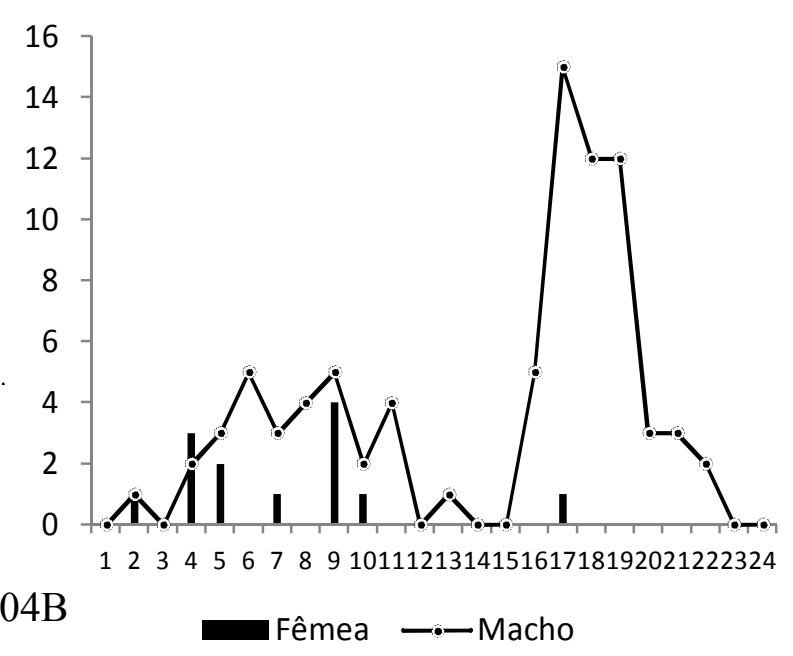



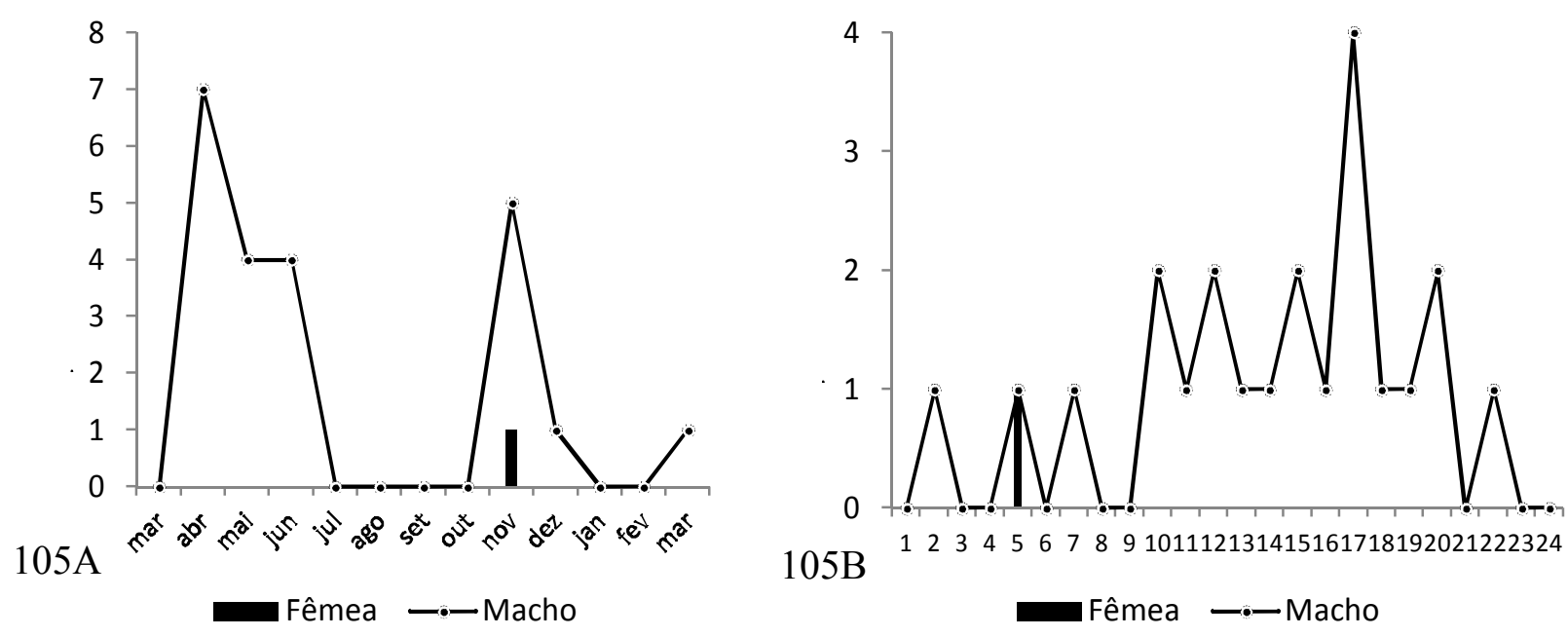

Figuras 102-105. Distribuição sazonal (A) e circadiana (B) de (102) Dirphiopsis epiolina (R. Felder \& Rogenhofer, 1874); (103) Dirphiopsis picturata (Schaus, 1913); (104) Lonomia obliqua Walker, 1855; e (105) Periga falcata Walker, 1855, coletadas na Estação Biológica de Boraceia, Salesópolis, SP, Brasil entre março de 2012 e março de 2013. 


\subsubsection{Oxyteninae}

Duas espécies de Oxyteninae foram registradas durante as amostragens, Oxytenis bicornis e Oxytenis modestia (Cramer, 1780). A primeira ocorreu praticamente o ano todo, não sendo registrada apenas no mês de abril de 2012; apresentou pico de atividade na primavera, entre setembro e novembro de 2012, quando $52 \%$ dos exemplares da espécie foram coletados e 36\% dos exemplares da subfamília, sendo todos desta espécie (Fig. 106). Já O. modestia apresentou distribuição sazonal mais restrita, tendo 59,3\% dos exemplares da espécie coletados apenas em fevereiro de 2013, influenciando diretamente no pico de distribuição da subfamília, quando entre janeiro e março de 2013 37,1\% dos exemplares foram coletados. A atividade circadiana seguiu a mesma tendência, com $O$. modestia apresentando atividade mais restrita ao longo da noite, $85,2 \%$ dos exemplares da espécie foram coletados entre 20:00h e 21:30h, representando $25,8 \%$ dos exemplares da subfamília, os quais, no mesmo período contribuíram com 29,2\% da abundância. Oxytenis bicornis apresentou o pico de atividade entre 22:00h e 00:30h, com 75,8\% da abundância da espécie e significando 52,8\% dos exemplares da subfamília (Fig. 107).

Oxytenis

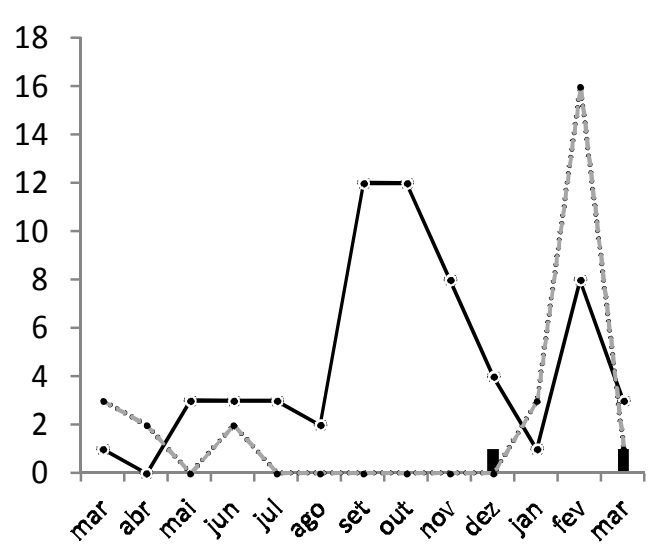

106

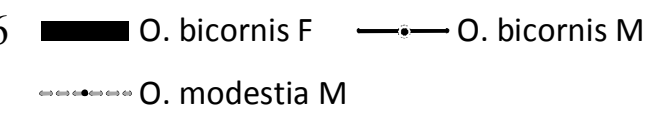

Oxytenis

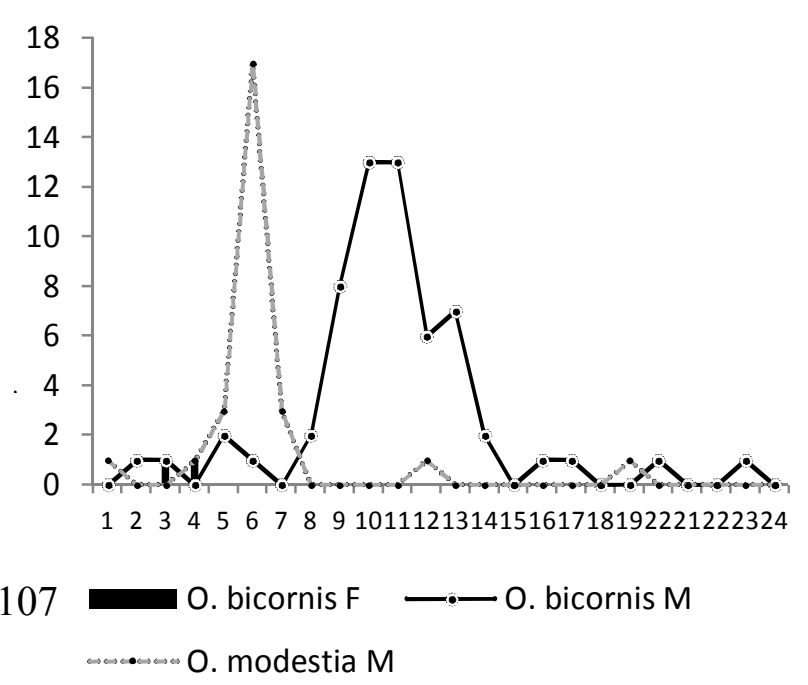

Figuras 106-107. Distribuição sazonal (106) e circadiana (107) de Oxytenis bicornis Jordan, 1924 e Oxytensi modestia (Cramer, 1780) (Oxyteninae), coletadas na Estação Biológica de Boraceia, Salesópolis, SP, Brasil entre março de 2012 e março de 2013. F = exemplares fêmeas; $M=$ exemplares machos. 


\subsubsection{Saturniinae}

A subfamília Saturniinae foi representada por oito espécies e dois gêneros, distribuídos em 143 exemplares. De um modo geral, as variações sazonais apresentaram relação mais alta do que nas outras subfamílias entre o número de espécies e a abundância de cada mês, exceto em julho de 2012, quando dos 11 exemplares coletados somente uma espécie esteve representada na amostra, e no pico da abundância, em setembro de 2012, quando foram coletados 32\% dos indivíduos (Fig. 108). A atividade circadiana dos exemplares estendeu-se por praticamente toda noite, não ocorrendo somente entre $04: 30 \mathrm{~h}$ e $05: 30 \mathrm{~h}$. No primeiro pico da noite, entre 19:00h e 21:00h, houve alta abundância (40,6\% do total), mas relativamente baixa representatividade de espécies; no segundo pico, entre $21: 30 \mathrm{~h}$ e $23: 30 \mathrm{~h}$ quando $30,1 \%$ dos indivíduos ocorreram, a representatividade das espécies foi maior (Fig. 109).
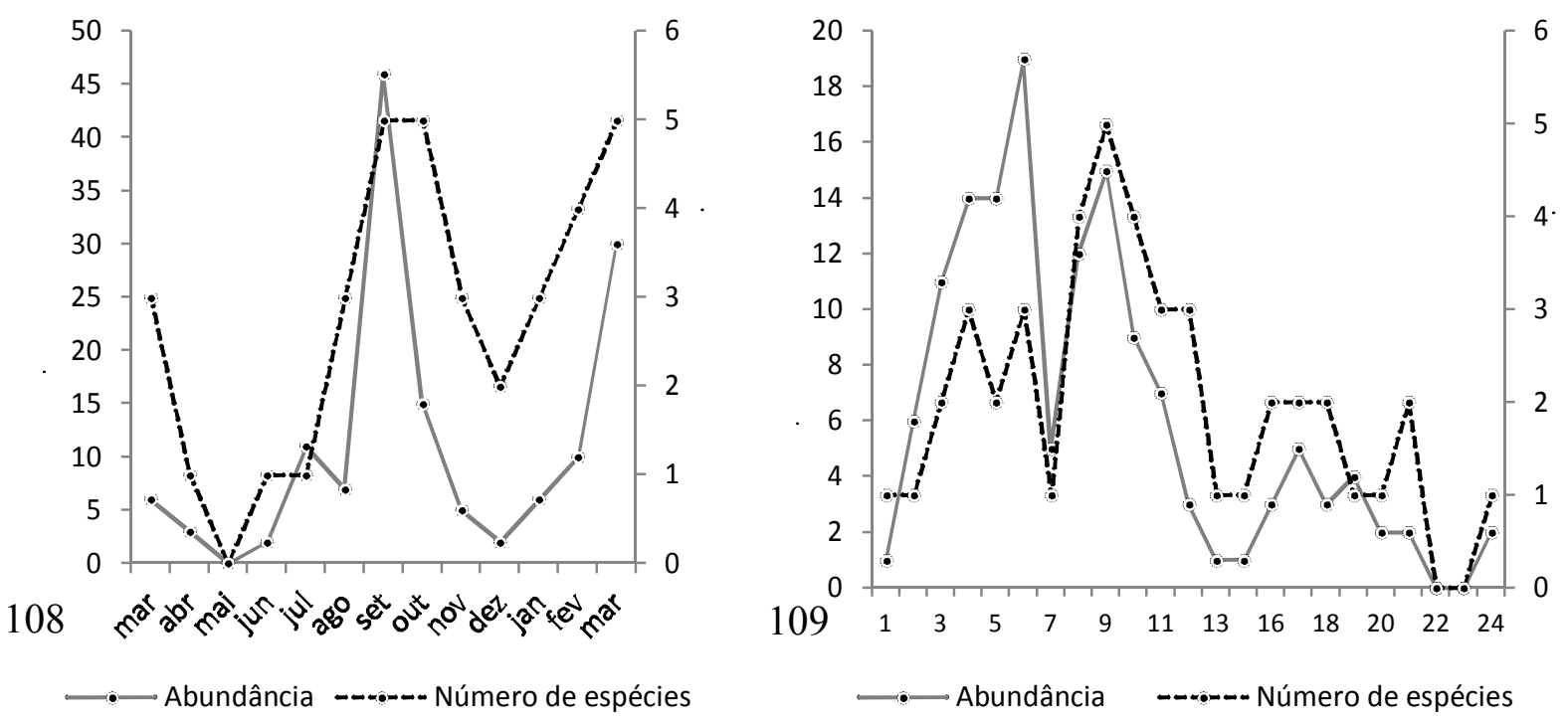

Figuras 108-109. Variação da abundância e do número de espécies de Saturniinae coletadas durante 13 meses na Estação Biológica de Boraceia, SP, Brasil.

Das oito espécies coletadas, quatro foram analisadas quanto às atividades sazonais e circadianas, duas do gênero Copaxa e duas do gênero Rothschildia. Os machos de Copaxa canella apresentaram ampla distribuição anual e não foram coletados apenas em março de 2013 (Fig. 110A). O pico de atividade foi em janeiro de 2013, quando 26,7\% dos machos foram coletados e dentre as oito fêmeas, seis foram coletadas em agosto. Copaxa decrescens Walker, 1855, por outro lado, demonstrou período de atividade mais restrita que $C$. canella, ocorrendo em cinco meses do ano com pico entre agosto e setembro, quando $77,3 \%$ dos machos foram coletados (Fig. 111A). A variação circadiana da abundância de ambas as espécies foi alternada. 
Copaxa canella demonstrou hábito de atividade no início da noite com nenhum macho coletado após $23: 00 \mathrm{~h}$, com $86,8 \%$ deles coletados entre 18:30h e 21:30h. As oito fêmeas coletadas ocorreram nos horários sincrônicos à atividade dos machos e nos intervalos de 01:30-02:00h e 02:30-03:00h. O hábito de atividade dos machos de $C$. decrescens tem início no final da atividade dos machos de $C$. canella e assim, o pico de atividade da primeira espécie é imediatamente posterior ao de $C$. canella, de modo que $90,9 \%$ dos machos de $C$. decrescens foram coletados entre 21:30h e 00:00h (Figs. 110B, 111B).

Ambas as espécies do gênero Rothschildia apresentaram distribuição sazonal com significativo sincronismo com picos bianuais em agosto de 2012 e entre janeiro e fevereiro de 2013 (Fig. 112A). Os machos de Rothschildia aurota (Cramer, 1775) ocorreram com 55\% de abundância em agosto e $25 \%$ entre janeiro e fevereiro, enquanto que os de Rothschildia hopfferi (C. \& R. Felder, 1859) ocorreram com 41,2\% de abundâncias em ambos os períodos mencionados (Fig. 113A). A distribuição circadiana dos machos de $R$. aurota teve ampla distribuição na segunda metade da noite, com 95\% deles capturados entre 00:30h e 04:30h. Já a distribuição dos machos de $R$. hopfferi foi oposta, com abundância dos indivíduos concentrada entre $18: 30 \mathrm{~h}$ e $21: 00 \mathrm{~h}(41,2 \%)$ e entre $23: 30 \mathrm{~h}$ e $00: 00 \mathrm{~h}(58,8 \%)$ (Figs. 112B, 113B).
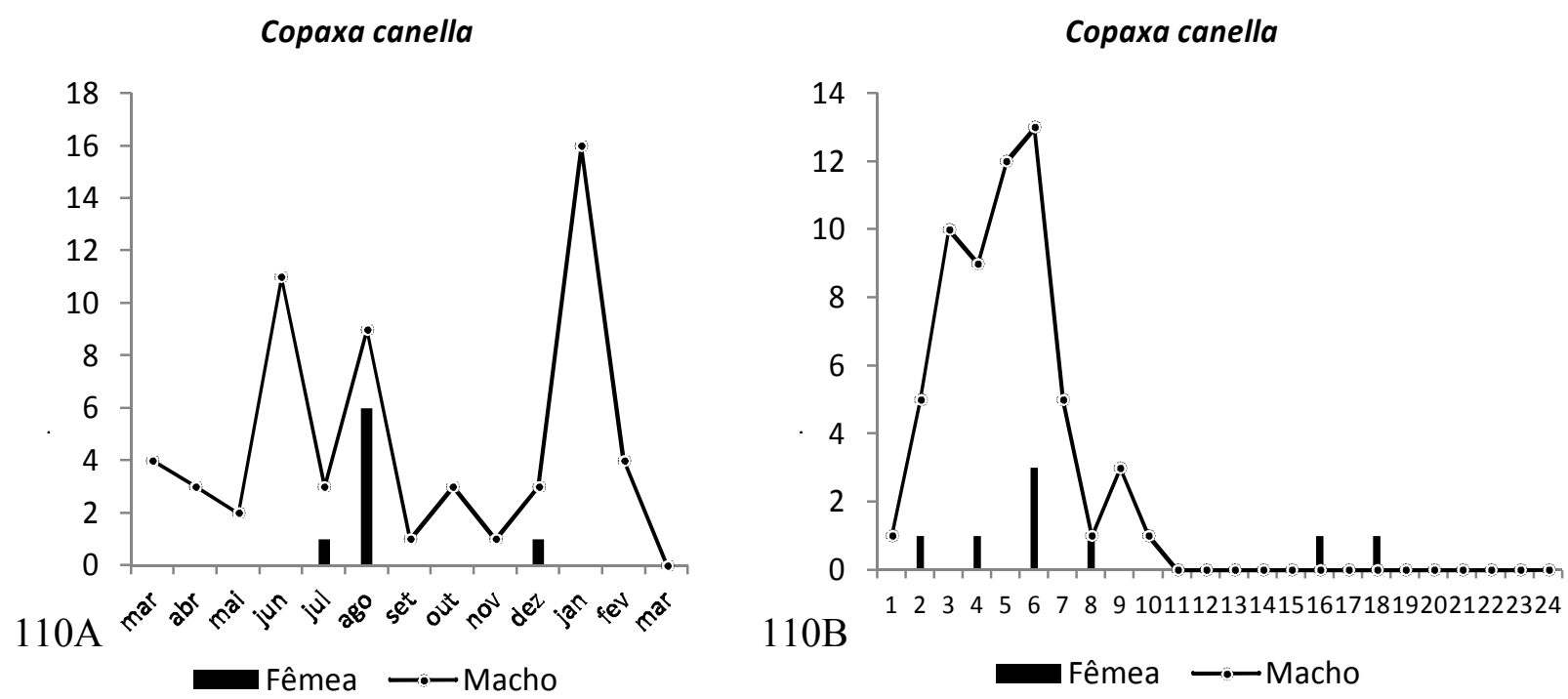
Copaxa decrescens

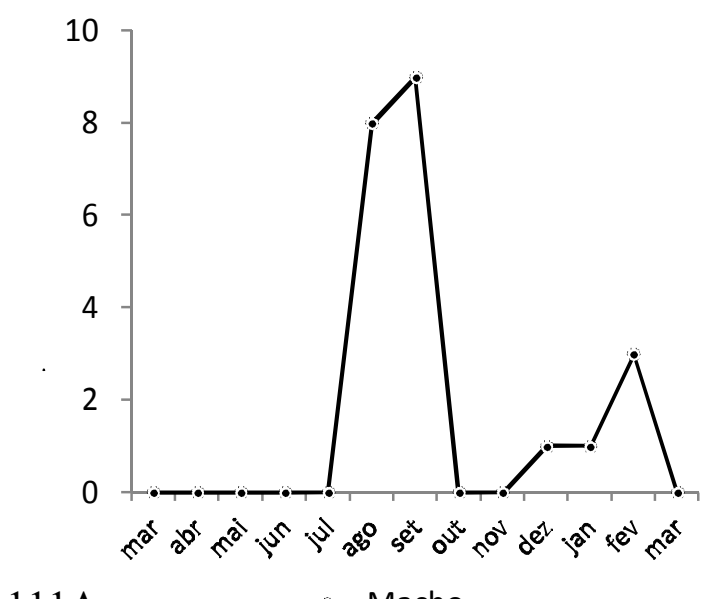

$111 \mathrm{~A}$

- - Macho

Rothschildia aurota

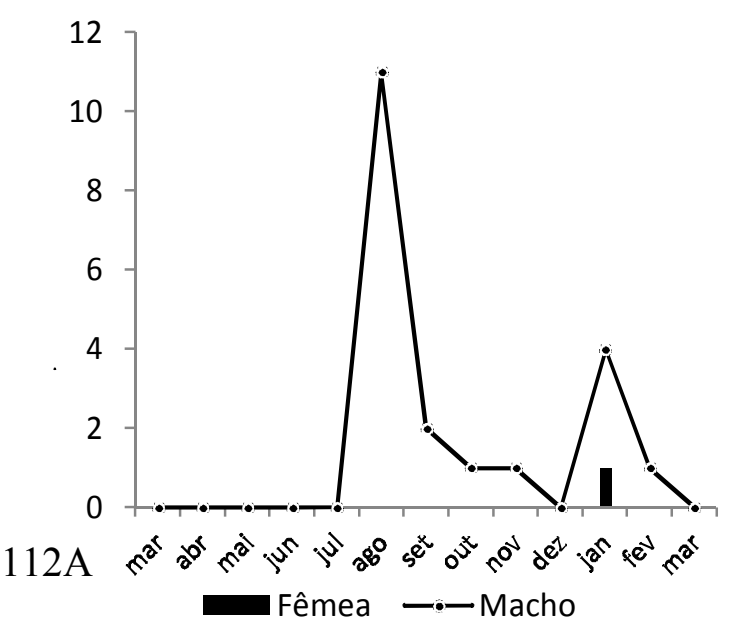

Rothschildia hopfferi

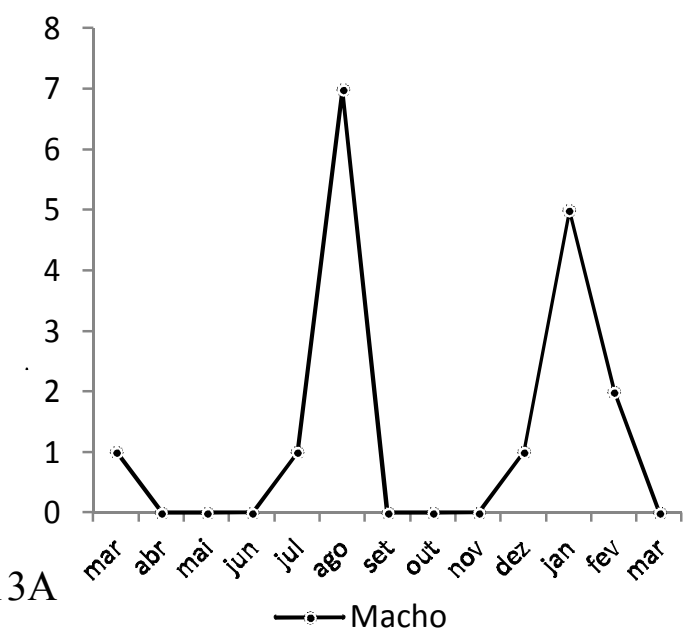

Copaxa decrescens

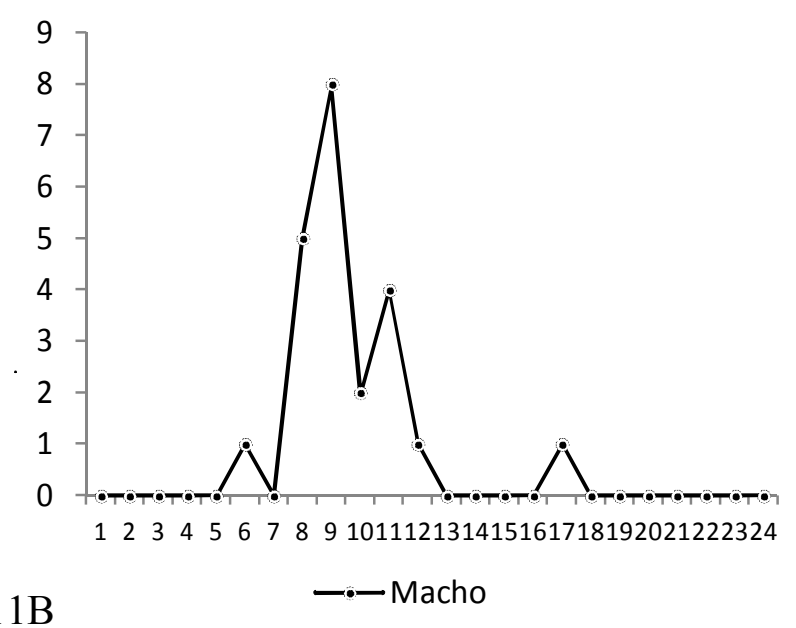

Rothschildia aurota

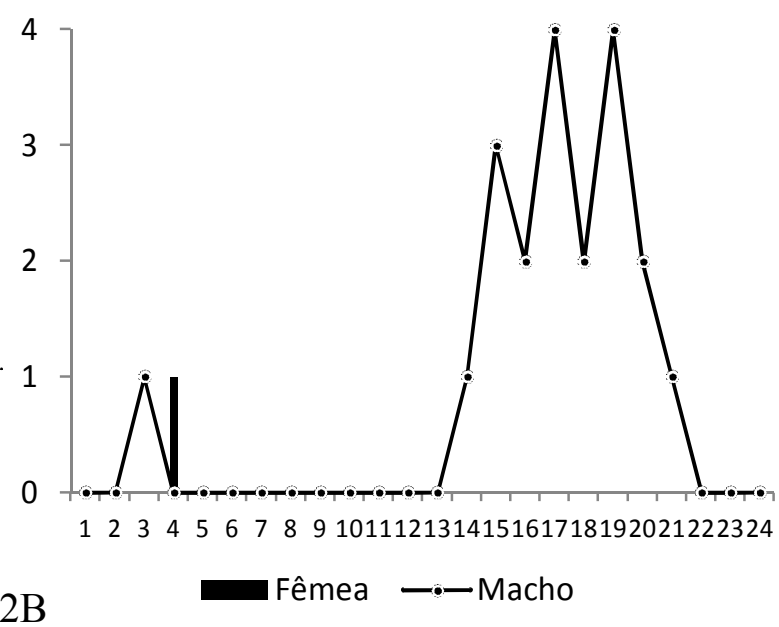

Rothschildia hopfferi

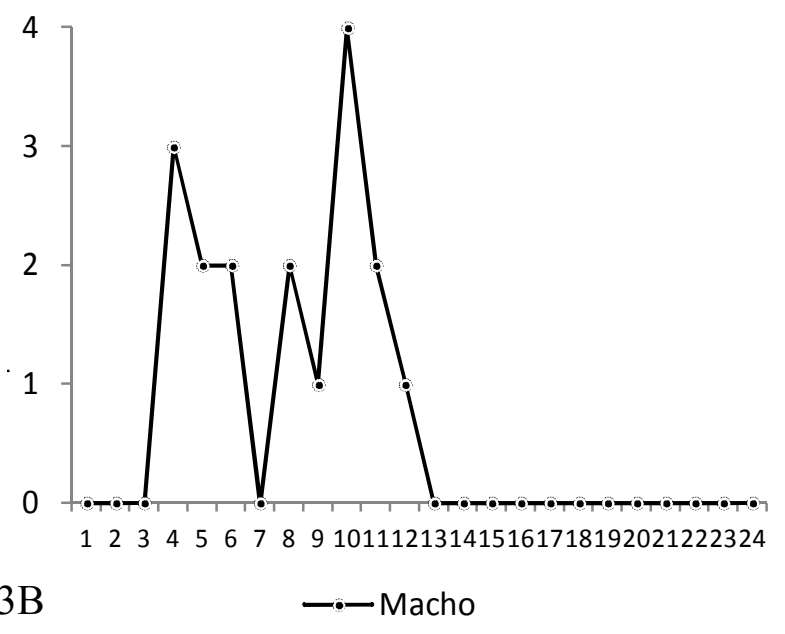

Figuras 110-113. Distribuição sazonal (A) e circadiana (B) de (110) Copaxa canella Walker, 1855; (111) Copaxa decrescens Walker, 1855; (112) Rothschildia aurota (Cramer, 1775); e (113) Rothschildia hopfferi (C. \& R. Felder, 1859) (Saturniinae), coletadas na Estação Biológica de Boraceia, Salesópolis, SP, Brasil entre março de 2012 e março de 2013. 
A alternância das espécies de Saturniinae ao longo da noite é nítida (Fig. 115), embora algumas espécies tenham sido representadas por poucos exemplares, algumas como C. canella, $C$. decrescens e mesmo $R$. aurota apresentaram momentos de atividade concentrados. A distribuição sazonal das espécies, entretanto, não apresentou alternância significativa, com seis das oito espécies coletadas entre setembro e outubro de 2012 (Fig. 114).

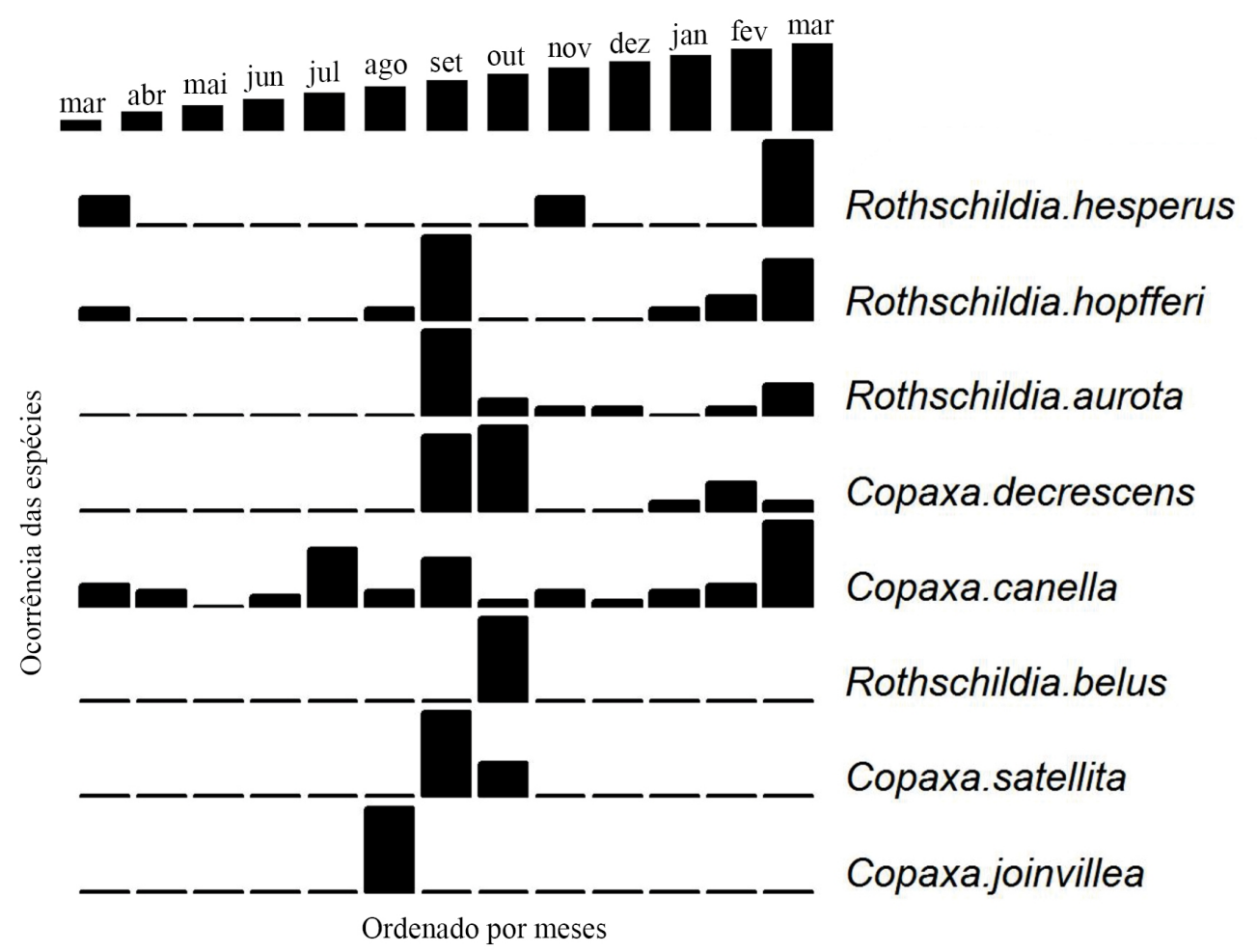

Figura 114. Ranque de abundância dos machos de cada uma das oito espécies de Saturniinae (143 exemplares) nos 13 meses (março a dezembro de 2012 e janeiro a março de 2013) de coleta, na Estação Biológica de Boraceia, SP, Brasil. 


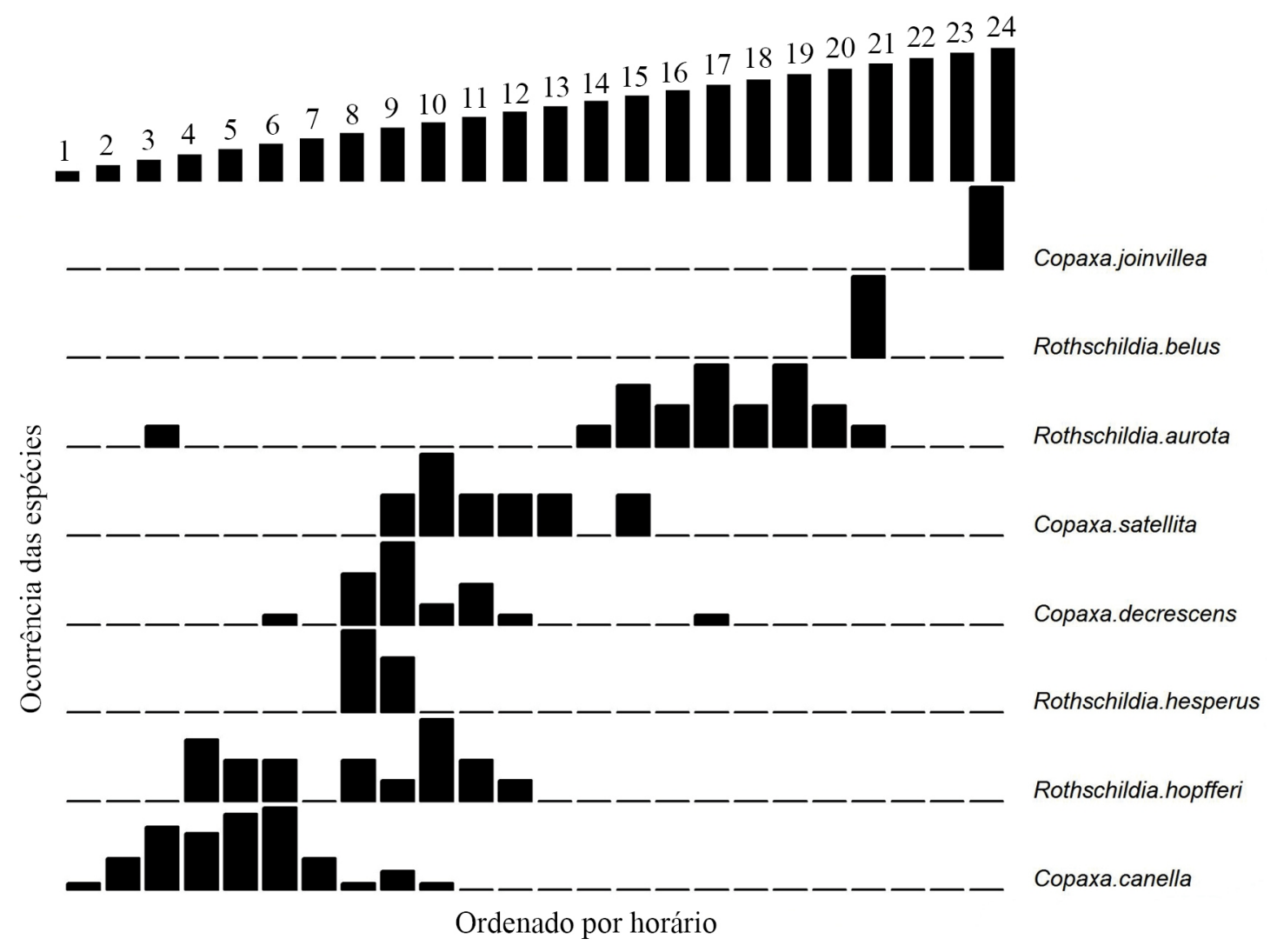

Figura 115. Ranque de abundância dos machos de cada uma das oito espécies de Saturniinae (143 exemplares) nos nos 13 meses (março a dezembro de 2012 e janeiro a março de 2013), sendo cada um dos 24 intervalos de tempo a soma dos seus respectivos intervalos nas 51 noites de coleta, na Estação Biológica de Boraceia, SP, Brasil.

Muitas são as razões que acometem os insetos à existência de atividade sazonal e à forma como esta atividade se apresenta. Para compreender de forma concisa a relação da atividade das espécies ao longo do ano é necessário conhecer a biologia de cada espécie avaliada e também compreender a relação entre o início, o pico e o fim da atividade sazonal de cada uma delas com variáveis ambientais, como temperatura, pluviosidade e umidade (Wolda 1988). Dessa forma, aprofundar o conhecimento dos dados gerados neste estudo requer grande levantamento bibliográfico do que se sabe sobre todas as espécies, e assim, tratar individualmente cada uma delas, no que concerne a distribuição sazonal de machos e fềmeas, longevidade dos adultos, duração da fase imatura e voltinismo. Como se sabe, o conhecimento da biologia de espécies Neotropicais de Saturniidae é pequeno frente à diversidade presente na região, tornando o aprofundamento do entendimento de cada espécie com seu ciclo sazonal um grande desafio. 
Situação semelhante ocorre com a atividade circadiana das espécies aqui estudadas, e apesar de não termos avançado na discussão sobre estes tópicos, é importante ressaltar a relevância dos dados coletados neste estudo para o auxílio da compreensão de fenômenos como a atração dos Saturniidae noturnos a fontes luminosas, assunto discutido por Janzen (1984), mas de forma hipotético-especulativa. Além disso, perceber que, de fato, há picos agudos na distribuição circadiana de abundância dos machos de determinadas espécies, e levando-se em consideração a família em estudo, alguns questionamentos surgem a partir dos resultados obtidos no presente estudo, tais como: i) caso os picos de atividades circadianas e sazonais das espécies aqui coletadas sejam corroborados para outras localidades, o que se pode esperar da existência de alguma barreira temporal entre os táxons em estudo?; ii) há relação entre a distribuição de abundância sazonal e circadiana das espécies com o polimorfismo intraespecífico?; iii) sabendo da existência de diversos casos de hibridismo em Saturniidae (Peigler 1977, 1978; Bridgehouse 2006; Vuattoux et al. 2001), qual a relação topológica entre táxons, filogeneticamente próximos, que apresentam ampla distribuição sazonal e/ou circadiana com aqueles de distribuição restrita?

No contexto explicitado no parágrafo anterior, a terceira parte do presente estudo, concentra um alto volume de dados os quais poderão ser aprofundados com o conhecimento acumulado sobre cada espécie, possibilitando responder algumas perguntas sobre aspectos da biologia de espécies, gêneros e subfamílias, além de auxiliar na elucidação de tópicos ainda mal resolvidos como a atração para fontes luminosas dos saturniídeos noturnos. 


\section{CONCLUSÕES}

1. Com o material de mais de 70 anos de coletas depositado no acervo do MZSP, foram registradas 119 espécies em 42 gêneros, dos 6.288 exemplares (5.738 machos, 549 fêmeas e um ginandromorfo) para a EBB, sendo seis destas, novos registros apontados entre 2012 e 2013.

2. A riqueza da fauna de Saturniidae da EBB continua semelhante à observada há quase 70 anos. A alta riqueza de espécies coletada em um único ponto demonstra que a área de estudo é de grande importância para manutenção da diversidade de Saturniidae da Mata Atlântica.

3. Houve grande variação no número de intervalos de tempo com registros das diferentes temperaturas, havendo assim, poucos intervalos com registros de temperaturas entre as mais baixas ou as mais elevadas, o que dificultou o estabelecimento da relação entre abundância e riqueza com o gradiente térmico, entretanto, houve indícios de que entre $15^{\circ} \mathrm{C}$ e $17,9^{\circ} \mathrm{C}$ a atividade dos adultos de Saturniidae seja maior.

4. A abundância e o número de espécies tiveram pouca variação ao longo do ano, tendo a primavera e o verão as menores concentrações de abundâncias. A abundância tendeu a aumentar ao longo da noite, e o número de espécies a reduzir discretamente.

5. O número de fêmeas coletadas foi muito baixo comparado ao número de machos. A abundância e a riqueza das fềmeas tiveram redução ao longo da noite, enquanto a abundância dos machos apresentou leve aumento, mas a riqueza manteve-se praticamente estável.

6. As espécies tiveram alternância de atividade ao longo do ano e da noite. Ao longo da noite as espécies presentes nos intervalos de tempo antes da meia noite foram bastante distintas daquelas presentes nos intervalos após a meia noite, e os intervalos do primeiro momento foram mais distantes entre si na composição das espécies do que foram os intervalos do segundo momento. 
7. As atividades sazonais e circadianas da maioria das espécies apresentaram picos agudos indicando que o estudo mais aprofundado da relação dos saturniídeos com suas atividades circadianas e sazonais podem auxiliar em definições taxonômicas mais robustas e também em entender tópicos associados ao comportamento das espécies. 


\section{REFERÊNCIAS BIBLIOGRÁFICAS}

Anderson, M.J. 2001. A new method for non-parametric multivariate analysis of variance. Austral Ecology, 26: 32-46.

Balcázar-Lara, M.A. \& Wolfe, K.L. 1997. Cladistics of the Ceratocampinae (Lepidoptera: Saturniidae). Tropical Lepidoptera, 8(2): 1-53.

Balke, M.; Gómez-Zurita, J.; Ribera, I.; Viloria, A.; Zillikens, A.; Steiner, J.; García, M.; Hendrich, L. \& Vogler, A.P. 2008. Ancient associations of aquatic beetles and tank bromeliads in the Neotropical forest canopy. Proceedings of the National Academy of Science, 105(17): 6356-6361.

Bebber, D.P.; Marriott, F.H.C.; Gaston, K.J.; Harris, S.A. \& Scotland, S.W. 2007. Predicting unknown species numbers using discovery curves. Proceedings of the Royal Society B, 274: $1651-1658$.

Bertoluci, J. \& Rodrigues, M.T.U. 2002. Seasonal patterns of breeding activity of Atlantic Rainforest anurans at Boracéia, Southeastern Brazil. Amphibia-Reptilia, 23(2): 161-167. Bispy, F.A.; Shimura, J.; Ruggiero, M.; Edwards, J. \& Haeuser, C. 2002. Taxonomy, at the click of a mouse. Informatics and taxonomy are working together to achieve more than either could alone. Nature, 418: 367.

Brechlin, R. \& Meister, F. 2011. Fünfzig neue Ceratocampinae (Lepidoptera: Saturniidae). Entomo-Satsphingia, 4(3): 5-58.

Bridgehouse, D.W. 2006. A case of natural hybridization between Hyalophora cecropia and Hyalophora columbia (Lepidoptera: Saturniidae) in Nova Scotia. Northeastern Naturalist, 13(1): 29-34.

Brown Jr., K.S. 1991. Conservation of neotropical environments: insects as indicators. In: Collins, N.M. \& Thomas, J.A. (Eds.). The conservation of insects and their habitats. London, Academic Press, p. 349-404.

Brown Jr., K.S. 1992. Borboletas da Serra do Japi: diversidade, hábitats, recursos alimentares e variação temporal. In: Morellato, L.P.C. (Ed.). História Natural da Serra do Japi. Ecologia e preservação de uma área florestal no Sudeste do Brasil. Campinas, UNICAMP/FAPESP, p. 142-187.

Brown Jr., K.S. 1996a. Diversity of Brazilian Lepidoptera: history of study, methods for measurements, and use as indicator for genetic, specific and system richness. In: Bicudo, 
C.E.M. \& Menezes, N.A. (Eds.). Biodiversity in Brazil: a first approach. São Paulo, Instituto de Botânica/CNPq, p. 121-153.

Brown Jr., K.S. 1996b. The use of insects in the study, inventory, conservation and monitoring of biological diversity in neotropical habitats, in relation to traditional land use systems. Decline and Conservation of Butterflies in Japan, 3: 128-149.

Brown Jr., K.S. \& Brown, G.G. 1992. Habitat alteration and species loss in Brazilian forests. In: Whitmore, T.C. \& Sayer, J. (Eds.). Tropical deforestation and species extinction. London, Chapman \& Hall, p. 119-142.

Brown Jr., K.S. \& Freitas, A.V.L. 1999. Lepidoptera. In: Brandão, C.R.F. \& Cancello, E.M. (Eds.). Invertebrados Terrestres, V. Biodiversidade do Estado de São Paulo, Brasil: Síntese do conhecimento ao final do século XX. São Paulo, FAPESP, p. 225-243.

Brown Jr., K.S. \& Freitas, A.V.L. 2000a. Diversidade de Lepidoptera em Santa Teresa, Espírito Santo. Boletim do Museu de Biologia Mello Leitão, 11/12: 71-118.

Brown Jr., K.S. \& Freitas, A.V.L. 2000b. Atlantic forest butterflies: indicators for landscape conservation. Biotropica, 32(4b): 934-956.

Camargo, A.J.A. 2007. A new species of Hylesia Hübner (Lepidoptera: Saturniinae: Hemileucinae) from Brazilian Cerrado. Revista Brasileira de Zoologia, 21(1): 199-202. Camargo, A.J.A. de \& Becker, V. 1999. Saturniidae (Lepidoptera) from the Brazilian Cerrado: Composition and biogeographic relatinships. Biotropica, 31(4): 696-705.

Camargo, A.J.A. de; Soares, R. dos S. \& Torezani, K.R. de S. 2008. Saturniidae (Lepidoptera) do Cerrado: Biodiversidade e aspectos biogeográficos. In: II Simpósio Internacional Savanas Tropicais e IX Simpósio Nacional Cerrado: Desafios e estratégias para equilíbrio entre sociedade, agronegócio e recursos naturais. Livro de Resumos. Brasília, DF, 6p

Cancello, E.M.; Silva, R.R.; Vasconcellos, A.; Reis, Y.T. \& Oliveira, L.M. 2014. Latitudinal Variation in Termite Species Richness and Abundance along the Brazilian Atlantic Forest Hotspot. Biotropica, 46(4): 441-450.

Carvalho, C.T. de. 1965. Bionomia de pequenos mamíferos. Revista de Biologia Tropical, 13(12): 239-257.

Carvazere, V.; Moraes, G.P. \& Silveira, L.F. 2010. Boracéia Biological Station: na ornithological review. Papeis Avulsos de Zoologia, 50(13): 189-201.

Colwell, R.K. 2013. EstimateS: Statistical estimation of species richness and shared species from samples. Version 9. Disponível em http://purl.oclc.org/estimates. Acesso em maio de 2014. 
Colwell R.K. \& Coddington, J.A. 1994. Estimating terrestrial biodiversity through extrapolation. Philosophical Transactions: Biological Sciences, 345: 101-118.

Colwell, R.K.; Chao, A.; Gotelli, N.J.; Lin, S; Mao, C.X.; Chazdon, R.L. \& Longino, J.T. 2012. Models and estimator linking individual-based and sample-based rarefaction, extrapolation and comparison of assemblages. Journal of Plant Ecology, 5(1): 3-21.

Colwell, R.K.; Mao, C.X. \& Chang, J. 2004. Interpolating, extrapolating and comparing incidence-based accumulation curves. Ecology, 85(10): 2717-2727.

Corseuil, E. 2013. Página pessoal. Prof. Elio Corseuil. Disponível em http://www.corseuil.com/. Acesso em abril 2014.

Costa, C.; Vanin, S.A. \& Casari-Chen, S.A. 1988. Larvas de Coleoptera do Brasil. São Paulo, Museu de Zoologia, Universidade de São Paulo. 282p.

Custodio Filho, A. 1989. Flora da Estação Biológica de Boraceia: Listagem de espécies. Revista do Instituto Florestal, 1(1):161-199.

D’Abrera, B. 1995. Saturniidae Mundi. Saturniid moths of the world. Part. I. Keltern, Goecke \& Evens. 177p.

D’Abrera, B. 1998. Saturniidae Mundi. Saturniid moths of the world. Part III. Keltern, Goecke \& Evens. 171p.

Dean, W.B. 1995. With broadax and firebrand: the destruction of the Brazilian Atlantic Forest. Berkeley, University of California Press. $x x+482 p$.

Duarte, M.; Carlin, L.F. \& Marconato, G. 2008. Light-attracted hawkmoths (Lepidoptera: Sphingidae) of Boracéia, municipality of Salesópolis, state of São Paulo, Brazil. Check List, 4(2): 123-136.

Duarte, M.; Marconato, G.; Specht, A. \& Casagrande, M.M. 2012. Capítulo 37: Lepidoptera. In: Rafael, J.A.; Melo, G.A.R.; Carvalho, C.J.B. de; Casari, S. \& Constantino, R. Insetos do Brasil: Diversidade e Taxonomia. Ribeirão Preto, Holos, p. 625-682.

Ferro, V.G. \& Diniz, I.R. 2007. Arctiidae (Insecta: Lepidoptera) da Estação Bilógica de Boraceia (Salesópolis, São Paulo, Brasil). Biota Neotropica, 7(3): 331-338.

Fisher, B.L. 1999. Improving inventory efficiency: A case study of leaf litter ant diverstiy in Madagascar. Ecological Applications, 9(2): 714-731.

Froehlich, C.G. 2004. Anacroneuria (Plecoptera) from Boraceia Biologica Satation, São Paulo State, Brazil. Aquatic Insect, 26(1): 53-63.

Gardiner, B.O.C. 1982. A silkmoth rearer's handbook. $3^{\text {rd }}$ edition. UK, Ashford Kent. xiii + 26 plts +255 p. (The Amateur Entomologist, 12). 
Gaston, K.J. 1991. Body size and probability of description: the beetle fauna of Britain. Ecological Entomology, 16(4): 505-508.

Gewin, V. 2002. All living things, online. Nature, 418: 362-363.

Gilbert, L.E. 1984. The biology of butterfly communities. In: Vane-Wright, R.I. \& Ackery, P.R. (Eds.). The biology of butterflies. London, Academic Press, p. 41-54.

Godfray, H.C.J. 2002. Challenges for taxonomy. Nature, 417: 17-19.

Góes, R. de. 2005. Os duendes de seis patas e a cidade mutante. O lado mágico da natureza na São Paulo dos anos 50. São Paulo, Geração Editorial. 174p.

Gotelli, N.J. \& Colwell, R.K. 2001. Quantifying biodiversity: procedures and pitfalls on the measurement and comparisons of species richness. Ecology Letters, 4: 379-371.

Hammer, O.; Harper, D.A.T. \& Rian, P.D. 2001. Past: Palaeonthological statistics software package for education and data analysis. Version. 1.37. Disponível em http://palaeoelectronica.org/2001_1/past/issue1_01.htm. Acesso em junho de 2014.

Heppner, J.B. 1998. Classification of Lepidoptera Part 1. Introduction. Holarctic Lepidoptera, 5(suppl.1): $148+6 \mathrm{p}$.

Heyer, W.R.; Rand, A.S.; Gonçalvez da Cruz, C.A.; Peixoto, O.L. \& Nelson, C.E. 1990. Frogs of Boraceia. Arquivos de Zoologia, 31(4): 231-410.

Heywood, V.H. \& Watson, R.T. 1995. Global Biodiversity Assessment. Cambridge, University Press. xi + 1140p.

Hulbert, S.H. 1971. The nonconcept of species diversity: A critic and alternative parameters. Ecology, 52(4): 577-586.

Janzen, D.H. 1984. Two ways to be a tropical big moth: Santa Rosa saturniids and sphingids. In: Dawkings, R. \& Ridley, M (Eds.). Oxford Surveys in Evolutionary Biology, 1: 85140.

Janzen, D.H. \& Hallwachs, W. 2009. Dynamic database for an inventory of the macrocaterpillar fauna, and its food plants and parasitoids, of Area de Conservacion Guanacaste (ACG), northwestern Costa Rica (nn-SRNP-nnnnn voucher codes). Disponível em http://janzen.sas.upenn.edu. Acesso em junho de 2012.

Kremen, C.; Colwell, R.K.; Erwin, T.L.; Murphy, D.D.; Noss, R.F. \& Sanjayan, M.A. 1993. Terrestrial Arthropod Assemblanges: their use in conservation planning. Conservation Biology, 7(4): 796-808.

Kristensen, N.P.; Scoble, M.J. \& Karsholt, O. 2007. Lepidoptera phylogeny and systematic: the state of inventorying moth and butterfly diversity. Zootaxa, 1668: 699-747. 
Leemans, R. \& Cramer, W.P. 1991. The IIASA Database from Mean Monthly Values of Temperature, Precipitation, and Cloudiness on a Global Terrestrial Grid. RR-91-18. International Institute for Applied Systems Analysis, Luxemburg, Austria. 61p. Lemaire, C. \& Minet, J. 1998. The Bombycoidea and their relatives. In: Kristensen, N.P. (Ed.). Lepidoptera: Moths and Butterflies. 1: Evolution, Systematics and Biogeography. Handbook of Zoology, IV: Arthropoda: Insecta. Part. 35. Berlin and New York, Walter de Gruyter, p. 321-353.

Lemaire, C. 1978. Les Attacidae américains. The Attacidae of America (=Saturniidae). Attacinae. C. Lemaire, Neuilly-sur-Seine. 178figs +49 plts $+238 p$.

Lemaire, C. 1980. Les Attacidae américains. The Attacidae of America (= Saturniidae). Arsenurinae. C. Lemaire, Neuilly-sur-Seine. 170figs +76 plts $+199 p$.

Lemaire, C. 1988. Les Saturniidae américains. The Saturniidae of America. Los Saturnidos Americanos (= Anttacidae). Ceratocampinae. Museo Nacional de Costa Rica, San José. 379 figs $+64 p l t s+480 p$.

Lemaire, C. 2002. The Saturniidae of America - Hemileucinae. Germany, Keltern, Goecke \& Evers. 140plts $+1388 \mathrm{p}$.

Lewinsohn, T.M. \& Prado, P.I. 2002. Biodiversidade brasileira: síntese do estado atual do conhecimento. São Paulo, Editora Contexto. 176p.

Longino, J.T. \& Colwell, R.K. 1997. Biodiversity assessment using structured inventory: capturing the ant fauna of a tropical rain forest. Ecological Applications, 7(4): 1263-1277.

Lorini, M.L. \& Persson, V.G. 1990. Nova espécie de Leontopithecus Lesson, 1840, do sul do Brasil (Primates, Callitrichidae). Boletim do Museu Nacional, Nova Série Zoologia, 338: $1-13$.

Maddisson, D.R.; Schultz, K.S. \& Maddisson, W.P. 2007. The tree of life web project. Zootaxa, 1668: $19-40$.

Marinoni, R.C.; Dutra, R.R.C. \& Casagrande, M.M. 1997. Levantamento da fauna entomológica do Paraná. III. Saturniidae (Lepidoptera). Revista Brasileira de Zoologia, 14(2): 473-495.

Marques, A.C. \& Lamas, C.J.E. 2006. Taxonomia Zoológica no Brasil: Estado da Arte, expectativas e sugestões de ações futuras. Papéis Avulsos de Zoologia, 46(13): 139-174.

Meiner, R. \& Lim, G.S. 2009. Conflict, Convergent evolution, and the relative importance of immatures and adult characters in endopterygote phylogenetics. Annual Review of Entomology, 10(29): 85-104. 
Mielke, C.G.C.; Nauman, S. \& Brosch, U. 2005. Notes on Neotropical Saturniidae: Description of the females of Citheronia volcan, Adeloneivia minuta, Kentroleuca novaholandensis, Gamelia remissoides and Arsenura thomsoni thomsoni (Lepidoptera: Saturniidae). Nachrichten des Entomologischen Vereins Apollo ust, 26(4): 177-180.

Miller, J.C. 1993. Insect natural history, multi-species interactions and biodiversity in ecosystems. Biodiversity and Conservation, 2: 233-241.

Mittermeier, R.A.; Myers, N.; Thomsen, J.B.; Fonseca, G.A.B. da \& Olivieri, S. 1998. Biodiversity hotspots and major tropical wilderness areas: approaches to setting conservation priorities. Conservation Biology, 12: 516-520.

Mosher, E. 1914. The classification of the pupae of the Ceratocampidae and Hemileucidae. Annals of Entomological Society of America, 7: 277-300.

Mosher, E. 1916. The classification of the pupae of the Saturniidae. Annals of Entomological Society of America, 9: 136-158.

Myers, N., Mittermeier, R.A.; Mittermeier, C.G.; Fonseca, G.A.B. da \& Kent, J. 2000. Biodiversity hotspots for conservation priorities. Science, 403: 853-858.

Novotný, V. \& Basset, Y. 2000. Rare species in communities of tropical insect herbivores: pondering the mistery of singletons. OIKOS, 89: 562-572.

Nunes, F.G.; Prestes, A.S. \& Corseuil, E. 2004. Mariposas do gênero Rothschildia (Lepidoptera, Saturniidae) registradas para o Rio Grande do Sul, Brasil. Biociências, 12(1): 31-36.

Oliveira-Filho, A.T. \& Fontes, M.A.L. 2000. Patterns of floristic differentiation among Atlantic Forests in Southeastern Brazil and the influence of climate. Biotropica, 34: 793-810.

Otero, L.S. \& Marigo, L.C. 1990. Borboletas. Beleza e comportamento de espécies brasileiras. Rio de Janeiro, Marigo Comunicação Visual. 127p.

Peigler, R.S. 1977. Hybridization of Callosimia (Saturniidae). Journal of the Lepidopterist's Society, 31(1): 23-34.

Peigler, R.S. 1978. Hybrids between Callosomia and Samia (Saturniidae). Journal of the Lepidopterist's Society, 32(3): 191-197.

Peigler, R.S. 1993. Cladistics analysis of the genera of the subfamily Arsenurinae (Saturniidae). Journal of the Lepidopterists' Society, 47(3): 211-228.

Pinto, L.P.; Bedê, L.; Paese, A.; Fonseca, M.; Paglia, A. \& Lamas, I. 2006. Mata Atlântica Brasileira: Os Desafios para Conservação da Biodiversidade de um Hotspot Mundial. In: 
Rocha, C.F.D.; Bergallo, H.G.; Sluys, M.V. \& Alves, M.A.S. (Eds.). Biologia da Conservação: Essências. São Carlos, Rima, p. 91-118.

Pinto, L.P.S.; Costa, J.P. de O.; Fonseca, G.A.B. da \& Costa, C.M.R. 1997. Mata Atlântica: ciência, conservação e políticas. Documentos Ambientais, Secretaria do Meio Ambiente, Governo do Estado de São Paulo, São Paulo.

Pontes, A.R.M.; Malta, A. \& Asfora, P.H. 2006. A new species of capuchin monkey, genus Cebus Erxleben (Cebidae, Primates): found at the very brink of extinction in the Pernambuco Endemism Centre. Zootaxa, 1200: 1-12.

Prestes, A.S.; Nunes, F.G. \& Corseuil, E. 2009. Arsenurinae and Ceratocampinae (Saturniidae) of Rio Grande do Sul, Brazil. Journal of the Lepidopterist's Society, 63(4): 214-232.

R Development Core Team. 2014. R: A language and environment for statistical computing. R Foundation for Statistical Computing, Vienna, Austria. ISBN 3-900051-070. Disponível em http://www.R-project.org. Acesso em julho 2014.

Racheli, L. \& Racheli, T. 2005. An update checklist of the Saturniidae of Ecuador. Part I: Hemileucinae (Lepidoptera: Saturniidae). SHILAP Revista de Lepidoptera, 33(130): 203-223.

Racheli, L. \& Racheli, T. 2006. An update checklist of the Saturniidae of Ecuador. Part II: Arsenurinae, Ceratocampinae, Saturniinae (Lepidoptera: Saturniidae). SHILAP Revista de Lepidoptera, 34(135): 197-211.

Regier, J.C.; Grant, M.C.; Mitter, C.; Cook, C.P.; Peigler, R.S. \& Rougerie, R. 2008. Phylogenetic relationships of wild silkmoths (Lepidoptera: Saturniidae) inferred from four protein-coding nucelar genes. Systematic Entomology, 33: 219-228.

Ribeiro, M.C.; Jean, P.M.; Alexandre, C.M.; Flávio, J.P. \& Márcia, M.H. 2009. The Brazilian Atlantic Forest: How much is left, and how is the remaining forest distributed? Implications for conservation. Biological Conservation, 142: 1141-1153.

Rougerie, R. \& Estradel, Y. 2008. Morphology of the preimaginal stages of the African emperor moth Bunaeopsis licharbas (Maassen and Weyding): phylogenetically informative characters within the Saturniinae (Lepidoptera: Saturniidae). Journal of Morphology, 269: 207-232.

Santos, F.L. dos. 2012. Riqueza, abundância e variação temporal de Saturniidae e Sphingidae (Lepidoptera, Bombycoidea) na localidade de Vossoroca, Tijuca do Sul, Paraná, Brasil. 52 f. Dissertação (Mestrado em Ciências Biológicas, área de concentração em Entomologia) - Universidade Federal do Paraná, Paraná. 
Schlick-Steiner, B.C.; Steiner, F.M.; Seifern, B.; Stauffer, C.; Christian, E. \& Crozier, R.H. 2010. Integrative taxonomy: a multisource approach to exploring biodiversity. Annual Review of Entomology, 55: 421-438.

Scoble, M.J. 1995. The Lepidoptera, form, function and diversity. Oxford, The Natural History Museum in association with Oxford University press. 404p.

Setzer, J. 1946. Atlas climático e ecológico do Estado de São Paulo. Comissão Interestadual da Bacia Paraná-Uruguai. 61p.

Silva , J.M.C., Coelho, G. \& Gonzaga, L.P. 2003. Discovered on the brink of extinction: a new species of Pygmy-Owl (Strigidae: Glaucidium) from Atlantic Forest of northeastern Brazil. Ararajuba, 10: 123-130.

SOS Mata Atlântica. 2012. Atlas de Remanescentes. Disponível em http://mapas.sosma.org.br/. Acesso em junho de 2014.

Sparrow, H.R.; Sisk, T.D.; Ehrlich, P.R. \& Murphy, D.D. 1994. Techniques and Guidelines for Monitoring Neotropica Butteflies. Conservation Biology, 8(3): 800- 809.

Specht, A.; Corseuil, E. \& Formentini, A.C. 2005. Lepidopteros de importância médica ocorrentes no Rio Grande do Sul. III. Saturniidae - Hemileucinae. Biociências, 13(2): 149162.

Specht, A.; Corseuil, E. \& Formentini, A.C. 2008. 5 - Saturniidae, Hemileucinae. In: Specht, A.; Corseuil, E. \& Abella, H.B. (Orgs.). Lepidópteros de importância médica. Principais espécies no Rio Grande do Sul. Pelotas, Rio Grande do Sul, Editora Useb, p. 81-114 + 17 pranchas.

Specht, A.; Formentini, A.C. \& Corseuil, E. 2006. Biologia de Hylesia nigricans (Berg.) (Lepidoptera, Saturniidae, Hemileucinae). Revista Brasileira de Entomologia, 23(1): 248-255.

Stone, S.E. 1991. Foodplants of world Saturniidae. The Lepidopterist's Society, William E. Miller Ed., Colorado, USA. 186p.

Stork, N.E. \& Samways, M.J. 1995. Inventorying and monitoring. In: Heywood, V.H. (Ed.). Global Biodiversity Assessment. Cambridge, University Press, p. 453-543.

Travassos Filho, L. \& Camargo, H.F.A. 1958. A Estação Biológica de Boracéia. Arquivos de Zoologia de São Paulo, 11: 1-21.

van Nieukerken, E.J.; Kaila, L.; Kitching, I.J.; Kristensen, N.P.; Lees, D.C.; Minet, J.; Mitter, C.; Mutanen, M.; Regier, J.C.; Simonsen, T.J.; Wahlberg, N.; Yen, S.-H.; Zahiri, R.; Adamski, D.; Baixeras, J.; Bartsch, D.; Bengtsson, B.Å.; Brown. J.W.; Bucheli, S.R.; 
Davis, D.R.; De Prins, J.; De Prins, W.; Epstein, M.E.; Gentili-Poole, P.; Gielis, C.; Hättenschwiler, P.; Hausmann, A.; Holloway, J.D.; Kallies, A.; Karsholt, O.; Kawahara, A.Y.; Koster, S.(JC); Kozlov, M.; Lafontaine, J.D.; Lamas, G.; Landry, J.-F..; Lee, S.; Nuss, M.; Penz, C.; Rota, J.; Schmidt, B.C.; Schintlmeister, A.; Sohn, J-C.; Solis, M.A.; Tarmann, G.M.; Warren, A.D.; Weller, S.; Yakovlev, R.V.; Zolotuhin, V.; Zwick, A. 2011. Order Lepidoptera Linnaeus, 1758. In: Zhang, Z.Q. (Ed.). Animal biodiversity: An outline of higher level classification and survey of taxonomic richness. Zootaxa, 3148: 212-221.

Viviani, V.R. \& Santos, R.M. dos. 2012. Bioluminescent Coleoptera of Biological Station of Boraceia (Salesópolis, SP, Brazil): diversity, bioluminescence and habitat distribution. Biota Neotropica, 12(3): 21-34.

Vuattoux, R.; Ades, D.; Lemaître, R. \& Cocault, R. 2001. Hybridation entre Graellsia isabelae (Graëlls) mâle et Actias isis (Sonthonnax) femalle (Lépidoptères, Saturniidés). Insectes, 123(4): 17-18.

Wheeler, Q.D. 2008. Undisciplined thinking: morphology and Hennig's unfinished revolution. Systematics Entomology, 33: 2-7.

Wolda, H. 1988. Insect seasonality: Why? Annual Review of Ecology and Sistematics, 19: 118.

Wolfe, K.L. 2005: A resurrection of Copaxa canella flavobrunnea Bouvier, 1930 and elevation to species status, with illustration of the early stages Lepidoptera: Saturniidae. Nachrichten des Entomologischen Vereins Apollo ust, 26(1-2): 31-33

Yela, J.L. \& Holyoak, M. 1997. Effects of moonlight and meteorological factors on light and bait trap catches of noctuid moths (Lepidoptera: Noctuidae). Environmental Entomology, 26: $1283-1290$.

Zwick, A.; Regier, J.C.; Mitter, C. \& Cummings, M.P. 2011. Increased gene sampling yields robust support for higher-level clades within Bombycoidea (Lepidoptera). Systematic Entomology, 36(1), 31-43. 


\section{ANEXOS}

Anexo A. Primeira página do protocolo utilizado durante as coletas.

\begin{tabular}{|c|c|c|c|c|c|c|}
\hline \multirow{2}{*}{\multicolumn{2}{|c|}{$\begin{array}{l}\text { Data: } \\
\mathbf{N}^{0} \text { espécimes } \\
\end{array}$}} & \multicolumn{3}{|c|}{ Local: } & \multirow{2}{*}{\begin{tabular}{|r|} 
Campanha: \\
Umidade \% \\
\end{tabular}} & \multirow{2}{*}{$\begin{array}{r}\text { Coleta } \\
\text { Obs. } \\
\end{array}$} \\
\hline & & & Intervalo & ${ }^{\circ} \mathrm{C}$ & & \\
\hline \multirow[t]{13}{*}{ Outros } & Saturniidae & & & & & \\
\hline & & T 1 & $18: 00-18: 30 h$ & & & \\
\hline & & Т 2 & $18: 30-19: 00 h$ & & & \\
\hline & & T 3 & $19: 00-19: 30 h$ & & & \\
\hline & & T 4 & $19: 30-20: 00 h$ & & & \\
\hline & & T 5 & $20: 00-20: 30 h$ & & & \\
\hline & & Т 6 & $20: 30-21: 00 h$ & & & \\
\hline & & T 7 & $21: 00-21: 30 h$ & & & \\
\hline & & T 8 & $21: 30-22: 00 h$ & & & \\
\hline & & Т 9 & $22: 00-22: 30 h$ & & & \\
\hline & & T 10 & $22: 30-23: 00 h$ & & & \\
\hline & & T 11 & $23: 00-23: 30 h$ & & & \\
\hline & & T 12 & $23: 30-00: 00 h$ & & & \\
\hline & & & $18: 00-00: 00 h$ & \multicolumn{2}{|l|}{ DATA: } & TOTAL: \\
\hline & & T 13 & $00: 00-00: 30 h$ & & & \\
\hline & & T 14 & $00: 30-01: 00 h$ & & & \\
\hline & & T 15 & 01:00 - 01:30h & & & \\
\hline & & T 16 & $01: 30-02: 00 h$ & & & \\
\hline & & T 17 & $02: 00-02: 30 h$ & & & \\
\hline & & T 18 & $02: 30-03: 00 \mathrm{~h}$ & & & \\
\hline & & T 19 & $03: 00-03: 30 h$ & & & \\
\hline & & Т 20 & $03: 30-04: 00 \mathrm{~h}$ & & & \\
\hline & & T 21 & $04: 00-04: 30 h$ & & & \\
\hline & & Т 22 & $04: 30-05: 00 h$ & & & \\
\hline & & Т 23 & $05: 00-05: 30 h$ & & & \\
\hline & & Т 24 & $05: 30-06: 00 h$ & & & \\
\hline & & & $18: 00-06: 00 h$ & DATA : & & TOTAL: \\
\hline
\end{tabular}


Anexo B. Segunda página do protocolo utilizado durante as coletas.

\begin{tabular}{|c|c|c|}
\hline Data: & Local: & Campanha: \\
\hline UND & Quantidade / Espécies & \\
\hline T 1 & & \\
\hline T 2 & & \\
\hline T 3 & & \\
\hline T 4 & & \\
\hline T 5 & & \\
\hline T 6 & & \\
\hline T 7 & & \\
\hline T 8 & & \\
\hline T 9 & & \\
\hline T 10 & & \\
\hline T 11 & & \\
\hline T 12 & & \\
\hline T 13 & & \\
\hline T 14 & & \\
\hline T 15 & & \\
\hline T 16 & & \\
\hline T 17 & & \\
\hline T 18 & & \\
\hline T 19 & & \\
\hline T 20 & & \\
\hline T 21 & & \\
\hline T 22 & ] & \\
\hline T 23 & | & \\
\hline T 24 & & \\
\hline
\end{tabular}


Anexo C. Lista do material dissecado. Somente machos foram dissecados (pp.126-127).

\begin{tabular}{|c|c|c|c|}
\hline Etiqueta & $N^{0}$ de tombo & Espécie & Localidade \\
\hline 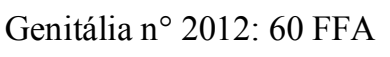 & MZSP 21907 & Automeris melanops & BR, São Paulo, Salesópolis \\
\hline Genitália $n^{\circ}$ 2012: 14 FFA & MZSP 18719 & Catacantha ferruginea & BR, São Paulo, Salesópolis \\
\hline Genitália ${ }^{\circ}$ 2012: 43 FFA & MZSP 17307 & Catacantha ferruginea & BR, São Paulo, Salesópolis \\
\hline Genitália $\mathrm{n}^{\circ}$ 2012: 54 FFA & MZSP 24197 & Catacantha ferruginea & BR, São Paulo, Salesópolis \\
\hline 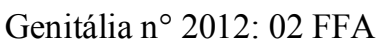 & MZSP 17901 & Cerodirphia sp.1 & BR, São Paulo, Salesópolis \\
\hline 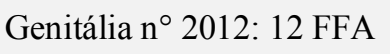 & MZSP 17444 & Cerodirphia sp.1 & BR, São Paulo, Salesópolis \\
\hline 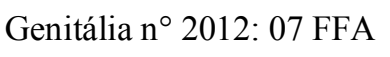 & MZSP 17776 & Cerodirphia vagans & BR, São Paulo, Salesópolis \\
\hline Genitália n 2012: 10 FFA & MZSP 19721 & Copaxa canella & $\begin{array}{l}\text { Criação. Fêmea de: BR, São } \\
\text { Paulo, Salesópolis, EBB }\end{array}$ \\
\hline Genitália n 2012: 17 FFA & MZSP 19722 & Copaxa canella & $\begin{array}{l}\text { Criação. Fêmea de: BR, São } \\
\text { Paulo, Salesópolis, EBB }\end{array}$ \\
\hline Genitália ${ }^{\circ}$ 2012: 20 FFA & MZSP 24146 & Dirphia avia & BR, São Paulo, São Paulo \\
\hline 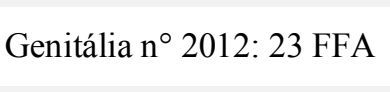 & MZSP 24145 & Dirphia avia & $\begin{array}{l}\text { BR, São Paulo, Campos do } \\
\text { Jordão }\end{array}$ \\
\hline 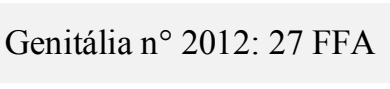 & MZSP 24148 & Dirphia avia & $\begin{array}{l}\text { BR, Rio de Janeiro, } \\
\text { Petrópolis }\end{array}$ \\
\hline 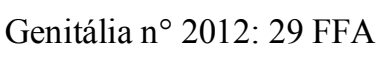 & MZSP 24147 & Dirphia avia & BR, São Paulo, São Paulo \\
\hline Genitália $\mathrm{n}^{\circ}$ 2012: 30 FFA & MZSP 24149 & Dirphia avia & $\begin{array}{l}\text { BR, Santa Catarina, Rio } \\
\text { Vermelho }\end{array}$ \\
\hline Genitália ${ }^{\circ}$ 2012: 32 FFA & MZSP 24150 & Dirphia avia & BR, Distrito Federal , NA \\
\hline Genitália ${ }^{\circ} 2012: 39$ FFA & MZSP 24151 & Dirphia avia & $\begin{array}{l}\text { BR, São Paulo, Campos do } \\
\text { Jordão }\end{array}$ \\
\hline Genitália ${ }^{\circ}$ 2012: 01 FFA & MZSP 24191 & Dirphia muscosa & BR, São Paulo, Salesópolis \\
\hline 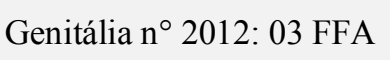 & MZSP 18506 & Dirphia muscosa & BR, São Paulo, Salesópolis \\
\hline Genitália $n^{\circ}$ 2012: 05 FFA & MZSP 18488 & Dirphia muscosa & BR, São Paulo, Salesópolis \\
\hline Genitália ${ }^{\circ}$ 2012: 09 FFA & MZSP 24188 & Dirphia muscosa & BR, São Paulo, Salesópolis \\
\hline Genitália ${ }^{\circ}$ 2012: 13 FFA & MZSP 24189 & Dirphia muscosa & BR, São Paulo, Salesópolis \\
\hline Genitália $\mathrm{n}^{\circ}$ 2012: 15 FFA & MZSP 18502 & Dirphia muscosa & BR, São Paulo, Salesópolis \\
\hline 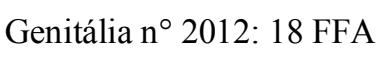 & MZSP 24190 & Dirphia muscosa & BR, São Paulo, Salesópolis \\
\hline Genitália $n^{\circ}$ 2012: 22 FFA & MZSP 24192 & Dirphia muscosa & BR, São Paulo, Salesópolis \\
\hline 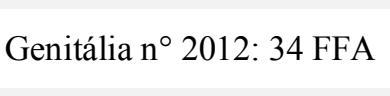 & MZSP 24154 & Dirphia muscosa & $\begin{array}{l}\text { BR, Santa Catarina, Nova } \\
\text { Teutônia }\end{array}$ \\
\hline Genitália $\mathrm{n}^{\circ}$ 2012: 36 FFA & MZSP 24153 & Dirphia muscosa & $\begin{array}{l}\text { BR, Santa Catarina, Rio } \\
\text { Vermelho }\end{array}$ \\
\hline Genitália $\mathrm{n}^{\circ}$ 2012: $41 \mathrm{FFA}$ & MZSP 24152 & Dirphia muscosa & BR, Bahia, Camacan \\
\hline Genitália $\mathrm{n}^{\circ}$ 2012: 45 FFA & MZSP 17762 & Gamelia remissoides & BR, São Paulo, Salesópolis \\
\hline 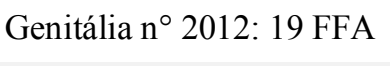 & MZSP 18196 & Hylesia ebalus & BR, São Paulo, Salesópolis \\
\hline Genitália $n^{\circ}$ 2012: 37 FFA & MZSP 18195 & Hylesia ebalus & BR, São Paulo, Salesópolis \\
\hline
\end{tabular}




\begin{tabular}{|c|c|c|c|}
\hline Etiqueta & $N^{0}$ de tombo & Espécie & Localidade \\
\hline 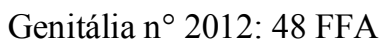 & MZSP 24155 & Hylesia ebalus & BR, São Paulo, Salesópolis \\
\hline 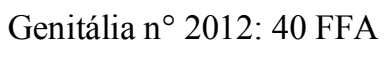 & MZSP 18129 & Hylesia munonia & BR, São Paulo, Salesópolis \\
\hline 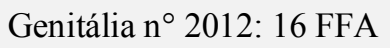 & MZSP 17373 & Hylesia oratex & BR, São Paulo, Salesópolis \\
\hline 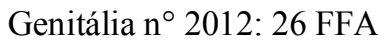 & MZSP 21095 & Hylesia sp.1 & BR, São Paulo, Salesópolis \\
\hline 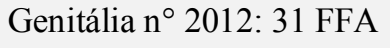 & MZSP 21093 & Hylesia sp.1 & BR, São Paulo, Salesópolis \\
\hline 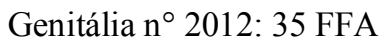 & MZSP 21097 & Hylesia sp. 1 & BR, São Paulo, Salesópolis \\
\hline 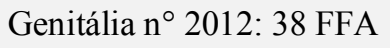 & MZSP 21094 & Hylesia sp. 1 & BR, São Paulo, Salesópolis \\
\hline 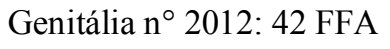 & MZSP 21092 & Hylesia sp. 1 & BR, São Paulo, Salesópolis \\
\hline 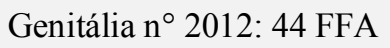 & MZSP 21090 & Hylesia sp. 1 & BR, São Paulo, Salesópolis \\
\hline 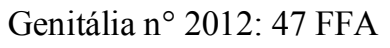 & MZSP 21091 & Hylesia sp. 1 & BR, São Paulo, Salesópolis \\
\hline 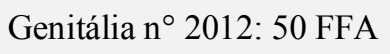 & MZSP 21089 & Hylesia sp.1 & BR, São Paulo, Salesópolis \\
\hline 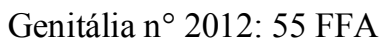 & MZSP 21088 & Hylesia sp. 1 & BR, São Paulo, Salesópolis \\
\hline 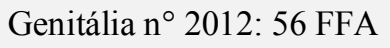 & MZSP 21096 & Hylesia sp.1 & BR, São Paulo, Salesópolis \\
\hline 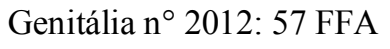 & MZSP 21107 & Hylesia sp.2 & BR, São Paulo, Salesópolis \\
\hline 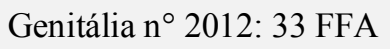 & MZSP 24193 & Hylesia sp.3 & BR, São Paulo, Salesópolis \\
\hline 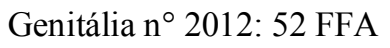 & MZSP 24195 & Hylesia sp. 3 & BR, São Paulo, Salesópolis \\
\hline 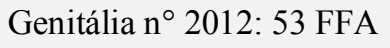 & MZSP 24196 & Hylesia sp.3 & BR, São Paulo, Salesópolis \\
\hline Genitália n 2012: 62 FFA & MZSP 24194 & Hylesia sp.3 & BR, São Paulo, Salesópolis \\
\hline 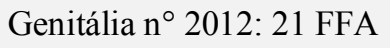 & MZSP 21098 & Hylesia vindex & BR, São Paulo, Salesópolis \\
\hline 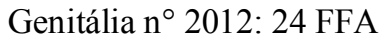 & MZSP 21101 & Hylesia vindex & BR, São Paulo, Salesópolis \\
\hline 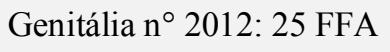 & MZSP 21099 & Hylesia vindex & BR, São Paulo, Salesópolis \\
\hline 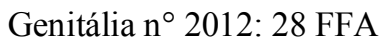 & MZSP 21102 & Hylesia vindex & BR, São Paulo, Salesópolis \\
\hline 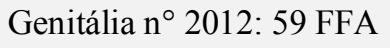 & MZSP 21100 & Hylesia vindex & BR, São Paulo, Salesópolis \\
\hline Genitália n 2012: 61 FFA & MZSP 21103 & Hylesia vindex & BR, São Paulo, Salesópolis \\
\hline 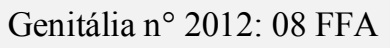 & MZSP 17163 & Oiticella brevis & BR, São Paulo, Salesópolis \\
\hline 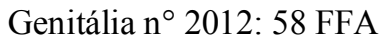 & MZSP 20314 & Oiticella brevis & BR, São Paulo, Salesópolis \\
\hline 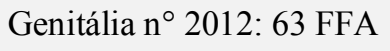 & MZSP 20170 & Oiticella brevis & BR, São Paulo, Salesópolis \\
\hline 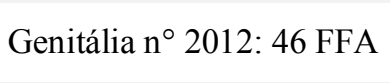 & MZSP 10358 & Oiticella luteciae & $\begin{array}{l}\text { BR, Santa Catarina, Rio } \\
\text { Vermelho }\end{array}$ \\
\hline 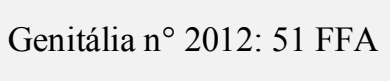 & MZSP 10306 & Oiticella luteciae & $\begin{array}{l}\text { BR, Santa Catarina, } \\
\text { Joinville }\end{array}$ \\
\hline 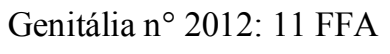 & MZSP 17494 & Pseudoautomeris coronis & BR, São Paulo, Salesópolis \\
\hline 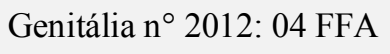 & MZSP 18112 & Pseudoautomeris hubneri & BR, São Paulo, Salesópolis \\
\hline 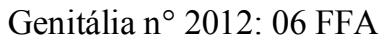 & MZSP 18109 & Pseudoautomeris hubneri & BR, São Paulo, Salesópolis \\
\hline 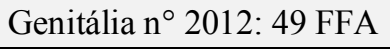 & MZSP 20186 & Travassosula subfumata & BR, São Paulo, Salesópolis \\
\hline
\end{tabular}


Anexo D. Lista do número de exemplares fotografados de todas as espécies organizadas por subfamílias e por ordem alfabética de espécies (pp. 128-130).

\begin{tabular}{|c|c|c|c|c|c|}
\hline & Rótulos de Linha & Macho & Fêmea & $\mathbf{N}^{\mathbf{0}}$ Exemplares & $\mathbf{N}^{0}$ espécies \\
\hline 1 & Arsenurinae & 11 & 5 & 16 & 10 \\
\hline 1 & Arsenura armida & 1 & 1 & 2 & \\
\hline 2 & Arsenura biundulata & 1 & 1 & 2 & \\
\hline 3 & Arsenura sylla & 1 & 1 & 2 & \\
\hline 4 & Copiopteryx derceto & 1 & & 1 & \\
\hline 5 & Copiopteryx sonthonnaxi & 2 & 1 & 3 & \\
\hline 6 & Loxolomia serpentina & 1 & & 1 & \\
\hline 7 & Paradaemonia mayi & 1 & & 1 & \\
\hline 8 & Paradaemonia platydesmia & 1 & & 1 & \\
\hline 9 & Rhescyntis pseudomartii & 1 & & 1 & \\
\hline 10 & Titaea tamerlan & 1 & 1 & 2 & \\
\hline 2 & Ceratocampinae & 20 & 10 & 30 & 18 \\
\hline 11 & Adeloneivaia acuta & 1 & & 1 & \\
\hline 12 & Adeloneivaia fallax & 1 & 1 & 2 & \\
\hline 13 & Adeloneivaia subangulata & 1 & 1 & 2 & \\
\hline 14 & Adelowalkeria flavosignata & 2 & 1 & 3 & \\
\hline 15 & Adelowalkeria tristygma & 1 & & 1 & \\
\hline 16 & Almeidella almeidai & 2 & & 2 & \\
\hline 17 & Cicia crocata & 1 & & 1 & \\
\hline 18 & Citheronia laocoon & 1 & 1 & 2 & \\
\hline 19 & Citheronia phoronea & 1 & & 1 & \\
\hline 20 & Eacles ducalis & 1 & 1 & 2 & \\
\hline 21 & Eacles imperialis & 1 & 1 & 2 & \\
\hline 22 & Eacles mayi & 1 & 1 & 2 & \\
\hline 23 & Neocarnegia basirei & 1 & 1 & 2 & \\
\hline 24 & Oiticella brevis & 1 & & 1 & \\
\hline 25 & Othorene cadmus & 2 & 1 & 3 & \\
\hline 26 & Othorene purpurascens & 1 & & 1 & \\
\hline 27 & Procitheronia principalis & & 1 & 1 & \\
\hline 28 & Procitheronia purpurea & 1 & & 1 & \\
\hline 3 & Hemileucinae & 108 & 45 & 153 & 56 \\
\hline 29 & Automerella aurora & 1 & 1 & 2 & \\
\hline 30 & Automerella flexuosa & 2 & 1 & 3 & \\
\hline 31 & Automeris basalis & 1 & 1 & 2 & \\
\hline 32 & Automeris beckeri & 1 & 1 & 2 & \\
\hline 33 & Automeris bilinea & 2 & & 2 & \\
\hline
\end{tabular}




\begin{tabular}{|c|c|c|c|c|c|}
\hline & Rótulos de Linha & Macho & Fêmea & $\mathbf{N}^{0}$ Exemplares & $\mathbf{N}^{0}$ espécies \\
\hline 34 & Automeris illustris & 1 & 1 & 2 & \\
\hline 35 & Automeris inornata & 2 & 1 & 3 & \\
\hline 36 & Automeris melanops & 1 & & 1 & \\
\hline 37 & Automeris tristis & 1 & & 1 & \\
\hline 38 & Automeropsis umbrata & 1 & & 1 & \\
\hline 39 & Catacantha ferruginea & 2 & 1 & 3 & \\
\hline 40 & Cerodirphia sp.1 & 3 & & 3 & \\
\hline 41 & Cerodirphia opis & 1 & 1 & 2 & \\
\hline 42 & Cerodirphia rosacordis & 1 & 1 & 2 & \\
\hline 43 & Cerodirphia vagans & 3 & 1 & 4 & \\
\hline 44 & Cerodirphia zikani & 1 & & 1 & \\
\hline 45 & Dirphia araucariae & 1 & & 1 & \\
\hline 46 & Dirphia baroma & 3 & 1 & 4 & \\
\hline 47 & Dirphia dolosa & 2 & 1 & 3 & \\
\hline 48 & Dirphia fornax & 1 & 1 & 2 & \\
\hline 49 & Dirphia muscosa & 9 & 2 & 11 & \\
\hline 50 & Dirphiopsis delta & 3 & & 3 & \\
\hline 51 & Dirphiopsis epiolina & 2 & 1 & 3 & \\
\hline 52 & Dirphiopsis multicolor & 1 & 1 & 2 & \\
\hline 53 & Dirphiopsis picturata & 1 & 1 & 2 & \\
\hline 54 & Dirphiopsis trisignata & 1 & 1 & 2 & \\
\hline 55 & Dirphiopsis wanderbilti & 2 & & 2 & \\
\hline 56 & Gamelia catharina & 1 & 2 & 3 & \\
\hline 57 & Gamelia remissoides & 3 & & 3 & \\
\hline 58 & Hidripa paranensis & 2 & & 2 & \\
\hline 59 & Hidripa perdix & 2 & 1 & 3 & \\
\hline 60 & Hylesia ebalus & 1 & & 1 & \\
\hline 61 & Hylesia falcifera & 3 & 2 & 5 & \\
\hline 62 & Hylesia maurex & & 1 & 1 & \\
\hline 63 & Hylesia metapyrrha & 2 & 1 & 3 & \\
\hline 64 & Hylesia munonia & 4 & & 4 & \\
\hline 65 & Hylesia nanus & 1 & & 1 & \\
\hline 66 & Hylesia oratex & 2 & & 2 & \\
\hline 67 & Hylesia paulex & 2 & 1 & 3 & \\
\hline 68 & Hylesia rufex & 2 & 1 & 3 & \\
\hline 69 & Hylesia scortina & 1 & 1 & 2 & \\
\hline 70 & Hylesia sp. & 6 & 2 & 8 & \\
\hline 71 & Hylesia vindex & 1 & 1 & 2 & \\
\hline 72 & Hyperchiria incisa & 1 & 1 & 2 & \\
\hline 73 & Hyperchirioides bulaea & 2 & 1 & 3 & \\
\hline
\end{tabular}




\begin{tabular}{llcccc}
\hline & Rótulos de Linha & Macho & Fêmea & $\mathbf{N}^{\mathbf{0}}$ Exemplares & $\mathbf{N}^{\mathbf{0}}$ espécies \\
\hline 74 & Leucanella gibbosa & 1 & 1 & 2 & \\
75 & Leucanella janeira & 2 & 1 & 3 & \\
76 & Lonomia obliqua & 4 & 2 & 6 & \\
77 & Molippa sabina & 1 & 1 & 2 & \\
78 & Periga circumstans & 2 & & 2 & \\
79 & Periga falcata & 2 & 2 & 4 & \\
80 & Prohylesia zikani & 1 & 1 & 2 & \\
81 & Pseudoautomeris brasiliensis & 2 & 1 & 3 & \\
82 & Pseudoautomeris coronis & 3 & 1 & 4 & \\
83 & Pseudoautomeris hubneri & 2 & 1 & 3 & \\
84 & Travassosula subfumata & 2 & & 2 & \\
\hline $\mathbf{4}$ & Oxyteninae & $\mathbf{9}$ & $\mathbf{2}$ & $\mathbf{1 1}$ & \\
85 & Oxytenis bicornis & 5 & 1 & 6 & \\
86 & Oxytenis modestia & 4 & 1 & 5 & \\
\hline $\mathbf{5}$ & Saturniinae & $\mathbf{1 2}$ & $\mathbf{4}$ & $\mathbf{1 6}$ & \\
87 & Copaxa canella & 4 & & 4 & \\
88 & Copaxa decrescens & 1 & 1 & 2 & \\
89 & Copaxa joinvillea & 1 & & 1 & \\
90 & Copaxa satellita & 1 & & 1 & \\
91 & Rothschildia aurota & 1 & 1 & 2 & \\
92 & Rothschildia belus & 1 & 1 & 2 & \\
93 & Rothschildia hesperus & 2 & 1 & 3 & \\
94 & Rothschildia hopfferi & 1 & & 1 & \\
& Total & $\mathbf{1 6 0}$ & $\mathbf{6 6}$ & $\mathbf{2 2 6}$ & \\
\hline & & & & & \\
\end{tabular}


Anexo E. Lista dos exemplares fotografados associados ao número de tombo e ao número da etiqueta relacionada à foto (pp. 131-136).

\begin{tabular}{|c|c|c|c|c|}
\hline Etiqueta & $\mathbf{N}^{0}$ Tombo & Subfamilia & Espécies & Sexo \\
\hline Foto 0001 & MZSP 17416 & Arsenurinae & Arsenura biundulata & Fêmea \\
\hline Foto 0002 & MZSP 16899 & Arsenurinae & Arsenura biundulata & Macho \\
\hline Foto 0003 & MZSP 16901 & Arsenurinae & Titaea tamerlan & Macho \\
\hline Foto 0004 & MZSP 17136 & Hemileucinae & Lonomia obliqua & Macho \\
\hline Foto 0005 & MZSP 17123 & Hemileucinae & Lonomia obliqua & Macho \\
\hline Foto 0006 & MZSP 17114 & Hemileucinae & Lonomia obliqua & Fêmea \\
\hline Foto 0007 & MZSP 17147 & Oxyteninae & Oxytenis bicornis & Macho \\
\hline Foto 0008 & MZSP 17152 & Hemileucinae & Automeris illustris & Macho \\
\hline Foto 0009 & MZSP 17145 & Saturniinae & Copaxa canella & Macho \\
\hline Foto 0010 & MZSP 17158 & Oxyteninae & Oxytenis modestia & Macho \\
\hline Foto 0011 & MZSP 16919 & Arsenurinae & Arsenura armida & Macho \\
\hline Foto 0012 & MZSP 17161 & Ceratocampinae & Adeloneivaia acuta & Macho \\
\hline Foto 0013 & MZSP 17163 & Ceratocampinae & Oiticella brevis & Macho \\
\hline Foto 0014 & MZSP 17304 & Hemileucinae & Hylesia munonia & Macho \\
\hline Foto 0015 & MZSP 17298 & Hemileucinae & Hylesia metapyrrha & Fêmea \\
\hline Foto 0016 & MZSP 17444 & Hemileucinae & Cerodirphia sp. 1 & Macho \\
\hline Foto 0017 & MZSP 17440 & Hemileucinae & Hylesia nanus & Macho \\
\hline Foto 0018 & MZSP 17434 & Hemileucinae & Leucanella gibbosa & Macho \\
\hline Foto 0019 & MZSP 16917 & Ceratocampinae & Eacles imperialis & Macho \\
\hline Foto 0020 & MZSP 17287 & Hemileucinae & Pseudoautomeris coronis & Macho \\
\hline Foto 0021 & MZSP 17293 & Hemileucinae & Pseudoautomeris coronis & Fêmea \\
\hline Foto 0022 & MZSP 17442 & Hemileucinae & Cerodirphia vagans & Fêmea \\
\hline Foto 0023 & MZSP 17638 & Hemileucinae & Hylesia munonia & Macho \\
\hline Foto 0024 & MZSP 16910 & Ceratocampinae & Othorene cadmus & Macho \\
\hline Foto 0025 & MZSP 16909 & Arsenurinae & Copiopteryx sonthonnaxi & Fêmea \\
\hline Foto 0026 & MZSP 16906 & Arsenurinae & Copiopteryx sonthonnaxi & Macho \\
\hline Foto 0027 & MZSP 16911 & Ceratocampinae & Neocarnegia basirei & Macho \\
\hline Foto 0028 & MZSP 16912 & Saturniinae & Rothschildia hopfferi & Macho \\
\hline Foto 0029 & MZSP 17135 & Hemileucinae & Lonomia obliqua & Macho \\
\hline Foto 0030 & MZSP 16913 & Saturniinae & Rothschildia hesperus & Macho \\
\hline Foto 0031 & MZSP 17316 & Hemileucinae & Hylesia oratex & Macho \\
\hline Foto 0032 & MZSP 17373 & Hemileucinae & Hylesia oratex & Macho \\
\hline Foto 0033 & MZSP 17634 & Hemileucinae & Hylesia munonia & Macho \\
\hline Foto 0034 & MZSP 17607 & Hemileucinae & Hylesia metapyrrha & Macho \\
\hline Foto 0035 & MZSP 17531 & Hemileucinae & Hylesia metapyrrha & Macho \\
\hline Foto 0036 & MZSP 17514 & Hemileucinae & Pseudoautomeris coronis & Macho \\
\hline Foto 0037 & MZSP 17494 & Hemileucinae & Pseudoautomeris coronis & Macho \\
\hline Foto 0038 & MZSP 17630 & Hemileucinae & Hylesia munonia & Macho \\
\hline
\end{tabular}




\begin{tabular}{|c|c|c|c|c|}
\hline Etiqueta & $\mathbf{N}^{\mathbf{0}}$ Tombo & Subfamilia & Espécies & Sexo \\
\hline Foto 0039 & MZSP 17771 & Ceratocampinae & Adeloneivaia fallax & Macho \\
\hline Foto 0040 & MZSP 17775 & Hemileucinae & Cerodirphia vagans & Macho \\
\hline Foto 0041 & MZSP 17901 & Hemileucinae & Cerodirphia sp.1 & Macho \\
\hline Foto 0041 & MZSP 17755 & Hemileucinae & Periga falcata & Macho \\
\hline Foto 0042 & MZSP 17758 & Oxyteninae & Oxytenis modestia & Macho \\
\hline Foto 0043 & MZSP 17762 & Hemileucinae & Gamelia remissoides & Macho \\
\hline Foto 0044 & MZSP 17776 & Hemileucinae & Cerodirphia vagans & Macho \\
\hline Foto 0046 & MZSP 17899 & Hemileucinae & Cerodirphia vagans & Macho \\
\hline Foto 0047 & MZSP 18005 & Oxyteninae & Oxytenis bicornis & Macho \\
\hline Foto 0048 & MZSP 18021 & Hemileucinae & Dirphiopsis delta & Macho \\
\hline Foto 0049 & MZSP 18019 & Hemileucinae & Hylesia rufex & Macho \\
\hline Foto 0050 & MZSP 18106 & Oxyteninae & Oxytenis bicornis & Macho \\
\hline Foto 0051 & MZSP 18017 & Hemileucinae & Leucanella janeira & Macho \\
\hline Foto 0052 & MZSP 18109 & Hemileucinae & Pseudoautomeris hubneri & Macho \\
\hline Foto 0053 & MZSP 18113 & Hemileucinae & Pseudoautomeris hubneri & Fêmea \\
\hline Foto 0054 & MZSP 18112 & Hemileucinae & Pseudoautomeris hubneri & Macho \\
\hline Foto 0055 & MZSP 18123 & Hemileucinae & Periga circumstans & Macho \\
\hline Foto 0056 & MZSP 18126 & Hemileucinae & Automeris bilinea & Macho \\
\hline Foto 0057 & MZSP 18124 & Saturniinae & Copaxa canella & Macho \\
\hline Foto 0058 & MZSP 18103 & Hemileucinae & Hidripa perdix & Macho \\
\hline Foto 0059 & MZSP 18201 & Hemileucinae & Dirphiopsis picturata & Macho \\
\hline Foto 0060 & MZSP 18203 & Ceratocampinae & Othorene cadmus & Macho \\
\hline Foto 0061 & MZSP 18135 & Oxyteninae & Oxytenis modestia & Macho \\
\hline Foto 0062 & MZSP 18127 & Hemileucinae & Dirphia araucariae & Macho \\
\hline Foto 0063 & MZSP 18186 & Hemileucinae & Hylesia scortina & Macho \\
\hline Foto 0064 & MZSP 18190 & Arsenurinae & Rhescyntis pseudomartii & Macho \\
\hline Foto 0065 & MZSP 18254 & Hemileucinae & Cerodirphia sp. & Macho \\
\hline Foto 0066 & MZSP 18196 & Hemileucinae & Hylesia ebalus & Macho \\
\hline Foto 0067 & MZSP 18294 & Hemileucinae & Dirphia baroma & Fêmea \\
\hline Foto 0068 & MZSP 18276 & Hemileucinae & Dirphia baroma & Macho \\
\hline Foto 0069 & MZSP 18280 & Hemileucinae & Dirphia baroma & Macho \\
\hline Foto 0070 & MZSP 18217 & Hemileucinae & Dirphiopsis wanderbilti & Macho \\
\hline Foto 0071 & MZSP 18296 & Hemileucinae & Dirphia baroma & Macho \\
\hline Foto 0072 & MZSP 18232 & Hemileucinae & Dirphia dolosa & Macho \\
\hline Foto 0073 & MZSP 18235 & Hemileucinae & Dirphia dolosa & Fêmea \\
\hline Foto 0074 & MZSP 18505 & Hemileucinae & Dirphia muscosa & Macho \\
\hline Foto 0075 & MZSP 18227 & Hemileucinae & Cerodirphia zikani & Macho \\
\hline Foto 0076 & MZSP 18236 & Hemileucinae & Gamelia remissoides & Macho \\
\hline Foto 0077 & MZSP 18506 & Hemileucinae & Dirphia muscosa & Macho \\
\hline Foto 0078 & MZSP 18488 & Hemileucinae & Dirphia muscosa & Macho \\
\hline
\end{tabular}




\begin{tabular}{|c|c|c|c|c|}
\hline Etiqueta & $\mathbf{N}^{\mathbf{0}}$ Tombo & Subfamilia & Espécies & Sexo \\
\hline Foto 0079 & MZSP 18484 & Hemileucinae & Dirphia muscosa & Fêmea \\
\hline Foto 0080 & MZSP 21147 & Hemileucinae & Hylesia paulex & Fêmea \\
\hline Foto 0081 & & Hemileucinae & Hylesia sp. & Fêmea \\
\hline Foto 0082 & & Hemileucinae & Hylesia sp. & Fêmea \\
\hline Foto 0083 & MZSP 21148 & Hemileucinae & Hylesia falcifera & Fêmea \\
\hline Foto 0084 & & Hemileucinae & Hylesia $\mathrm{sp}$. & Macho \\
\hline Foto 0085 & & Hemileucinae & Hylesia sp. & Macho \\
\hline Foto 0086 & & Hemileucinae & Hylesia sp. & Macho \\
\hline Foto 0087 & & Hemileucinae & Hylesia sp. & Macho \\
\hline Foto 0088 & MZSP 21149 & Hemileucinae & Hylesia vindex & Macho \\
\hline Foto 0089 & & Hemileucinae & Hylesia sp. & Macho \\
\hline Foto 0090 & & Hemileucinae & Hylesia sp. & Macho \\
\hline Foto 0091 & MZSP 21142 & Hemileucinae & Hylesia maurex & Fêmea \\
\hline Foto 0092 & MZSP 09960 & Ceratocampinae & Adeloneivaia fallax & Fêmea \\
\hline Foto 0093 & MZSP 18826 & Hemileucinae & Dirphia muscosa & Macho \\
\hline Foto 0094 & MZSP 18827 & Hemileucinae & Dirphia muscosa & Macho \\
\hline Foto 0095 & MZSP 18828 & Hemileucinae & Dirphia muscosa & Macho \\
\hline Foto 0096 & MZSP 18829 & Hemileucinae & Dirphia muscosa & Macho \\
\hline Foto 0097 & MZSP 18830 & Hemileucinae & Dirphia muscosa & Macho \\
\hline Foto 0098 & MZSP 18831 & Hemileucinae & Dirphia muscosa & Macho \\
\hline Foto 0099 & MZSP 18832 & Hemileucinae & Dirphia muscosa & Fêmea \\
\hline Foto 0100 & MZSP 19937 & Hemileucinae & Automeris bilinea & Macho \\
\hline Foto 0101 & MZSP 19398 & Hemileucinae & Automeris beckeri & Macho \\
\hline Foto 0102 & MZSP 19316 & Hemileucinae & Travassosula subfumata & Macho \\
\hline Foto 0103 & MZSP 18824 & Hemileucinae & Dirphiopsis picturata & Fêmea \\
\hline Foto 0104 & MZSP 18825 & Hemileucinae & Automerella aurora & Macho \\
\hline Foto 0105 & MZSP 19384 & Hemileucinae & Catacantha ferruginea & Macho \\
\hline Foto 0106 & MZSP 18833 & Hemileucinae & Lonomia obliqua & Fêmea \\
\hline Foto 0107 & MZSP 19385 & Hemileucinae & Automeris basalis & Macho \\
\hline Foto 0108 & MZSP 19386 & Hemileucinae & Gamelia catharina & Fêmea \\
\hline Foto 0109 & MZSP 19387 & Hemileucinae & Hidripa paranensis & Macho \\
\hline Foto 0110 & MZSP 19388 & Hemileucinae & Hidripa paranensis & Macho \\
\hline Foto 0111 & MZSP 19399 & Saturniinae & Copaxa joinvillea & Macho \\
\hline Foto 0112 & MZSP 19391 & Hemileucinae & Dirphiopsis epiolina & Fêmea \\
\hline Foto 0113 & MZSP 19392 & Hemileucinae & Dirphiopsis epiolina & Macho \\
\hline Foto 0114 & MZSP 19393 & Hemileucinae & Dirphiopsis epiolina & Macho \\
\hline Foto 0115 & MZSP 19394 & Hemileucinae & Hylesia scortina & Fêmea \\
\hline Foto 0116 & MZSP 19395 & Arsenurinae & Copiopteryx derceto & Macho \\
\hline Foto 0117 & MZSP 19396 & Arsenurinae & Copiopteryx sonthonnaxi & Macho \\
\hline Foto 0118 & MZSP 18516 & Saturniinae & Copaxa canella & Macho \\
\hline
\end{tabular}




\begin{tabular}{|c|c|c|c|c|}
\hline Etiqueta & $\mathbf{N}^{\mathbf{0}}$ Tombo & Subfamilia & Espécies & Sexo \\
\hline Foto 0119 & MZSP 18513 & Saturniinae & Copaxa canella & Macho \\
\hline Foto 0120 & MZSP 21904 & Hemileucinae & Automeris melanops & Macho \\
\hline Foto 0121 & MZSP 19223 & Arsenurinae & Paradaemonia mayi & Macho \\
\hline Foto 0122 & MZSP 19082 & Hemileucinae & Automeris inornata & Macho \\
\hline Foto 0123 & MZSP 19359 & Hemileucinae & Automeris inornata & Macho \\
\hline Foto 0124 & MZSP 19365 & Hemileucinae & Automeris inornata & Fêmea \\
\hline Foto 0125 & MZSP 19259 & Ceratocampinae & Othorene cadmus & Fêmea \\
\hline Foto 0126 & MZSP 20307 & Ceratocampinae & Adeloneivaia subangulata & Macho \\
\hline Foto 0127 & MZSP 20258 & Hemileucinae & Gamelia remissoides & Macho \\
\hline Foto 0128 & MZSP 19443 & Ceratocampinae & Eacles mayi & Macho \\
\hline Foto 0129 & MZSP 07077 & Ceratocampinae & Eacles mayi & Fêmea \\
\hline Foto 0130 & MZSP 19861 & Ceratocampinae & Eacles ducalis & Macho \\
\hline Foto 0131 & MZSP 19390 & Hemileucinae & Travassosula subfumata & Macho \\
\hline Foto 0132 & MZSP 19967 & Ceratocampinae & Eacles ducalis & Fêmea \\
\hline Foto 0133 & MZSP 06927 & Ceratocampinae & Eacles imperialis & Fêmea \\
\hline Foto 0134 & MZSP 19731 & Ceratocampinae & Procitheronia principalis & Fêmea \\
\hline Foto 0135 & MZSP 19674 & Ceratocampinae & Procitheronia purpurea & Macho \\
\hline Foto 0136 & MZSP 19596 & Ceratocampinae & Almeidella almeidai & Macho \\
\hline Foto 0137 & MZSP 07684 & Ceratocampinae & Almeidella almeidai & Macho \\
\hline Foto 0138 & MZSP 21908 & Hemileucinae & Hylesia rufex & Fêmea \\
\hline Foto 0139 & MZSP 21129 & Hemileucinae & Hylesia rufex & Macho \\
\hline Foto 0140 & MZSP 19890 & Ceratocampinae & Othorene purpurascens & Macho \\
\hline Foto 0141 & MZSP 19975 & Ceratocampinae & Citheronia phoronea & Macho \\
\hline Foto 0142 & MZSP 19920 & Ceratocampinae & Adelowalkeria flavosignata & Macho \\
\hline Foto 0143 & MZSP 20182 & Ceratocampinae & Adelowalkeria flavosignata & Macho \\
\hline Foto 0144 & MZSP 10158 & Ceratocampinae & Adelowalkeria flavosignata & Fêmea \\
\hline Foto 0145 & MZSP 19903 & Ceratocampinae & Adelowalkeria tristygma & Macho \\
\hline Foto 0146 & MZSP 19661 & Hemileucinae & Pseudoautomeris brasiliensis & Macho \\
\hline Foto 0147 & MZSP 19275 & Hemileucinae & Pseudoautomeris brasiliensis & Fêmea \\
\hline Foto 0148 & MZSP 19187 & Hemileucinae & Pseudoautomeris brasiliensis & Macho \\
\hline Foto 0149 & MZSP 20139 & Hemileucinae & Molippa sabina & Fêmea \\
\hline Foto 0150 & MZSP 20138 & Hemileucinae & Molippa sabina & Macho \\
\hline Foto 0151 & MZSP 19884 & Hemileucinae & Leucanella gibbosa & Fêmea \\
\hline Foto 0152 & MZSP 19083 & Hemileucinae & Automerella aurora & Fêmea \\
\hline Foto 0153 & MZSP 20433 & Hemileucinae & Hylesia paulex & Macho \\
\hline Foto 0154 & MZSP 20242 & Hemileucinae & Hylesia paulex & Macho \\
\hline Foto 0155 & MZSP 20067 & Hemileucinae & Hylesia falcifera & Macho \\
\hline Foto 0156 & MZSP 20068 & Hemileucinae & Hylesia falcifera & Macho \\
\hline Foto 0157 & MZSP 20080 & Hemileucinae & Hylesia falcifera & Macho \\
\hline Foto 0158 & MZSP 20886 & Hemileucinae & Hylesia falcifera & Fêmea \\
\hline
\end{tabular}




\begin{tabular}{|c|c|c|c|c|}
\hline Etiqueta & $\mathbf{N}^{\mathbf{0}}$ Tombo & Subfamilia & Espécies & Sexo \\
\hline Foto 0159 & MZSP 20925 & Hemileucinae & Hylesia vindex & Fêmea \\
\hline Foto 0160 & MZSP 20095 & Hemileucinae & Prohylesia zikani & Macho \\
\hline Foto 0161 & MZSP 21909 & Hemileucinae & Prohylesia zikani & Fêmea \\
\hline Foto 0162 & MZSP 19317 & Hemileucinae & Periga circumstans & Macho \\
\hline Foto 0163 & MZSP 20425 & Hemileucinae & Periga falcata & Macho \\
\hline Foto 0164 & MZSP 19984 & Hemileucinae & Gamelia catharina & Macho \\
\hline Foto 0165 & MZSP 19193 & Hemileucinae & Gamelia catharina & Fêmea \\
\hline Foto 0166 & MZSP 20127 & Hemileucinae & Dirphiopsis trisignata & Macho \\
\hline Foto 0167 & MZSP 21910 & Hemileucinae & Dirphiopsis trisignata & Fêmea \\
\hline Foto 0168 & MZSP 20205 & Hemileucinae & Cerodirphia opis & Macho \\
\hline Foto 0169 & MZSP 20214 & Hemileucinae & Cerodirphia opis & Fêmea \\
\hline Foto 0170 & MZSP 20290 & Saturniinae & Copaxa decrescens & Macho \\
\hline Foto 0171 & MZSP 20414 & Saturniinae & Rothschildia aurota & Macho \\
\hline Foto 0172 & MZSP 20413 & Saturniinae & Rothschildia aurota & Fêmea \\
\hline Foto 0173 & MZSP 03739 & Arsenurinae & Arsenura sylla & Macho \\
\hline Foto 0174 & MZSP 03742 & Arsenurinae & Arsenura sylla & Fêmea \\
\hline Foto 0175 & MZSP 01404 & Saturniinae & Rothschildia hesperus & Fêmea \\
\hline Foto 0176 & MZSP 20415 & Saturniinae & Rothschildia hesperus & Macho \\
\hline Foto 0177 & MZSP 16643 & Saturniinae & Copaxa decrescens & Fêmea \\
\hline Foto 0178 & MZSP 19505 & Saturniinae & Copaxa satellita & Macho \\
\hline Foto 0179 & MZSP 19552 & Hemileucinae & Automeris basalis & Fêmea \\
\hline Foto 0180 & MZSP 21911 & Hemileucinae & Catacantha ferruginea & Fêmea \\
\hline Foto 0181 & MZSP 21912 & Hemileucinae & Catacantha ferruginea & Macho \\
\hline Foto 0182 & MZSP 18721 & Oxyteninae & Oxytenis bicornis & Macho \\
\hline Foto 0183 & MZSP 20009 & Oxyteninae & Oxytenis bicornis & Macho \\
\hline Foto 0184 & MZSP 20429 & Oxyteninae & Oxytenis bicornis & Fêmea \\
\hline Foto 0185 & MZSP 18136 & Oxyteninae & Oxytenis modestia & Macho \\
\hline Foto 0186 & MZSP 24414 & Oxyteninae & Oxytenis modestia & Fêmea \\
\hline Foto 0187 & MZSP 21138 & Hemileucinae & Hidripa perdix & Macho \\
\hline Foto 0188 & MZSP 18204 & Hemileucinae & Dirphiopsis delta & Macho \\
\hline Foto 0189 & MZSP 18711 & Hemileucinae & Dirphiopsis delta & Macho \\
\hline Foto 0190 & MZSP 21158 & Hemileucinae & Automerella flexuosa & Macho \\
\hline Foto 0191 & MZSP 20142 & Hemileucinae & Hyperchiria incisa & Macho \\
\hline Foto 0192 & MZSP 21913 & Hemileucinae & Hyperchiria incisa & Fêmea \\
\hline Foto 0193 & MZSP 19963 & Hemileucinae & Periga falcata & Fêmea \\
\hline Foto 0194 & MZSP 20890 & Hemileucinae & Automeris tristis & Macho \\
\hline Foto 0195 & MZSP 21165 & Hemileucinae & Automerella flexuosa & Fêmea \\
\hline Foto 0196 & MZSP 17166 & Hemileucinae & Automerella flexuosa & Macho \\
\hline Foto 0197 & MZSP 07234 & Ceratocampinae & Citheronia laocoon & Fêmea \\
\hline Foto 0198 & MZSP 07180 & Ceratocampinae & Citheronia laocoon & Macho \\
\hline
\end{tabular}




\begin{tabular}{|c|c|c|c|c|}
\hline Etiqueta & $\mathbf{N}^{\mathbf{0}}$ Tombo & Subfamilia & Espécies & Sexo \\
\hline Foto 0199 & MZSP 02881 & Hemileucinae & Periga falcata & Fêmea \\
\hline Foto 0200 & MZSP 19215 & Hemileucinae & Automeris beckeri & Fêmea \\
\hline Foto 0201 & MZSP 19882 & Arsenurinae & Loxolomia serpentina & Macho \\
\hline Foto 0202 & MZSP 21914 & Hemileucinae & Hidripa perdix & Fêmea \\
\hline Foto 0203 & MZSP 20189 & Ceratocampinae & Cicia crocata & Macho \\
\hline Foto 0204 & MZSP 16675 & Hemileucinae & Hyperchirioides bulaea & Fêmea \\
\hline Foto 0205 & MZSP 21915 & Hemileucinae & Hyperchirioides bulaea & Macho \\
\hline Foto 0206 & MZSP 21916 & Hemileucinae & Hyperchirioides bulaea & Macho \\
\hline Foto 0207 & MZSP 19973 & Hemileucinae & Dirphiopsis multicolor & Macho \\
\hline Foto 0208 & MZSP 21895 & Hemileucinae & Dirphiopsis multicolor & Fêmea \\
\hline Foto 0209 & MZSP 21431 & Hemileucinae & Cerodirphia rosacordis & Macho \\
\hline Foto 0210 & MZSP 21439 & Hemileucinae & Cerodirphia rosacordis & Fêmea \\
\hline Foto 0211 & MZSP 19990 & Hemileucinae & Lonomia obliqua & Macho \\
\hline Foto 0212 & MZSP 19342 & Hemileucinae & Dirphiopsis wanderbilti & Macho \\
\hline Foto 0213 & MZSP 19507 & Hemileucinae & Dirphia dolosa & Macho \\
\hline Foto 0214 & MZSP 20195 & Hemileucinae & Dirphia fornax & Macho \\
\hline Foto 0215 & MZSP 20199 & Hemileucinae & Dirphia fornax & Fêmea \\
\hline Foto 0216 & MZSP 20281 & Arsenurinae & Paradaemonia platydesmia & Macho \\
\hline Foto 0217 & MZSP 20019 & Hemileucinae & Automeris illustris & Fêmea \\
\hline Foto 0218 & MZSP 01191 & Saturniinae & Rothschildia belus & Macho \\
\hline Foto 0219 & MZSP 16700 & Saturniinae & Rothschildia belus & Fêmea \\
\hline Foto 0220 & MZSP 18530 & Ceratocampinae & Neocarnegia basirei & Fêmea \\
\hline Foto 0221 & MZSP 21917 & Hemileucinae & Automeropsis umbrata & Macho \\
\hline Foto 0222 & MZSP 21918 & Hemileucinae & Leucanella janeira & Fêmea \\
\hline Foto 0223 & MZSP 21919 & Hemileucinae & Leucanella janeira & Macho \\
\hline Foto 0224 & MZSP 18565 & Ceratocampinae & Adeloneivaia subangulata & Fêmea \\
\hline Foto 0225 & MZSP 20023 & Arsenurinae & Arsenura armida & Fêmea \\
\hline Foto 0226 & MZSP 20417 & Arsenurinae & Titaea tamerlan & Fêmea \\
\hline
\end{tabular}


Anexo F. Exemplares fotografados agrupados por subfamília e nomes de espécie em ordem alfabética. Medidas após símbolo de macho e fêmea correspondem à envergadura do exemplar. Vista dorsal, foto da esquerda e vista ventral, foto da direita.

Arsenurinae Jordan, 1922
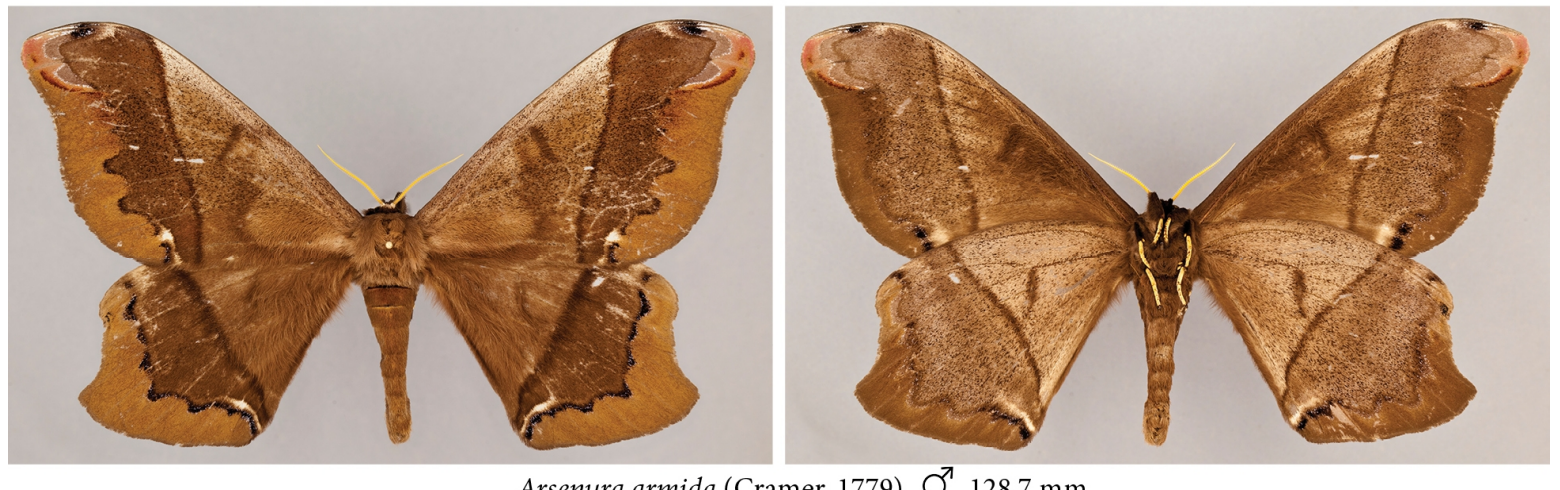

Arsenura armida (Cramer, 1779) $0^{7} 128,7 \mathrm{~mm}$
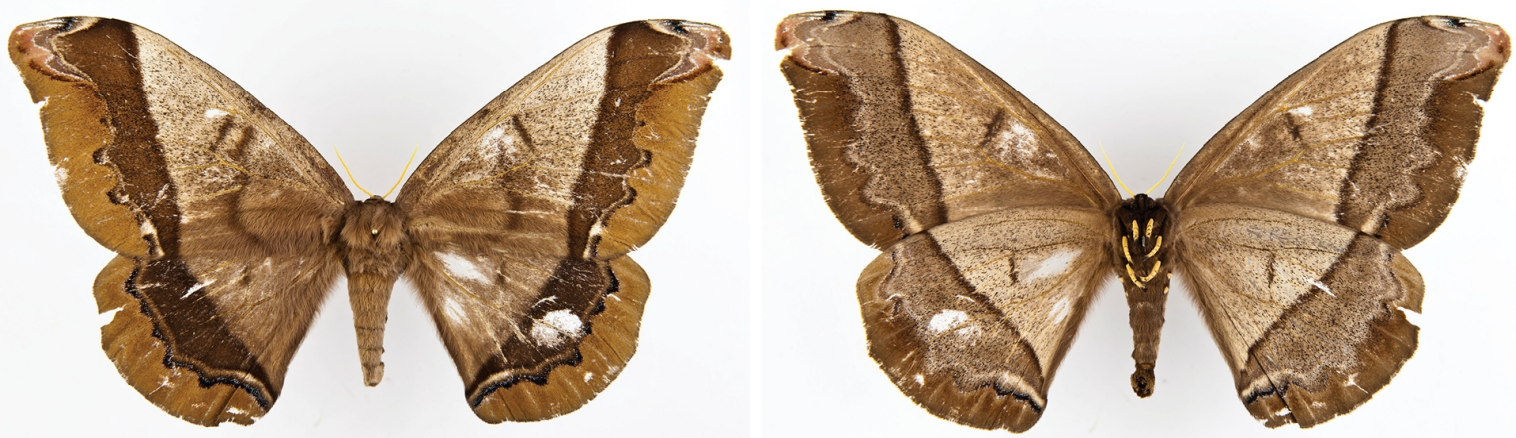

Arsenura armida (Cramer, 1779) $\bigcirc \quad 128,7 \mathrm{~mm}$
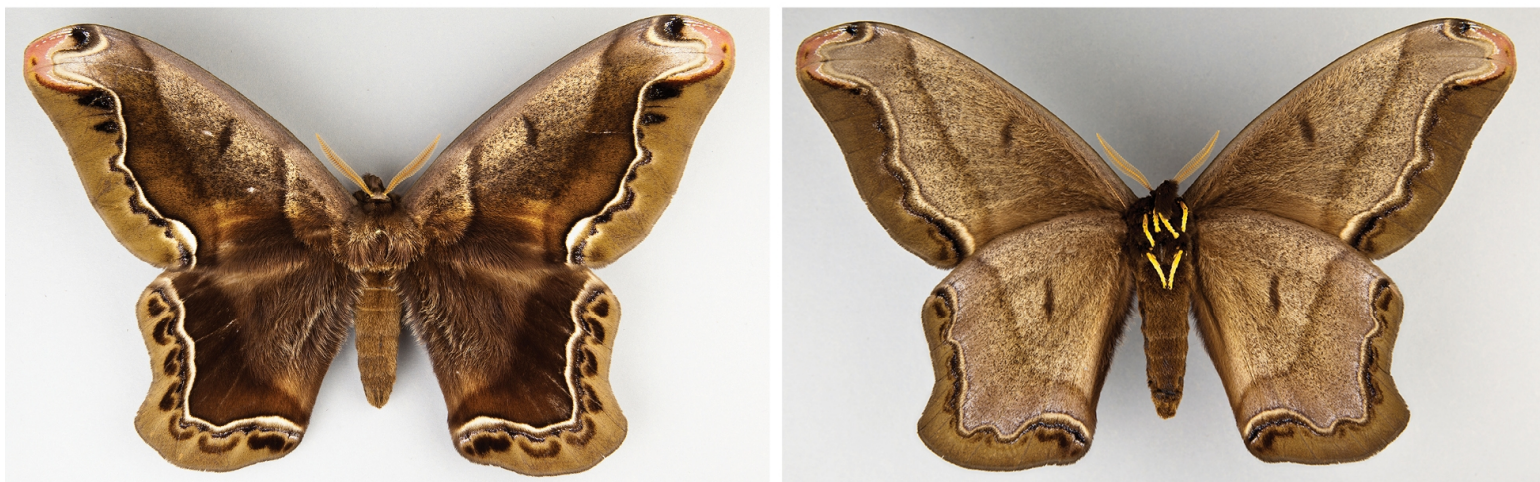

Arsenura biundulata Schaus, $1906 \mathrm{O}^{7} 166 \mathrm{~mm}$
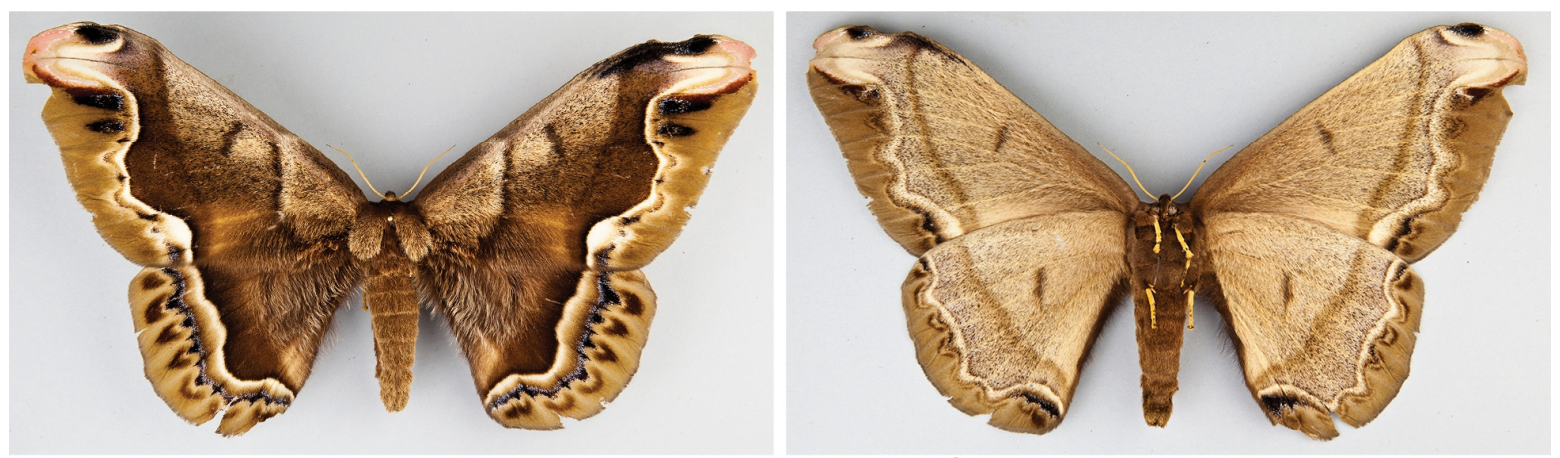

Arsenura biundulata Schaus, 1906 ○ $177 \mathrm{~mm}$ 
Arsenurinae Jordan, 1922
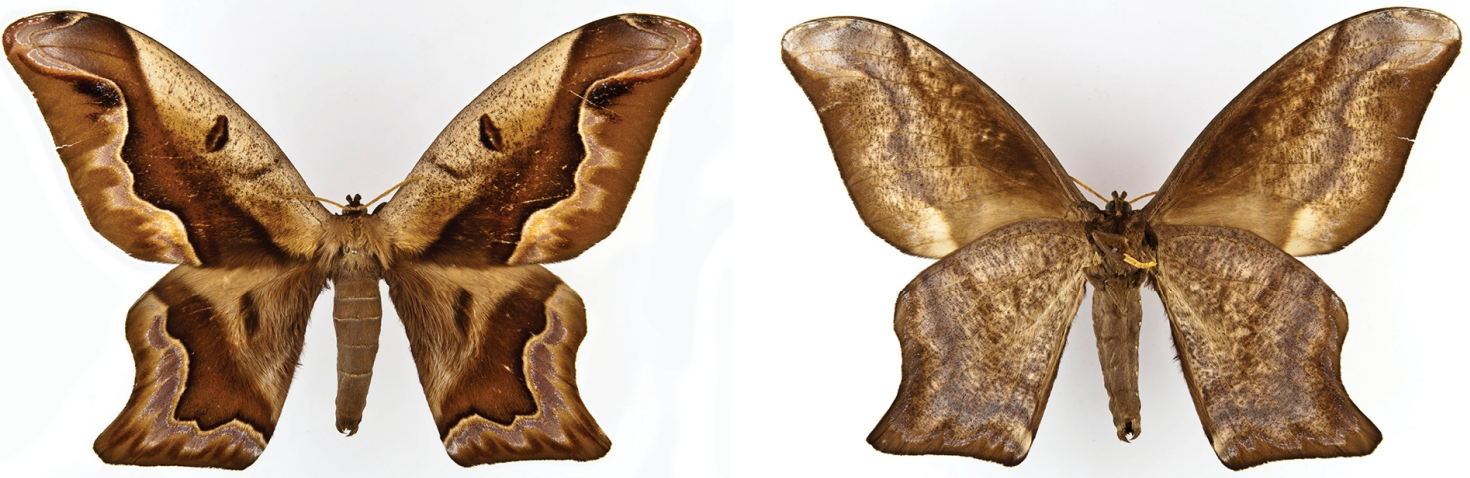

Arsenura sylla (Cramer, 1779) $\sigma^{7} 180 \mathrm{~mm}$
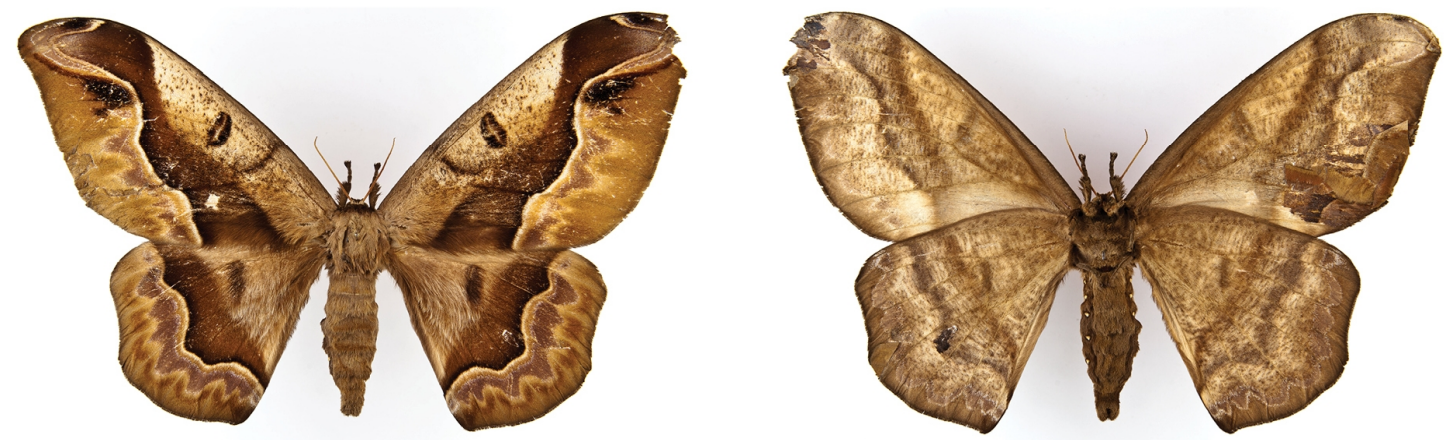

Arsenura sylla (Cramer, 1779) $\stackrel{+}{190 \mathrm{~mm}}$
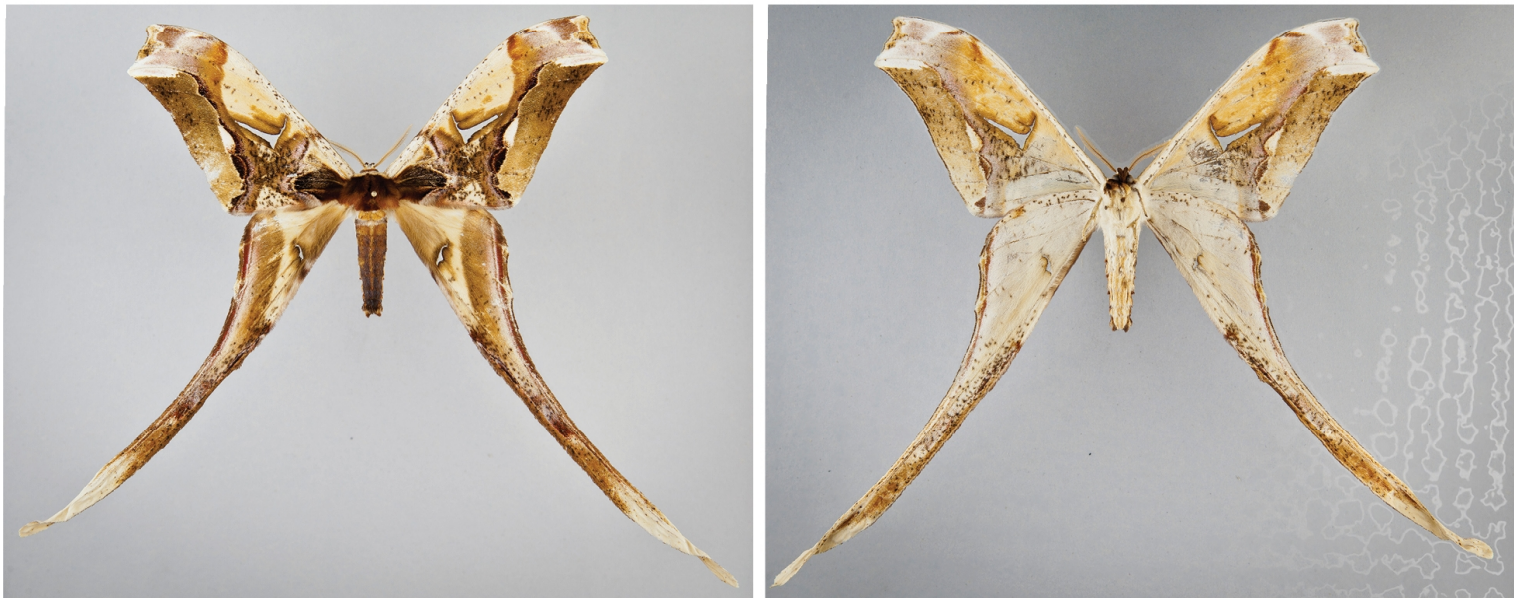

Copiopteryx descerco (Maassen, [1872]) $\mathrm{O}^{7} 118 \mathrm{~mm}$
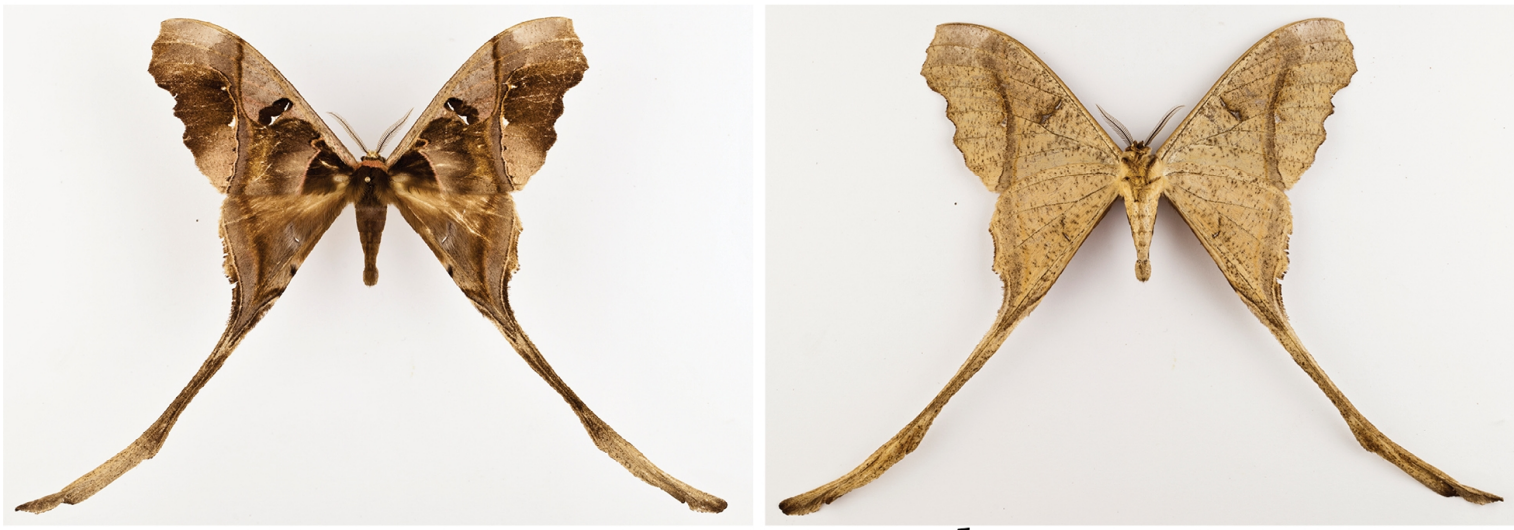

Copiopteryx sonthonnaxi Ém. André, 1905 Ơ 94,4 mm 
Arsenurinae Jordan, 1922
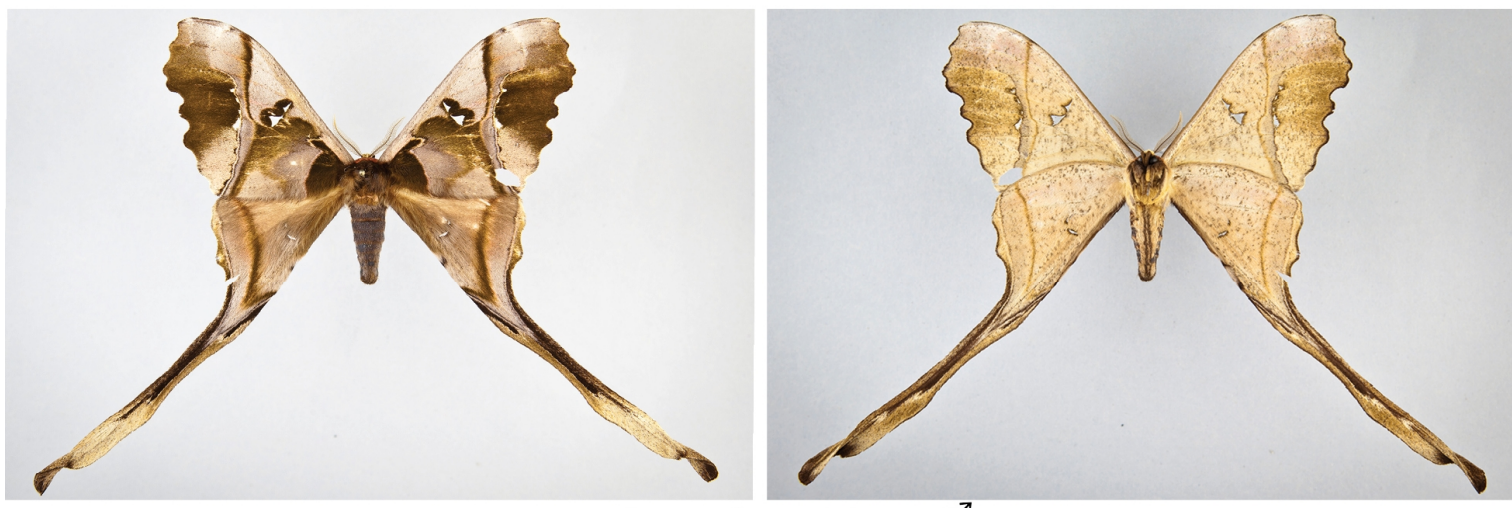

Copiopteryx sonthonnaxi Ém. André, 1905 Ơ 94,5 mm
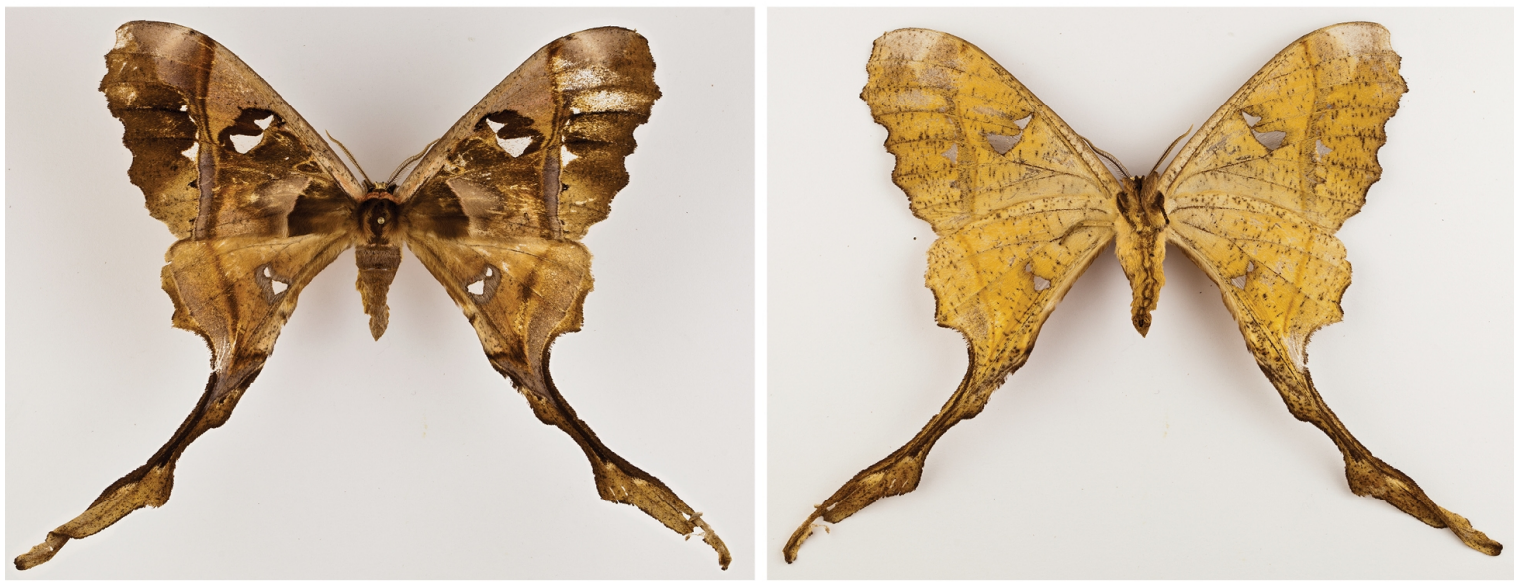

Copiopteryx sonthonnaxi Ém. André, 1905 ○ 101,8 mm
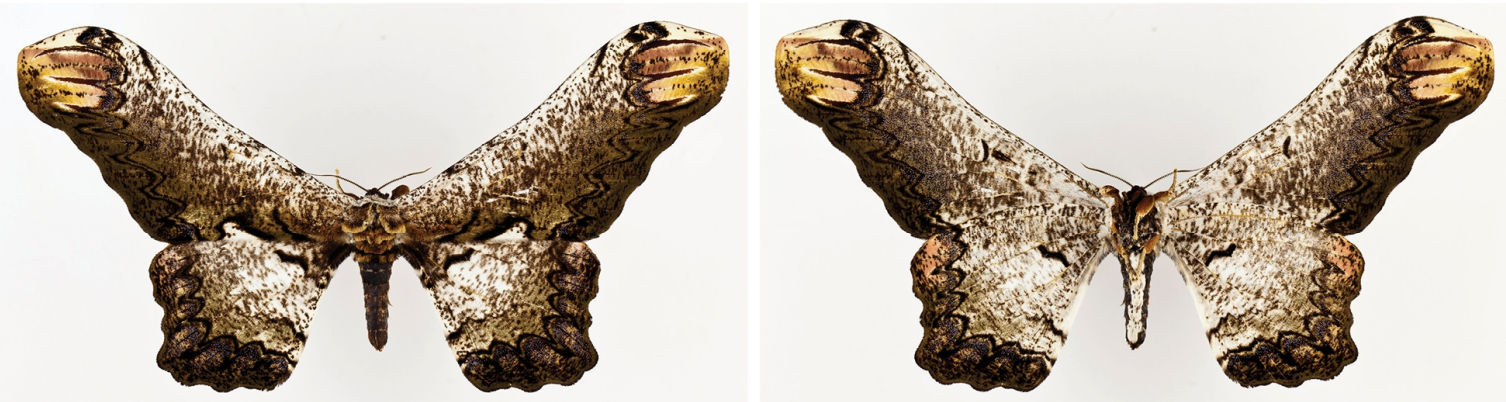

Loxolomia serpentina Maassen, $1869 \bigcirc^{7} 147,3 \mathrm{~mm}$
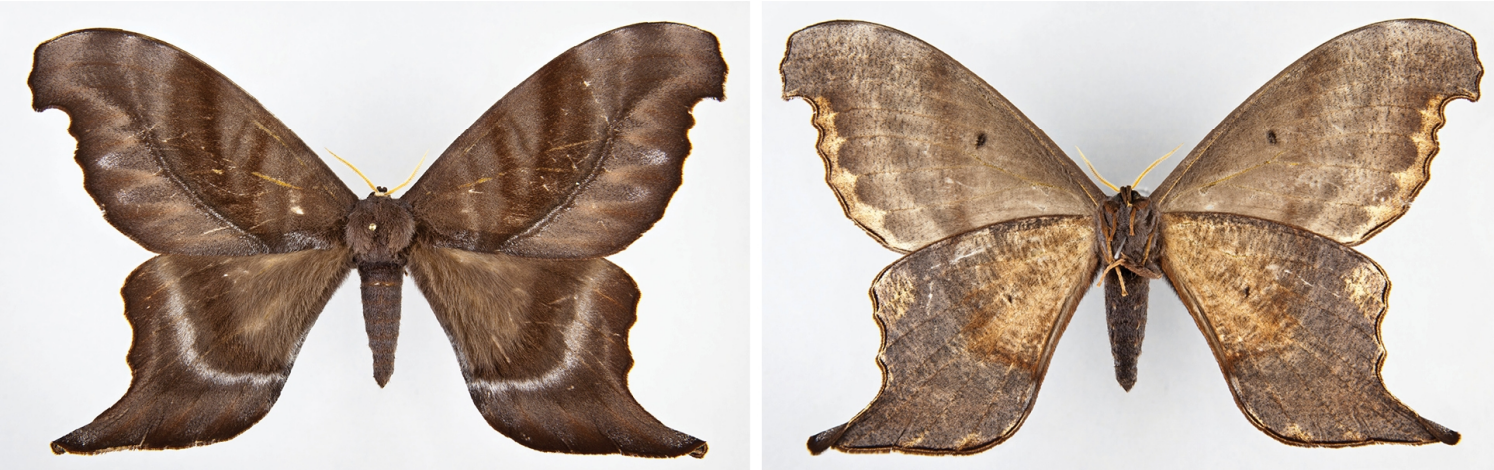

Paradaemonia mayi (Jordan, 1922) $\sigma^{7} 140,2$ mm 
Arsenurinae Jordan, 1922
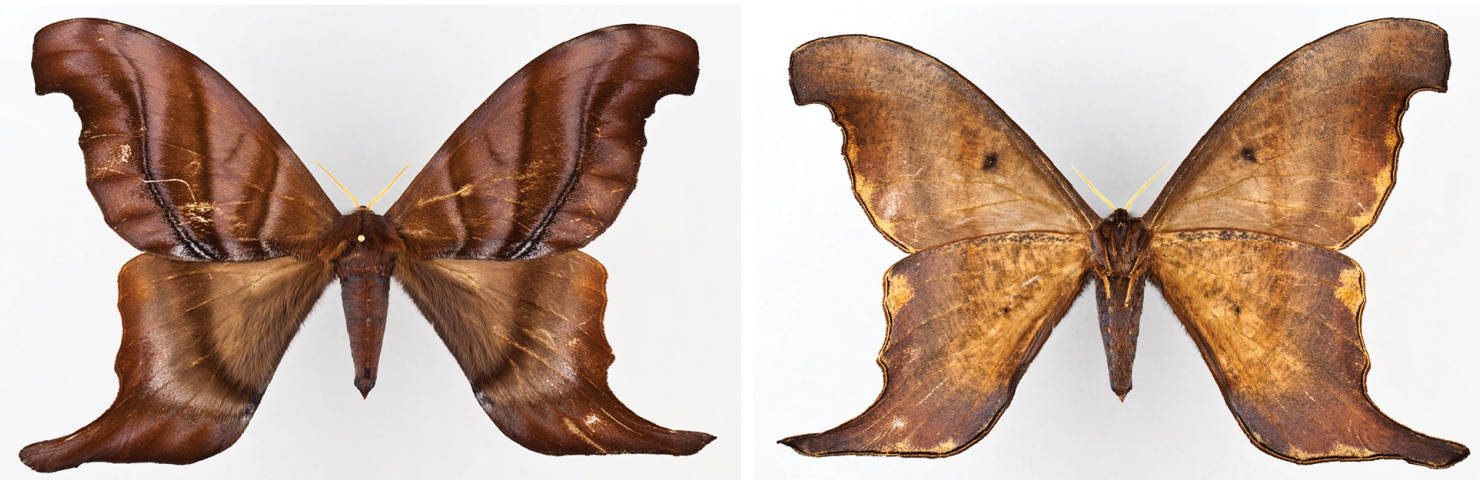

Paradaemonia pluto (Wastwood 11854) $\quad \bigcirc^{7} 140,2 \mathrm{~mm}$
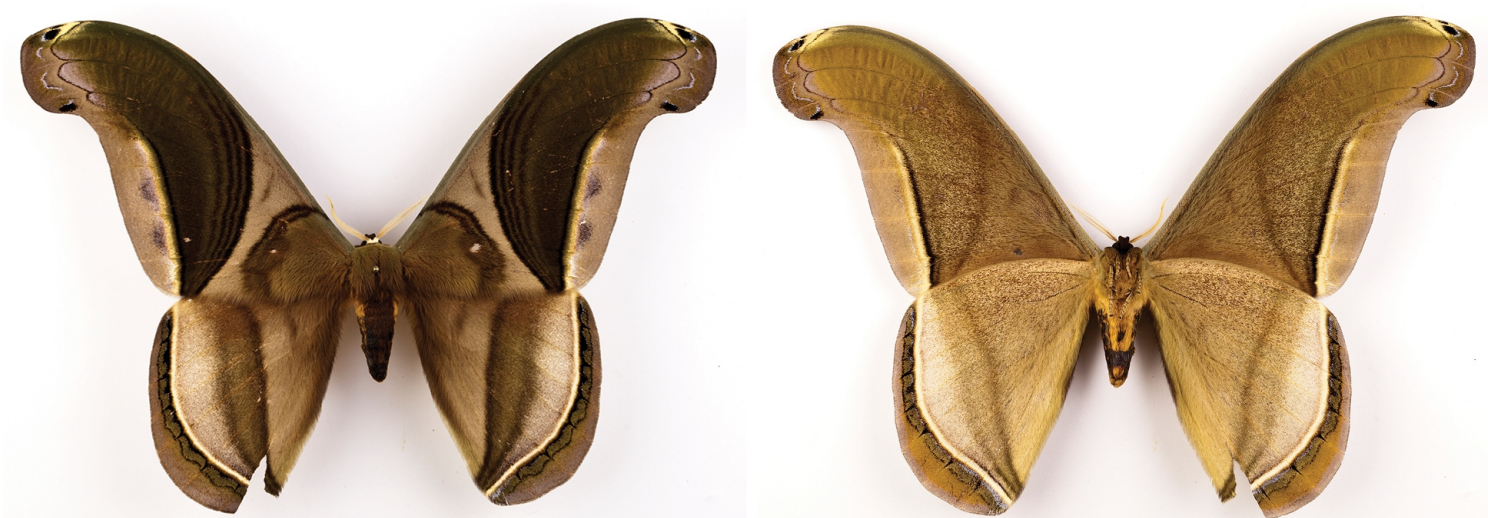

Rhescyntis pseudomartii Lemaire, $1976 \quad O^{7} 158,5 \mathrm{~mm}$
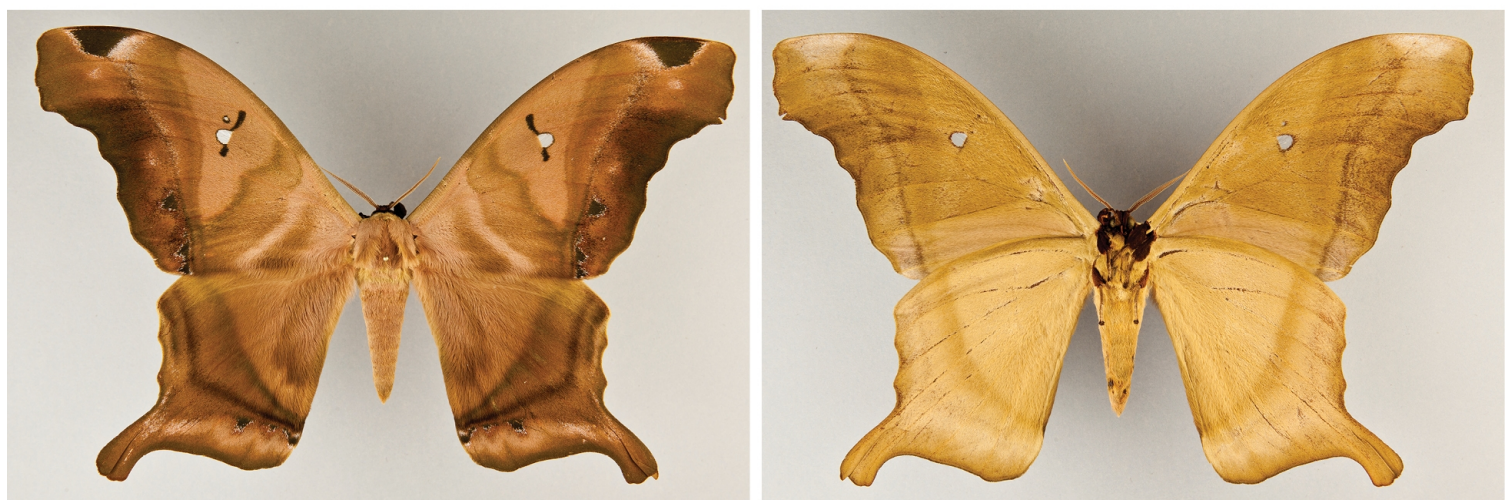

Titaea tamerlan (Maassen, 1869) $\sigma^{7} 164 \mathrm{~mm}$
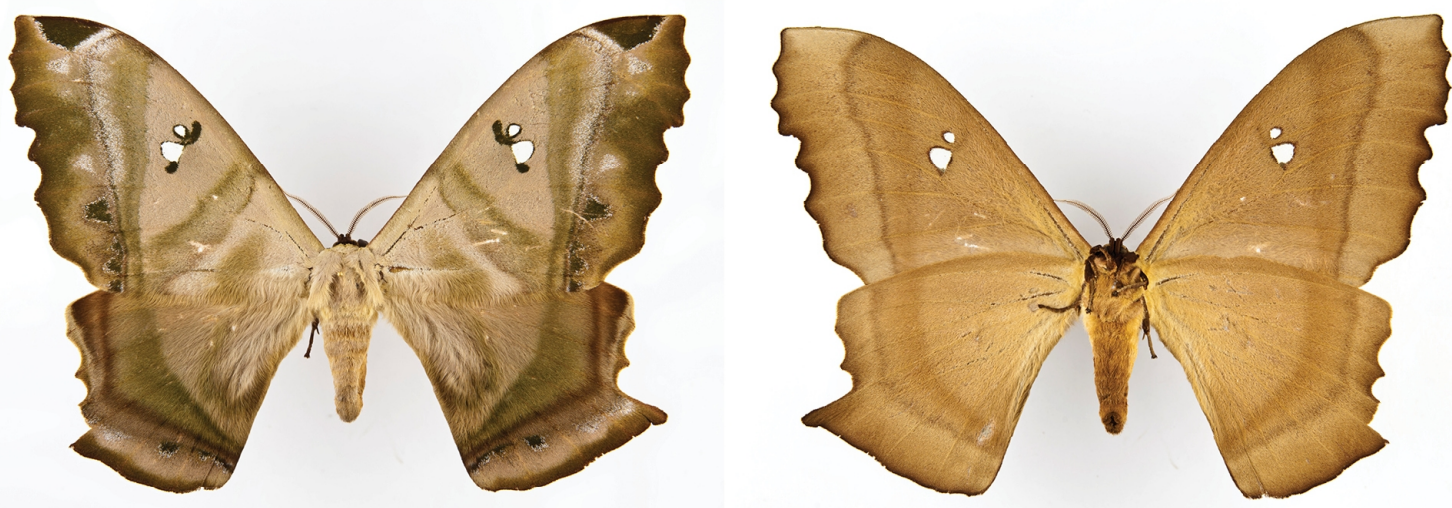

Titaea tamerlan (Maassen, 1869) $@ 151,5 \mathrm{~mm}$ 
Ceratocampinae Harris, 1922
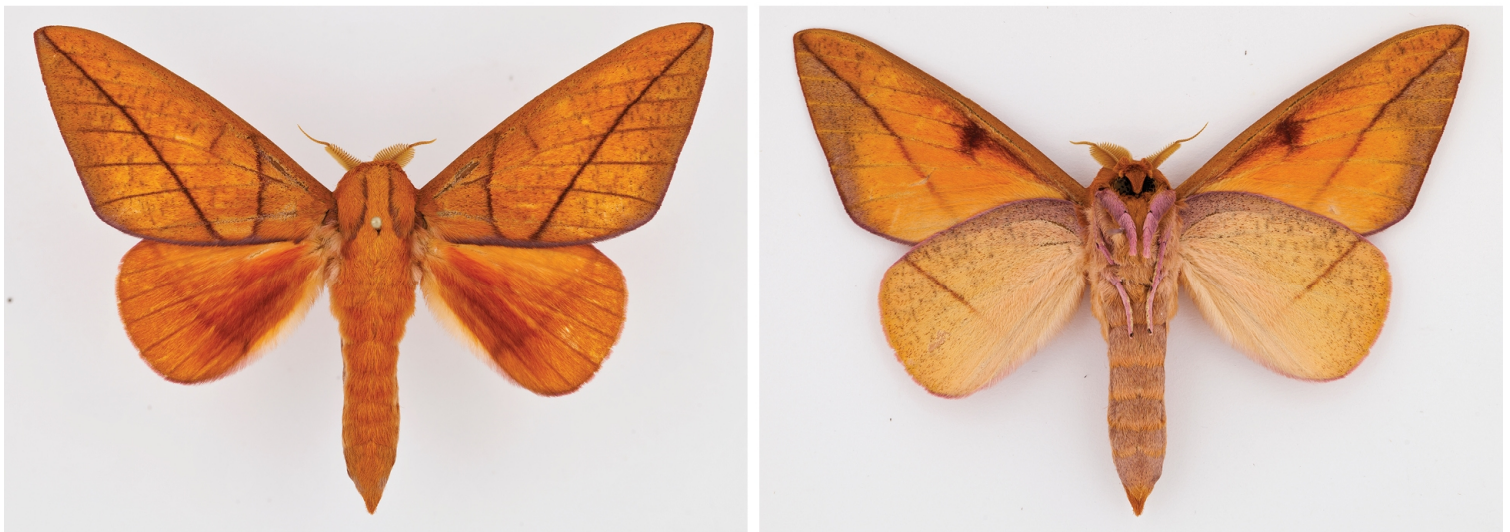

Adeloneivaia fallax (Boisduval, 1872) Ơ $68,8 \mathrm{~mm}$
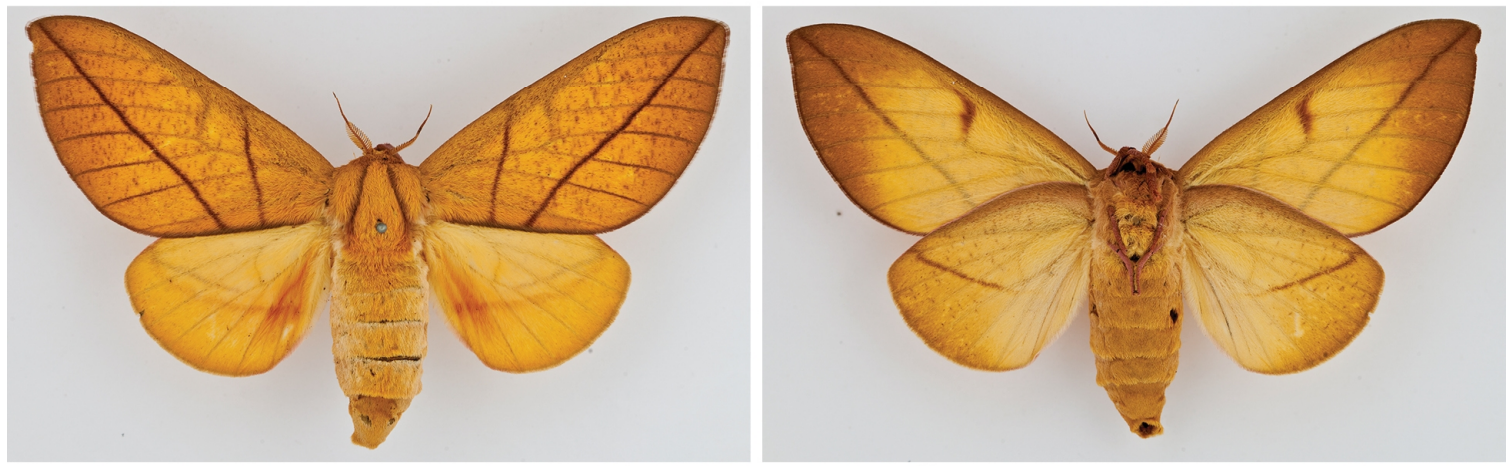

Adeloneivaia fallax (Boisduval, 1872) ㅇ $91,9 \mathrm{~mm}$
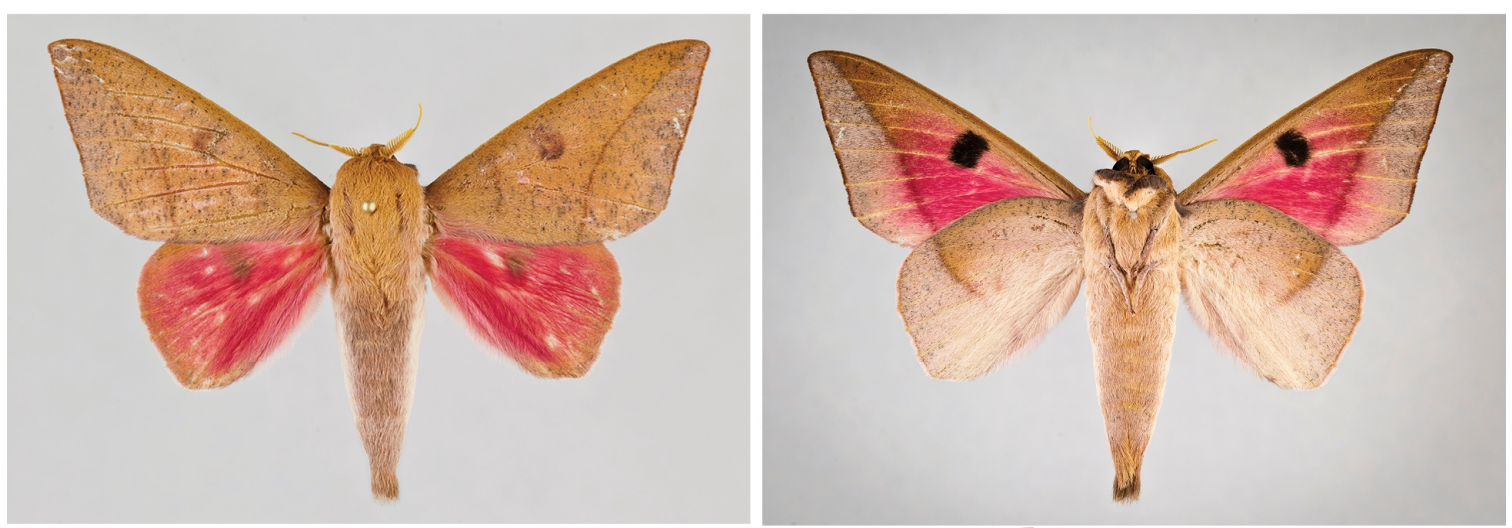

Adeloneivaia subangulata (Herrich Schäffer, [1855]) $O^{7} 61 \mathrm{~mm}$
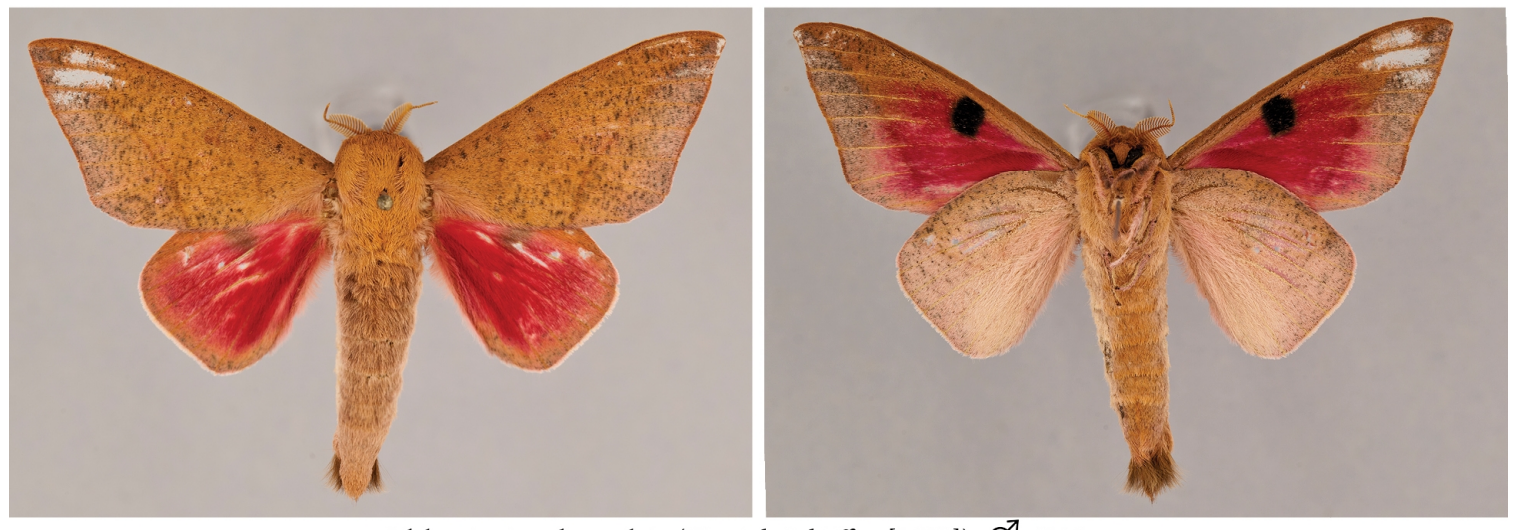

Adeloneivaia subangulata (Herrich Schäffer, [1855]) $O^{7} \quad 57,2 \mathrm{~mm}$ 
Ceratocampinae Harris, 1922
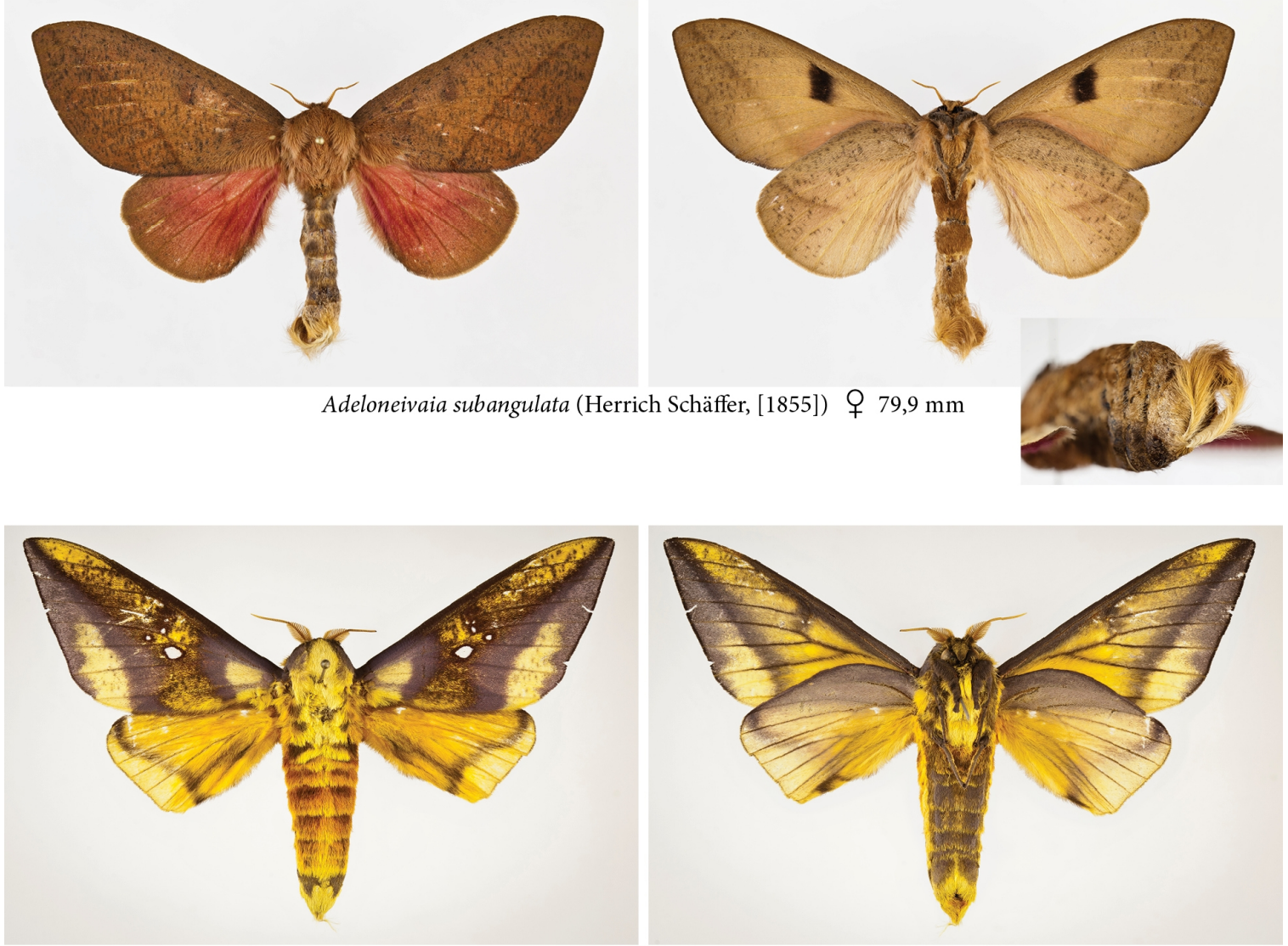

Adelowalkeria flavosignata (Walker, 1865) $\bigcirc^{7} 84,7 \mathrm{~mm}$
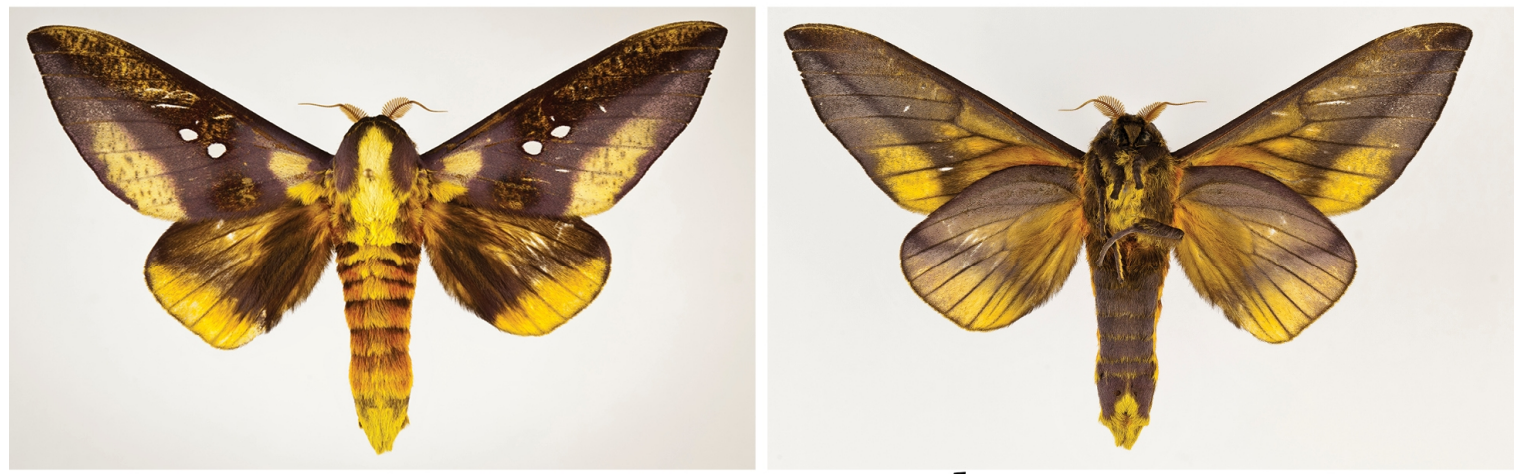

Adelowalkeria flavosignata (Walker, 1865) $\sigma^{7} \quad 85,3 \mathrm{~mm}$
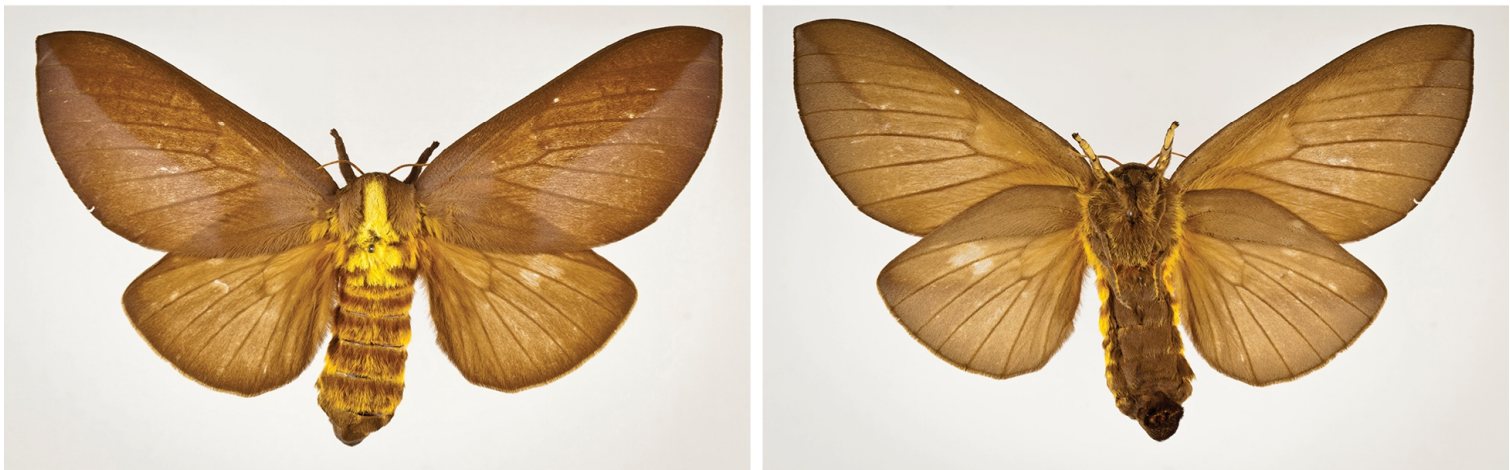

Adelowalkeria flavosignata (Walker, 1865) $\quad 100,3 \mathrm{~mm}$ 
Ceratocampinae Harris, 1922
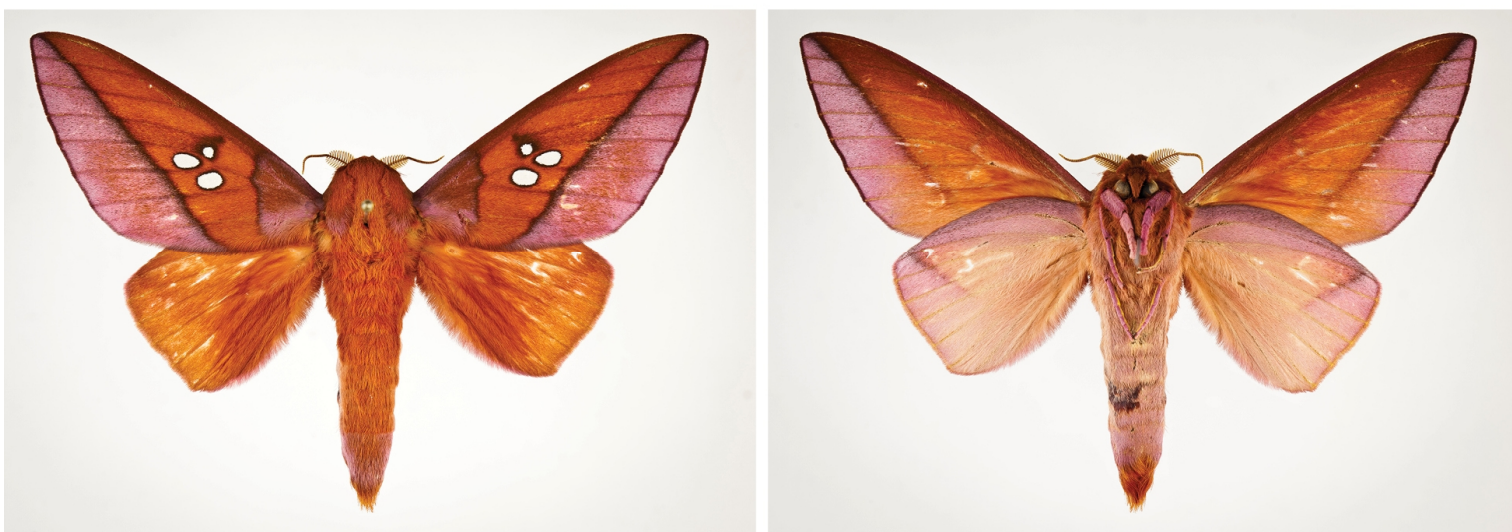

Adelowalkeria tristygma (Boisduval, 1872) O 74,4 mm
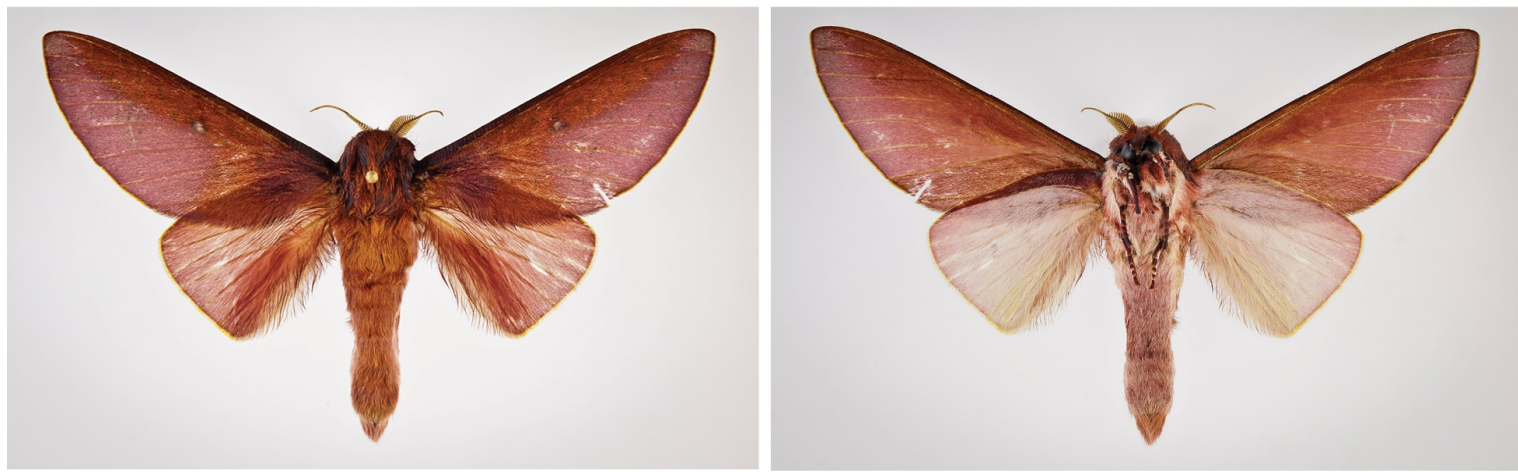

Almeidella almeidai Oiticica, $1946 \quad \sigma^{7} \quad 74,1 \mathrm{~mm}$
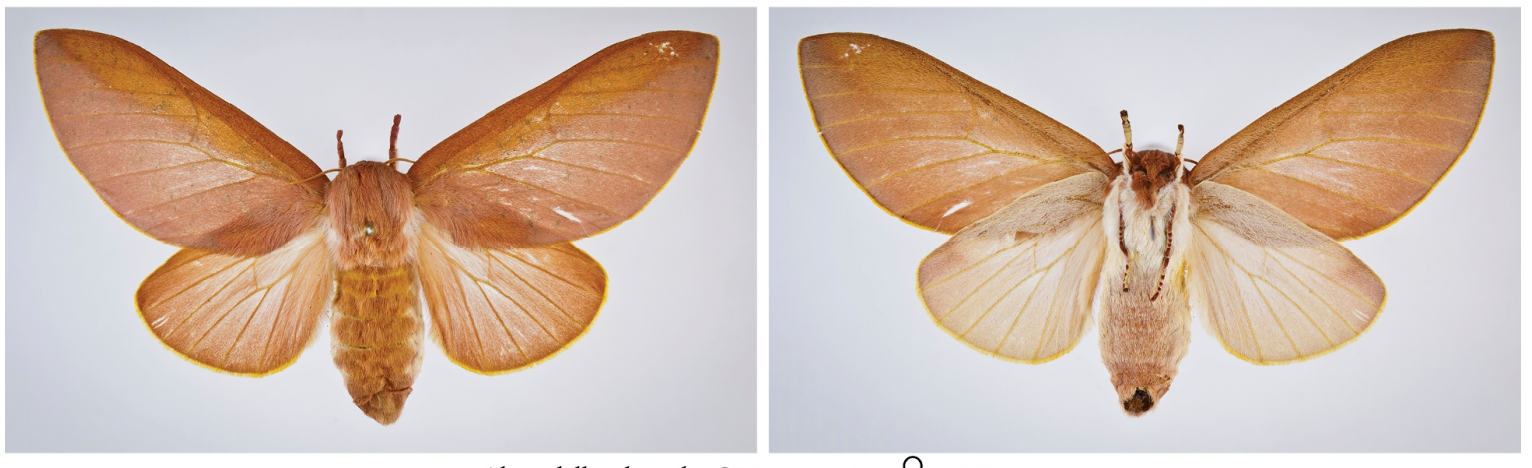

Almeidella almeidai Oiticica, 1946 † $82,9 \mathrm{~mm}$
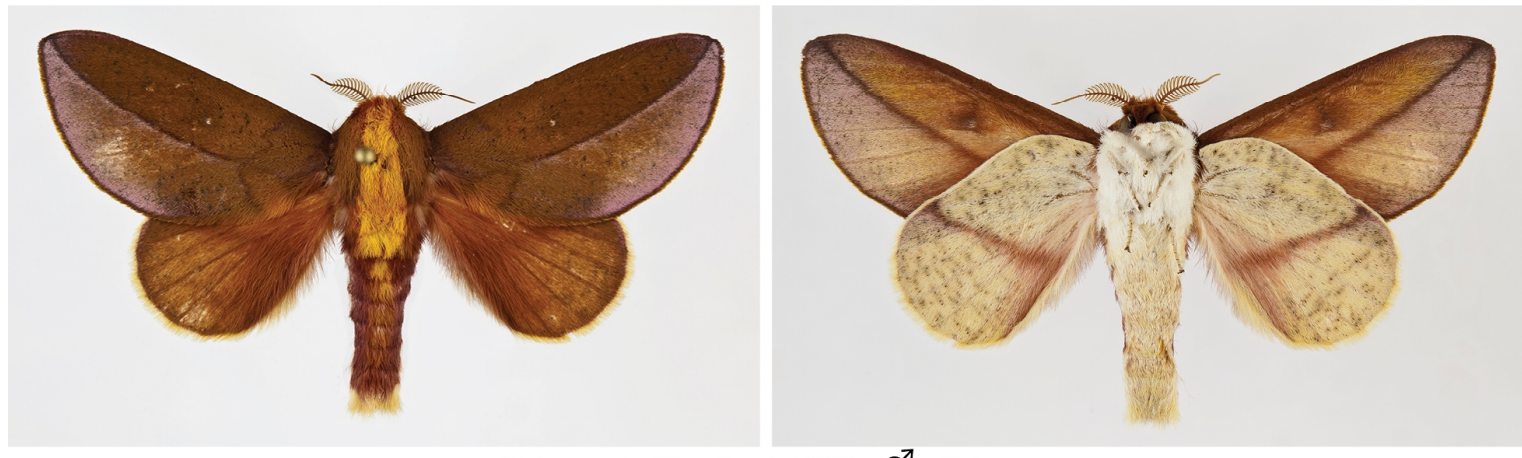

Cicia crocata (Boisduval, 1872) $\sigma^{7} 42,4 \mathrm{~mm}$ 
Ceratocampinae Harris, 1922
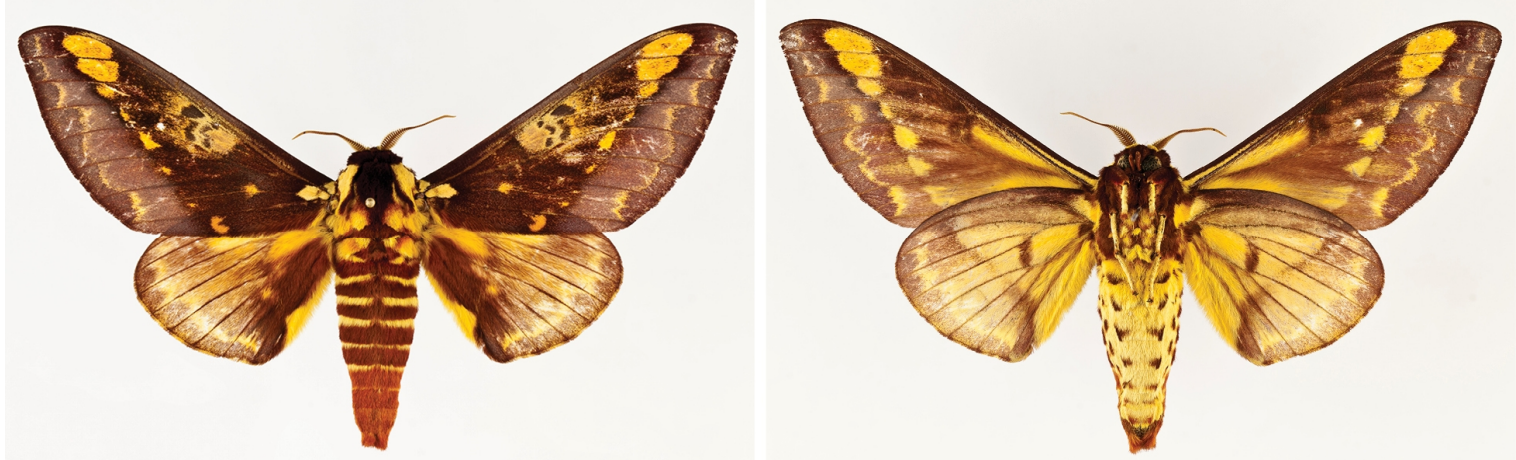

Citheronia phoronea (Cramer, 1779) $\quad \sigma^{7} 100,5 \mathrm{~mm}$
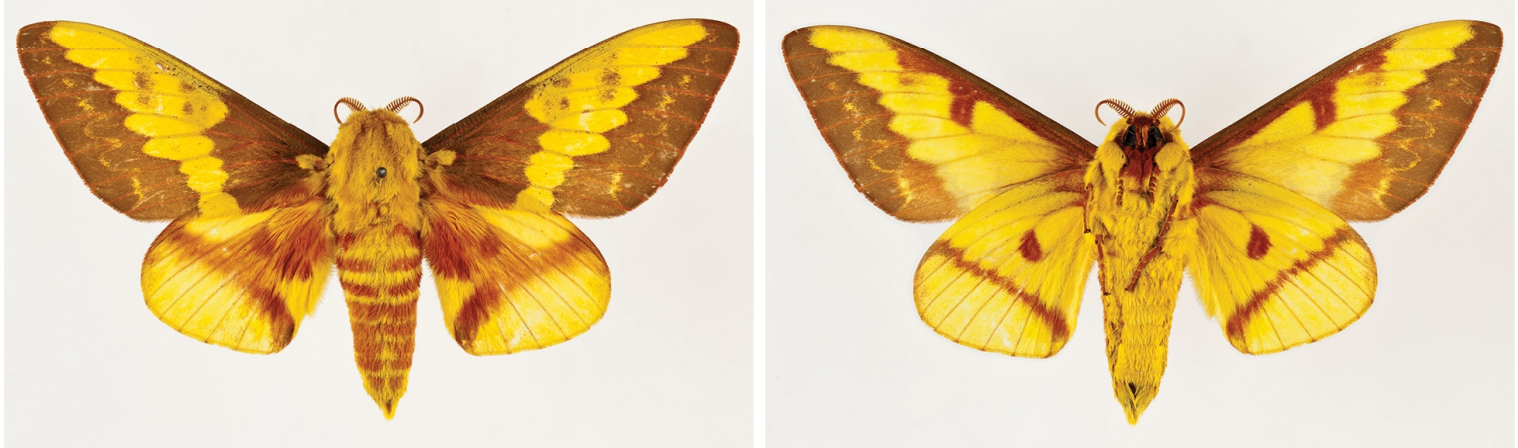

Citheronia laocoon (Cramer, 1777) Љ $89,2 \mathrm{~mm}$
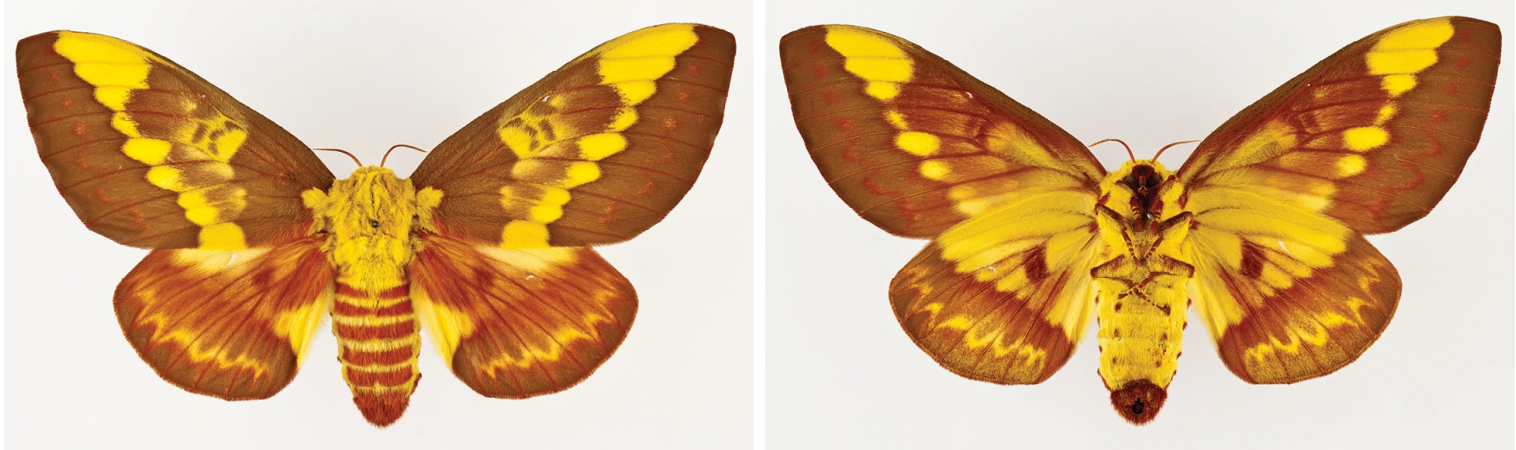

Citheronia laocoon (Cramer, 1777) $\quad$ 113,2 mm
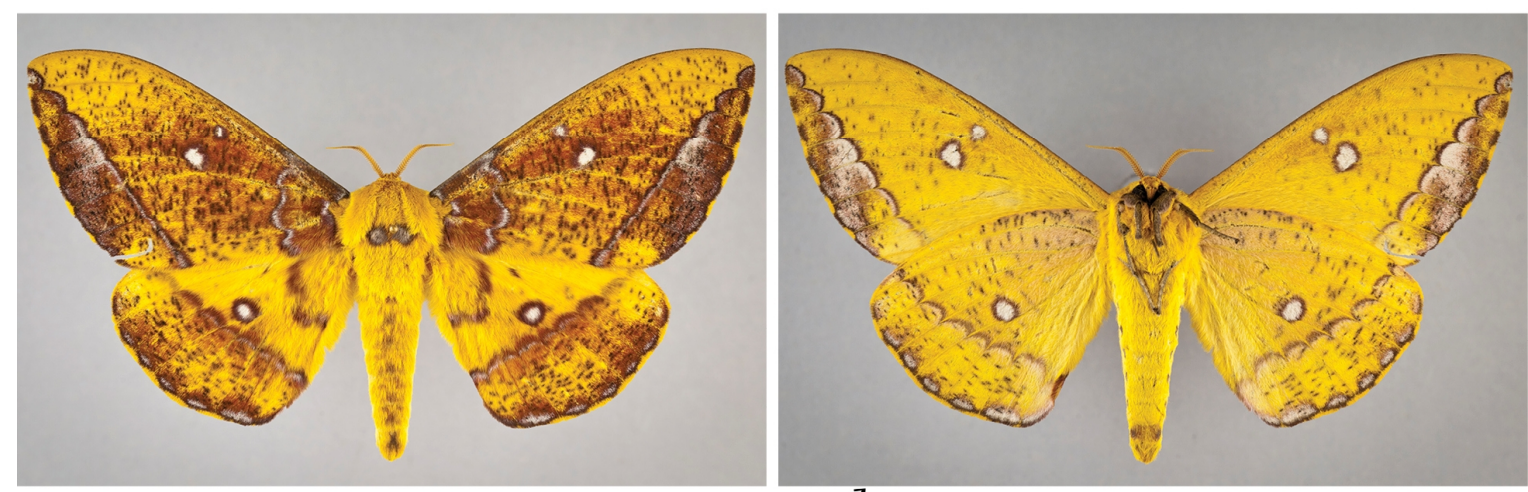

Eacles ducalis (Walker, 1855)

$O^{7} 111 \mathrm{~mm}$ 
Ceratocampinae Harris, 1922
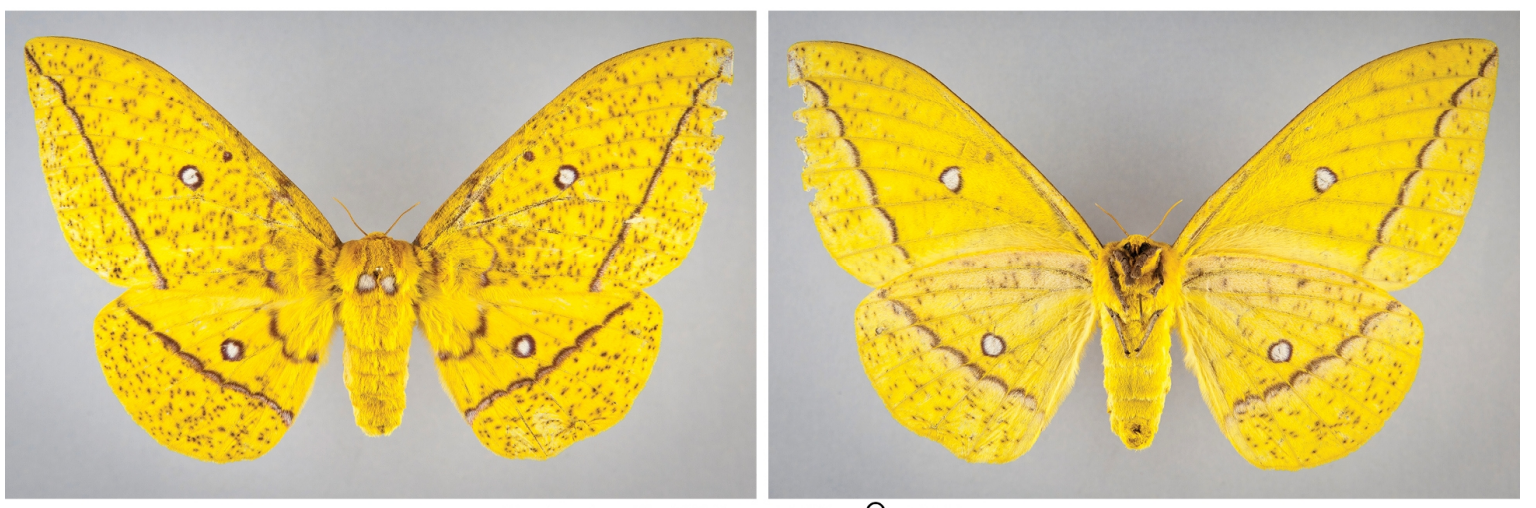

Eacles ducalis (Walker, 1855) † 127,2 mm
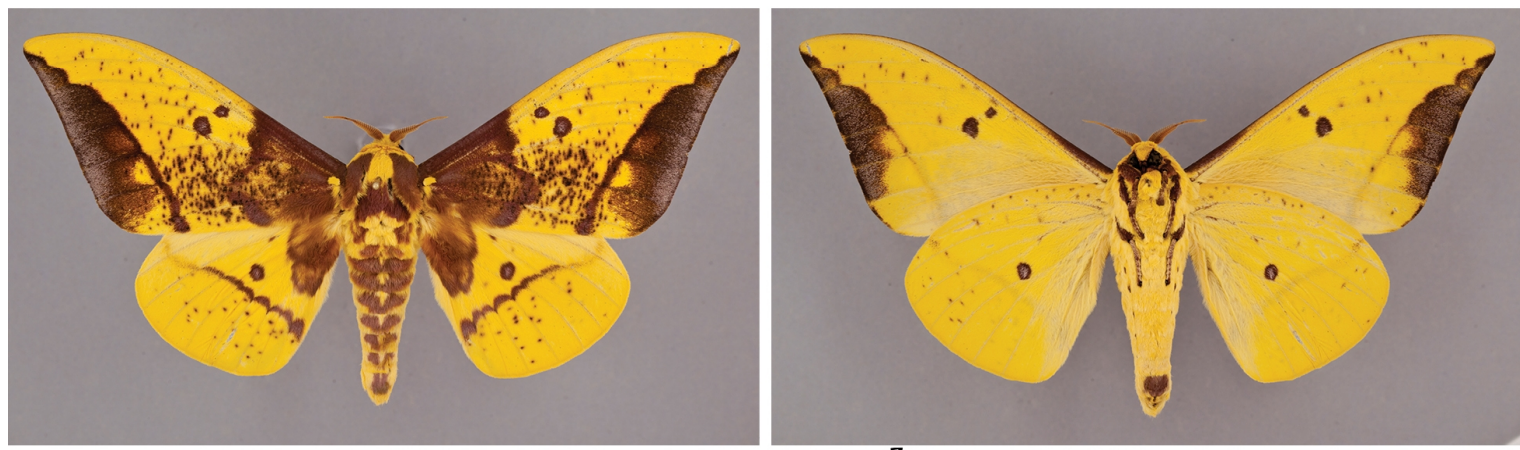

Eacles imperialis (Drury, 1773) $\sigma^{7} 119,5 \mathrm{~mm}$
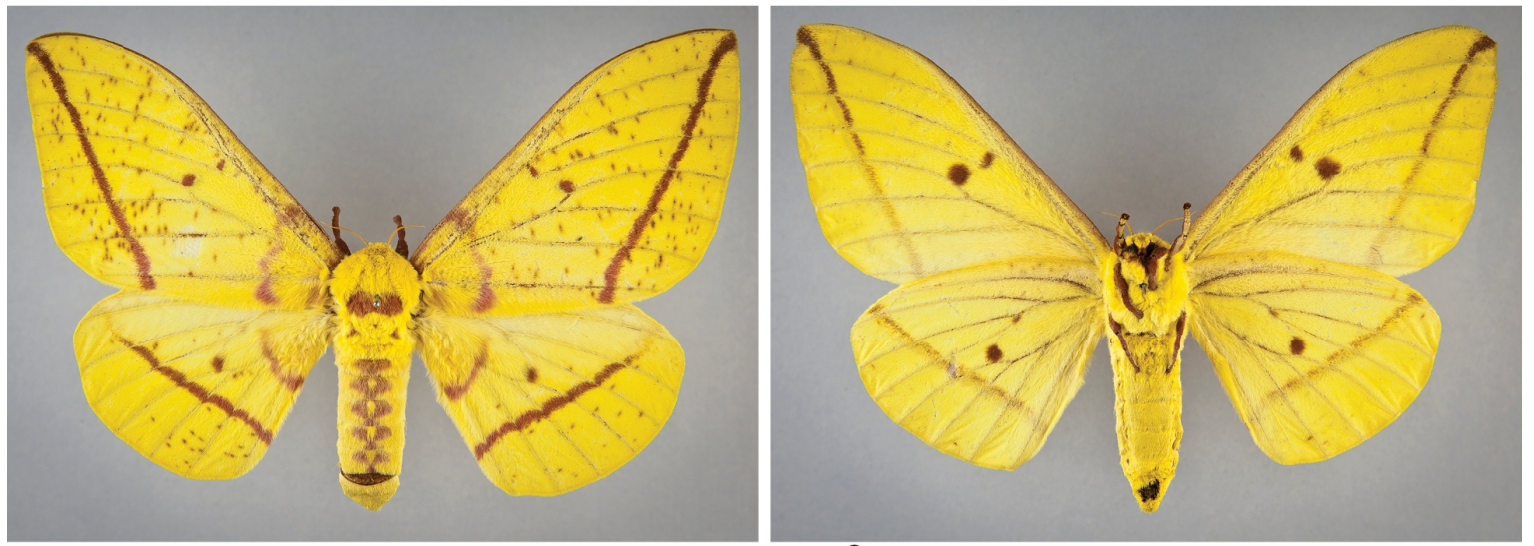

Eacles imperialis (Drury, 1773) $\quad$ ○ $125,6 \mathrm{~mm}$
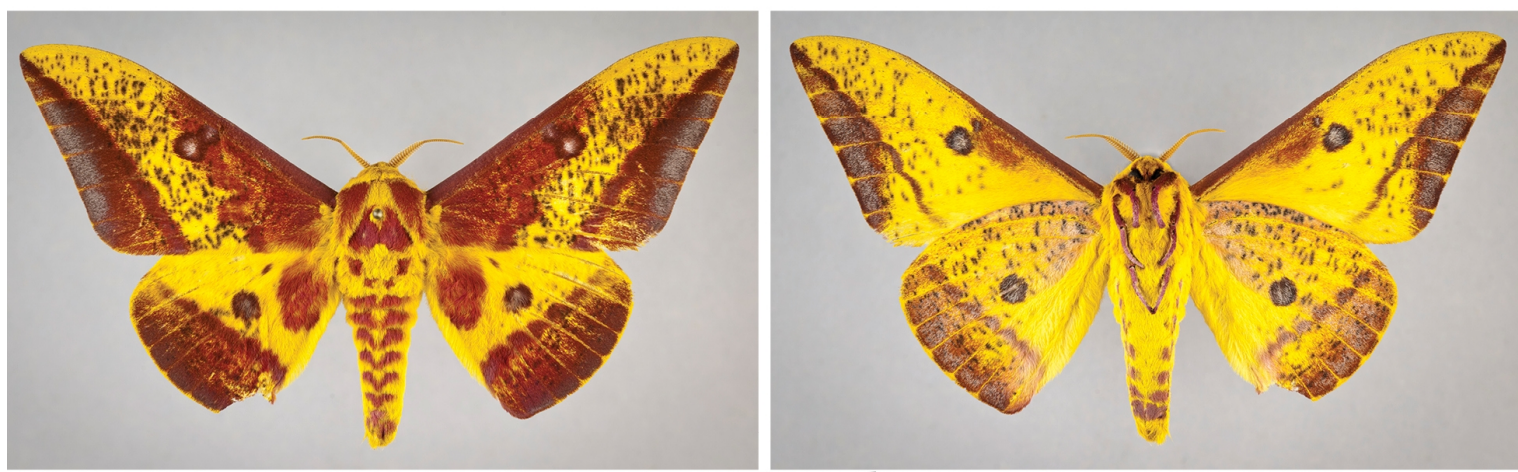

Eacles mayi Schaus, $1920 \quad O^{7} 95,7 \mathrm{~mm}$ 
Ceratocampinae Harris, 1922
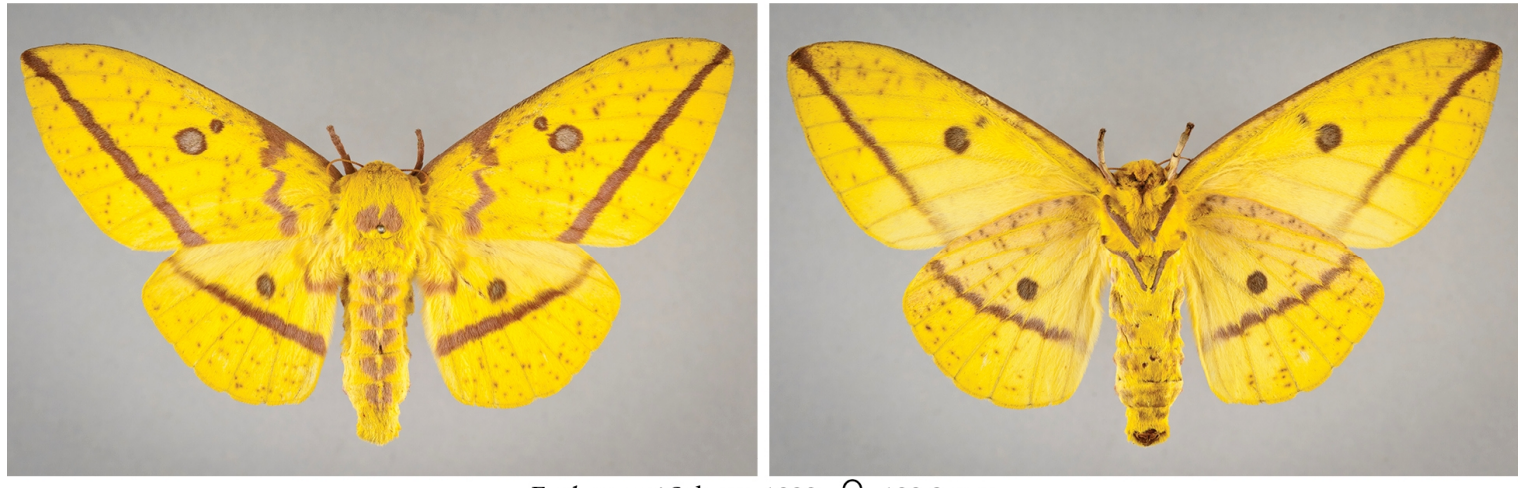

Eacles mayi Schaus, 1920 ㅇ 100,3 mm
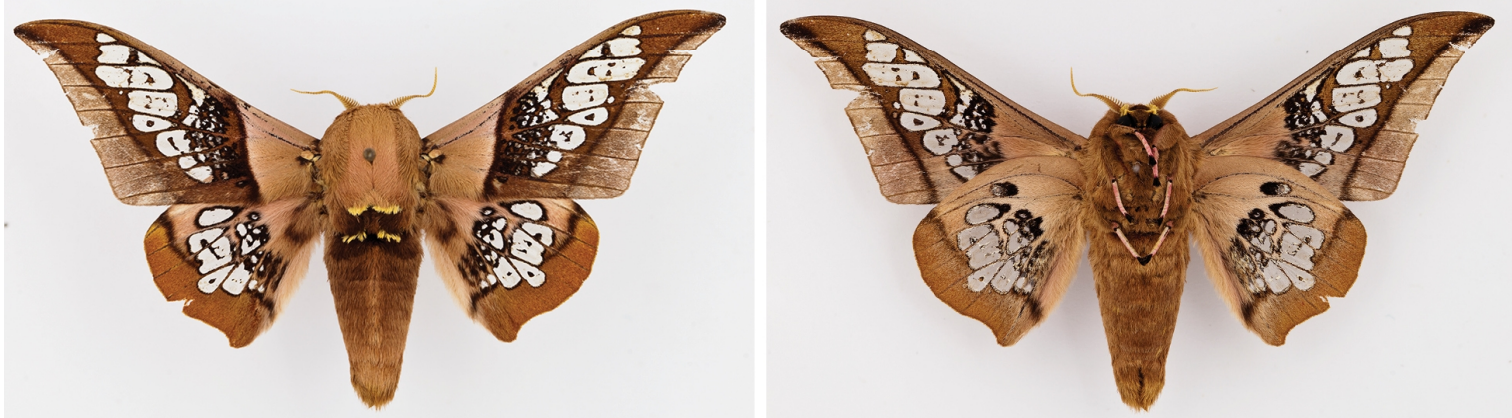

Neocarnegia basirei (Schaus, 1892) $\overbrace{}^{\pi} \quad 33,4 \mathrm{~mm}$
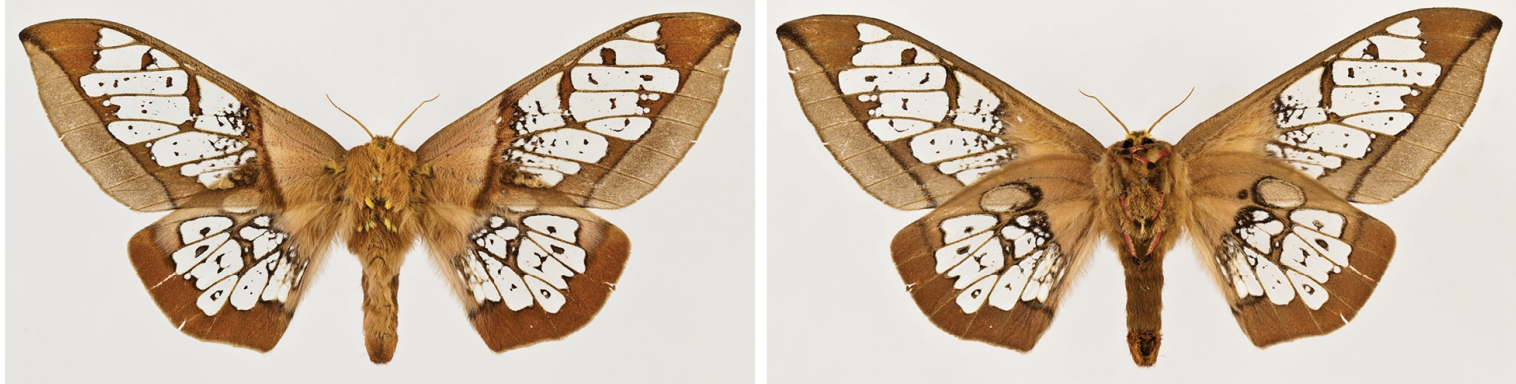

Neocarnegia cf. basirei (Schaus, 1892) $\quad$ @ $85,5 \mathrm{~mm}$
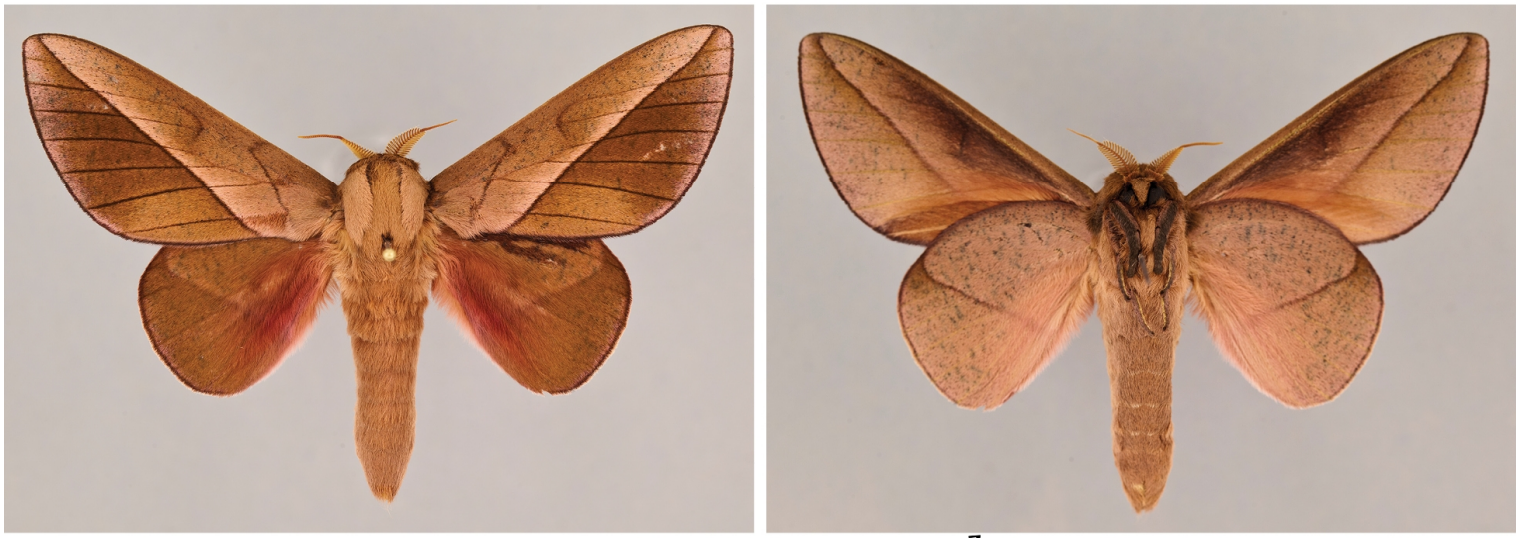

Oiticella convergens Herrich-Schäffer, [1855]) $\quad \sigma^{7} \quad 66,5 \mathrm{~mm}$ 